\title{
Estudios paleoclimáticos del Paleógeno y Mioceno inferior del centro y sur de la Patagonia argentina en base a la anatomía de maderas fósiles
}

\author{
DANIELA P. RUIZ
}

Tesis para optar por el título de Doctorado en Ciencias Naturales

Directores:

Dr. Roberto R. Pujana - Dr. Leandro C. A. Martínez 
El árbol más alto un día fue semilla 
Dedicatoria

Resumen

Abstract

Agradecimientos

1. Fundamentos

2. Objetivos

2.1. Generales

2.2. Específicos

3. Antecedentes

3.1. Anatomía del leño como indicador climático 4

3.2. Inferencias paleoclimáticas en las formaciones de estudio

Fm. Cerro Bororó (Paleoceno-Chubut)

Fm. Salamanca (Paleoceno-Chubut)

Fm. Río Turbio (Eoceno-Oligoceno-Santa Cruz)

Fm. Río Guillermo (Oligoceno)

Río Leona (Mioceno)

1. Cuenca San Jorge

1.1. Fm. Cerro Bororó 14

1.2. Fm. Salamanca 17

2. Cuenca Austral 20

2.1. Fm. Río Turbio $\quad 21$

2.2. Fm. Río Guillermo $\quad 25$

2.3. Fm. Río Leona 28

1. Materiales estudiados $\quad 34$

1.1. Actuales 34

1.2. Fósiles 34

Fm. Cerro Bororó (Paleoceno) $\quad 34$

Fm. Salamanca (Paleoceno) 35

Fm. Río Turbio, Fm. Río Guillermo y Fm. Río Leona (Eoceno- 35

2. Técnicas de preparación utilizadas. 36

2.1. Cortes petrográficos 36

2.2. Peels de acetato 36

2.3. Preparados para MEB (Microscopio Electrónico de Barrido) 36

3. Observación y descripción del material 36

4. Mediciones 37

5. Métodos de estudio 38 
5.1. Ecuaciones propuestas por Wiemann et al. $(1998,1999)$

5.2. Anillos de crecimiento 40

5.3. Índices de Vulnerabilidad y Mesomorfía. 42

5.4. Método del Coxistence Approach (CA) o pariente vivo más cercano 42

5.5. Caracteres eco-xilológicos 43

5.6. Terminología utilizada para la temperatura 45

1. Puesta a prueba de las ecuaciones de Wiemann et al. $(1998,1999)$ en maderas actuales

2. Formación Cerro Bororó

2.1. Ecuaciones propuestas por Wiemann et al. $(1998,1999)$

2.2. Anillos de crecimiento 50

2.3. Índices de Vulnerabilidad y Mesomorfía 55

2.4. Método del Coexistence Approach (CA) 56

2.5. Caracteres eco-xilológicos 68

3. Formación Salamanca $\quad \mathbf{7 0}$

3.1. Sistemática paleobotánica 70

Podocarpoxylon multiparenchymatosum Pujana et Ruiz $\quad 70$

$\begin{array}{ll}\text { Cupressinoxylon austrocedroides Nishida } & 73\end{array}$

Cupressinoxylon atabeae Ruiz, Brea, Raingemborn et Matheos 76

cf. Cupressinoxylon $\quad 79$

Xilotipo 1

Myrceugenellites sp. $\quad 84$

Xilotipo 2

Xilotipo $3 \quad 90$

3.2. Ecuaciones propuestas por Wiemann et al. $(1998,1999)$

3.3. Anillos de crecimiento 93

3.4. Índices de Vulnerabilidad y Mesomorfía 97

3.5. Método del Coxistence Approach (CA) 97

3.6. Caracteres eco-xilológicos 98

4. Formación Río Turbio $\quad \mathbf{1 0 0}$

4.1. Sistemática paleobotánica 100

Phyllocladoxylon antarcticum Gothan $\quad 100$

cf. Phyllocladoxylon 102

aff. Agathoxylon antarcticus 103

Caldcluvioxylon sp. 105

$\begin{array}{ll}\text { Xilotipo } 4 & 107\end{array}$

$\begin{array}{ll}\text { aff. Nothofagoxylon sp. } 1 & 109\end{array}$

aff. Nothofagoxylon sp. $2 \quad 110$

4.2. Ecuaciones propuestas por Wiemann et al. $(1998,1999)$

4.3. Anillos de crecimiento 111

Miembro inferior $\quad 112$

Miembro superior $\quad 114$

4.4. Índices de Vulnerabilidad y Mesomorfía 120

4.5. Método del Coexistence Approach (CA) 120 
4.6. Caracteres eco-xilológicos $\quad 120$

5. Formación Río Guillermo $\quad \mathbf{1 2 4}$

$\begin{array}{ll}\text { 5.1. Anillos de crecimiento } & 124\end{array}$

5.2. Índices de Vulnerabilidad y Mesomorfía 128

5.3. Consideraciones generales 128

6. Formación Río Leona $\quad \mathbf{1 3 0}$

6.1. Ecuaciones propuestas por Wiemann et al. $(1998,1999)$

6.2. Anillos de crecimiento 131

6.3. Índices de Vulnerabilidad y Mesomorfía 138

6.4. Método del Coexistence Approach (CA) 139

6.5. Caracteres eco-xilológicos 152

$\begin{array}{ll}\text { Capítulo 5: Discusión } & 156\end{array}$

1. Ecuaciones de Wiemann et al. $(1998,1999)$ en maderas actuales 157

$\begin{array}{ll}\text { 2. Paleoceno } & \mathbf{1 6 0}\end{array}$

2.1. Paleoclima inferido previamente en Patagonia y Antártida en base a 159

2.2. Paleoclima inferido en base a maderas 166

Formación Cerro Bororó $\quad 166$

Formación Salamanca $\quad 171$

Comparación con otros bosques paleocenos $\quad 174$

3. Eoceno-Oligoceno $\mathbf{1 7 6}$

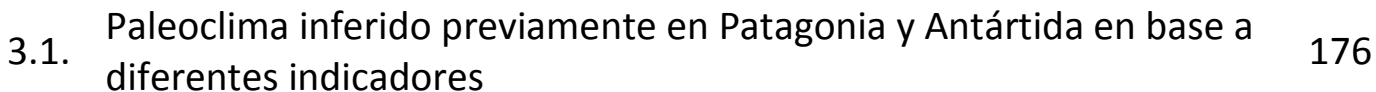

3.2. Paleoclima inferido en base a maderas 184

Formación Río Turbio $\quad 184$

Formación Río Guillermo 186

4. Mioceno temprano $\mathbf{1 8 8}$

4.1. Paleoclima inferido previamente en Patagonia y Antártida en base a 188

4.2. Paleoclima inferido en base a maderas 189

5. Resumen de los cambios climáticos acaecidos desde el Paleoceno al 195

$\begin{array}{lr}\text { Capítulo 6: Conclusiones } & 197\end{array}$

1. Puesta a prueba de las ecuaciones de Wiemann et al. $(1998,1999) \quad 198$

2. Material estudiado 198

3. Métodos de estudio paleoclimáticos aplicados 199

4. Paleoclima a lo largo del Paleógeno y comienzo del Neógeno 199

5. Comparación con los resultados obtenidos a partir de otros indicadores 201

6. Proyecciones futuras 201

$\begin{array}{ll}\text { Bibliografía } & 202\end{array}$

$\begin{array}{ll}\text { Apéndice } & 222\end{array}$ 
A mi Nonita María y el Nono Juan 


\section{RESUMEN}

El xilema secundario (madera) es un tejido vegetal encargado, entre otras funciones, del transporte del agua. Es por ello que, las variaciones climáticas que afectan la disponibilidad de este recurso, pueden ser visualizados en la estructura anatómica del leño. En base a esto, el objetivo de la presente tesis fue aplicar diversos métodos y técnicas utilizando la anatomía de las maderas para inferir condiciones paleoambientales y estudiar los cambios climáticos transcurridos durante el Paleógeno (Paleoceno, Eoceno y Oligoceno) y el Mioceno temprano en el centro y sur de la Patagonia. Además se realizaron las descripciones y el estudio sistemático correspondiente en aquellos ejemplares que no fueron estudiados con anterioridad a la presente tesis. Las metodologías aplicadas para realizar las inferencias paleoclimáticas fueron: 1) Ecuaciones propuestas por Wiemann y colaboradores para el cálculo de la temperatura media anual y las precipitaciones medias anuales; 2) Índice de Vulnerabilidad e Índice de Mesomorfía; 3) Estudio de anillos de crecimiento; 4) Coexistance Approach o método del pariente vivo más cercano; 5) Análisis de caracteres ecoxilológicos. Las ecuaciones propuestas por Wiemann y colaboradores (basadas principalmente en taxones actuales del hemisferio norte), fueron puestas a prueba con taxones presentes actualmente en distintas regiones de Argentina y Chile.

El material estudiado proviene de numerosas localidades donde afloran cinco formaciones: Fm. Cerro Bororó y Fm. Salamanca, ambas de edad daniana (Paleoceno inferior), Fm. Río Turbio (Eoceno-Oligoceno), Fm. Río Guillermo (Oligoceno-Mioceno inferior) y Fm. Río Leona (Mioceno inferior). Las primeras dos ubicadas en la Cuenca del Golfo San Jorge al este de la provincia del Chubut y las tres restantes en la Cuenca Austral, al suroeste de la provincia de Santa Cruz.

En total se analizaron 550 muestras correspondientes a leños permineralizados. Se revisaron los nueve ejemplares de la Fm. Cerro Bororó (una conífera y ocho angiospermas leñosas) estudiados por Petriella en 1972 y se concluyó que es necesario efectuar una sinonimia (con las dos especies de Weinmannioxylon) y una enmienda de diagnosis con cambio de género (de Bridelioxylon americanum). Además, se incluyeron 12 nuevos ejemplares de la misma formación (todos ellos Podocarpoxylon mazzonii). De la Fm. Salamanca se estudiaron de forma completa 17 
ejemplares, incluyendo las descripciones anatómicas y las determinaciones. Hay cuatro especies de coníferas, incluída una especie nueva (Podocarpoxylon multiparenchymatosum Pujana et Ruiz, Cupressinoxylon austrocedroides Nishida, Cupressinoxylon artabeae Ruiz, Brea, Raingemborn et Matheos y cf. Cupressinoxylon) y cuatro angiospermas leñosas que serán publicadas como nuevos taxones (Myrceugenellites sp., Xilotipo 1, Xilotipo 2 y Xilotipo 3). Se analizaron 81 ejemplares de la Fm. Río Turbio, muchos de ellos estaban mal preservados pero varios pudieron ser descriptos e identificados (Phyllocladoxylon antarcticum Gothan, cf. Phyllocladoxylon Gothan, aff. Agathoxylon antarcticus (Poole \& Cantrill) Pujana, Santillana et Marenssi, Caldcluvioxylon sp., aff. Nothofagoxylon sp. 1, aff. Nothofagoxylon sp. 2 y Xilotipo 4). Además se incluyeron en el estudio paleoclimático las dos Podocarpaceae descriptas anteriormente por Pujana (2008). De la Fm. Río Guillermo se vieron unos 39 ejemplares y de la Fm. Río Leona unos 392. Ellos solo se fueron utilizados para los estudios pleoclimáticos (cuando el estado de preservación así lo permitió) y no se realizaron nuevas descripciones ya que todo el material se correspondía con las 2 coníferas y las 13 angiospermas leñosas ya mencionadas por Pujana (2007, 2008, 2009a, b).

A grandes rasgos, se concluyó que el clima fue inicialmente meso-megatérmico $\left(20^{\circ} \mathrm{C}-24^{\circ} \mathrm{C}\right)$ a incluso megatérmico $\left(>24^{\circ}\right)$ en el Paleoceno (Fms. Cerro Bororó y Salamanca), luego mesotérmico $\left(14^{\circ}-20^{\circ} \mathrm{C}\right)$ en el Eoceno medio (miembro inferior de la Fm. Río Turbio) y llegando a un clima microtérmico $\left(<14^{\circ} \mathrm{C}\right)$ en el Eoceno tardío/Oligoceno temprano (miembro superior de la Fm. Río Turbio). La temperatura se mantuvo más o menos estable a lo largo del Oligoceno y luego se volvió a un clima mesotérmico en el Mioceno temprano ( $F m$. Río Leona). Por otro lado, las precipitaciones fueron muy abundante (2000 $\mathrm{mm}$ anuales o más) durante el Paleoceno, existiendo una estacionalidad muy poco marcada por periodos menos lluviosos al final de la temporada de crecimiento pero sin llegar a sequías. A lo largo del Eoceno esta abundancia de las precipitaciones persistieron, pero con una estacionalidad mucho más marcada. En el Oligoceno se produciría un descenso de las precipitaciones, que vuelven a aumentar en el Mioceno temprano pero manteniendo una temporada seca que marca la estacionalidad. Estos resultados concuerdan en gran 
medida con los obtenidos previamente por otros autores a partir de diferentes indicadores como ser impresiones foliares y palinomorfos.

\section{ASTRACT}

Secondary xylem (wood) is a plant tissue in charge of water transport (among other functions). Consequently, climatic variations affecting water availability can be detected from the wood anatomy structure. The aim of this thesis consists in applying different methods and techniques using wood anatomy to infer paleoenvironmental conditions and to study climatological changes during the Paleogene (Paleocene, Eocene, Oligocene) and Early Miocene in Central and Southern Patagonia. Additionally, descriptions and systematic study of those previously unstudied material were made. The applied methodologies were: 1) Equations proposed by Wiemann and colleagues for mean annual temperature and mean annual precipitation inference; 2) Vulnerability and Mesomorphy Indexes; 3) Growth rings analysis; 4) Coexistence Approach or Nearest Living Relative method; 5) Analysis of ecoxylology characters. Also, the Wiemann and colleagues equations (based principally in living taxa from the Northern Hemisphere), were tested with living taxa from Argentina and Chile.

The study material comes from different localities were five formations crop out: Cerro Bororó Fm. and Salamanca Fm., both Danian in age (Lower Paleocene), Río Turbio Fm. (Eocene-Oligocene), Río Guillermo Fm. (Oligocene-Lower Miocene) and Río Leona Fm. (Lower Miocene). The two former are part of the Golfo San Jorge Basin in Chubut province, and the latter three are part of the Austral Basin in the southwest Santa Cruz province.

A total of 550 samples of permineralized woods were analyzed. The nine samples (one conifer and eight angiosperms) originally studied by Petriella (1972) were reviewed and it is proposed to synonymize the two Weinmannioxylon species, and make a diagnosis emendation and a genera transfer of Bridelioxylon americanum. Other 12 samples were included from the same formation, all of them assigned to Podocarpoxylon mazzonii. From the Salamanca Formation 17 samples were studied, including anatomical descriptions and systematical assignments. There are four 
conifers including a new species (Podocarpoxylon multiparenchymatosum Pujana et Ruiz, Cupressinoxylon austrocedroides Nishida, Cupressinoxylon artabeae Ruiz, Brea, Raingemborn et Matheos y cf. Cupressinoxylon) and four angiosperms to be published as new taxa (Myrceugenellites sp., Xilotipo 1, Xilotipo 2 y Xilotipo 3). From the Río Turbio Fm. 81 samples were seen, some of them had a bad preservation but others could be described and assigned to a taxonomic unit (Phyllocladoxylon antarcticum Gothan, cf. Phyllocladoxylon Gothan, aff. Agathoxylon antarcticus (Poole \& Cantrill,) Pujana, Santillana et Marenssi, Caldcluvioxylon sp., aff. Nothofagoxylon sp. 1, aff. Nothofagoxylon sp. 2 and Xilotipo 4). Podocarpaceae species described before by Pujana (2008) were also included in the paleoclimatic study. In addition, 39 samples from Río Guillermo Fm. and 392 samples from Río Leona Fm. were analyzed. They were only used for paleoclimatic inferences (when the preservation allowed it) and new descriptions were not made because all the new material correspond to the species mentioned by Pujana (2008, 2009a,b) ( 2 conifers and 13 angiosperms).

In general terms, the conclusion was that during the Paleocene the climate was meso-megatermal $\left(20^{\circ} \mathrm{C}-24^{\circ} \mathrm{C}\right)$ to megatermal $\left(>24^{\circ}\right)$ (Cerro Bororó and Salamanca Fms.) and mesotermal $\left(14^{\circ}-20^{\circ} \mathrm{C}\right)$ in the middle Eocene (Lower Member of Río Turbio Fm.) or even microtermal $\left(<14^{\circ} \mathrm{C}\right)$ in the late Eocene/Oligocene (Upper Member of Río Turbio Fm.). The temperature maintained stable along the Oligocene and then it came back to a mesotermal climate in the Early Miocene (Fm. Río Leona). On the other hand, precipitations were abundant (2000 annual mm or even more) during the Paleocene, with a marked seasonality with less rainy periods but never reaching droughts. Along the Eocene these abundant precipitations and humidity persisted but with a much more marked seasonality. Apparently, during the Oligocene precipitations rates descended but they rise again in the Lower Miocene, always maintaining a dry season. These results in general agree with those obtained previously by different authors from other indicators as for example leaf remains and palynomorphs. 


\section{AGRADECIMIENTOS}

a Roberto (Oti) mi director, quien me dio un tema de investigación, me brindó gran parte del material de estudio, el lugar de trabajo, la posibilidad de realizar viajes de campaña, y todo el apoyo y la ayuda que necesité siempre

a Leandro mi director quien me guió y aconsejó en todo, desde que era estudiante de grado e hice mi primer pasantía, durante mis becas de grado y finalmente en el desarrollo de esta tesis

a Mariana mi codirectora de beca, quien a pesar de la distancia también estuvo en todo momento cuando me surgieron dudas y me brindó parte del material de estudio y otros recursos

a los geólogos Sol y Marcelo que me dieron una ayuda enorme con la geología en un viaje de campo

a Bari, Lu y Lau mis colegas y amigas del MACN por su compañía, ayuda y consejos tanto en lo académico como en lo personal

a los paleobotánicos del MACN, Sebastián Mirabelli, Carlos Grepi, Carolina Panti, Luis Palazzesi, Viviana Barreda, Sol Noetinger, Pedro Gutiérrez, Damián Fernández, Martín Carrizo y Ezequiel Vera por sus diversas colaboraciones en la elaboración de la tesis

a Analía Artabe quien me brindó muchas facilidades en mis comienzos como paleobotánica en el Museo de La Plata

a la cátedra de Morfología Vegetal de la FCNyM, amigos y colegas con quienes me inicié en el estudio de las maderas y en la docencia

a la gente del herbario del MACN por facilitarme material de la xiloteca y por los gratos momentos compartidos

a los chicos de paleovetebrados de "viajes Kelenken", Guille, Sebas, Mati, Mauro y el Mendo, quienes fueron una excelente compañía en muchos de mis viajes hacia o desde el museo a casa

a mis amigos, Dumont, Lulu, Ángela, Cesar, Ozzy, Maga, Marce, Marti, Marquiqui, Juan, Valen y Sabrina que siempre están, y otros que no alcanzo a nombrar pero que en algún momento estuvieron presentes

a mi equipo de futbol (Changui, Bren, Marisil, Lau, Jesy, Pau, Sari, Jor, Pili, Jime, Ire)

a mi mamita de mamá y mi papiño que siempre me alentaron a seguir mis sueños y me acompañaron y me ayudaron en todos los aspectos posibles para que así fuera; $y$ al resto de la familia que también siempre me apoyó, Gaby, Dany, Lauti, Valen, Benja la titi, la abuela Isabel, la tía Nachi y el tío Mi, Naly, Tuto, Berna y Alfon

a Miguelón, el mejor hermano y amigo, con quien compartí el departamento durante el desarrollo de esta tesis y que vivió de cerca todos los altibajos que experimenté, apoyándome, acompañándome y sacándome una sonrisa siempre 
a los jurados de tesis Dra. Tania Dutra, Dra. Luján Luna y Dr. Luis Palazzesi por las correcciones y los comentarios.

Los fondos que posibilitaron la realización de esta tesis de doctorado provienen de:

- Museo Argentino de Ciencias Naturales

- CONICET

- Agencia Nacional de Promoción Científica y Tecnológica

- Facultad de Ciencias Naturales y Museo, Universidad Nacional de La Plata 


\section{1}

\section{INTRODUCCIÓN}

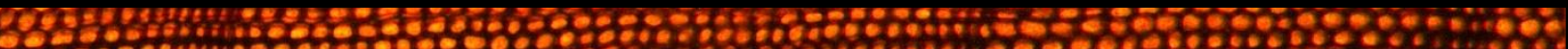
W

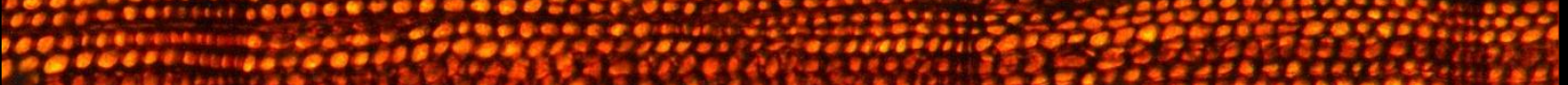

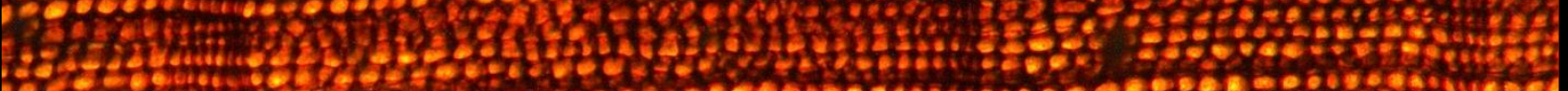

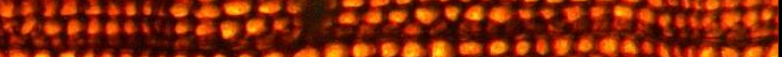
Fe

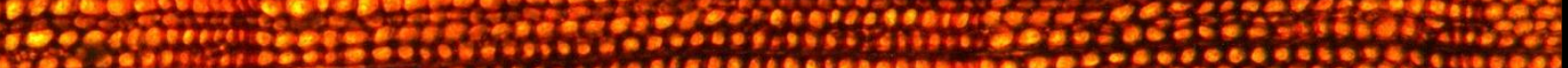

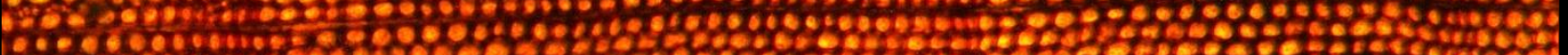

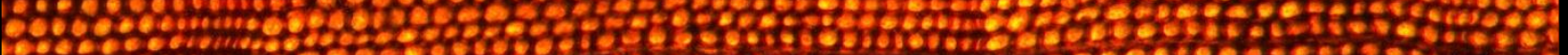

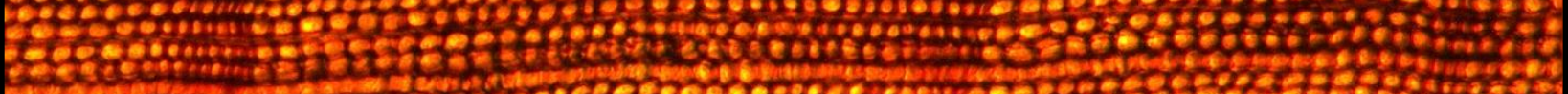

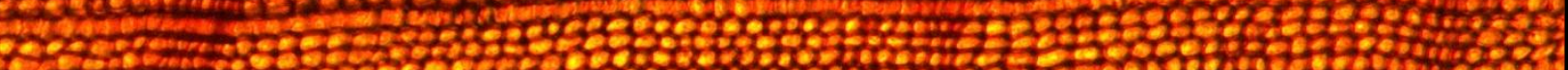

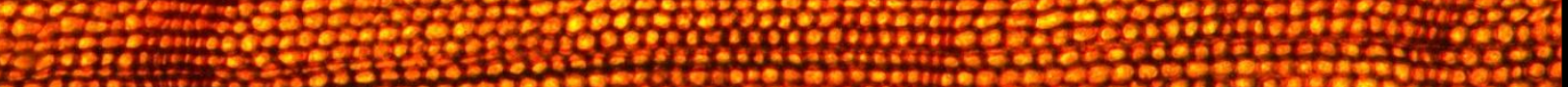
cose

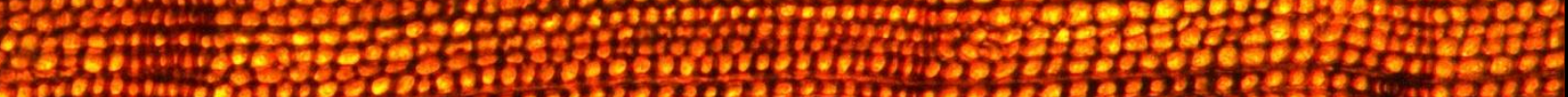

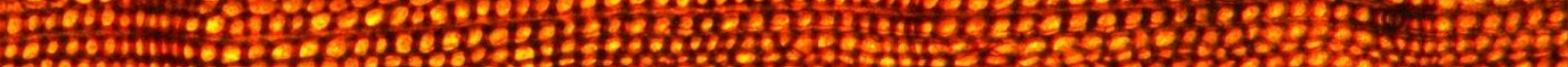
F

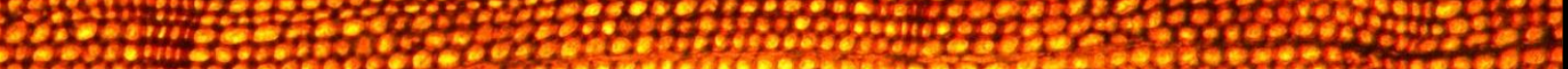

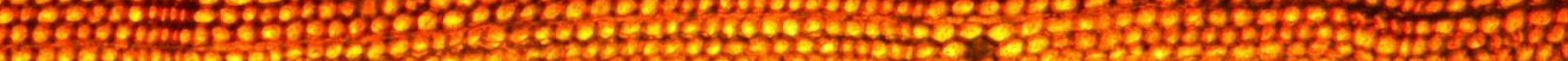

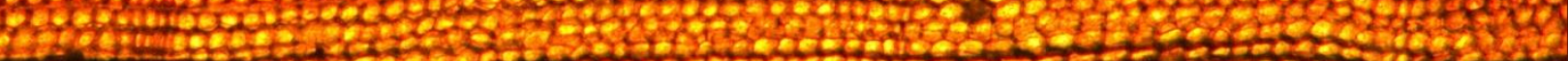

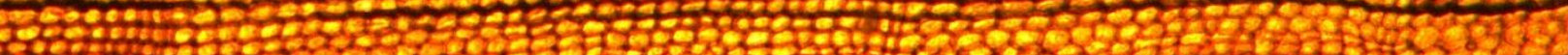

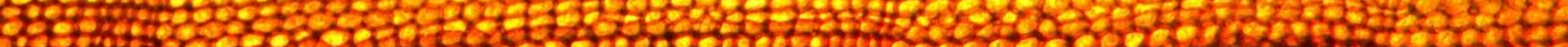
Q3.

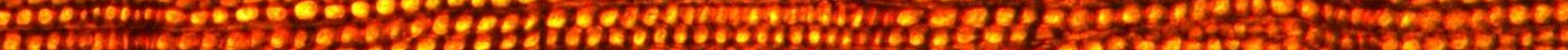

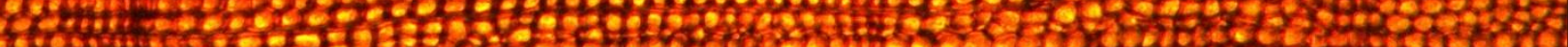
2.60.7.

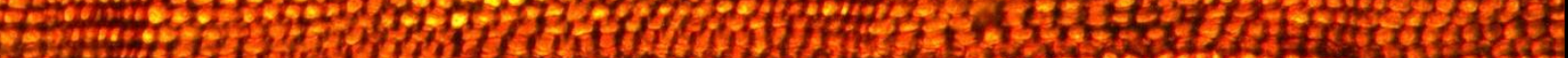

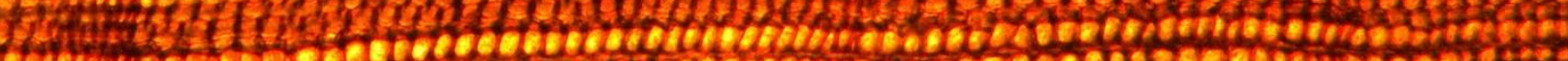

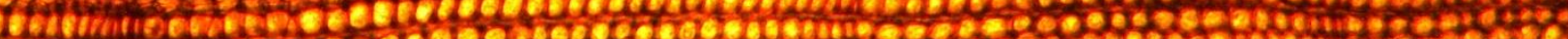

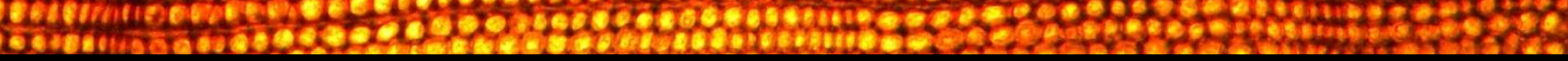

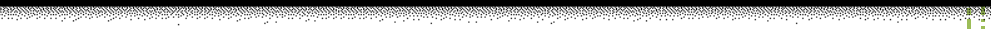

DANIELA P. RUIZ 


\section{FUNDAMENTOS}

El leño, madera o xilema secundario, es un tejido que cumple diversas funciones, es medio de soporte más importante y, junto con el floema, constituye una vía simplástica tridimensional a través de la cual se transportan sustancias moleculares fundamentales para el desarrollo de la planta (Beck, 2010). Además, es el principal sistema de transporte del agua por lo cual, las variaciones de parámetros ambientales y climáticos que afecten la disponibilidad de este recurso, pueden ser detectados en la estructura anatómica de este tejido.

Varios autores han concluido que la anatomía de la madera, en áreas geográficas muy separadas, puede ser muy similar cuando el clima lo es, aun cuando sean floras muy distintas en lo referente a la composición taxonómica (Bass, 1986). Desde comienzos del siglo pasado se evidenció que la anatomía de la madera era un buen indicador climático y varios índices fueron desarrollados en base a los caracteres del leño, correlacionando dichos rasgos de la madera con factores ambientales (Bailey \& Tupper, 1918; Frost, 1930a, b, 1931; Fritts, 1976; Carlquist, 1977; Creber, 1977; Creber \& Chaloner, 1984a, b; Wheeler \& Baas, 1991, 1993; Wiemann et al., 1998, 1999). Sin embargo, dichos autores confeccionaron sus bases de datos mayoritariamente con taxones del hemisferio norte, siendo en ese hemisferio en donde dichos índices son comúnmente aplicados.

En la presente tesis se pretende aplicar la metodología desarrollada por los citados autores en fósiles de distintas edades comprendiendo el Paleógeno y el Mioceno inferior. Asimismo, se pone a prueba la eficacia de las ecuaciones propuestas por Wiemann et al. $(1998,1999)$ con taxones actuales del sur de Sudamérica. Los resultados alcanzados aportarán nuevos datos sobre las condiciones paleoclimáticas que prevalecieron a lo largo de este intervalo de tiempo en la Patagonia. 


\section{OBJETIVOS}

\subsection{Objetivos generales}

- Aplicar diversos métodos y técnicas utilizando la anatomía del leño para inferir condiciones ambientales, principalmente en fósiles y brevemente en actuales.

- Analizar los cambios climáticos transcurridos durante el Paleógeno y el Mioceno en el centro y sur de la Patagonia, en base al estudio de las maderas fósiles.

- Comparar los resultados logrados con los obtenidos por otros medios (proxies), como ser: estudios de improntas foliares, palinomorfos, microfósiles, datos sedimentológicos, etc.

- Contribuir a establecer el paleoclima y los cambios acaecidos en el área de estudio durante el Paleógeno y el Mioceno, comparando los resultados que surjan de este estudio con los datos provenientes de otras formaciones coetáneas.

\subsection{Objetivos específicos}

- Poner a prueba (con taxones australes actuales) las ecuaciones para el cálculo de temperaturas medias anuales (MAT) y precipitaciones medias anuales (MAP) propuestas por Wiemann et al. $(1998,1999)$.

- Revisar o realizar las descripciones y asignaciones sistemáticas de los ejemplares utilizados para el estudio plaeoclimático cuándo se requiera (Fm. Cerro Bororó, Fm. Salamanca y Fm. Río Turbio).

- Emplear las diversas ecuaciones y técnicas ya conocidas para establecer las características ambientales en la Patagonia a partir de la anatomía de la madera en taxones fósiles. Algunas de las ecuaciones y técnicas a seguir son:

- Ecuaciones para el cálculo de la temperatura media anual, rango de temperatura media anual, temperatura media del mes más frío y precipitación media anual (Wiemann et al., 1998, 1999).

○ Estudio de anillos de crecimiento (Fritts, 1976; Creber, 1977, Falcon-Lang, 2000a, b).

- Índices de vulnerabilidad y mesomorfía de Carlquist (1977). 
- Método del Coexistence Approach o del pariente vivo más cercano (NLR o Nearest Living Relative) de Mosbrugger \& Utescher (1997).

- Caracteres eco-xilológicos.

Los materiales analizados fueron recolectados en el centro y sur de Patagonia (provincias del Chubut y de Santa Cruz). Dichos fósiles provienen de sedimentos de las siguientes formaciones de edades que van del Paleoceno al Mioceno: Cerro Bororó, Salamanca, Río Turbio, Río Guillermo y Río Leona.

- Cotejar los datos logrados con otros datos paleoclimáticos obtenidos en estudios previos realizados por diversas áreas (e.g. sedimentología, palinología, micropaleontología, etc.).

- Finalmente, con la información obtenida, intentar establecer un modelo paleoclimático para el Paleógeno y el Mioceno inferior de Patagonia.

\section{ANTECEDENTES}

\subsection{Anatomía del leño como indicador climático}

Las relaciones entre la anatomía del xilema secundario y los factores climáticos fueron propuestas por los primeros anatomistas de la madera (i.e. Bailey \& Tupper 1918; Douglass, 1919; Frost, 1930a, b).

Douglass $(1919,1920)$ fue de los pioneros en relacionar el ancho de los anillos de crecimiento con la disponibilidad de agua, al estudiar las coníferas del hemisferio norte. Él razonó que en los años más secos se producirían anillos más angostos y así se podría utilizar el ancho de los anillos como un medio para calcular el tiempo y el clima. Remarcó el hecho de hallar patrones de anillos de gran similitud en lugares geográficamente muy distantes pero con un clima en común, lo que indicaba que dichos patrones representarían un registro de las condiciones ambientales sobre la región. Fue Douglass quien desarrolló el índice de sensibilidad media y lo definió como "la diferencia entre dos anillos sucesivos dividido la media". También acuñó por primera vez los términos "complaciente" y "sensitivo", aplicables a los leños según posean anillos aproximadamente del mismo tamaño, o muy variables entre ellos (Douglass, 1919, 1920, 1928, 1936). 
Fritts (1976), describió los conceptos y principios básicos del campo de la dendrología, haciendo hincapié en el subcampo de la dendroclimatología; entendiéndose ésta como la ciencia encargada del estudio dendrocronológico del clima pasado y presente. Además, trató la variación de los procesos físicos y biológicos que están involucrados en la relación medioambiente-crecimiento. Describió las características de crecimiento y discutió los procesos fisiológicos que más contribuyen a las variaciones anuales en el ancho de los anillos. Las variables ambientales importantes que limitan cada proceso fueron descriptas, y éstas se relacionaron tanto con factores meteorológicos, como con la cantidad de energía y agua en el lugar. También, presentó modelos biológicos que relacionan la precipitación y la temperatura del aire con la variación en el ancho de los anillos. Por último, trató con características y análisis estadísticos de los anillos, y describió maneras de calibrar las variaciones en el ancho de los anillos con las variaciones en el clima. Fritts (1976) en su libro expuso numerosas aproximaciones a la reconstrucción de climas del pasados, utilizando datos de anillos de crecimiento, manteniendo además en vigencia el índice de sensibilidad media propuesto por Douglass (1936).

Los autores anteriormente mencionados fueron algunos de los primeros, y más destacados, en notar el valor de los anillos de crecimiento a la hora de inferir las condiciones bajo las que vivió el árbol o arbusto en cuestión. Desde entonces, se han publicado numerosos trabajos y libros documentando la relación existente entre los anillos de crecimiento y las condiciones ambientales bajo las cuales éstos se forman. Estos trabajos establecen que (como la producción de una anillo puede llevar varios meses) ellos sirven a modo de registro de los factores externos que influyeron en la planta durante la temporada de crecimiento y por esto son fuente de información detallada acerca de la estacionalidad, las condiciones anuales de crecimiento, la disponibilidad de agua, las temperaturas limitantes y la productividad del bosque (Scott, 1972; Chaloner \& Creber, 1973; Creber, 1977; Hughes et al., 1982; Creber \& Chaloner, 1984a, b; Schweingruber, 1988, 2007; Creber \& Francis, 1999; Vaganov et al., 2006; Boninsegna et al., 2009).

Los anillos (o alteraciones en éstos) también pueden desarrollarse debido a causas no directamente climatológicas, como ser el daño de insectos (Creber, 1977; 
Schweingruber, 1988) o la caducidad de las hojas (Falcon-Lang, 2000a, b), y también responden a un patrón genético. No obstante, los estudios señalan que es un método confiable y hoy en día los anillos de crecimiento son el carácter de la madera más comúnmente utilizado en lo que a inferencias climáticas se refiere. La dendroclimatología es mencionada en literatura específica de paleoclimatología (Gornitz, 1995) y hay numerosos trabajos en los cuales se analizan anillos de crecimiento en leños fósiles (Chapman, 1994; Brea, 1993, 1998a; Taylor \& Ryberg, 2007; Brea et al., 2005a, b, 2007, 2008a; Fletcher et al., 2015; entre otros).

Entre los caracteres anatómicos utilizados para estudios de clima se destaca Carlquist (1977), quien creó los Índice de Vulnerabilidad y de Mesomorfía. Estos están basados en ciertos caracteres anatómicos del leño de angiospermas (principalmente de características asociadas a los elementos de vaso) y se correlacionan con la conductividad hídrica y la disponibilidad de agua en el ambiente.

Más recientemente, Wiemann et al. $(1998,1999)$ desarrollan ecuaciones para estimar diversos parámetros climáticos, como ser la Temperatura Media Anual (MAT) y la Precipitación Media Anual (MAP), utilizando regresiones simples y múltiples. Estas se basan en la correlación existente entre algunos caracteres anatómicos de angiospermas leñosas (i.e. tipo de placa de perforación, disposición de los vasos, diámetro de los vasos, presencia de engrosamientos espiralados, disposición y abundancia del parénquima axial, tipos de radios, entre otros) y los parámetros climáticos a calcular. Los autores también utilizan las ecuaciones para el cálculo de paleotemperaturas a partir de maderas fósiles (Wiemann et al., 1999). Cabe destacar que el material empleado para sus estudios provenía en su mayoría del hemisferio norte y en los cuatro casos en los que eran del hemisferio sur, se trataba de latitudes muy bajas, prácticamente en el ecuador. Algunos de los que han utilizado estas ecuaciones para el cálculo de paleoclimas son Sakala (2007), Licht et al. (2015) y Brea et al. (2012, 2015) (éstos últimos en el hemisferio sur).

Otro índice de importancia a la hora de establecer paleoclimas es el "Nearest living relative" (NLR) o pariente vivo más cercano, el cual utiliza los requerimientos climáticos del pariente vivo más próximo al taxón fósil en estudio, o bien a una 
asociación florística, para estimar el paleoclima bajo el cual dicho taxón o asociación vivió. El método del "Coexistence Aprroach" (CA), ideado por Mosbrugger \& Utescher (1997), sigue la filosofía del NLR, asumiendo que los requerimientos climáticos de un taxón fósil son similares a aquellos del pariente más cercano desde el punto de vista sistemático. Esta técnica ha demostrado ser eficiente para reconstrucciones climáticas terrestres en el Cenozoico, brindando especialmente buenos resultados con parámetros climáticos relacionados con la temperatura y la humedad. Se puede aplicar a fósiles de diferente índole, entre ellos a los leños permineralizados (Sakala, 2007; Brea et al., 2015; Licht et al., 2015).

En los últimos años, han sido publicados algunos trabajos que reúnen éstos índices y metodologías y los aplican a las maderas fósiles de determinadas localidades a fin de estimar como era el clima en la región (Sakala, 2007; Licht, 2015; MartínezCabrera et al., 2014). Algunos de dichos trabajos fueron realizados en el hemisferio sur (Poole et al., 2005; Brea et al., 2015).

\subsection{Inferencias paleoclimáticas en las formaciones de estudio}

\section{Fm. Cerro Bororó (Paleoceno-Chubut):}

Petriella (1972) publica "Estudios de maderas petrificadas del terciario inferior del área central de Chubut (Cerro Bororó)". En el mencionado trabajo (producto del desarrollo de su tesis doctoral) hace una excelente descripción del material estudiado, lo determina y lo compara con otros taxones, tanto fósiles como actuales, llegando a conclusiones biogeográficas y paleoambiantales. Si bien este trabajo es remarcable, el mismo Petriella señala que, en lo referente al clima, la única evidencia que surge del material es la presencia de anillos de crecimiento poco demarcados. Agrega que el resto de las condiciones climáticas deben, por lo tanto, ser deducidas teniendo en cuenta la distribución geográfica y la frecuencia latitudinal y altitudinal de los taxones afines a los fósiles.

Archangelsky (1973) y Archangelsky \& Romero (1974) hacen muy escasos comentarios sobre las condiciones ambientales bajo las que se habrían encontrado las plantas productoras de algunas de las esporas y granos de polen que describen. 
Petriella \& Archangelsky (1975) presentan un trabajo que integra la información de sus estudios previos, junto con información de paleontología de vertebrados, micropaleontología y sedimentología, con el fin de realizar una reconstrucción de las comunidades vegetales y el clima imperante en el Paleoceno del Chubut. Aquí también hacen mención a la Fm. Salamanca.

Arguijo $(1979,1981)$, argumenta un clima templado en base a la presencia de palmeras.

Más recientemente Volkheimer et al. (2007) y Scafati et al. (2009) efectúan nuevos estudios paleopalinológicos con material proveniente de Cerro Bororó, y hacen comentarios acerca de los requerimientos de temperaturas cálidas de la palinoflora.

Los mencionados estudios paleobotánicos y paleopalinológicos concuerdan en que durante el Daniano, en el área de Cerro Bororó, el régimen climático habría sido templado cálido y con una marcada humedad. Las conclusiones en base al estudio de la sedimentología del lugar también coinciden con estos resultados (Andreis et al., 1973).

\section{Fm. Salamanca (Paleoceno-Chubut):}

En cuanto a la Fm. Salamanca las publicaciones referentes a la localidad estudiada en la presente tesis (Estancia Las Violetas) $y$, por consiguiente, las menciones de cómo habría sido el paleoclima, son mínimas (Somoza et al., 1995; Futey et al., 2012, Ruiz et al. 2017).

De cualquier manera, esta formación aflora en otras localidades que han sido más estudiadas y que cuentan con abundante información de cómo habrían sido las condiciones climáticas en esa época. Por ejemplo, Romero (1968) hace algunos comentarios acerca de las probables temperaturas del Paleoceno inferior en base a la presencia de restos de palmeras. Luego, propone una diferenciación en tres paleofloras en el sur de Sudamérica (neotropical, mixta y antártica) y menciona a la Fm. Salamanca como perteneciente a la paleoflora neotropical (Romero, 1986).

En base a un estudio interdiciplinario, Matheos et al. (2005) dan a conocer las condiciones paloecológicas y paleoambientales de los bosques fósiles Víctor Szlápelis y Bosque José Ormaechea (Fm. Salamanca, Provincia del Chubut). Allí integran los 
resultados obtenidos a partir de esporas de algas, briofitas y helechos, granos de polen, dinoflagelados, fitolitos, estomatocistos, radiolarios, espículas de esponjas, compresiones e impresiones foliares, troncos permineralizados y el análisis composicional y textural de las sedimentitas portadoras de dicha fauna y flora.

Posteriormente, Brea et al. (2005a, b, 2011) realizan un estudio de los anillos de crecimiento de maderas fósiles, a fin de obtener inferencias paleoclimáticas en los bosques Víctor Szlápelis, Ormaechea y Ameghino, todos ubicados en la provincia del Chubut y en afloramientos pertenecientes a la Fm. Salamanca.

Iglesias (2007) en su tesis doctoral, realiza aportes a la paleoecología de la Fm. Salamanca en base al estudio de impresiones foliares, incluyendo el cálculo de paleotemperaturas. Consecutivamente, Iglesias y colaboradores (2007) calculan el MAT y el MAP de la Fm. Salamanca en base a márgenes foliares (Iglesias et al., 2007).

Zucol et al. (2008) hacen mención a las probables condiciones paleoambientales de los bosques fósiles Víctor Szlápelis y Bosque José Ormaechea a partir del estudio de microfósiles silíceos.

Clyde y colaboradores (2014) calculan la edad de la formación en base a foraminíferos, nanofósiles calcáreos, dinoflagelados, isótopos y paleomagnetismo. Allí mencionan brevemente que la presencia de ciertos palinomorfos darían indicios de cómo fue el paleoambiente.

Todos los autores mencionados concuerdan en que la Formación Salamanca se habría desarrollado en condiciones de clima cálido y húmedo.

\section{Fm. Río Turbio (Eoceno-Oligoceno-Santa Cruz):}

Hünicken (1955, 1967), en base a asociaciones florísticas, hace una breve mención a que el clima fue en principio cálido y húmedo, aunque no muy marcado, ya que permitía el desarrollo de algunos elementos florísticos de clima algo más templado en las partes altas del relieve. En cambio, hacia el tope de la formación habría llegado a climas templado fríos.

Volkheimer (1971) menciona que en el Eoceno medio las floras habrían sido más tropicales. 
Romero (1977) compara asociaciones vegetales actuales y fósiles de la formación, concluyendo que la vegetación existente en el Eoceno de la zona de Río Turbio debió desarrollarse en un área con un clima marítimo y templado, sin extremos de temperatura y con lluvias abundantes. Luego, Troncoso \& Romero (1998), infieren un clima cálido en base a la composición paleoflorística de la formación, la cual es asignada como una "paleoflora mixta con Nothofagus".

Brea (1993) realizó inferencias paleoclimáticas a partir de los anillos de crecimiento de Nothofagoxylon ruei Salard, concluyendo que el taxón habría crecido en una región de clima templado con estacionalidad marcada.

Panti $(2010,2014)$ hace inferencias sobre la temperatura del Eoceno de Santa Cruz en base a impresiones foliares provenientes de la Fm. Río Turbio, incluyendo la temperatura media anual. Determina que el clima fue templado cálido y resalta la diferencia de temperatura entre los miembros inferior y superior de la Formación Río Turbio (más bajas hacia el superior).

Fernández (2018) estudia la palinoflora de la formación y en base a los posibles requerimientos de los elementos de las asociaciones encontradas, concluye que el clima era templado cálido, húmedo y marítimo, sin temperaturas extremas y con fluctuaciones menores en el régimen de precipitaciones.

\section{Fm. Río Guillermo (Oligoceno-Santa Cruz):}

Hünicken (1995) cita condiciones climáticas cálidas o templadas húmedas en esta formación en base a las características de las tafofloras que examina.

Panti $(2010,2011)$ también estudia impresiones foliares y menciona que, de acuerdo a la composición florística, el clima habría sido templado-frío.

\section{Fm. Río Leona (Mioceno-Santa Cruz):}

Los estudios previos que hacen mención al paleoclima de esta formación, de edad miocena, son escasos. Hay breves menciones en los trabajos de Barreda et al. (2009) y Césari et al. (2015). Ambos trabajos se basan en las asociaciones florísticas encontradas y concluyen que el clima era templado y húmedo. 


\section{2}

\section{MARCO GEOGRÁFICO Y GEOLÓGICO}

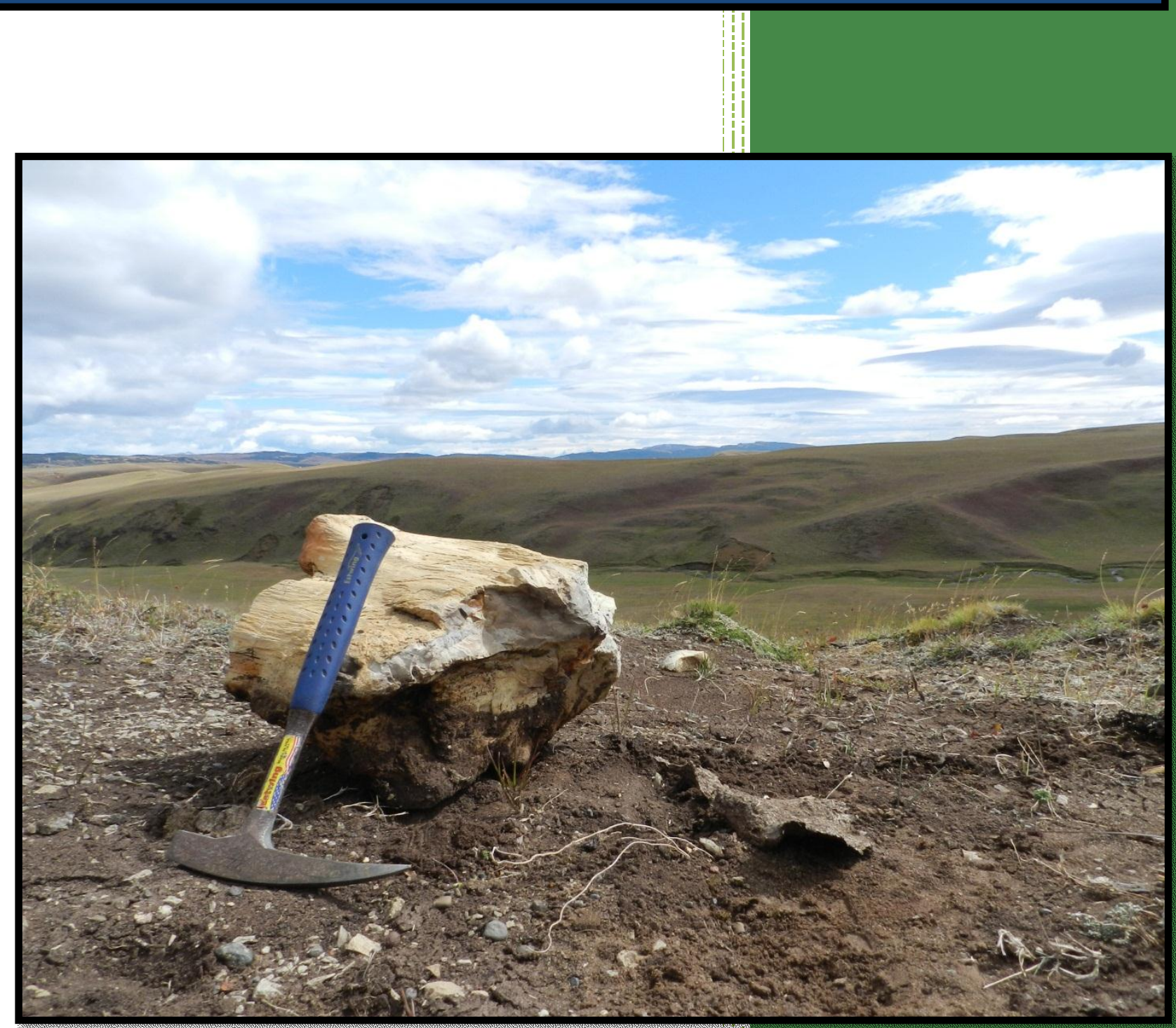

Daniela P. Ruiz 
El material estudiado proviene de formaciones que comprenden temporalmente gran parte del Paleógeno y parte del Neógeno (Fig. 2.1). Dichas formaciones afloran en distintas localidades pertenecientes a dos cuencas de gran importancia en el extremo austral de Sudamérica. Ellas son la Cuenca del Golfo San Jorge y la Cuenca Austral (Figs. 2.1 y 2.2).

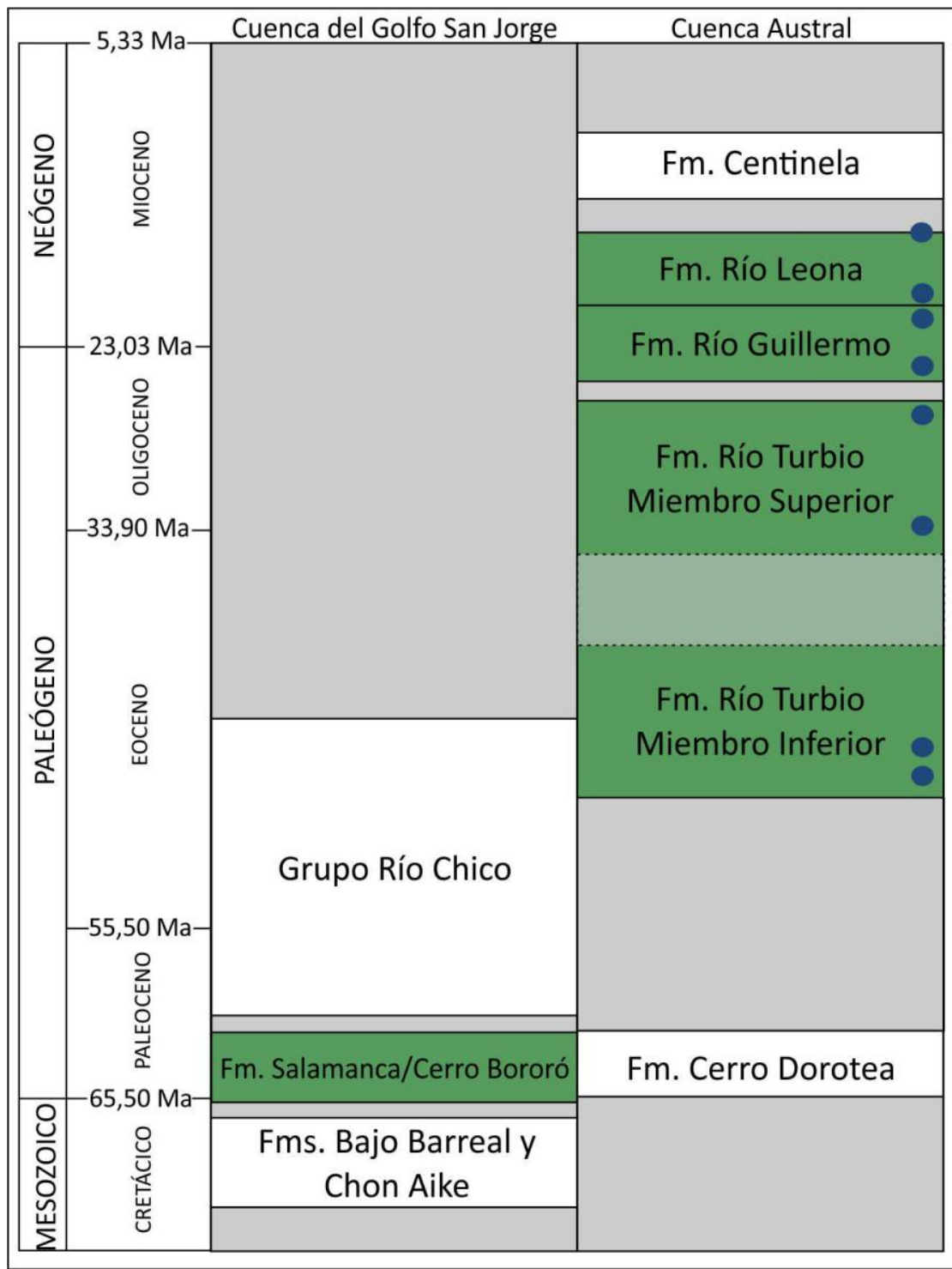

Fig. 2.1. Cuadro estratigráfico. Los puntos en azul indican las dataciones de Fosdick et al. (2011, 2015). 


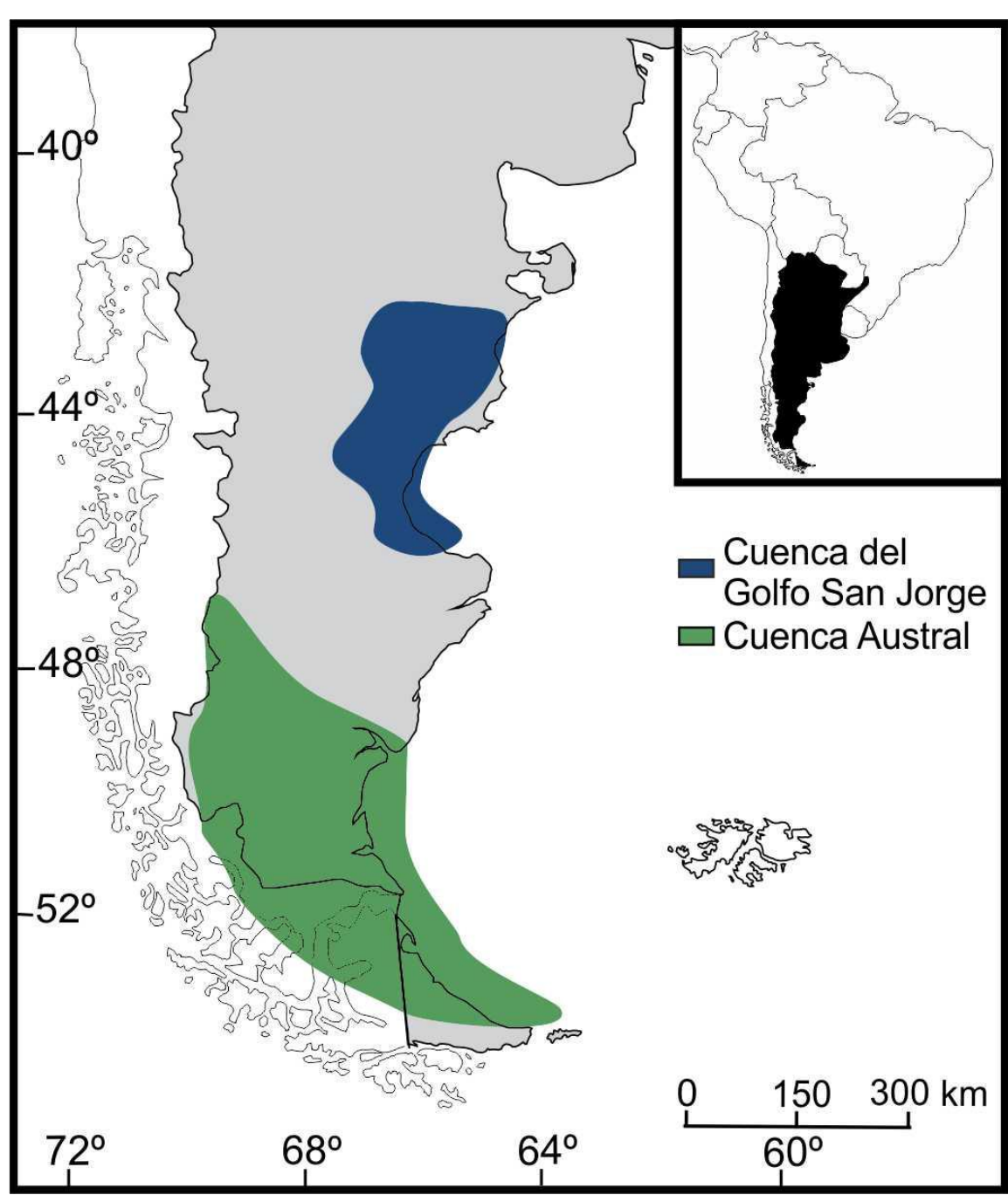

Fig. 2.2. Mapa de cuencas. Cuenca del Golfo San Jorge y Cuenca Austral ubicadas en la Patagonia argentina. Modificado de Marenssi et al., 2005 y Scafati et al., 2009.

\section{CUENCA DEL GOLFO SAN JORGE}

La cuenca del Golfo San Jorge (Fig. 2.2) se desarrolla en dirección este-oeste entre dos áreas relativamente positivas: el Macizo Norpatagónico por el norte y el Macizo del Deseado por el sur, con una superficie total de $170.000 \mathrm{~km}^{2}$ (Sylwan, 2001).

Es una cuenca intracontinental extensional ligada a la ruptura de Gondwana y la apertura de la parte sur del Océano Atlántico durante el Jurásico. La mayor parte del relleno de la cuenca son depósitos piroclásticos y epiclásticos que van desde el Jurásico al Mioceno (Barcat et al., 1989; Fitzgerald et al., 1990). 


\subsection{Formación Cerro Bororó}

La Formación Cerro Bororó aflora en el cerro homónimo ubicado a $40 \mathrm{~km}$ al oeste de la localidad de Las Plumas, en el departamento de Mártires, provincia del Chubut, Argentina (Fig. 2.3).
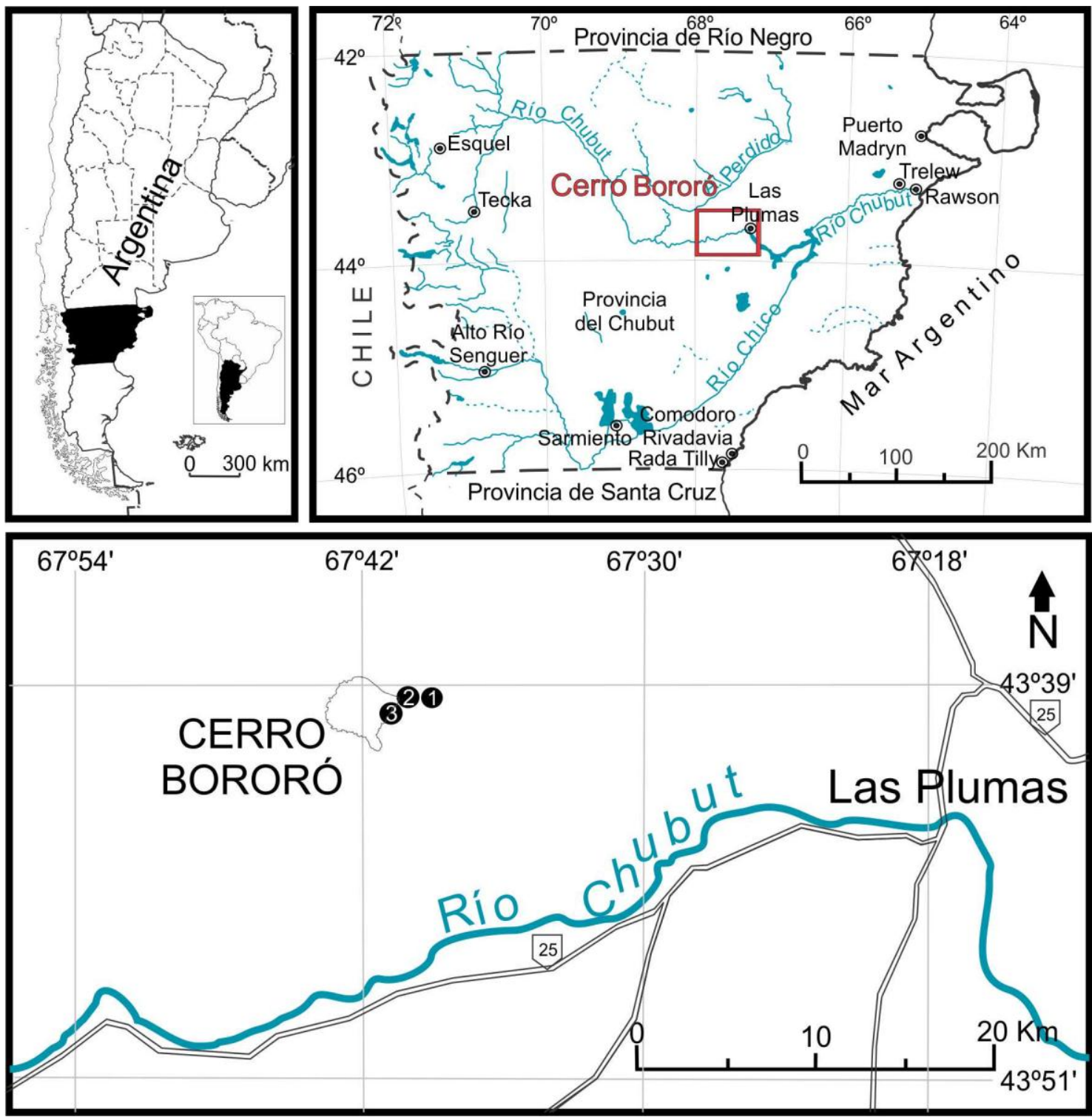

Fig. 2.3. Zona de Cerro Bororó (Fm. Cerro Bororó). 1. Nivel de coníferas - Puesto Fernández. 2. Nivel de angiospermas. 3. Nivel de cicadales. Mapa adaptado de Petriella (1972).

Anzulovich \& Raso (1961) reconocieron las unidades allí aflorantes, dos de las cuales fueron consideradas equivalentes a las Formaciones Salamanca y Río Chico. Petriella (1972) distinguió estas dos unidades como Fm. Cerro Bororó y Fm. Puesto Fernández. Andreis et al. (1973) señalan que la mayor parte del Cerro Bororó está constituido por la formación de igual nombre y que dicha formación se divide en tres 
miembros (inferior, medio y superior). Actualmente se la vuelve a mencionar como Formación Salamanca (Anselmi et al., 2004) según las correlaciones efectuadas por Spalletti (1980) y Panza (1981). Dado que sigue siendo la misma formación y es solo una cuestión nomenclatural, a los fines prácticos en esta tesis, se refiere a este afloramiento en particular como Formación Cerro Bororó (separada del resto de la Formación Salamanca), porque así es considerada en toda la literatura referente a la zona.

La Formación Cerro Bororó tiene una potencia que oscila entre 112 m y 276 m, con psamitas gruesas en su base, coquinas en el miembro medio y psamitas finas y pelitas hacia el final de la columna (Fig. 2.4). Yace en aparente concordancia sobre la Formación Bajo Barreal (Cretácico Superior) y por encima, en discordancia erosiva, se encuentran las "psamitas y conglomerados morados" (Andreis et al., 1973). De acuerdo a estudios microfaunísticos, se le asigna a la formación una edad paleocena, más concretamente daniana (Bertels, 1973). Las capas se conformaron en un medio ácueo fluvial y litoral (Andreis et al., 1973).

En la zona se realizaron estudios de leños y estípites petrificados (Archangelsky et al., 1969; Petriella, 1972; Arguijo, 1979, 1981), varios estudios paleopalinológicos (Archangelsky, 1973, 1976; Romero, 1973; Archangelsky \& Romero, 1974; Archangelsky \& Zamaloa, 1986; Volkheimer et al., 2007; Scafati et al., 2009) y los análisis microfaunísticos de Bertels (1973).

Los materiales aquí estudiados son los colectados por Petriella (1972) quien diferenció tres niveles fosilíferos donde se hallaron leños petrificados: 1) miembro inferior, nivel portador de troncos de coníferas; 2) miembro superior, nivel de Angiospermas; 3) también miembro superior, nivel de Cicadales (Fig. 2.4) (Andreis et al., 1973). Además se estudiaron ejemplares colectados del nivel inferior por la Dra. M. Brea en una campaña realizada en el año 1999. 


\section{Sección "Facies Fernández"}

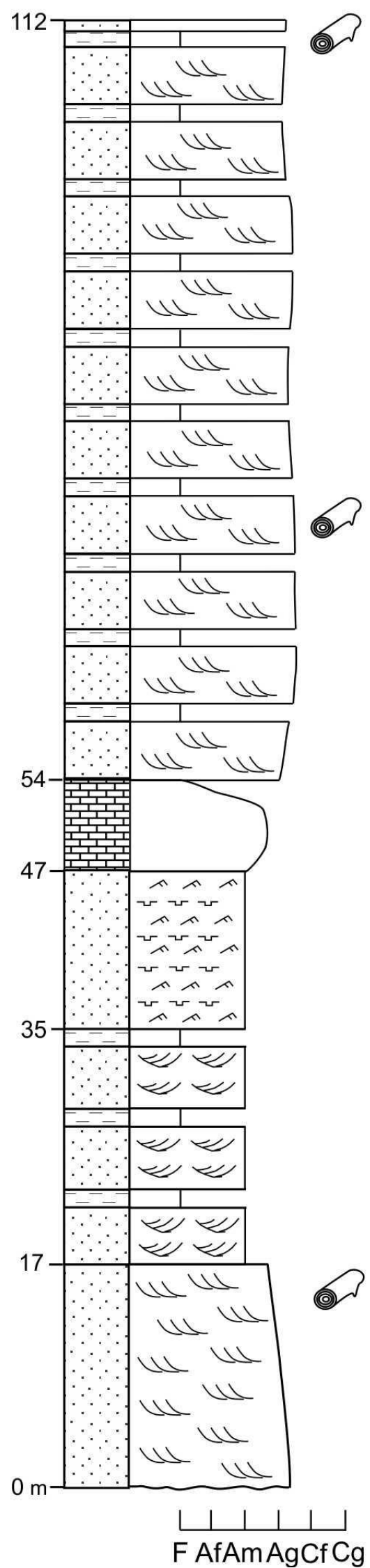

\section{REFERENCIAS}

Pelita

$\because \therefore$ Arenisca

臣置 Calizas

$\square$ Masivo

Lineación "parting"

NA⿵ Ondulitas

Estratificación entrecruzada en artesa

Estratificación entrecruzada

() Leños fósiles

Fig. 2.4. Columna estratigráfica de la Fm. Cerro Bororó. Adaptada a partir de Petriella (1972) y Andreis et al. (1973). 


\subsection{Formación Salamanca}

La unidad en cuestión representa la primera ingresión atlántica en la Cuenca del Golfo San Jorge (Feruglio, 1949) y aflora en varias localidades en el centro-sur de la provincia del Chubut (Fitzgerald et al., 1990) (Fig. 2.5).

Estos estratos fueron estudiados por Feruglio (1949), quien los denominó "Salamanquense". Lesta \& Ferello (1972) le asignan un nombre formal como Formación Salamanca y Andreis et al. (1975) la dividen en dos miembros: Miembro Hansen y Miembro Bustamante.
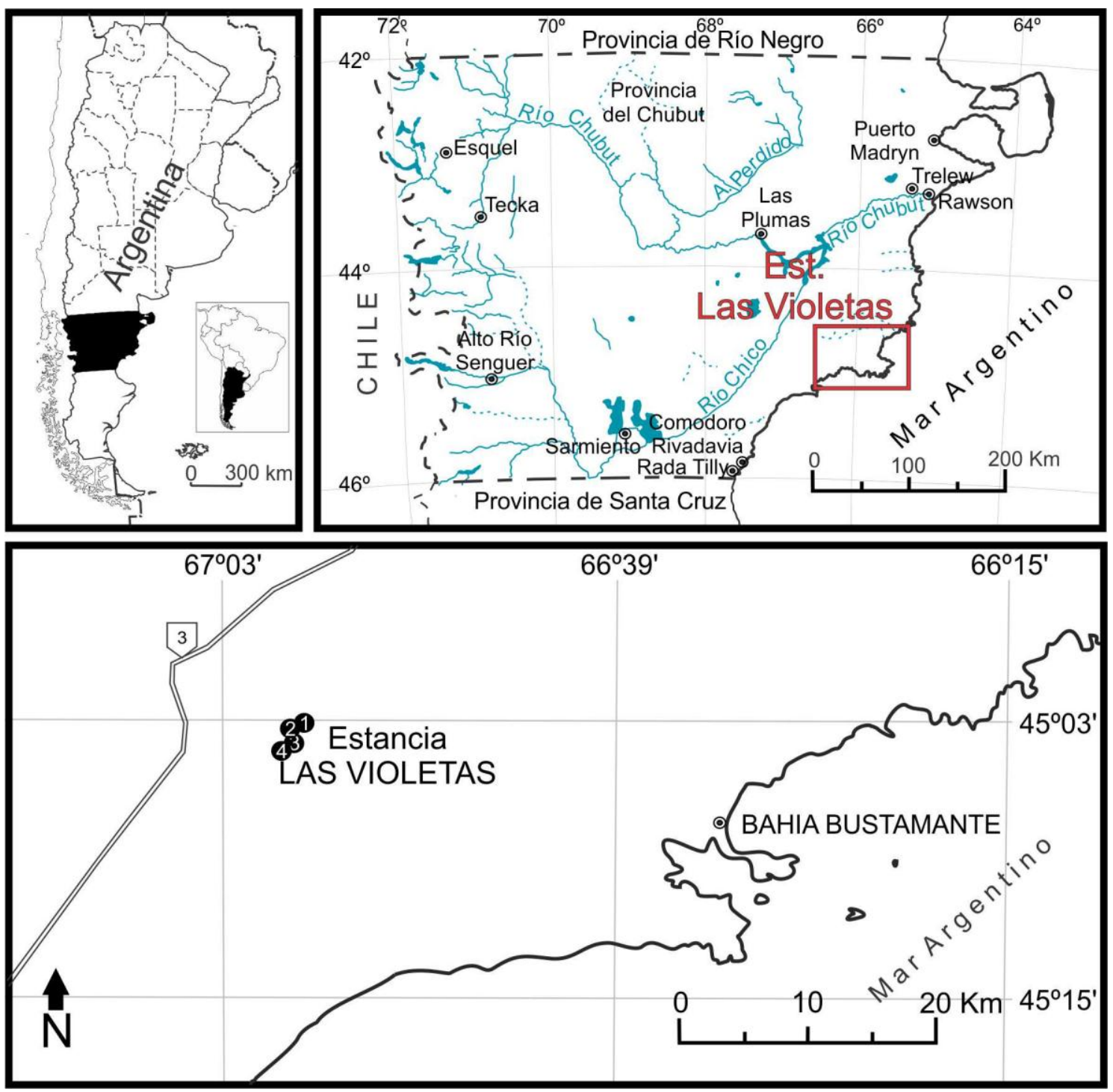

Fig. 2.5. Localidad de Estancia Las Violetas (Fm. Salamanca). 1. Nivel L1. 2. Nivel L2. 3. Nivel L3. 4. Nivel L4.

En dicha localidad, la sucesión cuenta con aproximadamente $15 \mathrm{~m}$ de espesor que van de un grano fino verdoso hasta un fango negruzco (Fig. 2.6). Apoya en 
discordancia sobre la Formación Chon Aike (Andreis et al., 1975) y se encuentra por debajo de los "Niveles transicionales" definidos por Raingemborn et al. (2010), a los que le sigue el Grupo Río Chico (Paleoceno inferior-Eoceno medio) (Raingemborn et al., 2014).

La Formación Salamanca tiene una edad daniana comprendida entre los 65,7 y los 63,5 Ma, según datos palinológicos y estudio de isótopos (Clyde et al., 2014). La sección fosilífera superior en la Estancia Las Violetas fue asignada al Chron 27r por Futey et al., (2012) y previamente por Somoza et al. (1995). Dicho chron está datado en 63,5 y 62,5 Ma. La Fm. Salamanca es correlacionable con la anteriormente mencionada Fm. Cerro Bororó (Bertels, 1973; Andreis et al., 1973; Chebli \& Serraiotto, 1974).

La Formación Salamanca cuenta con registro de microfósiles de invertebrados (Camacho, 1967; Méndez, 1966; Chebli \& Serraiotto, 1974; Zucol et al., 2008; Clyde et al., 2014), bivalvos y braquiópodos (Chebli \& Serraiotto, 1974), equinoideos (Parma \& Casadío, 2005), tortugas y cocodrilos (Staesche, 1929; Simpson, 1937; Bona, 2005, 2007; Bona \& De La Fuente, 2005), mamíferos (Bonaparte et al., 1993; Bonaparte \& Morales, 1997; Pascual et al., 1992, 2002; Forasiepi \& Martinelli, 2003; Gelfo \& Pascual, 2001; Gelfo, 2007; Gelfo et al., 2007, 2009). También hay abundantes restos vegetales, incluyendo impresiones/compresiones foliares (Martínez, 1992; Iglesias, 2007; Iglesias et al., 2007; Jud et al., 2017), impresiones/compresiones de flores (Jud et al., 2017), leños permineralizados (Berry, 1932; Ragonese, 1980; Brea et al., 2005 a, b, 2007, 2008b, 2011), estípites de palmeras (Romero, 1968) y granos de polen y esporas (Archangelsky, 1973, 1976; Romero, 1973; Archangelsky \& Romero, 1974; Archangelsky \& Zamaloa, 1986; Clyde et al., 2014). Específicamente en la localidad de la Estancia Las Violetas hay registros de troncos, estípites, frutos y semillas permineralizadas e impresiones de hojas (Berry, 1932; Somoza et al., 1995). Los frutos y semillas, que corresponden a palmeras fueron estudiados en detalle por Futey et al. (2012) y los troncos son los estudiados en este trabajo de tesis y recientes publicaciones (Ruiz et al., 2017). 


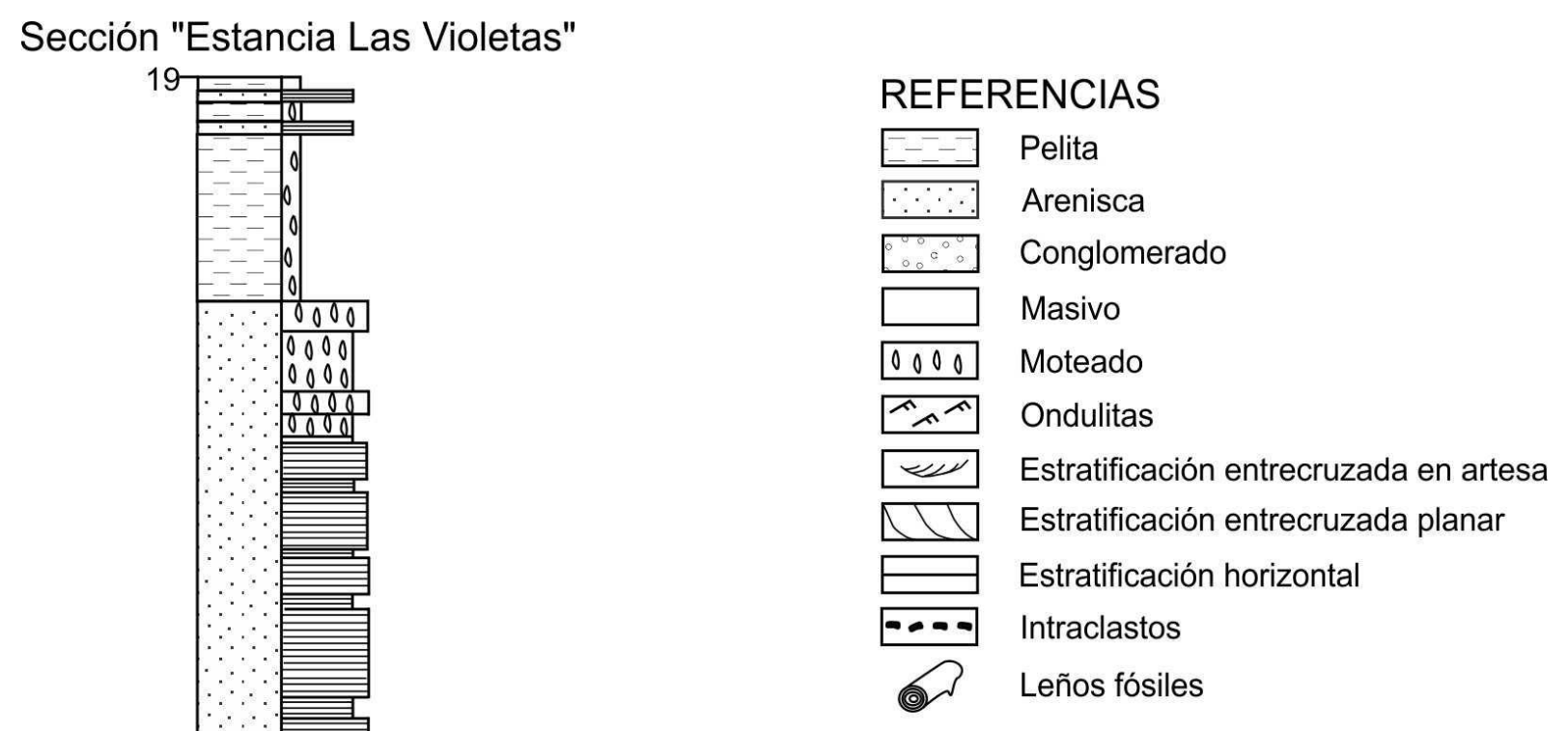


El material de la Formación Salamanca proviene de una única localidad: Estancia Las Violetas $\left(45^{\circ} 04^{\prime} \mathrm{S}\right.$ y $66^{\circ} 59^{\prime} \mathrm{W}$ ) (Fig. 2.5), que corresponde al miembro superior (Miembro Hansen). Allí se identificaron 4 niveles fosilíferos: nivel L1 (con ramitas, estípites de palmera, y también frutos de palmeras), nivel L2 (troncos de gimnospermas y frutos de palmeras), nivel L3 (troncos de angiospermas y restos varios de palmeras) y nivel L4 (troncos de gimnospermas y angiospermas y frutos de palmeras). En la presente tesis se estudian los leños de los niveles L2 y L3 (Figs. 2.5, $2.6,2.7)$.
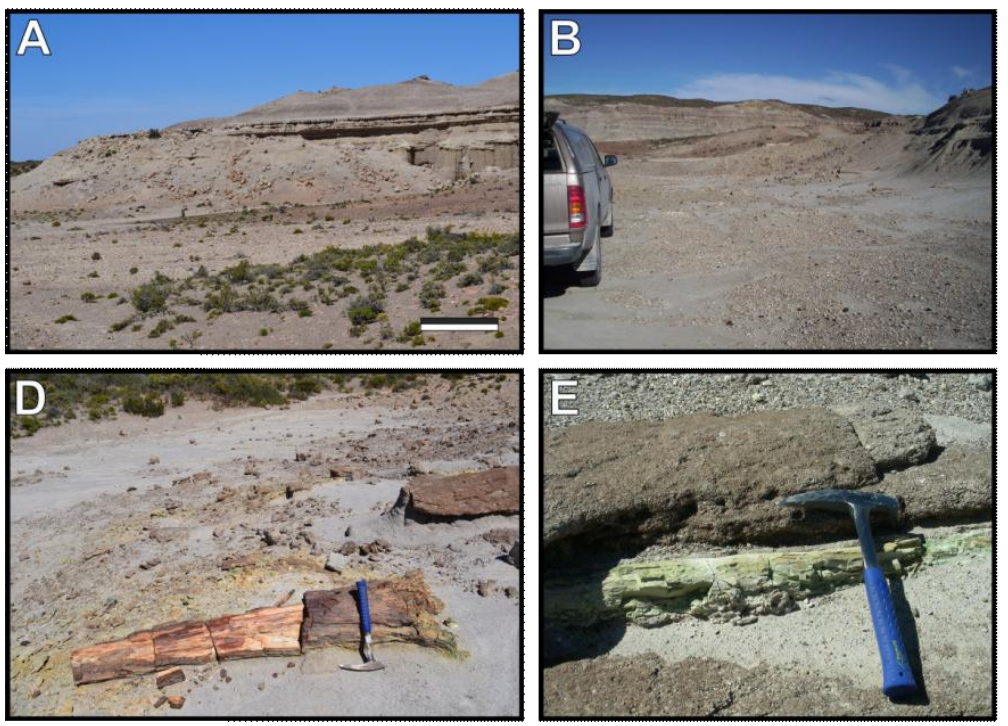

Fig. 2.7. Vista general de algunos de los afloramientos de la Fm. Salamanca. A: vista general de la localidad. B,C: nivel L2. D: nivel L3. E,F. Detalle de muestras en el campo. Escala A: 1 m.

\section{CUENCA AUSTRAL}

La Cuenca Austral o Cuenca de Magallanes se encuentra en el extremo más austral de Sudamérica (Fig. 2.2) y cuenta con más de $9000 \mathrm{~m}$ de sedimentos depositados desde el período Jurásico hasta el Cenozoico. La misma es una cuenca de retroarco cuyo inicio coincide con la apertura del Océano Atlántico (Russo et al., 1980; Biddle et al., 1986).

En el extremo sur de la provincia de Santa Cruz (Argentina), en el área cordillerana, afloran distintos depósitos entre los cuales se reconocen las Formaciones Río Turbio, Río Guillermo y Río Leona (Malumián \& Panza, 2000). 


\subsection{Formación Río Turbio}

Brandmayr (1945), fue el primero en estudiar los estratos de esta formación y distinguió dos secciones, una marina y una continental. Posteriormente, Hünicken (1955) designó como estratos de Río Turbio a los sedimentos pertenecientes a la sección marina de Brandmayr, que afloran en los alrededores de las minas de Río Turbio (Figs. 2.8 y 2.11), mientras que la sección continental se conoce ahora como Fm. Río Guillermo y Río Leona. Años más tarde, Leanza (1972) adoptó formalmente el nombre de Formación Río Turbio. Esta formación se divide tradicionalmente en dos miembros, inferior y superior (Furque \& Caballé, 1993).

La Formación Río Turbio cuenta con aproximadamente 600 m de espesor total (Fig. 2.9). Sobreyace la Formación Dorotea, separada de ésta mediante un contacto erosivo y un contacto disconforme la separa de la suprayacente Formación Río Guillermo (Furque \& Caballé, 1993).

Se sugierió una edad eocena media a eocena tardía para la formación en base al registro paleontológico de invertebrados y palinomorfos (Malumián \& Panza, 2000; Guerstein et al., 2010). Recientemente estudios geocronológicos de zircones datan al miembro inferior de la formación en 47-46 Ma, y el miembro superior en 33-26 Ma, extendiendo la edad de la formación hasta el Oligoceno y desplazando toda la columna estratigráfica utilizada hasta el momento (Fosdick et al., 2015).

Azcuy \& Amigo (1991) interpretaron el paleoambiente de la formación como costero marino dominado por oleaje y mareas, con un clima templado y sin temperaturas extremas. 

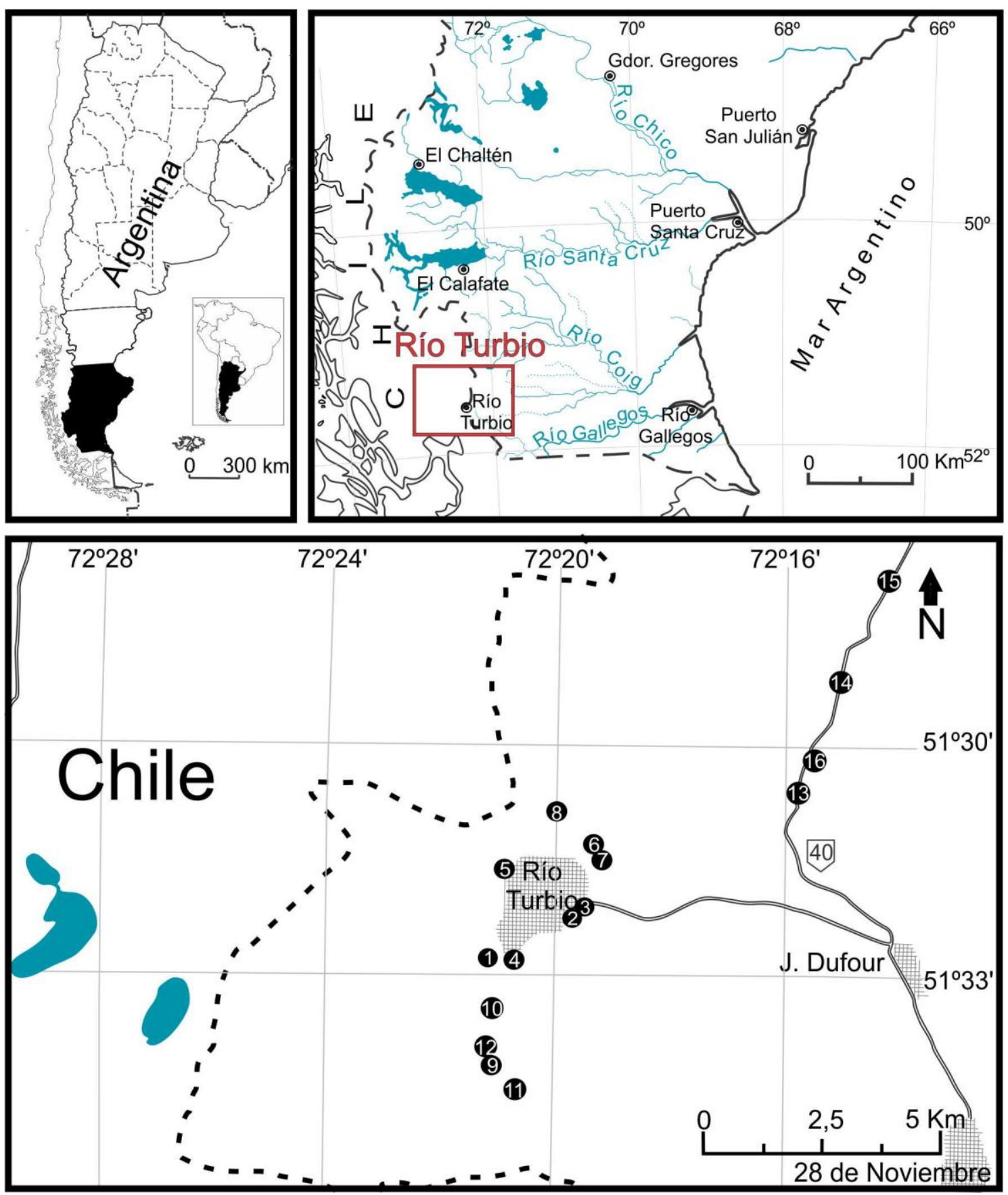

Fig. 2.8. Localidades fosilíferas en la zona de Río Turbio (Fm. Río Turbio-RT). 1. RT1. 2. RT2. 3. RT4. 4. RT5. 5. RT6. 6. RT17. 7. RT18. 8. RT20. 9. RT21. 10. RT23. 11. RT24. 12. RT28. 13. RT7. 14. RT12. 15. RT15. 16. RT16.

Fig. 2.9. Columna estratigráfica esquemática de dos secciones de la Formación Río Turbio. Adaptado de Pujana, 2008 (tomado de Marenssi inédito). La sección "Arroyo Santa Flavia" corresponde al miembro inferior y la sección "Estancia Primavera" al miembro superior. 


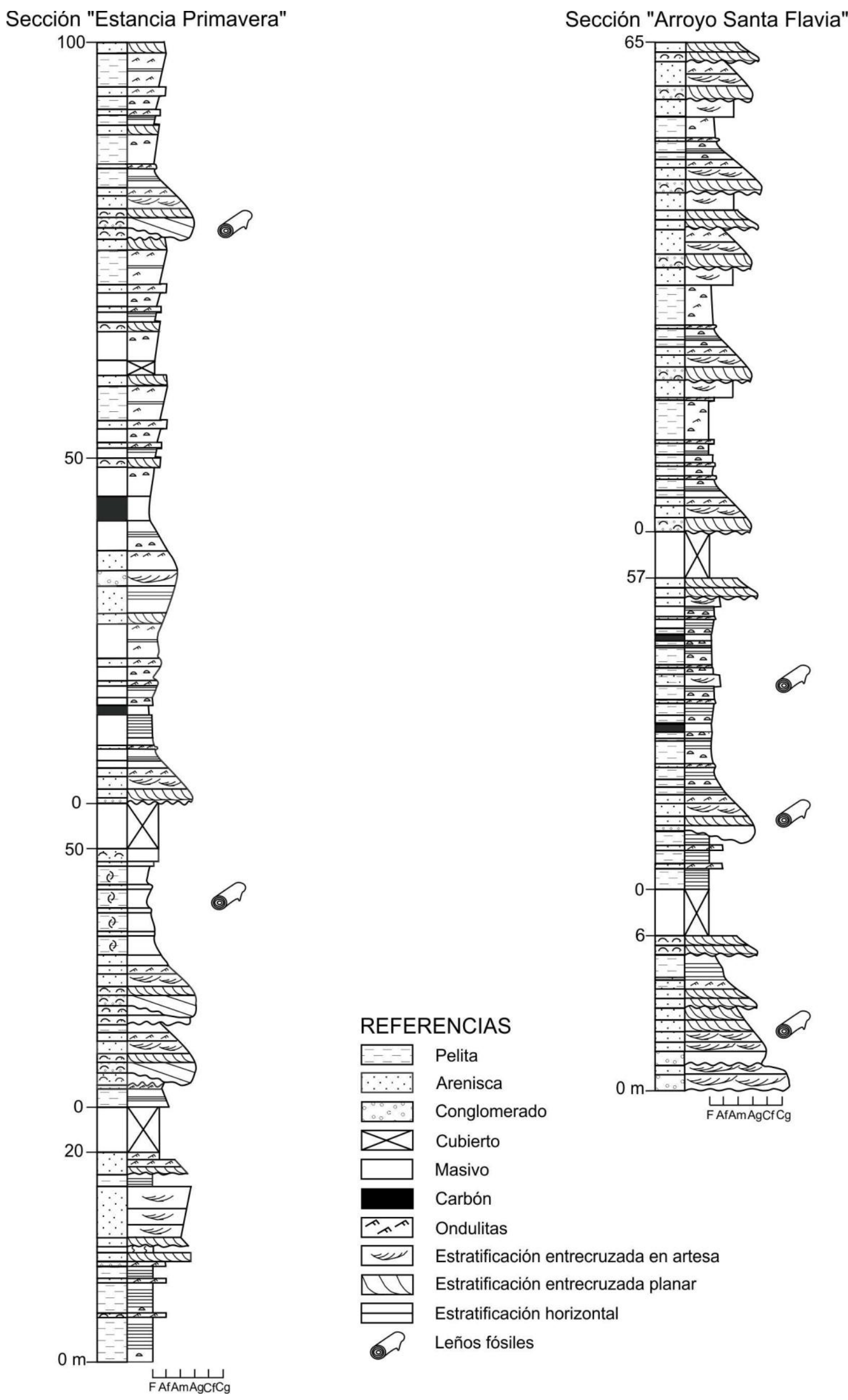



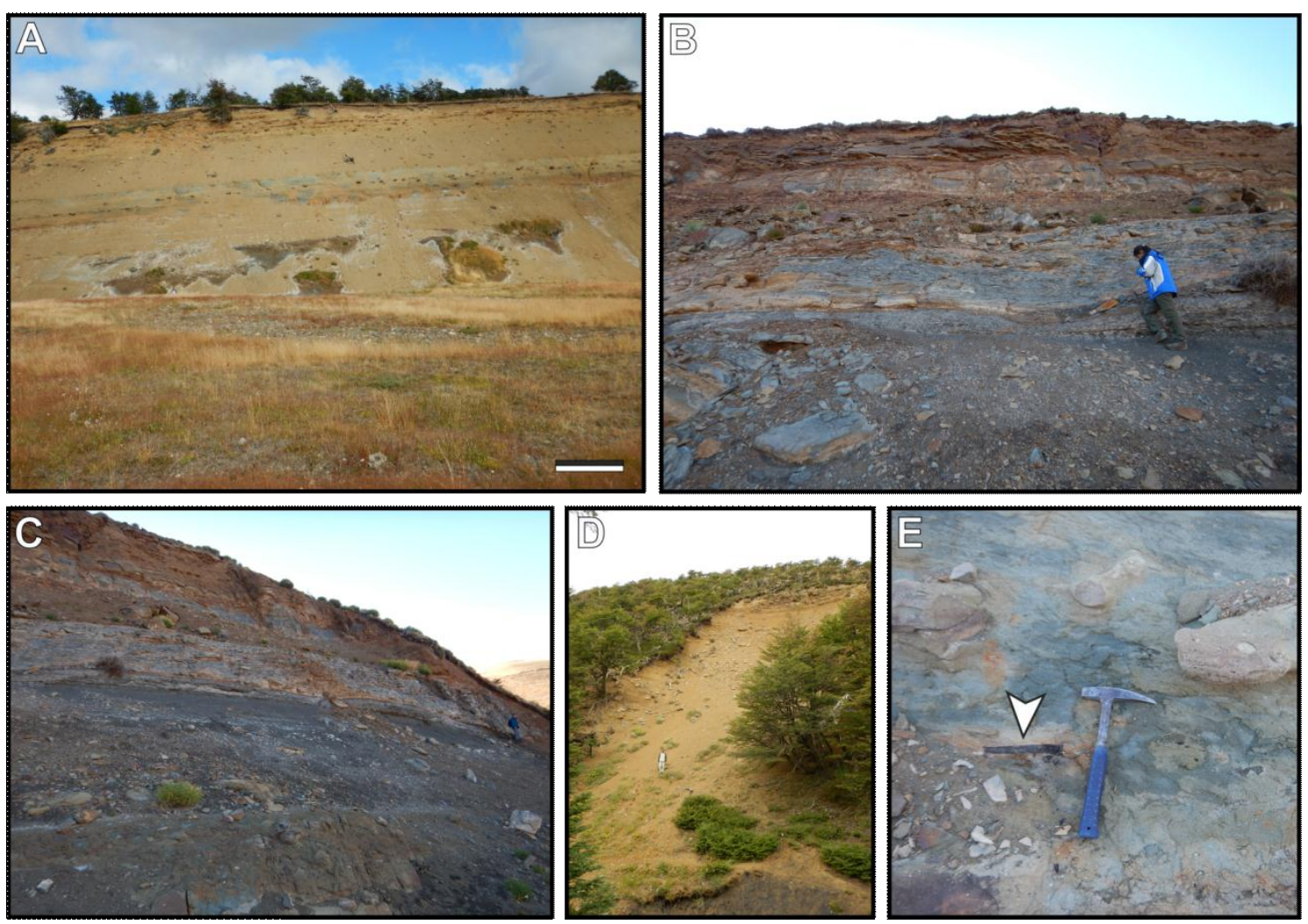

Fig. 2.10. Vista general de algunos de los afloramientos de la Fm. Río Turbio. A. Sección de Estancia primavera. B,C. RT9 D. RT24. E. Muestra en el campo.

Los primeros datos fosilíferos de la formación son aquellos aportados por Hünicken (1955) que cita la presencia de fósiles marinos de invertebrados (braquiópodos, lamelibranquios y gastrópodos), así como de restos continentales de plantas (pteridofitas, gimnospermas y angiospermas). Posteriormente, hay registros vegetales que incluyen raíces y tallos petrificados (Ancibor, 1989, 1990; Pujana, 2008; Pujana et al., 2009, Pujana \& Ruiz, 2017), hojas (Berry, 1937b; Frenguelli, 1941; Hünicken, 1955, 1967; Panti, 2010, 2014; Fernández et al., 2012) y polen (Archangelsky, 1972; Romero, 1977; Romero \& Zamaloa, 1985; Romero \& Castro, 1986; Fernández et al., 2012; Fernández, 2018). También hay registros de otros palinomorfos y microfósiles (incluidos dinoflagelados, diatomeas, foraminíferos y ostrácodos) mencionados por Archangelsky (1968, 1969), Archangelsky \& Fasola (1971), Malumián \& Caramés (1997), Guerstein et al. (2010, 2014) y González Estebenet et al. (2012, 2014, 2015).

En la presente tesis se estudia material proveniente de 20 localidades fosilíferas en los alrededores de Río Turbio denominadas con las siglas RT (referente a la Fm. Río Turbio) y un número (ver Tabla 2.1 y Figs. 2.8, 2.10 y 2.11). De estas localidades, 12 
corresponden al miembro inferior y ocho al miembro superior. Las coordenadas geográficas de cada localidad se detallan en la tabla 2.1.

\begin{tabular}{|c|c|c|c|}
\hline \multicolumn{2}{|r|}{ Miembro Inferior } & \multicolumn{2}{|c|}{ Miembro Superior } \\
\hline \multicolumn{2}{|r|}{ Fig. 2.8} & \multicolumn{2}{|r|}{ Fig. 2.8} \\
\hline Localidad & Coordenadas & Localidad & Coordenadas \\
\hline (1)RT1 & $51^{\circ} 32^{\prime} 58.0^{\prime \prime} \mathrm{S} ; 72^{\circ} 21^{\prime} 14.0^{\prime \prime} \mathrm{W}$ & (13)RT7 & $51^{\circ} 31^{\prime} 04.5^{\prime \prime S} ; 72^{\circ} 15^{\prime} 49.3^{\prime \prime} \mathrm{W}$ \\
\hline (2)RT2 & $51^{\circ} 32^{\prime} 31.5^{\prime \prime}$; $72^{\circ} 19^{\prime} 38.5^{\prime \prime} \mathrm{W}$ & (14)RT12 & $51^{\circ} 29^{\prime} 48.7^{\prime \prime S} ; 72^{\circ} 15^{\prime} 03.3^{\prime \prime} \mathrm{W}$ \\
\hline (3)RT4 & $51^{\circ} 32^{\prime} 23.7^{\prime \prime}$; $72^{\circ} 19^{\prime} 34.5^{\prime \prime} \mathrm{W}$ & (15)RT15 & $51^{\circ} 28^{\prime} 42.4^{\prime \prime S} ; 72^{\circ} 14^{\prime} 14.5^{\prime \prime} \mathrm{W}$ \\
\hline (4)RT5 & $51^{\circ} 32^{\prime} 55.0^{\prime \prime}$; $72^{\circ} 20^{\prime} 44.7^{\prime \prime} \mathrm{W}$ & (16)RT16 & $51^{\circ} 30^{\prime} 38.4^{\prime \prime S} ; 72^{\circ} 15^{\prime} 35.6^{\prime \prime} \mathrm{W}$ \\
\hline (5)RT6 & $51^{\circ} 31^{\prime} 52.6^{\prime \prime} \mathrm{S}, 72^{\circ} 20^{\prime} 54.3^{\prime \prime} \mathrm{W}$ & \multicolumn{2}{|r|}{ Fig. 2.11} \\
\hline (6)RT17 & $51^{\circ} 31^{\prime} 42.9^{\prime \prime S} ; 72^{\circ} 19^{\prime} 16.7^{\prime \prime} \mathrm{W}$ & Localidad & Coordenadas \\
\hline (7)RT18 & $51^{\circ} 31^{\prime} 48.5^{\prime \prime}$; $72^{\circ} 19^{\prime} 14.9^{\prime \prime} \mathrm{W}$ & (1)RT13 & $51^{\circ} 18^{\prime} 41.5^{\prime \prime S} ; 72^{\circ} 13^{\prime} 13.7^{\prime \prime} \mathrm{W}$ \\
\hline (8)RT20 & $51^{\circ} 31^{\prime} 16.5^{\prime \prime}$; $72^{\circ} 20^{\prime} 00.8^{\prime \prime} \mathrm{W}$ & (2)RT25 & $51^{\circ} 18^{\prime} 26.1^{\prime \prime S} ; 72^{\circ} 13^{\prime} 20.9^{\prime \prime} \mathrm{W}$ \\
\hline (9)RT21 & $51^{\circ} 33^{\prime} 51.6^{\prime \prime S} ; 72^{\circ} 21^{\prime} 12.0^{\prime \prime} \mathrm{W}$ & (3)RT9 & $51^{\circ} 27^{\prime} 21.5^{\prime \prime S} ; 72^{\circ} 13^{\prime} 44.9^{\prime \prime} \mathrm{W}$ \\
\hline (10)RT23 & $51^{\circ} 33^{\prime 2} 24.9^{\prime \prime}$; $72^{\circ} 21^{\prime} 05.7^{\prime \prime} \mathrm{W}$ & (4)RT27 & $51^{\circ} 27^{\prime} 33.0^{\prime \prime}$ S; $72^{\circ} 14^{\prime} 14.8^{\prime \prime} \mathrm{W}$ \\
\hline (11)RT24 & $51^{\circ} 34^{\prime} 19.0^{\prime \prime} \mathrm{S}, 72^{\circ} 20^{\prime} 41.0^{\prime \prime} \mathrm{W}$ & & \\
\hline (12)RT28 & $51^{\circ} 34^{\prime} 03.9^{\prime \prime}$ S; 72²1'09.4"W & & \\
\hline
\end{tabular}

Tabla 2.1: coordenadas de las localidades fosilíferas de la Fm. Río Turbio. Los números entre paréntesis indican el punto en la figura correspondiente.

\subsection{Formación Río Guillermo}

La formación en cuestión aflora en las cercanías de la localidad de Río Turbio (Fig. 2.11). Hünicken (1955) utilizó el nombre de estratos de Río Guillermo para designar a lo que Brandmayr (1945) había asignado originalmente como la sección continental de la Formación Río Turbio.

El espesor de la unidad llega a un máximo de 340 m (Malumián \& Panza, 2000), limita por debajo con la Fm. Río Turbio y por encima con la Fm. Río Leona, ambas de forma discordante. La edad de la formación fue considerada hasta muy recientemente como eocena tardía (Malumián \& Panza, 2000) a oligocena, en base a las edades de las formaciones sub- y suprayacentes. Fosdick et al. (2015) con datación por medio de zircones, determinaron que la unidad tiene 23,5 Ma, ubicando la base de la formación prácticamente en el límite Oligoceno-Mioceno. 

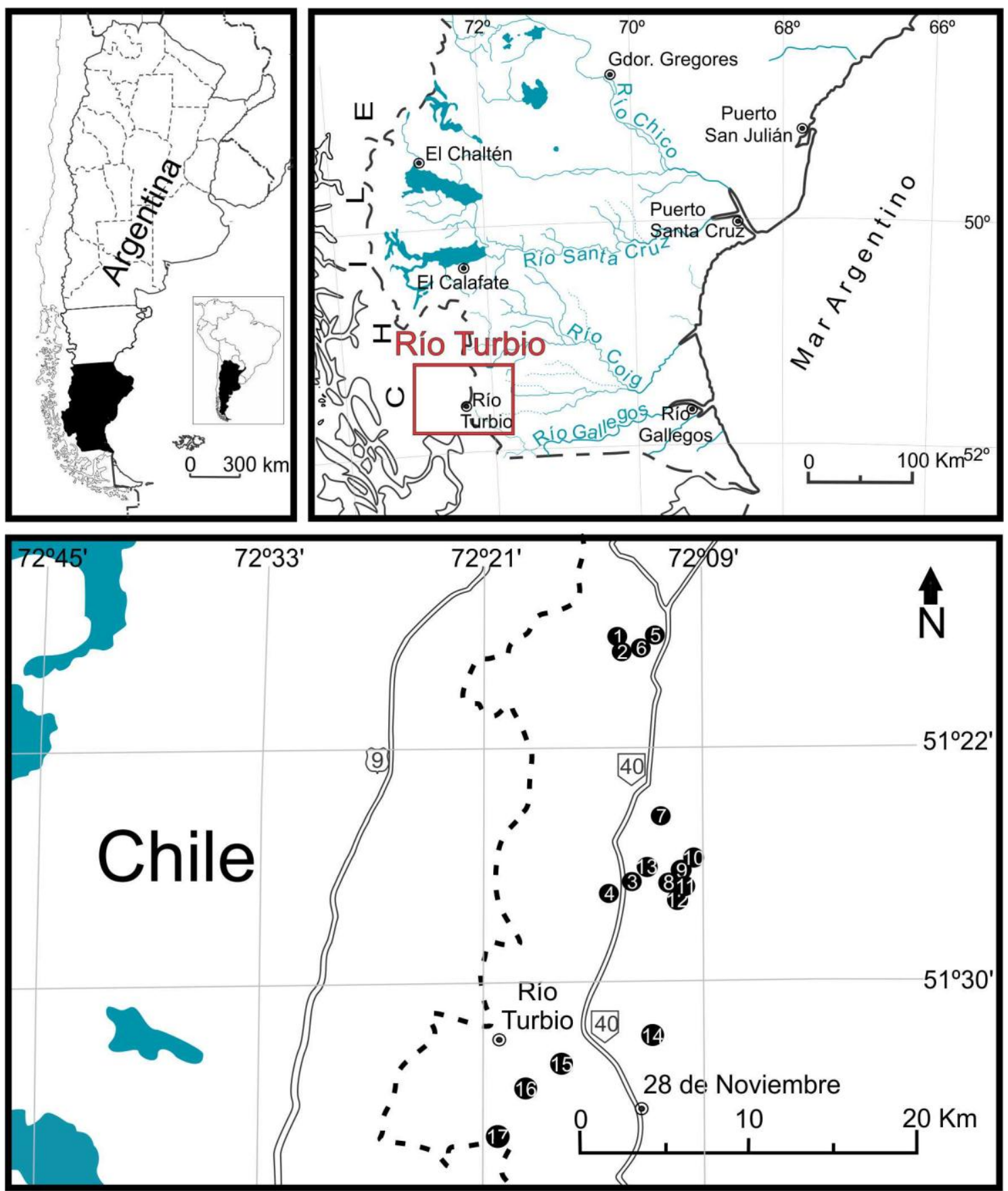

Fig. 2.11. Localidades en la Zona Río Turbio (Fms. Río Turbio, Río Guillermo y Río Leona).

1. RT13. 2. RT25. 3. RT9. 4. RT27. 5,6. Estancia Cancha Carrera. 7. Arroyo Oro. 8. RL33 y RL34.

9. $R L$ 35. 10. $R L$ 36. 11. RL37. 12. RL38. 13. $R G$ 15. 14. $R L$ 40. 15,16. Minas. 17. Cerro Dorotea.

Fig. 2.12. Columna estratigráfica esquemática de la Formación Río Guillermo. Adaptada de Pujana, 2008 (tomada de Marenssi inédito). El perfil corresponde a la zona de Arroyo Oro y Estancia Cancha Carrera. 


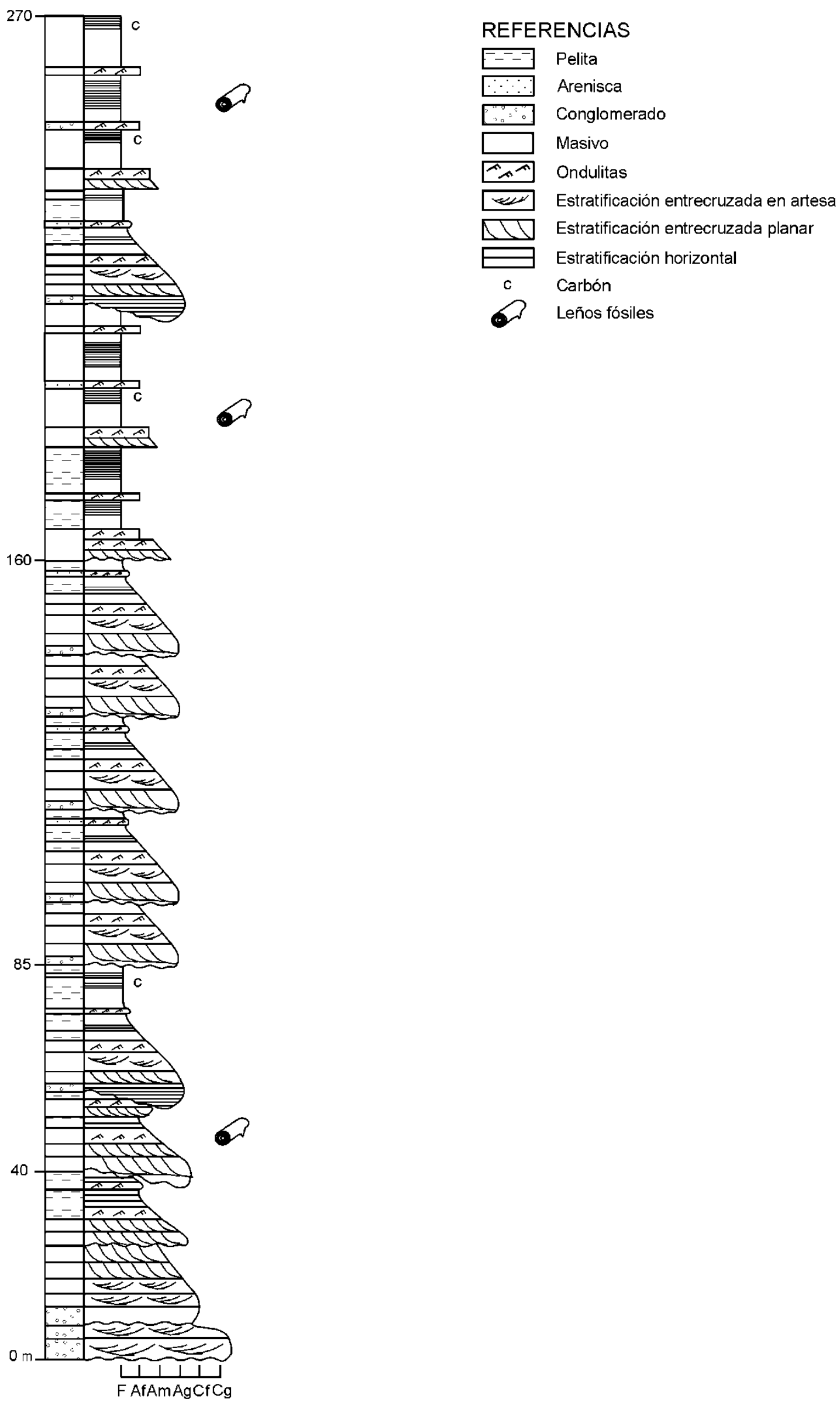


La formación Río Guillermo cuenta con diversos restos vegetales tanto de hojas (Dusén, 1899; Frenguelli, 1941; Hünicken, 1955, 1995; Panti, 2010, 2011; Vento et al., 2016), como de leños (Pujana, 2008).

En esta tesis se analizó material proveniente de siete localidades de muestreo (Figs. $2.11,2.13$ y 2.14). Sus nombres y coordenadas geográficas se detallan en la tabla 2.2 .

\begin{tabular}{|c|c|c|}
\hline \multicolumn{3}{|c|}{ Localidades de muestreo } \\
\hline Localidad & Punto en la Fig. 2.11 & Coordenadas \\
\hline \multirow[t]{2}{*}{ Estancia Cancha Carrera } & (5) & $51^{\circ} 18^{\prime} 29^{\prime \prime S} ; 72^{\circ} 11^{\prime} 53^{\prime \prime W}$ \\
\hline & (6) & $51^{\circ} 18^{\prime} 46^{\prime \prime S} ; 72^{\circ} 12^{\prime} 48^{\prime \prime W}$ \\
\hline Arroyo Oro & (7) & $51^{\circ} 24^{\prime} 37^{\prime \prime S} ; 72^{\circ} 11^{\prime} 29^{\prime \prime} \mathrm{W}$ \\
\hline RG15 & (13) & $51^{\circ} 26^{\prime} 35^{\prime \prime S} ; 72^{\circ} 12^{\prime} 37^{\prime \prime} \mathrm{W}$ \\
\hline \multirow[t]{2}{*}{ Minas } & (15) & $51^{\circ} 32^{\prime} 44^{\prime \prime} \mathrm{S} ; 72^{\circ} 16^{\prime} 58^{\prime \prime} \mathrm{W}$ \\
\hline & (16) & $51^{\circ} 33^{\prime} 35^{\prime \prime S} ; 72^{\circ} 18^{\prime} 56^{\prime \prime} \mathrm{W}$ \\
\hline Cerro Dorotea & (17) & $51^{\circ} 35^{\prime} 2^{\prime \prime S} ; 72^{\circ} 20^{\prime} 18^{\prime \prime} \mathrm{W}$ \\
\hline
\end{tabular}

Tabla 2.2: coordenadas de las localidades fosilíferas de la Fm. Río Guillermo.
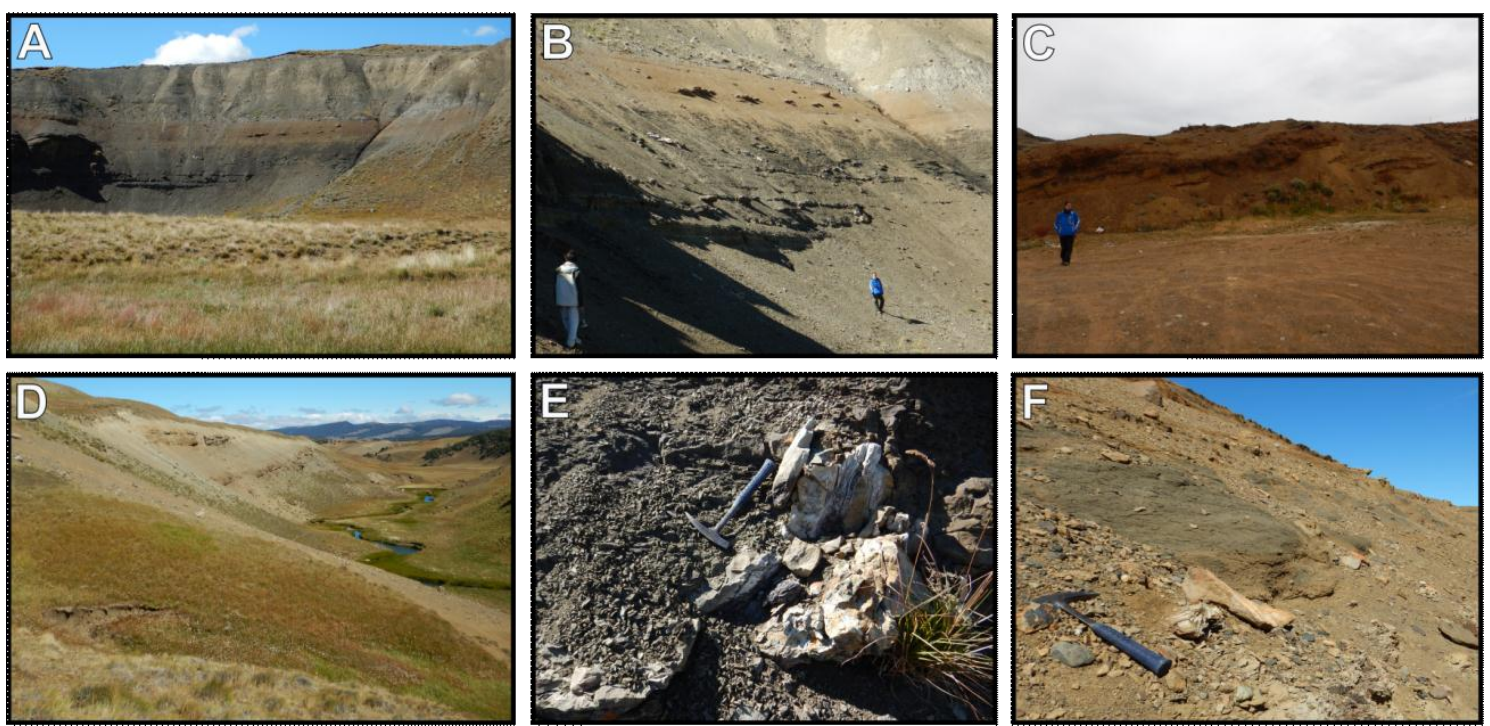

Fig. 2.13. Vista general de algunos de los afloramientos de la Fm. Río Guillermo. A,B: Ea. Cancha Carrera. C: Minas. D: Arroyo Oro. E,F: Muestras en el campo.

\subsection{Formación Río Leona.}

La Formación Río Leona también aflora en los alrededores de Río Turbio, así como en las cercanías de la localidad de El Calafate, donde tiene su mayor espesor (Malumián \& Panza, 2000) (Figs. 2.11 y 2.14). Esta formación fue definida por primera vez en 1944 por Feruglio. Posteriormente Furque (1973) la redefinió. 
La Formación Río Leona tiene un espesor aproximado de 200 m (Marenssi et al., 2005) (Fig. 2.1). En el área de El Calafate su base contacta discordantemente con la Formación Man Aike, de edad eocena media a tardía, datada en base a invertebrados marinos (Camacho et al., 2000), mientras que en la comarca de Río Turbio contacta con la Fm. Río Guillermo. En su techo contacta con la Formación Estancia 25 de Mayo (Cuitiño \& Scasso, 2010), formación que fue datada entre 20,05 Ma y 19,1 Ma por medio de zircones (Cuitiño et al., 2012). A partir de su ubicación entre estas formaciones se infería una edad oligocena pero, debido a los estudios radimétricos realizados para datar las Formaciones Río Guillermo (23,5 Ma) y Río Leona (19,6 Ma en una localidad chilena), la edad de la formación es actualmente considerada miocena (Fosdick et al., 2011, 2015).

Marenssi y colaboradores (2005) realizaron la interpretación paleoambiental de la formación en base a los depósitos aflorantes en dos localidades y concluyeron en que existió un sistema fluvial progradante durante la depositación de la unidad.

Además de los leños fósiles utilizados en la presente tesis y originalmente descriptos por Pujana (2007, 2008, 2009a, b), la formación cuenta con registros palinológicos (Barreda et al., 2009) y foliares (Frenguelli, 1941; Cesari et al., 2015).

\begin{tabular}{|c|c|c|}
\hline \multicolumn{3}{|c|}{ Localidades de muestreo } \\
\hline Localidad & Punto en la Fig. 2.11 & Coordenadas \\
\hline Arroyo Oro & (7) & $51^{\circ} 24^{\prime} 37^{\prime \prime S} ; 72^{\circ} 11^{\prime} 29^{\prime \prime W}$ \\
\hline RL33 & (8) & $51^{\circ} 27^{\prime} 11^{\prime \prime S} ; 72^{\circ} 11^{\prime} 9^{\prime \prime} \mathrm{W}$ \\
\hline RL34 & (8) & $51^{\circ} 27^{\prime} 11^{\prime \prime S} ; 72^{\circ} 11^{\prime} 2^{\prime \prime} \mathrm{W}$ \\
\hline RL35 & (9) & $51^{\circ} 26^{\prime} 54^{\prime \prime S} ; 72^{\circ} 10^{\prime} 38^{\prime \prime} \mathrm{W}$ \\
\hline RL36 & (10) & $51^{\circ} 26^{\prime} 46^{\prime \prime S}$; $72^{\circ} 10^{\prime} 26^{\prime \prime} \mathrm{W}$ \\
\hline RL37 & (11) & $51^{\circ} 27^{\prime} 17^{\prime \prime S} ; 72^{\circ} 11^{\prime} 6^{\prime \prime} \mathrm{W}$ \\
\hline RL38 & (12) & $51^{\circ} 27^{\prime} 50^{\prime \prime} \mathrm{S} ; 72^{\circ} 10^{\prime} 49^{\prime \prime} \mathrm{W}$ \\
\hline RL40 & (14) & $51^{\circ} 31^{\prime} 53.4^{\prime \prime S} ; 72^{\circ} 12^{\prime} 16.5^{\prime \prime W}$ \\
\hline Localidad & Punto en la Fig. 2.14 & \\
\hline Estancia La Meseta & (1) & $50^{\circ} 1^{\prime} 2 " \mathrm{~S} ; 71^{\circ} 55^{\prime} 22^{\prime \prime} \mathrm{W}$ \\
\hline Estancia La Laurita & $(2)$ & $50^{\circ} 06^{\prime} 32^{\prime \prime} \mathrm{S} ; 71^{\circ} 49^{\prime} 49^{\prime \prime} \mathrm{W}$ \\
\hline Cerro Calafate & (3) & $50^{\circ} 21^{\prime} 18^{\prime \prime} \mathrm{S} ; 72^{\circ} 10^{\prime} 12^{\prime \prime} \mathrm{W}$ \\
\hline Arroyo de los Guanaquitos & (4) & $\left.50^{\circ} 27^{\prime} 15^{\prime \prime} \mathrm{S} ; 72^{\circ} 14^{\prime} 12^{\prime \prime} \mathrm{W}\right)$ \\
\hline Arroyo de las Bandurrias & (5) & $50^{\circ} 31^{\prime} 24^{\prime \prime} \mathrm{S} ; 72^{\circ} 15^{\prime} 33^{\prime \prime} \mathrm{W}$ \\
\hline
\end{tabular}

Tabla 2.3: coordenadas de las localidades fosilíferas de la Fm. Río Leona.

Los leños fósiles utilizados para este estudio fueron colectados en 13 localidades detalladas en la tabla 2.3 y las figuras $2.11,2.14,2.16$. 

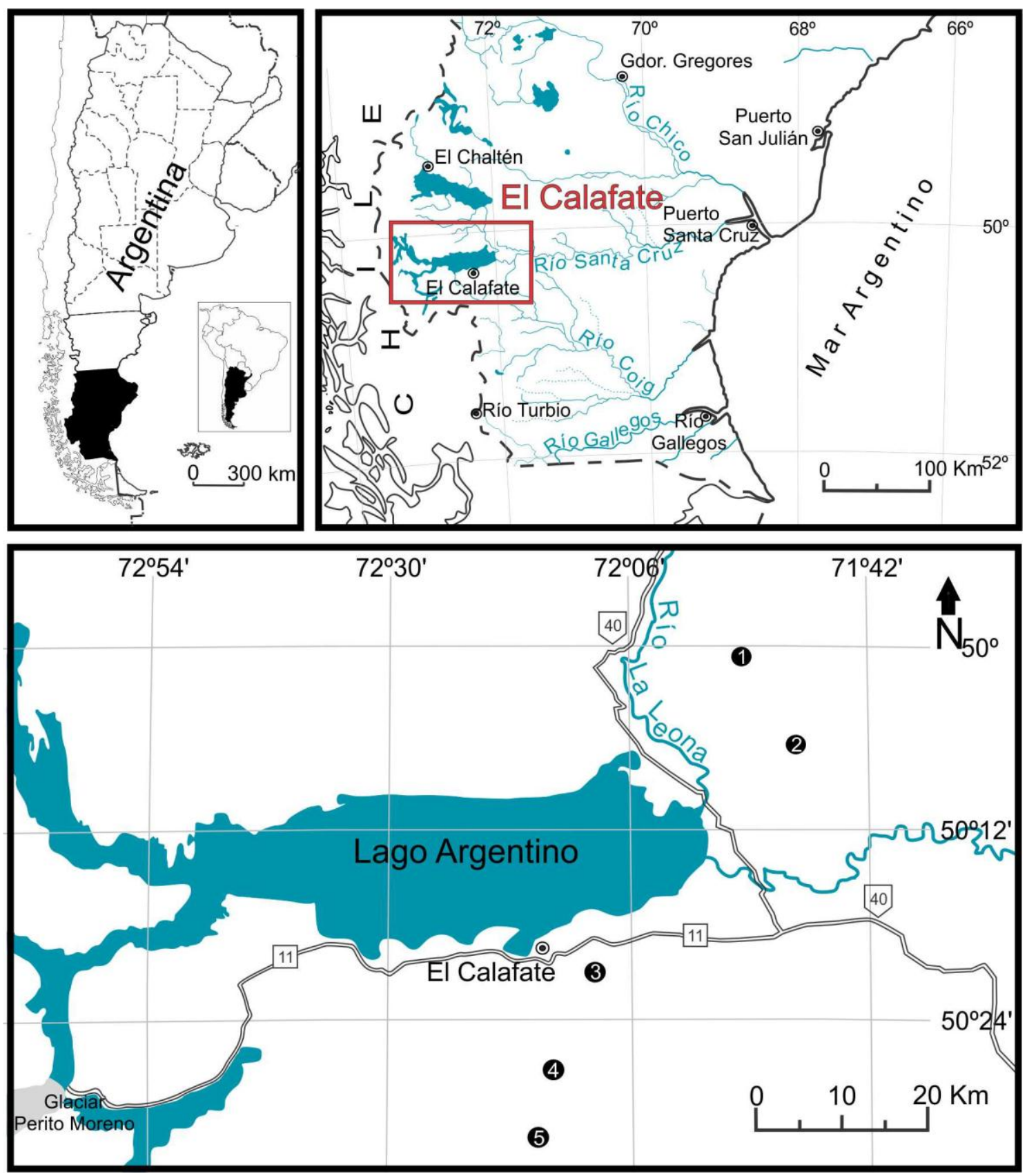

Fig. 2.14. Zona de El Calafate. 1. La Meseta. 2. La Laurita. 3. Cerro Calafate. 4. Arroyo de los Guanaquitos. 5. Arroyo de las Bandurrias. 


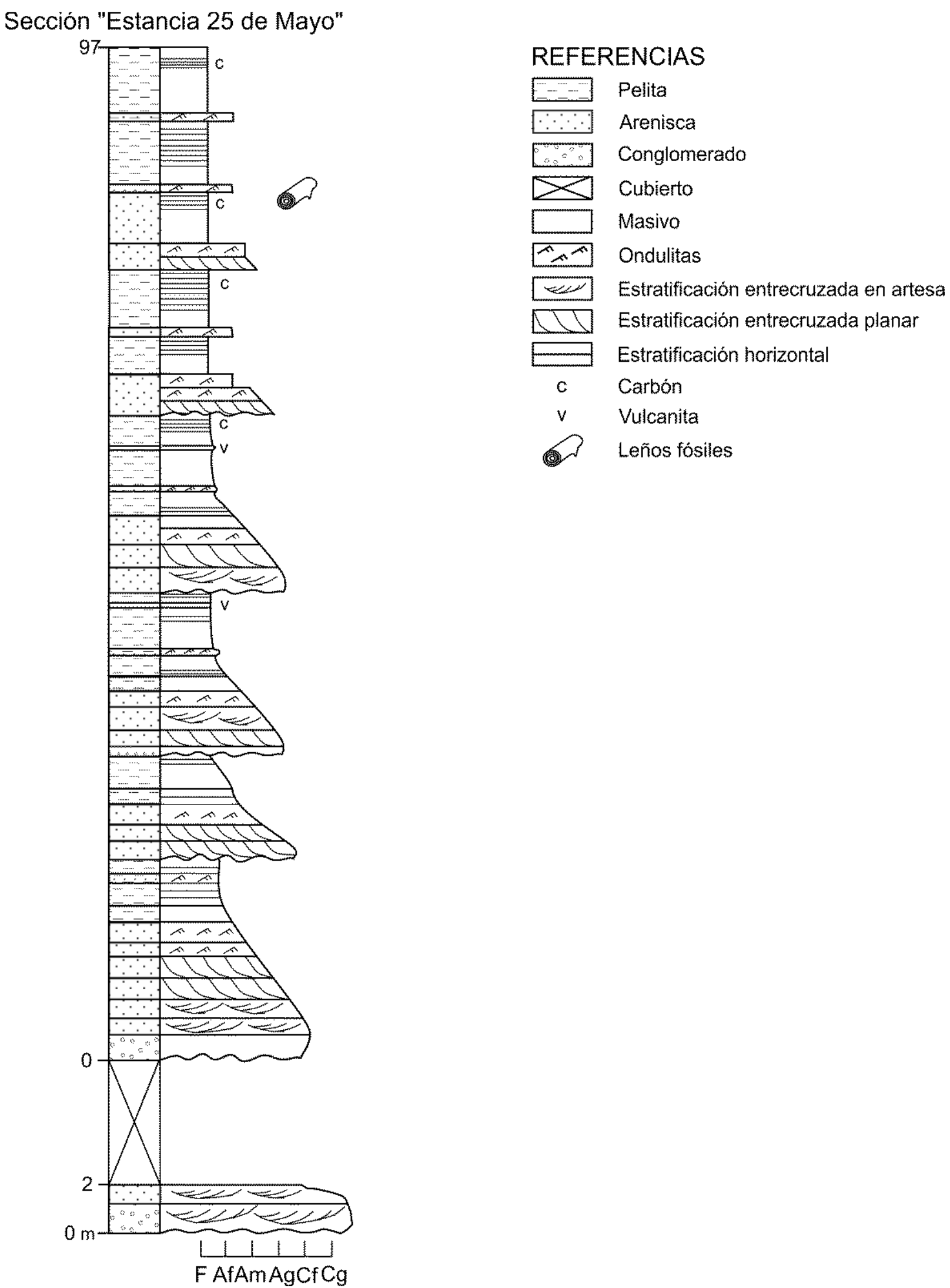

Fig 2.15. Columna estratigráfica esquemática de la Formación Río Leona. Adaptado de Marenssi et al., 2005. 


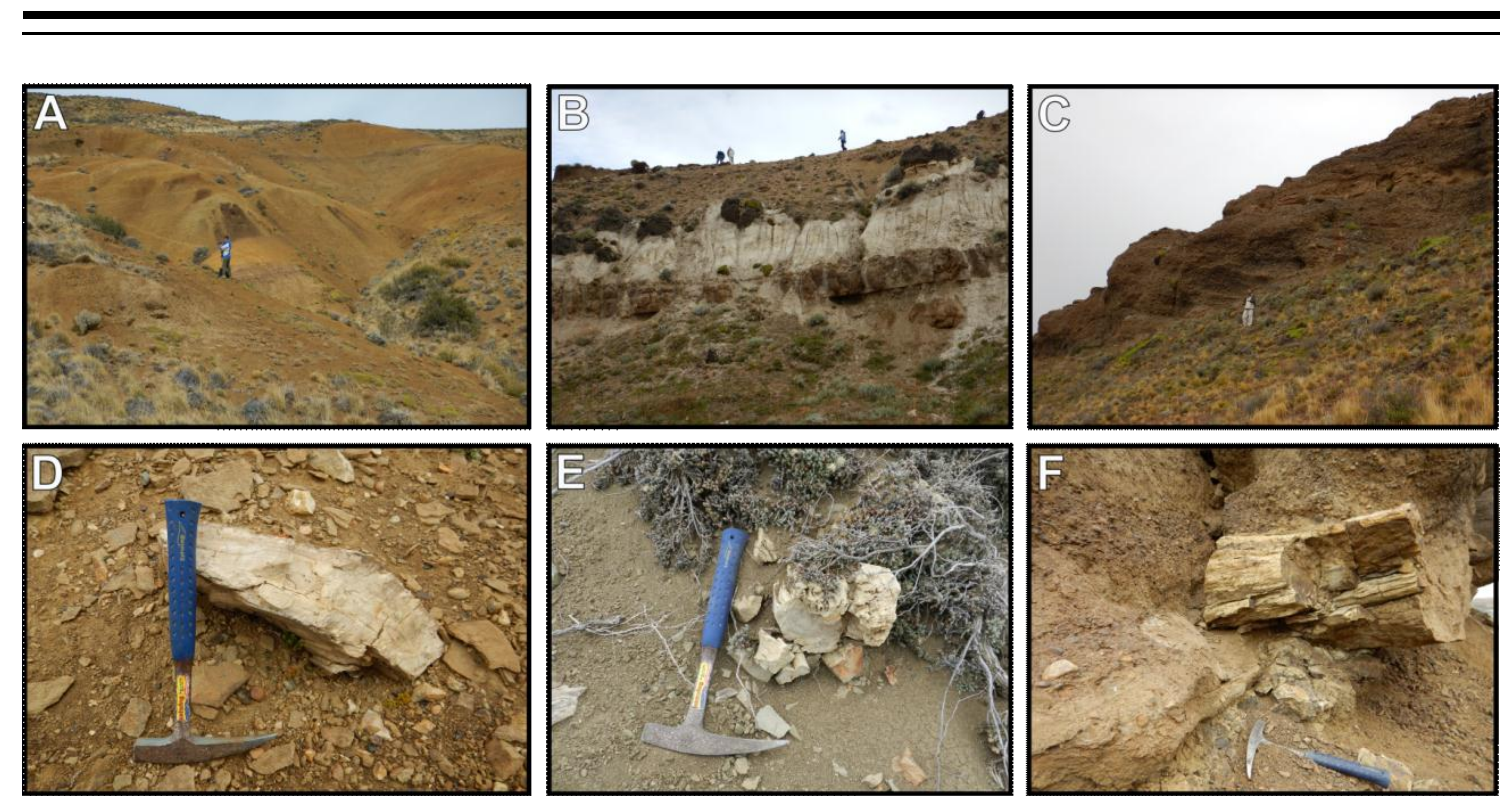

Fig. 2.16. Vista general de algunos de los afloramientos de la Fm. Río Leona. A. Cerro Calafate. B. RL 35. C. RL 40. D-F: Ejemplares en el campo. 


\section{3}

MATERIALES Y MÉTODOS

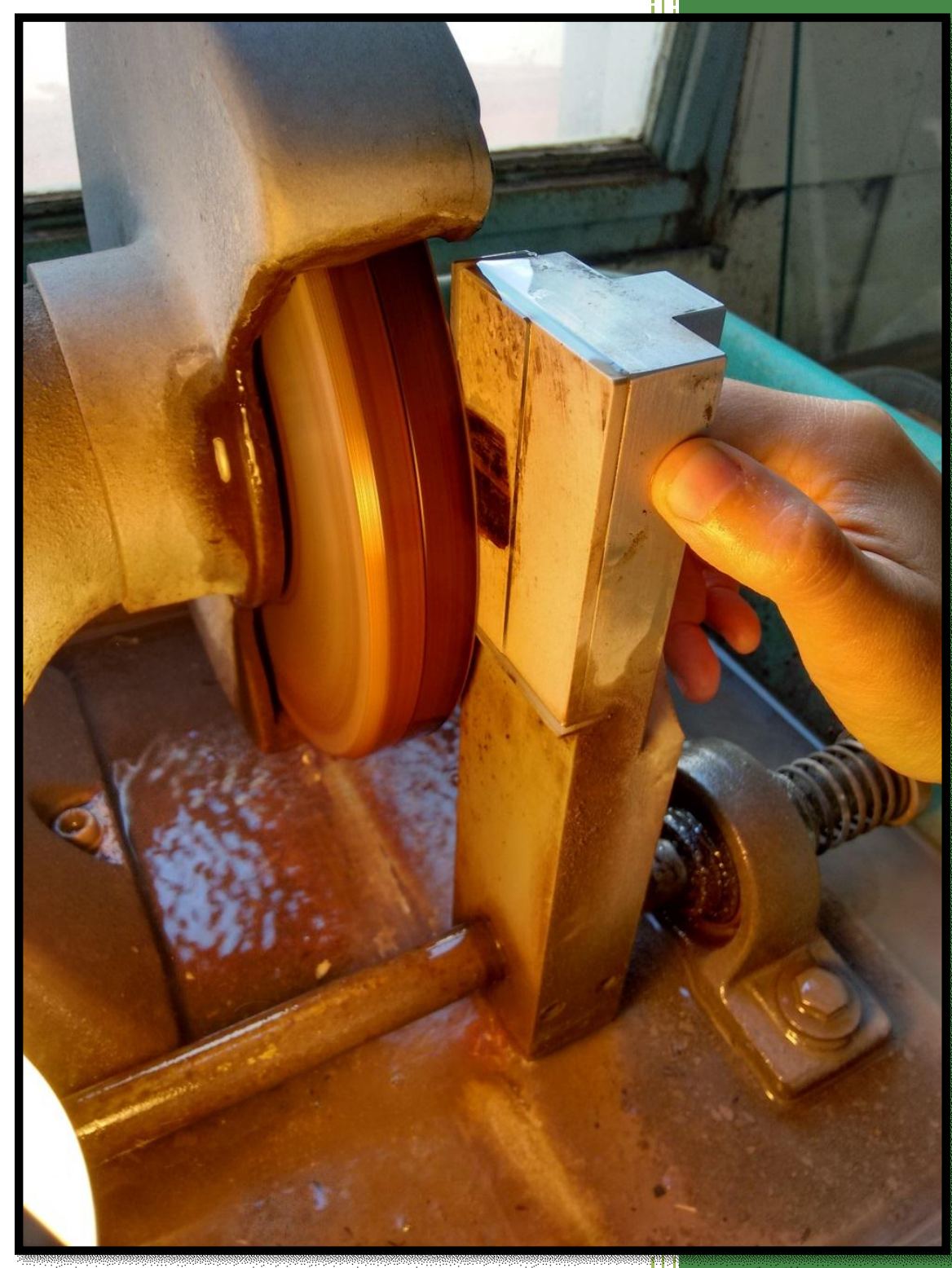

DANIELA P. RUIZ 


\section{MATERIALES ESTUDIADOS}

En la presente tesis se estudió principalmente material leñoso fósil, aunque previamente se analizaron muestras y datos de maderas actuales para poner a prueba algunas de las ecuaciones que se utilizaron y que se detallan más adelante en esta sección.

\subsection{Actuales}

Se recopilaron descripciones de maderas de especies actuales (Rancusi et al., 1987; Carlquist, 1995, 2003; Roth \& Giménez de Bolzón, 1997; Roth \& Giménez, 2006; Pujana et al., 2008; Roig \& Videla, 2009; Tortorelli, 1956). Dichas especies habitan en la parte más austral de Sudamérica, lo que comprendería distintas regiones del país y de Chile.

Se eligieron principalmente zonas de parques y reservas Nacionales, ya que son áreas conservadas y que cuentan con inventarios de las especies presentes (Dimitri, 1974, 1979; Santos Biloni, 1990; Roth \& Giménez de Bolzón, 1997, Roth \& Giménez 2006; Arroyo et al., 2000; Brown et al., 2009). En el apéndice I se listan las especies citadas para cada localidad y los caracteres utilizados.

\subsection{Fósiles}

Los leños permineralizados que se estudiaron provienen de las formaciones mencionadas en el capítulo anterior, que afloran en distintas localidades ubicadas en las provincias del Chubut y Santa Cruz. Los leños cuentan en todos los casos con una posición geográfica y estratigráfica definida. Previo a la realización de esta tesis, las muestras se encontraban en distintos grados de preparación y de estudio dependiendo la formación, por lo cual se detalla a continuación (por separado) el tratamiento que recibió cada grupo de muestras:

\section{Fm. Cerro Bororó (Paleoceno):}

Los ejemplares estudiados son los recolectados por el Dr. Petriella para el desarrollo de su tesis doctoral. Por consiguiente ya se contaba con preparados microscópicos. De todas formas, se realizaron nuevos peels de acetato y tacos para 
MEB. Además, se estudiaron nuevas muestras recolectadas por la Dra. Mariana Brea, estas también contaban con preparados listos para ser estudiados.

\section{Fm. Salamanca (Paleoceno):}

Varios leños fueron recolectados previamente por la Dra. Mariana Brea y ya contaban con cortes petrográficos para ser estudiados. Adicionalmente, se prepararon tacos para MEB y se realizó una nueva campaña en noviembre de 2016 donde se recolectaron más ejemplares. Se efectuaron cortes petrográficos y tacos para MEB de los nuevos materiales.

\section{Fm. Río Turbio, Fm. Río Guillermo y Fm. Río Leona (Eoceno-Mioceno):}

Gran parte del material fue recolectado y estudiado recientemente por el Dr. Roberto Pujana para el desarrollo de su tesis doctoral, por lo que ya estaban preparados para ser estudiados. Igualmente, se realizó un nuevo viaje de campo y con los nuevos ejemplares se realizaron cortes petrográficos y tacos para MEB.

En total se analizaron 21 ejemplares de la Fm. Bororó, 17 ejemplares de la Fm. Salamanca, 81 ejemplares de la Fm. Río Turbio, 39 ejemplares de La Formación Río Guillermo y 392 ejemplares de la Fm. Río Leona. Los taxones con los cuales se trabajó se resumen en tablas o en un apartado de "Sistemática Paleobotánica" al comienzo de los resultados correspondientes a cada formación en el capítulo IV (resultados). Asimismo, en el apéndice II, se listan dichos ejemplares con sus respectivos números de colección y lugares de repositorio.

Las maderas provienen de distintas edades geológicas y de diferentes regiones, por lo tanto éstas se hallan en diversos estados de preservación. Algunos ejemplares en donde los caracteres anatómicos requeridos no eran claramente observables, o evidenciaban alteraciones tafonómicas, fueron descartados (figuran en el apéndice como "mal preservados"). Esta medida es necesaria debido a que algunos de los análisis propuestos en este estudio requieren de la observación y/o medición minuciosa de determinados caracteres. 


\section{TÉCNICAS DE PREPARACIÓN UTILIZADAS}

\subsection{Cortes petrográficos}

Con una máquina cortadora de roca se realizaron cortes en los tres planos comúnmente utilizados en el estudio de anatomía de maderas (transversal, longitudinal radial y longitudinal tangencial). Cada corte se pulió y montó sobre un portaobjetos con adhesivos que solidifican con luz UV, para luego pulir la cara expuesta hasta alcanzar un grosor de alrededor de aproximadamente $30 \mu \mathrm{m}$. Finalmente se cubrió con un cubreobjetos y el mismo medio utilizado para adherir el fósil.

\subsection{Peels de acetato}

Se realizaron cortes de maderas fósiles en las tres secciones previamente mencionadas. Dichas superficies fueron pulidas y posteriormente atacadas con ácido clorhídrico y ácido fluorhídrico. El tiempo de tratamiento con ácidos varía de 15 a 30 segundos en el caso del ácido clorhídrico, y de 2 a 4 minutos en el caso del ácido fluorhídrico. Posteriormente se lavaron con agua, se aplicó acetona sobre las superficies tratadas y se adhirieron hojas de acetato. Una vez secas esas porciones de acetato, se despegaron para obtener los peels. Los peels obtenidos fueron montados sobre portaobjetos con bálsamo sintético y protegidos con cubreobjetos.

\subsection{Preparados para MEB (Microscopio Electrónico de Barrido)}

Se obtuvieron pequeños fragmentos de la madera (de menos de $1 \times 1 \times 1 \mathrm{~cm}$ ). Los mismos se pegaron a tacos de aluminio dejando expuestas las caras a observar (transversal, longitudinal radial y/o longitudinal tangencial) y se bañaron con oropaladio.

\section{OBSERVACIÓN Y DESCRIPCIÓN DEL MATERIAL}

Los cortes petrográficos y peels fueron observados en microscopios ópticos Leica DM2500 y fotografiados con cámara digital Leica DFC290.

Se utilizó el Microscopio Electrónico de Barrido (MEB) del Museo Argentino de Ciencias Naturales "Bernardino Rivadavia" (Philips XL30). 
Los ejemplares de la Formaciones Cerro Bororó, Río Guillermo y Río Leona ya contaban con descripciones anatómicas y asignaciones sistemáticas previas y no se incluyen en este trabajo de tesis. De cualquier manera, las más antiguas (i.e. Petriella, 1972) fueron revisadas. En el caso de la Fm. Salamanca, solo algunas muestras estaban brevemente descriptas en una comunicación (Brea et al., 2010), por lo que se incluyen aquí las descripciones completas y la sistemática. Parte de esta sistemática ya fue publicada de forma paralela a la realización de la tesis (Ruiz et al., 2017). En lo que respecta a la Fm. Río Turbio, parte del material ya estaba descripto por Pujana (2008), pero se incluyen descripciones anatómicas de los nuevos ejemplares colectados. La terminología anatómica empleada en todo momento sigue las recomendaciones de la Lista de Caracteres Microscópicos para la Identificación de Maderas de la IAWA, tanto la de angiospermas (IAWA Committee, 1989), como la de gimnospermas (IAWA Committee, 2004). Para las asignaciones sistemáticas se siguió a Philippe \& Bamford, 2008; Chase \& Reveal, 2009; Christenhusz et al., 2011 y APG IV (2016).

\section{MEDICIONES}

Para completar las fórmulas que se detallan más adelante se requiere, en ocasiones, medidas de algunos de los elementos celulares presentes en el leño. En todos los casos se realizó un mínimo de 30 mediciones por ejemplar para luego obtener un promedio. En las descripciones, dicho promedio se detalla seguido de los valores mínimos y máximos entre paréntesis. Se utilizó el programa "Image J" para medir digitalmente a través de fotografías.

En las angiospermas, para calcular la densidad de vasos, se consideraron aquellos que presentaban más de la mitad de su superficie dentro del área. En cuanto al largo de los elementos de vaso se tomaron en cuenta los extremos más alejados de cada uno, sin tener en cuenta los apéndices cuando presentes. Se midió el lumen tangencial de los vasos en la zona más ancha del mismo.

Los anillos de crecimiento se midieron tanto en gimnospermas como en angiospermas, siempre y cuando estuvieran lo suficientemente bien demarcados como para efectuar una medición precisa de al menos 10 anillos por ejemplar. Algunos de los 
cálculos realizados a partir de los anillos se efectuaron solo en las coníferas (detallados más adelante).

\section{MÉTODOS DE ESTUDIO}

Se emplearon una serie de métodos y ecuaciones diseñadas por diversos autores para obtener datos tanto de temperatura como de humedad del ambiente, los cuales se detallan a continuación. Cabe destacar que, dado que cada método presenta ciertos requerimientos para ser empleado, no todos pudieron ser aplicados a todas las muestras analizadas.

\subsection{Ecuaciones propuestas por Wiemann et al. $(1998,1999)$}

Las ecuaciones propuestas por Wiemann y colaboradores utilizan correlaciones simples y múltiples para el cálculo de variables climáticas. Se aplican a angiospermas leñosas y los caracteres empleados en las ecuaciones son los siguientes:

1. Vasos con placas de perforación escalariforme (mult).

2. Vasos con engrosamientos espiralados (spir).

3. Porosidad circular (RP).

4. Arreglo tangencial de los vasos (tang).

5. Diámetro promedio de los vasos menor a $100 \mu \mathrm{m}(<100 \mu \mathrm{m})$.

6. Fibras septadas (sept).

7. Radios comúnmente con más de 10 células de ancho (>10ser).

8. Radios heterogéneos con 4 o más filas de células erectas (het4+).

9. Radios estratificados (stor).

10. Radios exclusivamente homogéneos (homo).

11. Parénquima axial ausente o raro (abs).

12. Parénquima marginal presente (marg).

13. Parénquima predominantemente paratraqueal (para).

Se aplicaron todas las ecuaciones desarrolladas por Wiemann y colaboradores en su trabajo de 1998:

MAT ("Mean Annual Temperature") = $13,40-0,250$ (spir) + 0,637 (>10ser) + 0,255 (het4+) + 0,416 (stor) - 0,213 (abs) 
MART ("Mean Annual Range of Temperature") =

$4,16+0,319$ (spir) + 0,135 (<100 $\mu \mathrm{m})-0,373$ (>10ser) - 0,154 (het4+)

CMMT ("Cold Month Mean Temperature") =

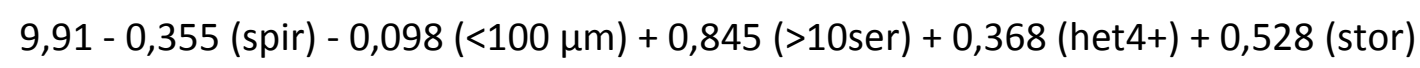

$-0,210$ (abs)

MAP ("Mean Annual Precipitation") =

$-6,06+6,332$ (sept) + 7,901 (abs)

DRY ("precipitation of the driest month") =

$6,81-0,186$ (mult) - 0,122 (sept)

Así como también otras 16 ecuaciones desarrolladas en 1999 para el cálculo del MAT:

1) $4,19+0,356$ (para)

2) $21,31+0,855$ (stor) $-0,258$ (marg)

3) $37,76-0,404(<100 \mu m)+0,277(R P)$

4) $25,14+0,785$ (stor) - 0,188 (marg) - 0,500 (abs)

5) $3,49+0,282$ (mult) $-0,215$ (homo) $+0,455$ (para)

6) $28,91-0,230$ (homo) $+0,781$ (stor) - 0,501 (abs)

7) $38,17+0,266$ (mult) - 0,212 (spir) - 0,437 (<100 $\mathrm{mm}$ ) + 0,391 (RP)

8) $7,46+0,428$ (tang) +0,309 (mult) - 0,277 (spir) - 0,169 (homo) +0,377 (para)

9) $-4,30+34,14$ (para)

10) $21,70+38,23$ (stor) $-20,29$ (marg)

11) $27,82-15,16(<100 \mu \mathrm{m})+24,17$ (stor)

12) $24,78+36,57$ (stor) - 15,61 (marg) - 16,41 (abs)

13) $14,80-16,89$ (homo) $+24,86$ (stor) $+14,92$ (para)

14) 30,47 - 19,39 (homo) + 35,35 (stor) - 19,27 (abs)

15) $17,07+25,23$ (stor) $-23,17$ (abs) $+13,79$ (sept)

16) $6,25+27,15$ (mult) $-15,72$ (spir) $-21,83(<100 \mu \mathrm{m})+16,88$ (RP) $+33,43$ (para)

Para aplicar estas ecuaciones, los paréntesis fueron reemplazados por el porcentaje de ocurrencia de los caracteres a los que hacen referencia. En el caso de las ecuaciones de la 9 a la 16 se utilizó el arcoseno de la raíz cuadrada de dicho 
porcentaje. Para obtener el porcentaje se efectuaron tablas en las cuales se colocó un "1" para indicar la presencia de un carácter, un "0" para indicar la ausencia de un carácter y "0,5" en los casos en los que los caracteres son variables.

Se emplearon la mayor cantidad posible de tipos de madera distintos en cada localidad, ya que se estima que un mejor resultado será obtenido cuanto mayor sea el número de tipos de madera utilizados.

Los errores estándar son: $1,7^{\circ} \mathrm{C}$ para el MAT, $2,4^{\circ} \mathrm{C}$ para el MART, $2,66^{\circ} \mathrm{C}$ para CMMT, $94 \mathrm{~cm}$ para MAP y 1,4 meses para DRY. Las pruebas de Wiemann et al. (1998) demostraron que las ecuaciones para cálculos de temperaturas dan resultados más precisos que en el caso de las precipitaciones. De cualquier manera, aquí se recurrió a todas las ecuaciones ya que los resultados obtenidos se cotejaron con otros provenientes de distintos métodos.

\subsection{Anillos de crecimiento}

Para estudiar los anillos de crecimiento se calcularon los siguientes parámetros estadísticos (en cada ejemplar que contara con un mínimo de 10 anillos medibles): espesor medio de anillos, espesor máximo de anillo, espesor mínimo de anillo, desviación estándar del espesor de los anillos (indicadores de la velocidad de crecimiento). También se calculó el porcentaje de leño temprano y leño tardío en las coníferas según Fritts (1976) y Creber \& Francis (1999) en anillos con más de 30 células de espesor.

Se empleó la fórmula para el cálculo del índice de sensibilidad anual (SA, representación estadística de la variación entre el ancho de un anillo y el consecutivo) y el de sensibilidad media (SM, variabilidad media en el ancho de anillos en una serie de los mismos) (Fritts, 1976; Creber \& Francis, 1999).

$$
\begin{gathered}
S A=\left|\frac{2\left(x_{t+1}-x_{t}\right)}{x_{t+1}+x_{t}}\right| \\
S M=\frac{1}{n-1} \sum_{t=1}^{t=n-1}\left|\frac{2\left(x_{t+1}-x_{t}\right)}{x_{t+1}+x_{t}}\right|
\end{gathered}
$$


La SA se representa en histogramas. Los resultados de SM pueden variar de 0 (todos los anillos exactamente del mismo ancho) a 1. Por convención se dice que aquellos valores por debajo de 0,3 pertenecen a maderas "complacientes" y aquellos por encima a maderas "sensitivas". Un valor de 0,3 indicaría que el suministro de agua del árbol era algo limitante y variable de año a año; un valor de 0,6 resultaría de un suministro de agua extremadamente restringido en promedio y un reaprovisionamiento muy variable cada año (Douglass 1928; Frittz, 1976; Creber \& Francis, 1999).

En los casos en los que se presentaban anomalías en los anillos, no se efectuaron cálculos ni mediciones, ya que éstas anomalías pueden ser producto de alteraciones a causa de factores no climáticos (como ser el fuego o enfermedades) (Fritts, 1976).

Se revisó la presencia y número de falsos anillos, como así también los anillos de heladas.

En aquellos ejemplares de coníferas que contaban con anillos de al menos 30 células de espesor se graficó la curva CSDM (Cumulative Sum of Deviation from the Mean) y se calculó el porcentaje de Skew y el RMI (Ring Markedness Index) propuestos por Falcon-Lang $(2000 a, b)$. Para esto, se midieron los diámetros radiales de cada traqueida en cinco hileras consecutivas de un anillo por ejemplar. La curva muestra la suma algebraica de cada desviación del diámetro radial medio. El skew muestra cuanto se aleja el zenit (punto más alto de la curva) del centro del gráfico. Esto nos marca si la planta era decidua (curva simétrica o con el skew hacia la izquierda) o si por el contrario era perenne (skew hacia la derecha). Por último, se calcula el porcentaje de disminución (x), el porcentaje de leño tardío (y) y a partir de ellos el RMI, de la siguiente manera:

$$
\mathrm{X}=\text { (diámetro máximo-diámetro mínimo)/diámetro máximo*100 }
$$

$\mathbf{Y}=$ número de células desde el zenit al final del anillo/número total de células del anillo * 100

$$
\mathbf{R M I}=x^{*} \mathrm{y} / 100
$$




\section{3. Índices de Vulnerabilidad y Mesomorfía}

Se utilizaron los dos índices propuestos por Carlquist (1977), a saber:

Índice de Vulnerabilidad= media diámetro de vasos $/$ media vasos por $\mathrm{mm}^{2}$

Índice de Mesomorfía= índice de vulnerabilidad $\mathrm{x}$ media largo de los elementos de vaso

Un valor bajo de vulnerabilidad (por debajo de 1,0) señala la capacidad para soportar estrés hídrico y/o congelamiento dado el gran número de vasos. Mientras que valores entre 1,0 y 2,5 aproximadamente indican mesomorfía. En cuanto al índice de mesomorfía, cuanto mayor es éste (valores de 200 o más) más mesomórfica (ambiente con alto grado de humedad) es la planta. Por el contrario, valores de 75 o menos son indicadores de ambientes xerofíticos (Carlquist, 1977).

\subsection{Método del Coxistence Approach (CA) o pariente vivo más cercano}

EI CA se aplica de la siguiente manera: suponiendo una determinada flora fósil, se procede a establecer el pariente vivo más próximo (NLR, por sus siglas en inglés) de cada taxón, junto con los requerimientos climáticos de los mismos que sean de interés para el estudio (ejemplo: temperatura media anual). Obtendremos en este caso un intervalo de temperatura en el que habita cada taxón actual y dichos intervalos se solaparán entre determinadas temperaturas. Aquellos valores extremos del solapamiento entre todos los taxones son tomados como la mejor estimación del MAT bajo el cual habrían vivido los taxones fósiles estudiados (Mosbrugger \& Utescher, 1997).

No se requiere que los parientes actuales convivan. El método utiliza solo la presencia de los taxones fósiles y no toma en consideración la abundancia relativa de éstos, debido a que esto puede ser afectado por el factor tafonómico. Asimismo, no se requiere que todos los taxones que conformaban la asociación vegetal inicial estén preservados. Teóricamente, funciona con todo tipo de fósil que contenga al menos un taxón del cual el NLR pueda ser determinado. Aun así, se recomienda utilizar al menos 10 taxones y la resolución climática del CA será mejor cuanto mayor sea el número de taxones considerados (Mosbrugger \& Utescher, 1997). Aquí se emplearon únicamente tallos permineralizados de coníferas y angiospermas. 
El CA está basado en las siguientes suposiciones: 1) se pueden identificar los taxones sistemáticamente relacionados a los taxones fósiles; 2) los requerimientos climáticos del taxón fósil son similares a los del NLR; 3) los requerimientos o tolerancias climáticas del NLR y, por consiguiente, los del taxón fósil, pueden derivarse a partir de su área de distribución; 4) los datos climáticos modernos utilizados son fiables y de buena calidad. Si alguna de estas asunciones falla, derivará en resultados erróneos o inconsistentes (Mosbrugger \& Utescher, 1997).

Con el fin de evitar este tipo de errores, se revisó abundante bibliografía específica para cada taxón en busca de los taxones actuales más emparentados con el mayor nivel de resolución posible (familia, género o especie). Dentro del material bibliográfico consultado se encuentran Metcalfe \& Chalk (1950), Petriella (1972), InsideWood (2004, en adelante), Dickinson (1977), Rancusi et al., (1987), Tortorelli, (1956), Coode (2004), entre otros.

En el presente estudio se aplicó el método para el cálculo de MAT y MAP. Para obtener los puntos de distribución de las especies/géneros actuales se utilizaron las bases de datos Global Biodiversity Information Facility (http://www.gbif.org/). Los valores actuales de temperaturas y precipitaciones medias bajo los cuales habitan los parientes vivos más próximos a las especies fósiles fueron tomados de la base de datos del WorldClim - Global Climate Data (http://www.worldclim.org/). Se empleó el programa QGIS para superponer los datos de distribuciones con la información climática en cada punto, a fin de extraer los valores medios de temperatura y de precipitaciones entre los cuales habitan los taxones actuales. Además, tanto la información referente a la distribución geográfica, como la información climatológica, fue corroborada y complementada con bibliografía en varios casos (Donoso Zegers, 2006).

\subsection{Caracteres eco-xilológicos}

Los "caracteres eco-xilológicos" no son un método en sí, sino más bien hace referencia a la importancia de determinados caracteres de la madera a la hora de analizar el leño en busca de evidencias de cómo habría sido el clima en el pasado. El principio es similar al del NLR en el sentido de que supone que, si un determinado 
carácter actualmente se presenta en mayor medida por ejemplo en zonas cálidas, un gran porcentaje de dicho carácter en el pasado geológico indicaría también un clima cálido para ese sitio. La diferencia radica en que aquí no son de importancia las afinidades botánicas, sino los caracteres mismos, independientemente de la sistemática y además no se llega a un resultado cuantitativo.

Lógicamente muchos de los caracteres aquí empleados, sino todos, son los mismos que se utilizaron en las ecuaciones de Wiemman et al. $(1998,1999)$. Esto es de esperar ya que los autores de estas ecuaciones, como ya se mencionó, utilizaron caracteres altamente correlacionables con los elementos del clima para formularlas. Nuevamente, la diferencia se halla en que las ecuaciones brindaban datos numéricos de temperatura y precipitaciones, mientras que aquí solo se asocian a términos cualitativos más amplios (templado, templado-cálido, húmedo, seco).

La metodología consistió básicamente en observar qué caracteres ecológicamente relevantes se hallaban en cada ejemplar, y qué indicaban los mismos en base a la información bibliográfica. Para ello se siguieron los trabajos de Van der Graaff \& Baas (1974), Baas (1982), Baas \& Xinying (1986), Baas \& Schweingruber (1987), Schweingruber (1988), Wheeler \& Baas (1991, 1993), Carlquist $(2001,2012)$, Wheeler et al., (2007), Baas \& Wheeler (2011), Plavcova et al. (2016), Soffiatti et al. (2016), Morris et al. (2018). Los autores antedichos arribaron a sus conclusiones por medio del estudio exhaustivo de numerosas muestras de madera recolectadas desde diferentes partes del globo, y cotejando con las características climáticas de los lugares de procedencia.

Algunos de los caracteres xilológicos más notables como indicadores paleoecológicos son: el tipo de porosidad, el diámetro de los vasos, la frecuencia de los vasos, el tipo de placa de perforación, la presencia de engrosamientos espiralados, la presencia de fibras septadas y el tipo de parénquima axial. En el capítulo de resultados, según fue pertinente, se hizo un análisis más detallado de cada uno señalando las condiciones climáticas a las que estarían vinculados. 
6. TERMINOLOGÍA UTILIZADA PARA LA TEMPERATURA

Para la temperatura se utilizaron los términos megatérmico $\left(>24^{\circ} \mathrm{C}\right)$, mesomegatérmicos $\left(20^{\circ}-24^{\circ} \mathrm{C}\right)$, mesotérmico $\left(14^{\circ}-20^{\circ} \mathrm{C}\right)$ y microtérmico $\left(<14^{\circ} \mathrm{C}\right)$ siguiendo a Burkart (1975) y Greenwood (1994). Se evitaron términos utilizados comúnmente en cálculos de paleotemperaturas como ser "tropical" o "subtropical" ya que los mismos también tienen connotaciones geográficas (Barreda \& Palazzesi, 2007). 


\section{4}

\section{RESULTADOS}
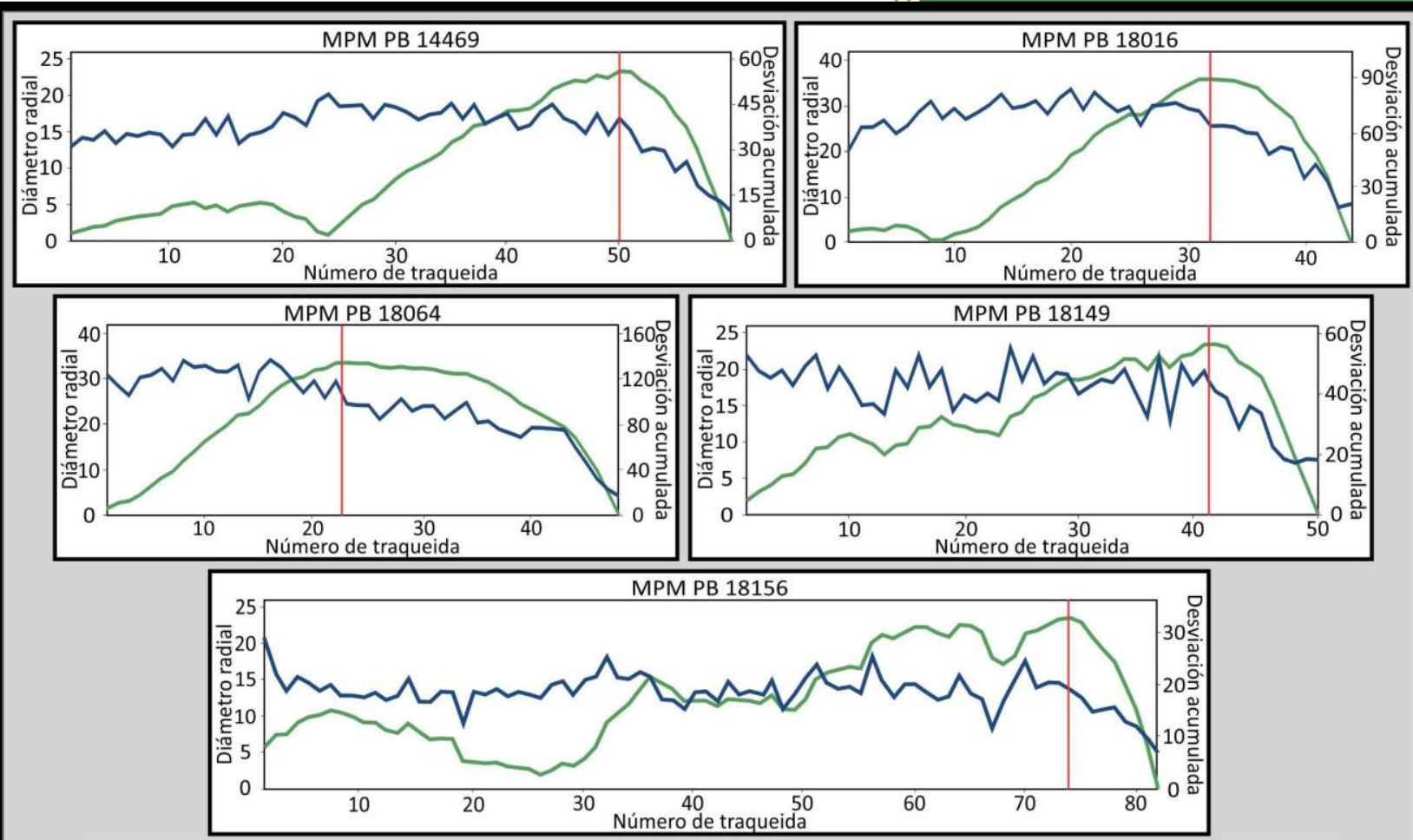

- Díametro medio de las traqtraqueidas de un anillo $=$ Suma acumulada absoluta de los diámetros radiales 


\section{PUESTA A PRUEBA DE LAS ECUACIONES DE WIEMANN ET AL. $(1998,1999)$ EN MADERAS ACTUALES}

Los anillos de crecimiento y su vinculación con el clima, así como la correlación existente entre la presencia de determinados caracteres con la temperatura y la humedad del ambiente, han sido ampliamente estudiados desde hace décadas tanto en el hemisferio norte como en el hemisferio sur (Fritts, 1976; Creber \& Chaloner, 1984a, b; Carlquist, 1977; Boninsegna \& Holmes, 1978; Boninsegna et al., 1988, 2009).

Wiemann et al. $(1998,1999)$ proponen ecuaciones para estimar el MAT y el MAP (entre otras) a partir de caracteres anatómicos de maderas angiospérmicas. Pero estas ecuaciones se basan mayoritariamente en taxones del hemisferio norte y solo en la publicación de 1998 utilizan datos de cuatro localidades del hemisferio austral, todas ellas de latitudes que no superan los $19^{\circ} \mathrm{S}$. Esto cuestiona la implementación de tales ecuaciones en regiones en el hemisferio sur, ya que el clima en general de los continentes australes, sobre todo hacia el sur de Sudamérica, difiere notablemente de aquellos del hemisferio norte (principalmente por la menor continentalidad) y además los taxones no son los mismos en ambos hemisferios. Es por estas razones que se evaluó la efectividad de las ecuaciones para el cálculo del MAT y el MAP propuestas por Wiemann et al. (1998, 1999, ver materiales y métodos), a fin de corroborar su efectividad en distintos lugares de Argentina y Chile, tratando así de cubrir el mayor rango geográfico posible al sur de los $20^{\circ}$ de latitud sur.

Las tablas 4.1 y 4.2 muestran los resultados que se obtuvieron al aplicar las distintas ecuaciones en zonas con diversos rangos de temperatura y precipitaciones a lo largo de Argentina y Chile (las tablas con los caracteres utilizados y las listas de especies de cada zona se encuentran en el apéndice I). En líneas generales, la mayor parte de las ecuaciones para el cálculo del MAT en la mayoría de las localidades, arrojan valores por encima o, en menor medida, por debajo de los valores de temperatura esperados (teniendo en cuenta el error estándar de $\pm 1,7^{\circ} \mathrm{C}$ ). Con las precipitaciones tampoco se obtuvieron los valores esperados, siendo todos ellos notablemente mayores. En este caso, sin embargo, los resultados concuerdan con los de los propios autores de las ecuaciones, quienes concluyeron que las mismas no son muy eficaces para el cálculo del MAP. 


\begin{tabular}{|c|c|c|c|c|c|c|c|c|c|}
\hline \multirow{2}{*}{\multicolumn{2}{|c|}{ Ec. 1998}} & $\begin{array}{l}\text { PN Los } \\
\text { Glaciares } \\
\text { (Santa } \\
\text { Cruz) }\end{array}$ & $\begin{array}{l}\text { PN Los } \\
\text { Alerces } \\
\text { (Chubut) }\end{array}$ & $\begin{array}{l}\text { PN Nahuel } \\
\text { Huapi (Río } \\
\text { Negro) }\end{array}$ & $\begin{array}{l}\text { Los Bellotos } \\
\text { (VII Región- } \\
\text { Chile) }\end{array}$ & $\begin{array}{c}\text { RP } \\
\text { Acambuco } \\
\text { (Salta) }\end{array}$ & $\begin{array}{l}\text { Chaco } \\
\text { seco }\end{array}$ & $\begin{array}{l}\text { Chaco } \\
\text { Húmedo }\end{array}$ & $\begin{array}{l}\text { PN Iguazú } \\
\text { (Misiones) }\end{array}$ \\
\hline & & $-10,7$ & 10,0 & 4,7 & 4,3 & 19,5 & 23,3 & 21,6 & 19,2 \\
\hline \multirow{16}{*}{ 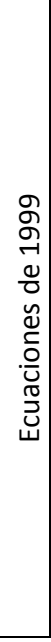 } & Ec. 1 & 12,6 & 14,4 & 10,3 & 15,8 & 32,0 & 36,5 & 32,3 & 29,9 \\
\hline & Ec. 2 & 21,3 & 21,6 & 20 & 18,3 & 34,4 & 31,2 & 29,1 & 35,6 \\
\hline & Ec. 3 & 9,4 & 2,8 & 0,7 & 3,7 & 17,1 & 16,5 & 16,1 & 13,0 \\
\hline & Ec. 4 & 25,1 & 12,5 & 16,3 & 7,30 & 0,1 & $-9,0$ & $-5,0$ & 3,7 \\
\hline & Ec. 5 & 20,6 & 20,8 & 18,5 & 23,3 & 38,4 & 34,1 & 28,9 & 37,6 \\
\hline & Ec. 6 & $-15,6$ & $-3,0$ & $-7,5$ & $-3,5$ & 33,8 & 29,2 & 22,5 & 32,0 \\
\hline & Ec. 7 & 42,1 & $-0,2$ & $-0,8$ & 0,2 & 16,1 & 15,2 & 14,5 & 13,1 \\
\hline & Ec. 8 & 19,1 & 19,3 & 15,2 & 18,2 & 37,7 & 33,2 & 29,3 & 36,2 \\
\hline & Ec. 9 & $-1,5$ & $-4,0$ & $-4,1$ & 1,0 & 0,9 & $-3,7$ & $-3,8$ & 0,7 \\
\hline & Ec. 10 & 21,7 & 21,7 & 21,6 & 20,5 & 23,1 & 21,8 & 21,8 & 23,3 \\
\hline & Ec. 11 & 25,5 & 27,6 & 27,6 & 25,3 & 27,9 & 27,8 & 27,8 & 27,7 \\
\hline & Ec. 12 & 22,1 & 24,6 & 24,5 & 21,5 & 25,0 & 24,8 & 24,8 & 25,1 \\
\hline & Ec. 13 & 16,0 & 14,9 & 14,9 & 16,3 & 19,2 & 15,0 & 15,0 & 19,1 \\
\hline & Ec. 14 & 27,3 & 30,2 & 30,1 & 27,7 & 31,7 & 30,4 & 30,3 & 31,6 \\
\hline & Ec. 15 & 14,7 & 17,0 & 16,9 & 15,2 & 18,3 & 17,2 & 17,2 & 18,4 \\
\hline & Ec. 16 & 7,4 & 6,3 & 6,3 & 7,1 & 9,1 & 6,5 & 6,5 & 9,4 \\
\hline & emp & $5,4(a)$ & $\begin{array}{c}5,4- \\
9,5(a)\end{array}$ & $\begin{array}{l}9,5(a) \\
5-8(c)\end{array}$ & $13,9(b)$ & $14-26(a)$ & $\begin{array}{c}20- \\
23(a)\end{array}$ & $20-23(a)$ & $20-21(a)$ \\
\hline
\end{tabular}

Tabla 4.1: valores obtenidos con las distintas ecuaciones para el cálculo del MAT en cada localidad y el MAT real de cada localidad (en grados centígrados). PN=Parque Nacional, RP=Reserva Provincial. (a) Apodaca et al., 2015; (b) Arroyo et al., 2000; (c)

https://www.nahuelhuapi.gov.ar/flora.html. En rojo los valores por encima del esperado y en azul los valores por debajo.

\begin{tabular}{|c|c|c|c|c|c|c|c|c|}
\hline & $\begin{array}{c}\text { PN Los } \\
\text { Glaciares } \\
\text { (Santa } \\
\text { Cruz) }\end{array}$ & $\begin{array}{l}\text { PN Los } \\
\text { Alerces } \\
\text { (Chubut) }\end{array}$ & $\begin{array}{c}\text { PN Nahuel } \\
\text { Huapi (Río } \\
\text { Negro) }\end{array}$ & $\begin{array}{l}\text { Los Bellotos } \\
\text { (VII Región- } \\
\text { Chile) }\end{array}$ & $\begin{array}{c}\text { RP } \\
\text { Acambuco } \\
\text { (Salta) }\end{array}$ & $\begin{array}{c}\text { Chaco } \\
\text { seco }\end{array}$ & $\begin{array}{l}\text { Chaco } \\
\text { Húmedo }\end{array}$ & $\begin{array}{l}\text { PN Iguazú } \\
\text { (Misiones) }\end{array}$ \\
\hline $\begin{array}{c}\text { MAP } \\
\text { calculado }\end{array}$ & 933,7 & 894,5 & 916,8 & 728,7 & 357,4 & 112,2 & 347,9 & 434,4 \\
\hline MAP real & 70-500(a) & $\begin{array}{c}70- \\
500(a)\end{array}$ & $\begin{array}{c}70-500(a) \\
350(c)\end{array}$ & 101(b) & $90-250(a)$ & $50(a)$ & 120(a) & $\begin{array}{c}150-200 \\
\text { (a) }\end{array}$ \\
\hline
\end{tabular}

Tabla 4.2: valores obtenidos con la ecuación para calcular el MAP en cada localidad y el MAP real de cada localidad (en cm). (a) Apodaca et al., 2015; (b) Arroyo et al., 2000. En rojo los valores por encima del esperado. 


\section{FORMACIÓN CERRO BORORÓ}

En la presente tesis se utilizaron los nueve ejemplares descriptos originalmente por Petriella (1972) y asignados a los taxones de la tabla 4.3. Dada la antigüedad de las descripciones y asignaciones brindadas, las mismas fueron revisadas previo a la realización del estudio paleoclimático. Algunas discrepancias encontradas con las descripciones y la sistemática de Petriella (1972) son comentadas más adelante en este capítulo (sección 2.4). Además, se analizaron 12 ejemplares colectados posteriormente en el nivel de coníferas, todos ellos asignables a la misma especie también descripta por Petriella (Podocarpoxylon mazzonii).

En el nivel fosilífero de coníferas, al tratarse de un bosque monoespecífico y compuesto exclusivamente por coníferas, solo se pudieron estudiar los anillos de crecimiento (presentes en algunos de los ejemplares).

El NF de angiospermas cuenta con seis maderas asignables a seis especies de dicotiledóneas y además también se registra P. mazzoni (tabla 4.3). En este nivel se pudieron aplicar todos los análisis a excepción del análisis de los anillos de crecimiento por el bajo número de anillos y el estado de preservación de los mismos.

Por último, en el NF de cycadales solo se registraron cycadales y palmeras, grupos no propicios para los estudios propuestos en la presente tesis por lo que solo se los menciona como evidencian de un cambio notable en la vegetación de la región.

\begin{tabular}{|l|l|}
\hline Coníferas & Podocarpoxylon mazzonii (Petriella) Müller-Stoll et Schultze-Motel \\
\hline \multirow{4}{*}{ Angiospermas } & Elaeocarpoxylon sloaneoides Petriella \\
\cline { 2 - 2 } & Euxylophoroxylon chiquichanense Petriella \\
\cline { 2 - 2 } & Weinmannioxylon multiperforatum Petriella \\
\cline { 2 - 2 } & Weinmannioxylon pluriradiatum Petriella \\
\cline { 2 - 2 } & Rhizophoroxylon spallettii Petriella \\
\cline { 2 - 2 } & Bridelioxylon americanum Petriella \\
\hline
\end{tabular}

Tabla 4.3: taxones estudiados.

\subsection{Ecuaciones propuestas por Wiemann et al. $(1998,1999)$}

Según Wheeler \& Baas (1991), algunos de los caracteres anatómicos (como ser los engrosamientos espiralados, la porosidad circular y los patrones elaborados de parénquima paratraqueal) necesarios para aplicar las ecuaciones de Wiemann et al. 
(1998, 1999), aún no habían evolucionado en el Paleoceno del hemisferio sur, lo que limita el uso de las ecuaciones propuestas. No se pudo realizar el cálculo del MART, ni el CMMT. Además, para el cálculo del MAT solo se pudieron utilizar las ecuaciones número 1, 5 y 9 de Wiemann et al. 1999. Wheeler \& Baas (1991) mencionan que tampoco estaba presente la estructura estratificada pero, actualmente, hay registros de dicho carácter en el hemisferio sur (Martínez, 2010; más adelante en el presente capítulo). De cualquier manera, el registro es muy escaso y lo más probable es que su mayoritaria ausencia se deba a la reciente aparición del carácter, por lo que no se considera prudente utilizarlo en las ecuaciones propuestas. Los datos utilizados se detallan en la tabla 4.4 y los resultados fueron los siguientes:

MAT ecuación 1: $16,56^{\circ} \mathrm{C}$

MAT ecuación 5: $22^{\circ} \mathrm{C}$

MAT ecuación 9: $-0,85^{\circ} \mathrm{C}$

MAP: $995,11 \mathrm{~cm}$

DRY: $-6,56$ meses

\begin{tabular}{|c|c|c|c|c|c|c|c|c|c|c|c|c|c|}
\hline & \multicolumn{13}{|c|}{ Caracteres anatómicos de la madera } \\
\hline & tang & $\mathrm{RP}$ & mult & spir & $\begin{array}{l}<100 \\
\text { um }\end{array}$ & sept & $>10$ ser & het4+ & homo & stor & abs & marg & para \\
\hline $\begin{array}{l}\text { Elaeocarpoxylon } \\
\text { sloaneoides }\end{array}$ & 0 & 0 & 0,5 & 0 & 1 & 1 & 0 & 0 & 0 & 0 & 1 & 0 & 1 \\
\hline $\begin{array}{l}\text { Euxylophoroxylon } \\
\text { chiquichanense }\end{array}$ & 0 & 0 & 0 & 0 & 0 & 0 & 0 & 0 & 1 & 0 & 1 & 0 & 1 \\
\hline $\begin{array}{l}\text { Weinmannioxylon } \\
\text { multiperforatum }\end{array}$ & 0 & 0 & 1 & 0 & 1 & 0 & 0 & 1 & 0 & 0 & 1 & 0 & 0 \\
\hline $\begin{array}{l}\text { Weinmannioxylon } \\
\text { pluriradiatum }\end{array}$ & 0 & 0 & 1 & 0 & 1 & 0 & 0 & 1 & 0 & 0 & 1 & 0 & 0 \\
\hline $\begin{array}{l}\text { Rhizophoroxylon } \\
\text { spallettii }\end{array}$ & 1 & 0 & 1 & 0 & 0 & 0 & 0 & 0 & 1 & 0 & 1 & 0 & 0 \\
\hline $\begin{array}{l}\text { Bridelioxylon } \\
\text { americanum }\end{array}$ & 0 & 0 & 0 & 0 & 0 & 1 & 0 & 0 & 1 & 0 & 1 & 0 & 0 \\
\hline
\end{tabular}

Tabla 4.4: matriz de datos empleada para aplicar las ecuaciones de Wiemann et al. (1998, 1999). Las abreviaciones de los caracteres son las mismas detalladas en materiales y métodos.

\subsection{Anillos de crecimiento}

Si bien Podocarpoxylon mazzonii, Weinmannioxylon multiperforatum, Elaeocarpoxylon sloaneoides, Euxylophoroxylon chiquichanense, Rhizophoroxylon spallettii y Bridelioxylon americanum presentan anillos de crecimiento, sólo las muestras de Podocarpoxylon mazzonii presentan anillos lo suficientemente bien delimitados como para efectuar una correcta medición y llevar a cabo los estudios correspondientes. Los demás ejemplares no eran propicios para el estudio de los 
anillos dado su número escaso y la difícil observación de los límites de los mismos por la preservación.

\begin{tabular}{|lccccccccc|}
\hline Ejemplar & $\begin{array}{c}\text { № } \\
\text { anillos }\end{array}$ & $\begin{array}{c}\text { № } \\
\text { falsos } \\
\text { anillos }\end{array}$ & $\begin{array}{c}\text { № anillos } \\
\text { de } \\
\text { heladas }\end{array}$ & $\begin{array}{c}\text { Ancho } \\
\text { medio }\end{array}$ & $\begin{array}{c}\text { Ancho } \\
\text { mín. }\end{array}$ & $\begin{array}{c}\text { Ancho } \\
\text { máx. }\end{array}$ & $\begin{array}{c}\text { Desv. } \\
\text { est. }\end{array}$ & SA & SM \\
\hline LPPB 9062 & 16 & 0 & 0 & 0,67 & 0,37 & 1,06 & 0,16 & $0,01-0,67$ & 0,28 \\
\hline MPEF-Pb 9275 & 28 & 0 & 0 & 1,14 & 0,39 & 2,57 & 0,48 & $0,03-1,14$ & 0,54 \\
\hline MPEF-Pb 9278 & 26 & 0 & 0 & 0,79 & 0,28 & 1,51 & 0,34 & $0,004-1,20$ & 0,40 \\
\hline MPEF-Pb 9279 & 12 & 0 & 0 & 1,67 & 0,65 & 2,25 & 0,50 & $0,10-0,93$ & 0,37 \\
\hline MPEF-Pb 9280 & 46 & 0 & 0 & 0,58 & 0,15 & 1,12 & 0,23 & $0,02-1,06$ & 0,39 \\
\hline MPEF-Pb 9281 & 29 & 0 & 0 & 0,51 & 0,25 & 1,10 & 0,15 & $0,05-1,02$ & 0,29 \\
\hline MPEF-Pb 9282 & 13 & 0 & 0 & 1,10 & 0,32 & 2,14 & 0,61 & $0,05-1,32$ & 0,46 \\
\hline MPEF-Pb 9283 & 26 & 0 & 0 & 0,74 & 0,29 & 1,15 & 0,22 & $0,004-0,87$ & 0,32 \\
\hline Promedio & 196 & 0 & 0 & 0,90 & 0,34 & 1,61 & 2,69 & $0,03-1,03$ & 0,38 \\
\hline
\end{tabular}

Tabla 4.5: resumen de los datos tomados de los anillos de crecimiento de Podocarpoxylon mazzonii. Valores de ancho en $\mathrm{mm}$.

Se analizaron ocho secuencias de entre 12 y 46 anillos, alcanzando un total de 196 anillos. Podocarpoxylon mazzonii cuenta con anillos en general bastante poco demarcados, con una transición muy gradual entre leño temprano y leño tardío, haciendo evidentes solo 1-4 células como pertenecientes al leño tardío. En aquellas muestras con anillos de más de 30 traqueidas de espesor se calculó el porcentaje de leño tardío según el método de Creber \& Chaloner (1984b). En promedio el leño temprano comprende el 71,02 \% del anillo y el leño tardío el 28,98 \% (Tabla 4.6). Los anillos son de un ancho promedio de $0,90(0,34-1,61) \mathrm{mm}$, el más delgado registrado es de $0,15 \mathrm{~mm}$ y el más ancho de $2,57 \mathrm{~mm}$ (Tabla 4.5).

No se registraron falsos anillos ni anillos de heladas, por lo que no habría habido grandes perturbaciones climáticas y/o ambientales. 

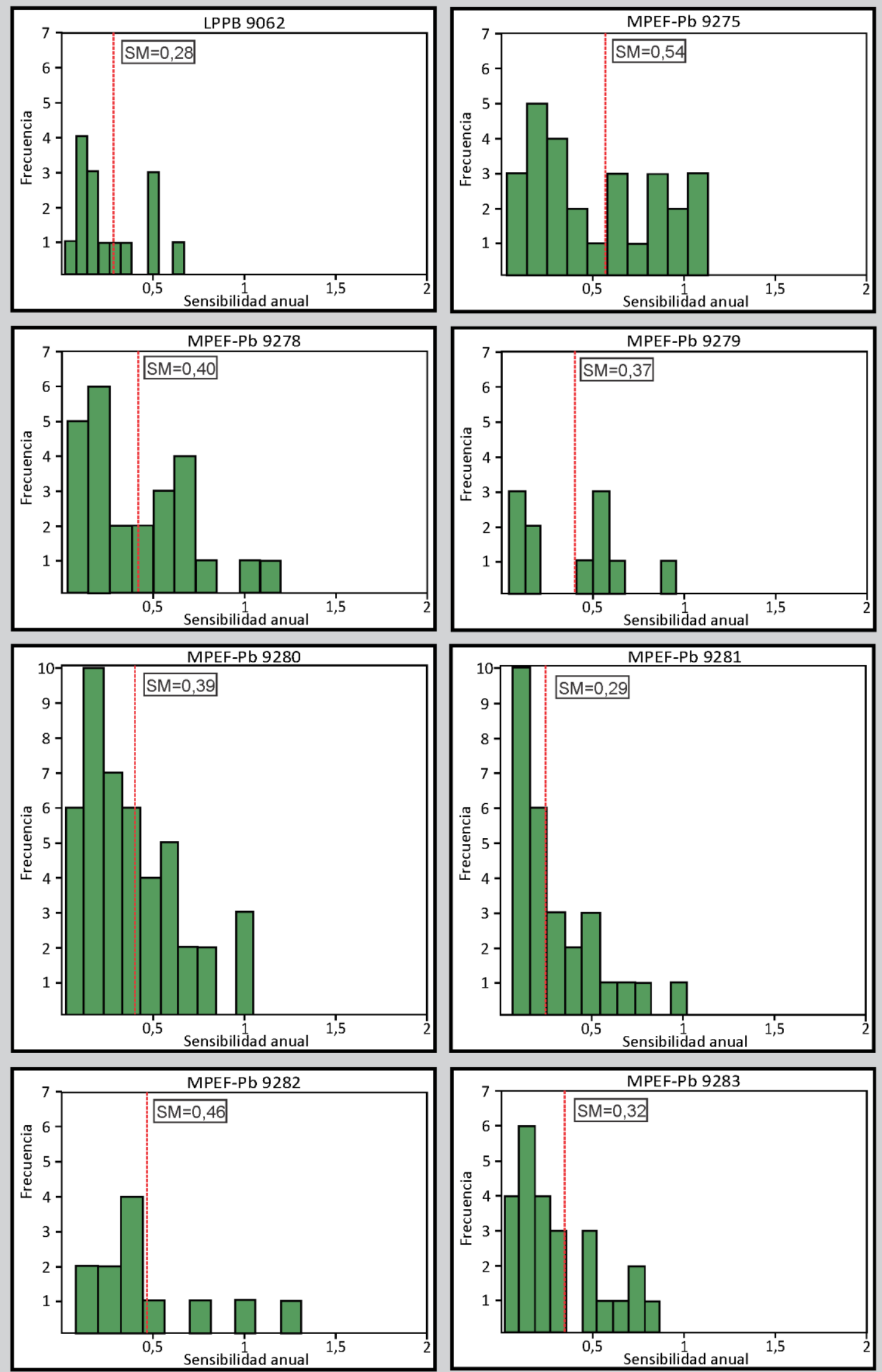

Fig. 4.1. Histogramas de Sensibilidad Anual (SA). Las líneas punteadas en rojo indica la Sensibilidad Media (SM). Todos los ejemplares corresponden a Podocarpoxylon mazzonii. 


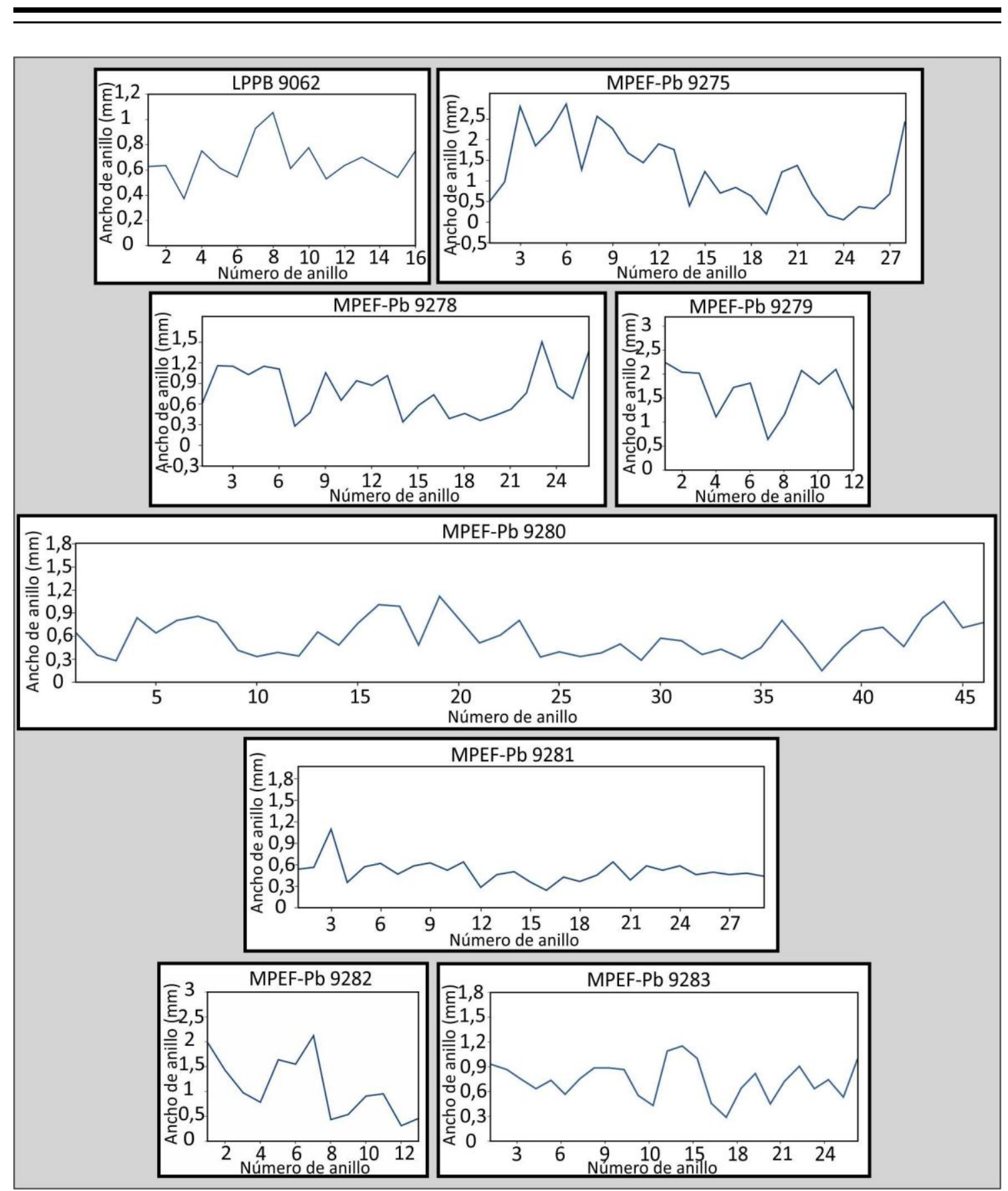

Fig. 4.2. Curvas de espesores de los anillos de crecimiento analizados. Todos los ejemplares corresponden a Podocarpoxylon mazzonii.

La SA mostró valores entre 0,03-1,03, la mayoría menores o iguales a 0,5 pero con algunos de alrededor de 1 que indicarían escasos eventos climáticos extremos como ser sequías (Tabla 4.5 y Fig. 4.1). La SM promedio es de 0,38, con valores entre 0,28 y 0,54 , indicando que se trataba de leños sensitivos que crecieron con condiciones climáticas variables (Tabla 4.5 y Fig. 4.2). 


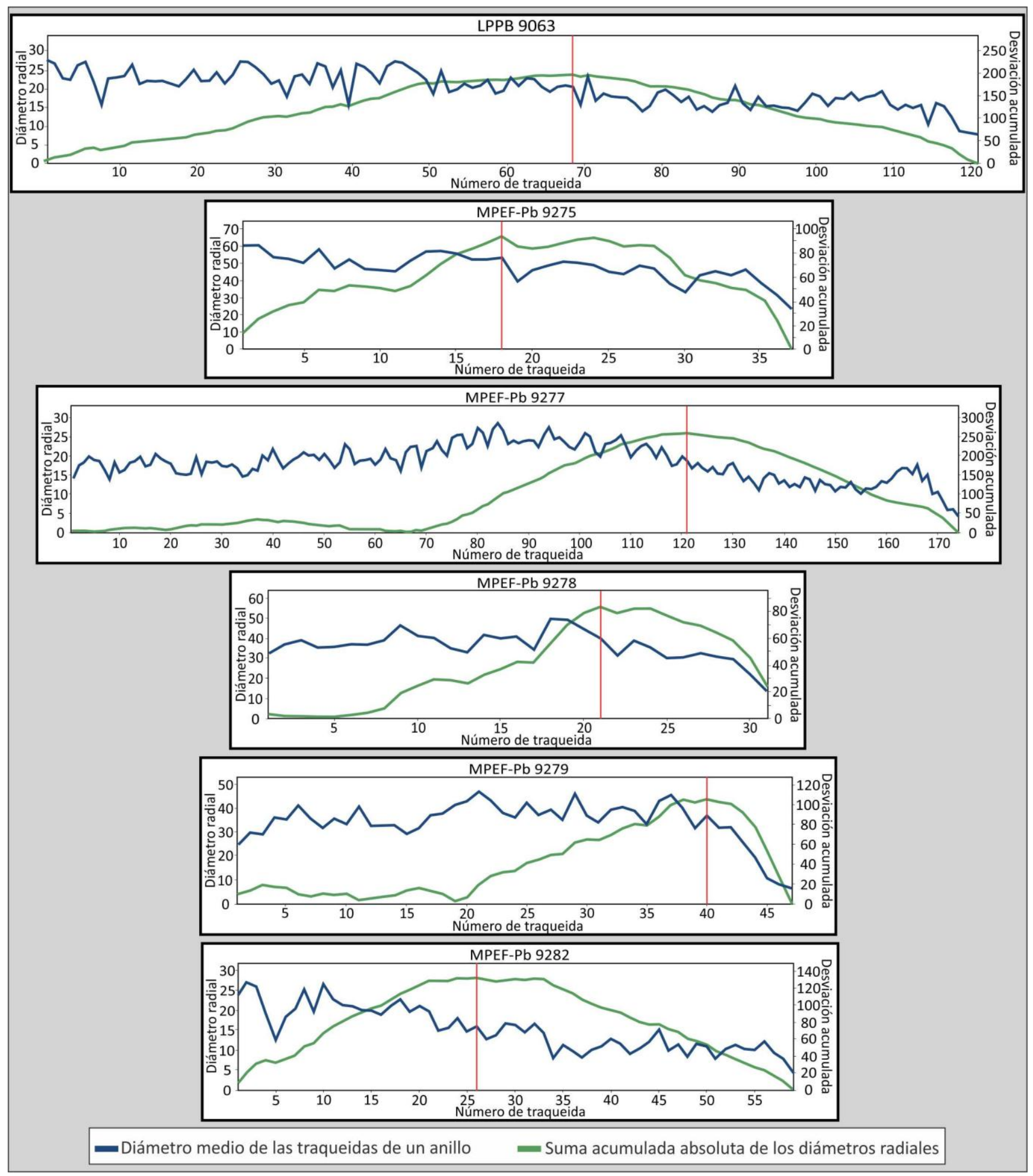

Fig. 4.3. Curvas CSDM. Podocarpoxylon mazzonii.

Los anillos son del tipo B y D según la clasificación de Creber \& Chaloner (1984b) (Fig. 4.3). Los de tipo B con mayor proporción de leño tardío indicarían un aporte de agua adecuado durante el período de crecimiento. Los D indican que la 
temporada de crecimiento fue relativamente uniforme pero con un evento terminal que provocó el cese de la actividad cambial.

El porcentaje de skew promedio de la especie es de $28,19 \%(2,70 \%-70,21 \%)$. Estos valores indicarían que se trata de una especie perennifolia (Tabla 4.6 y Fig. 4.3). La mayoría de los valores se corresponden con el skew de las actuales Podocarpaceae de Nueva Zelanda y Picea abies (L.) H. Karst., ambos con una retención foliar de entre 2-6 y 3-5 años respectivamente (Falcon-Lang, 2000a). El porcentaje de disminución es de $76,95 \%(61,18 \%-85,39 \%)$ y el RMI es $22,31(12,72-28,04)$ (Tabla 4.6$)$. Estos también concuerdan con los valores registrados para Picea abies por lo que la retención foliar seria entre 2 y 6 años (Falcon-Lang, 2000b).

\begin{tabular}{|lccccc|}
\hline \multicolumn{1}{|c}{ Ejemplar } & \% leño temprano & \% de leño tardío & Skew & $\%$ de disminución & RMI \\
\hline LPPB 9063 & $58,68 \%$ & $41,32 \%$ & $14,05 \%$ & $71,14 \%$ & 29,40 \\
\hline MPEF-Pb 9275 & $78,38 \%$ & $21,62 \%$ & $2,70 \%$ & $61,18 \%$ & 13,23 \\
\hline MPEF-Pb 9277 & $74,71 \%$ & $25,29 \%$ & $39,08 \%$ & $84,79 \%$ & 21,44 \\
\hline MPEF-Pb 9278 & $75,00 \%$ & $25,00 \%$ & $31,25 \%$ & $76,07 \%$ & 19,02 \\
\hline MPEF-Pb 9279 & $85,11 \%$ & $14,89 \%$ & $70,21 \%$ & $85,39 \%$ & 12,72 \\
\hline MPEF-Pb 9282 & $54,24 \%$ & $45,76 \%$ & $11,86 \%$ & $83,13 \%$ & 38,04 \\
\hline Promedio & $71,02 \%$ & $28,98 \%$ & $28,19 \%$ & $76,95 \%$ & 22,31 \\
\hline
\end{tabular}

Tabla 4.6: resumen de los datos tomados de los anillos de crecimiento de Podocarpoxylon mazzonii.

\section{3. Índices de Vulnerabilidad y Mesomorfía}

El índice de vulnerabilidad va desde 2,26 a 17,50 y el índice de mesomorfía toma valores entre un mínimo de 1304,92 y un máximo de 7805,04 (Tabla 4.7). Estos valores estarían señalando una alta disponibilidad de agua en el ambiente, probablemente debida a un régimen climático de lluvias abundantes.

\begin{tabular}{|lccccc|}
\hline & Diam. vasos & $\begin{array}{c}\text { No vasos por } \\
\mathrm{mm}^{2}\end{array}$ & $\begin{array}{c}\text { Largo de elem. } \\
\text { de vasos }\end{array}$ & Vulnerabilidad & Mesomorfía \\
\hline $\begin{array}{l}\text { Elaeocarpoxylon } \\
\text { sloaneoides }\end{array}$ & 72,37 & 32 & 577 & 2,26 & 1304,92 \\
\hline $\begin{array}{l}\text { Euxylophoroxylon } \\
\text { chiquichanense }\end{array}$ & 157,52 & 9 & 135 & 17,50 & 2362,80 \\
\hline $\begin{array}{l}\text { Weinmannioxylon } \\
\text { multiperforatum }\end{array}$ & 85,65 & 33 & 1260 & 2,59 & 3270,27 \\
\hline $\begin{array}{l}\text { Weinmannioxylon } \\
\text { pluriradiatum }\end{array}$ & 93,69 & 26 & 1212 & 3,60 & 4367,39 \\
\hline $\begin{array}{l}\text { Rhizophoroxylon } \\
\text { spallettii }\end{array}$ & 114,78 & 16 & 1088 & 7,17 & 7805,04 \\
\hline $\begin{array}{l}\text { Bridelioxylon } \\
\text { americanum }\end{array}$ & 139,82 & 17 & 465 & 8,22 & 3824,48 \\
\hline
\end{tabular}

Tabla 4.7: datos utilizados para calcular el índice de vulnerabilidad y el de mesomorfía. Medidas en $\mu \mathrm{m}$. 


\subsection{Método del Coexistence Approach (CA) o del pariente vivo más cercano Afinidad sistemática:}

Podocarpoxylon mazzonii - Originalmente fue asignado por Petriella (1972) al género Mesembrioxylon Seward, el cual carece actualmente de validez taxonómica por lo cual fue transferido al género Podocarpoxylon Gothan por Müller-Stoll \& SchultzeMotel (1990). En líneas generales la descripción de Petriella es afín con lo que se observó, sin embargo se hallaron diferencias tales como: la presencia de radios en parte triseriados e incluso tetraseriados en ocasiones (en adición a los uni y biseriados ya mencionados); y los campos de cruzamiento que poseen punteaduras de tipo "taxodioide" (sensu IAWA), con una abertura casi vertical y bordes delgados (Tabla 4.8). Este taxón posee afinidad con las Podocarpaceae por los tipos de campos de cruzamiento, en especial con los géneros como Podocarpus L'Hér. ex Pers. (entre otros), pero establecer un parentesco más específico se hace imposible por la gran similitud que poseen las maderas de las especies actuales correspondientes a dicha familia.

Weinmannioxylon pluriradiatum - El material consta de una excelente descripción por parte de Petriella (1972) quien crea este nuevo género y especie. En la actual revisión no se encontraron discrepancias con lo señalado por Petriella a excepción de la presencia de anillos. Además, se pudieron observar abundantes tílides y las punteaduras radio-vasculares elípticas, opuestas y semiareoladas (Tabla 4.9). El género se asignó a la familia Cunoniaceae en base a los siguientes caracteres: vasos predominantemente solitarios, placas de perforación exclusivamente escalariformes con numerosas barras, punteaduras radio-vasculares grandes, opuestas, escalariformes o transicionales, parénquima apotraqueal difuso o difuso agregado, ocasionalmente casi reticulado y fibrotraqueidas nunca tabicadas.

Weinmannioxylon multiperforatum - Especie también definida por Petriella, quien da una muy completa descripción, exceptuando el detalle de las punteaduras de las fibras, las cuales aclara que no se observan y que podrían tratarse en realidad de fibrotraqueidas. En la actual revisión del material se constató que, en efecto, se tratan de fibrotraqueidas con punteaduras areoladas de aberturas estrechas y cruzadas. Otro carácter, del que no se hace mención en la descripción original, es la presencia de 
escasos radios pluriseriados fusiformes (además de los pluriseriados con extremos uniseriados y los articulados) (Tabla 4.10). Estos caracteres sugieren que la segregación de Weinmannioxylon multiperforatum y $W$. pluriradiatum como dos especies distintas debería ser reconsiderada ya que las diferencias observadas podrían corresponder a variaciones intraespecíficas. Al margen de lo señalado, el ejemplar sigue tratándose de una especie de Weinmannioxylon y, por consiguiente, asignable a las Cunoniaceae en base a los caracteres mencionados anteriormente.

En resumen, ya sea que se trate de una o de dos especies, los leños estudiados presentan una gran similitud en todos sus caracteres con los actuales géneros de Cunoniaceae (e.g. Callicoma Andrews, Cunonia L., Pullea Schltr. y Weinmannia L.). Se considera que el género actual más afín al fósil descripto es Weinmannia, por hallarse en Sudamérica y además se encontraron granos de polen muy similares a los de este género en la misma zona (Archangelsky, 1973). Dentro de dicho género, se escogió como especie más afín a Weinmannia pinnata L., del noroeste de Sudamérica y Centroamérica. Esta especie presenta caracteres que concuerdan con ambas especies de Weinmannioxylon (ver tablas 4.9 y 4.10). Las únicas diferencias encontradas entre el género fósil y el actual son de carácter cuantitativo (diámetro promedio de vasos y número de vasos por $\mathrm{mm}^{2}$ ) (Dickinson, 1977).

Elaeocarpoxylon sloaneoides - En la actual revisión del material no se encontraron discrepancias con respecto a las observaciones hechas originalmente por Petriella (1972) al describir la especie (Tabla 4.11). Se la asigna como una Elaeocarpaceae, familia caracterizada por presentar anillos de crecimiento usualmente demarcados, vasos dispuestos en múltiples radiales, con placas de perforación mayoritariamente simples, pero ocasionalmente con algunas escalariformes, punteaduras radio-vasculares elongadas con bordes reducidos y verticales, oblicuas o escalariformes, fibras a veces septadas, parénquima difuso y en ocasiones terminal, radios heterocelulares uniseriados y multiseriados, estos últimos de hasta 7 células de ancho y de alto variable (Metcalfe \& Chalk, 1950; Coode, 2004). De los géneros presentes en dicha familia solo Aristotelia L'Hér. y Vallea Mutis ex L. f. no presentan cristales, al igual que la especie fósil, siendo Vallea quien presenta más caracteres en común con Elaeocarpoxylon sloaneoides (Tabla 4.11) (InsideWood, 2004 en adelante). 
Euxylophoroxylon chiquichanense - Se observaron exactamente los mismos caracteres mencionados por Petriella (1972) en la descripción original. La especie actual más similar encontrada es la Rutaceae Euxylophora paraensis Huber (Tabla 4.12).

Bridelioxylon americanum - Esta especie fue implementada por Petriella (1972) y relacionada con las Euphorbiaceae. Al revisar el material se hallaron notables diferencias con la descripción original (Tabla 4.13), por lo que sería oportuno hacer una enmienda a la diagnosis y probablemente transferir el ejemplar a otro género. Por un lado, las punteaduras intervasculares ornadas son un carácter clave para la asignación al género según su diagnosis original (Ramanujam, 1956) y en la muestra aquí estudiada no son ornadas o al menos la preservación no permite observar este carácter con la claridad necesaria. Por otro lado, se observan contenidos oleíferos en células parenquimáticas cuadrangulares terminales en los radios, así como también en células ubicadas de forma aislada entre las fibras. Este carácter, de importancia diagnóstica, no se encuentra en la diagnosis de la especie ni en la del género en cuestión. Tomando en cuenta la ausencia de punteaduras ornadas, la presencia de células oleíferas y el resto de los rasgos ya mencionados por Petriella (porosidad difusa con vasos solitarios o en series radiales de dos o hasta cuatro, placas de perforación simples, punteaduras alternas, parénquima axial escaso y difuso, y radios heterogéneos y heterocelulares), la especie estaría más emparentada con las Lauraceae actuales. Los miembros más australes de esta familia en Sudamérica son Beilschmiedia miersii (Gay) Kostern y Cryptocarya alba (Mol.) Looser, pero el primero presenta abundante parénquima paratraqueal y el segundo presenta abundante parénquima en bandas terminales (Rancusi et al., 1987), mientras que el fósil estudiado tiene parénquima apotraqueal difuso y escaso. Los géneros Ocotea Aubl., Nectandra Rol. ex Rottb. y Persea Mill., también presentes en Sudamérica se asemejan mucho más a B. americanum. La madera de los tres taxones citados es muy similar, siendo más común la presencia de placas escalariformes en Persea y más abundante el parénquima en Nectandra, por lo que se considera a Ocotea el género más afín con el fósil (Tortorelli, 1956; InsideWood, 2004 en adelante). Ocotea además, es el género que más comúnmente presenta tilosis y sus dos especies más australes que llegan 
hasta el norte argentino (O. acutifolia (Nees) Mez y O. puberula (Rich.) Nees) son notablemente similares al fósil.

Rhizophoroxylon spallettii - Petriella (1972) describió a esta madera como de porosidad difusa con vasos solitarios de contorno circular, placas escalariformes de entre 5 y 10 barras, punteaduras intervasculares opuestas o transicionales a alternas, escaso parénquima apotraqueal difuso y radios heterogéneos uni y multiseriados (hasta 5-seriados). En esta revisión se observaron también vasos en series radiales de 2-3 células, aparte de los solitarios mencionados por Petriella que siguen siendo la mayoría. Además, se observaron radios hasta 7-seriados y escasa tilosis (Tabla 4.14). Como el mismo Petriella (1972) destaca, R. spallettii no puede ser ubicada con precisión en ninguno de los tres grupos en los que se reúnen las maderas de Rizhophoraceae. Se diferencia del primer grupo por el tipo de punteaduras radiales (escalariformes en el grupo, opuestas a alternas en el fósil); del segundo grupo por el tipo de placa de perforación (simple en el grupo y escalariforme en el fósil); y del tercer grupo por el tipo de radios (mucha mayor cantidad de uniseriados en el grupo de los casi ausentes que hay en el fósil). Él argumenta que, a pesar de las claras diferencias, como presenta caracteres similares con los grupos uno y tres se trataría de una Rhizophoraceae con caracteres intermedios entre ambos grupos (Petriella, 1972). Si bien ciertamente podría tratarse de una Rhizophoraceae, tampoco hay una similitud de caracteres tan estrecha como para poder afirmarlo. Los mismos rasgos característicos se encuentran en otras familias, como ser las Calophyllaceae con el género Marila Sw. de Brasil, que se diferencia del fósil solo en presentar radios más altos y mayor proporción de uniseriados (InsideWood, 2004 en adelante). Lo mismo ocurre con las Clethraceae, presente en Sudamérica con características similares y solo diferenciadas por presentar radios más marcadamente heterogéneos y mayor proporción de radios uniseriados (Metcalfe \& Chalk, 1950; InsideWood, 2004 en adelante). Peumus boldus Mol. es una Monimiaceae presente en Chile, con radios muy similares a Rhizophoroxylon spallettii (Rancusi et al., 1987). Si bien esta especie en particular es claramente diferenciable por otros caracteres (e.g. mayoría de vasos dispuestos en series radiales, placas simples y engrosamientos helicoidales) dentro de la familia Monimiaceae son más habituales una mayoría de vasos solitarios y la 
presencia de placas escalariformes, que junto con los radios multiseriados y las punteaduras intervasculares opuestas a alternas (Metcalfe \& Chalk, 1950), harían de las Monimiaceae otra familia factible para ubicar a Rhizophoroxylon. La familia Myricaceae es otra familia común en el Neotrópico con la que se podría relacionar a la especie fósil aquí descripta. Las Myricaceae presentan porosidad difusa con los vasos dispuestos mayoritariamente de forma solitaria, placas escalariformes, punteaduras intervasculares opuestas a alternas, parénquima apotraqueal difuso y radios desde uniseriados a multiseriados de hasta ocho células de espesor; la única diferencia notable es el menor tamaño de los vasos (diámetro tangencial menor a $100 \mu \mathrm{m}$ ) (Metcalfe \& Chlak, 1950; InsideWood, 2004 en adelante). La familia Symplocaceae también presenta comúnmente los caracteres hallados en el fósil y también cuenta con representantes sudamericanos (Metcalfe \& Chalk, 1950; InsideWood, 2004 en adelante). Dado que son varias las familias dentro de las cuales se podría ubicar a Rhizophoroxylon spallettii, no se considera prudente relacionarlo con ninguna en particular, dejándolo por el momento como incertae sedis y descartándolo para el estudio del pariente vivo más cercano. 


\section{Podocarpoxylon mazzonii}

\section{Petriella (1972)}

\section{Este trabajo}

\begin{tabular}{|c|c|c|}
\hline $\begin{array}{l}\text { Presencia de } \\
\text { anillos }\end{array}$ & $\begin{array}{l}\text { Presentes, una o dos filas de } \\
\text { traqueidas aplanadas radialmente }\end{array}$ & $\begin{array}{l}\text { Presentes, una o dos filas de traqueidas } \\
\text { aplanadas radialmente }\end{array}$ \\
\hline $\begin{array}{l}\text { Contorno de las } \\
\text { traqueidas }\end{array}$ & Poligonales, cuadradas o rectangulares & Poligonales o cuadrangulares \\
\hline $\begin{array}{l}\text { Punteaduras } \\
\text { radiales }\end{array}$ & $\begin{array}{c}\text { Generalmente uniseriadas, } \\
\text { ocasionalmente biseriadas opuestas, } \\
\text { siempre circulares }\end{array}$ & $\begin{array}{c}\text { Generalmente uniseriadas, ocasionalmente } \\
\text { biseriadas opuestas, siempre circulares }\end{array}$ \\
\hline Radios & Uni o biseriados. Homocelulares & $\begin{array}{l}\text { Mayormente biseriados ya sea parcial o } \\
\text { totalmente, también uniseriados y } \\
\text { parcialmente triseriados, más raramente } \\
\text { parcialmente tetraseriados. Homocelulares }\end{array}$ \\
\hline $\begin{array}{l}\text { Campos de } \\
\text { cruzamiento }\end{array}$ & $\begin{array}{c}\text { Una o dos punteaduras fenestriformes } \\
\text { donde la areola es muy reducida o ha } \\
\text { desaparecido }\end{array}$ & $\begin{array}{l}\text { Una o dos punteaduras fenestriformes } \\
\text { o taxodioides }\end{array}$ \\
\hline $\begin{array}{l}\text { Traqueidas } \\
\text { septadas }\end{array}$ & Presentes & Presentes \\
\hline Parénquima axial & En duda & En duda \\
\hline Observaciones & $\begin{array}{l}\text { Meatos intercelulares. Crásulas. } \\
\text { Traqueidas con contenidos }\end{array}$ & $\begin{array}{l}\text { Meatos intercelulares. Crásulas. Traqueidas } \\
\text { con contenidos }\end{array}$ \\
\hline
\end{tabular}

Tabla 4.8: tabla comparativa entre los caracteres de Podocarpoxylon mazzonii observados por Petriella (1972) y en el presente trabajo de tesis. 


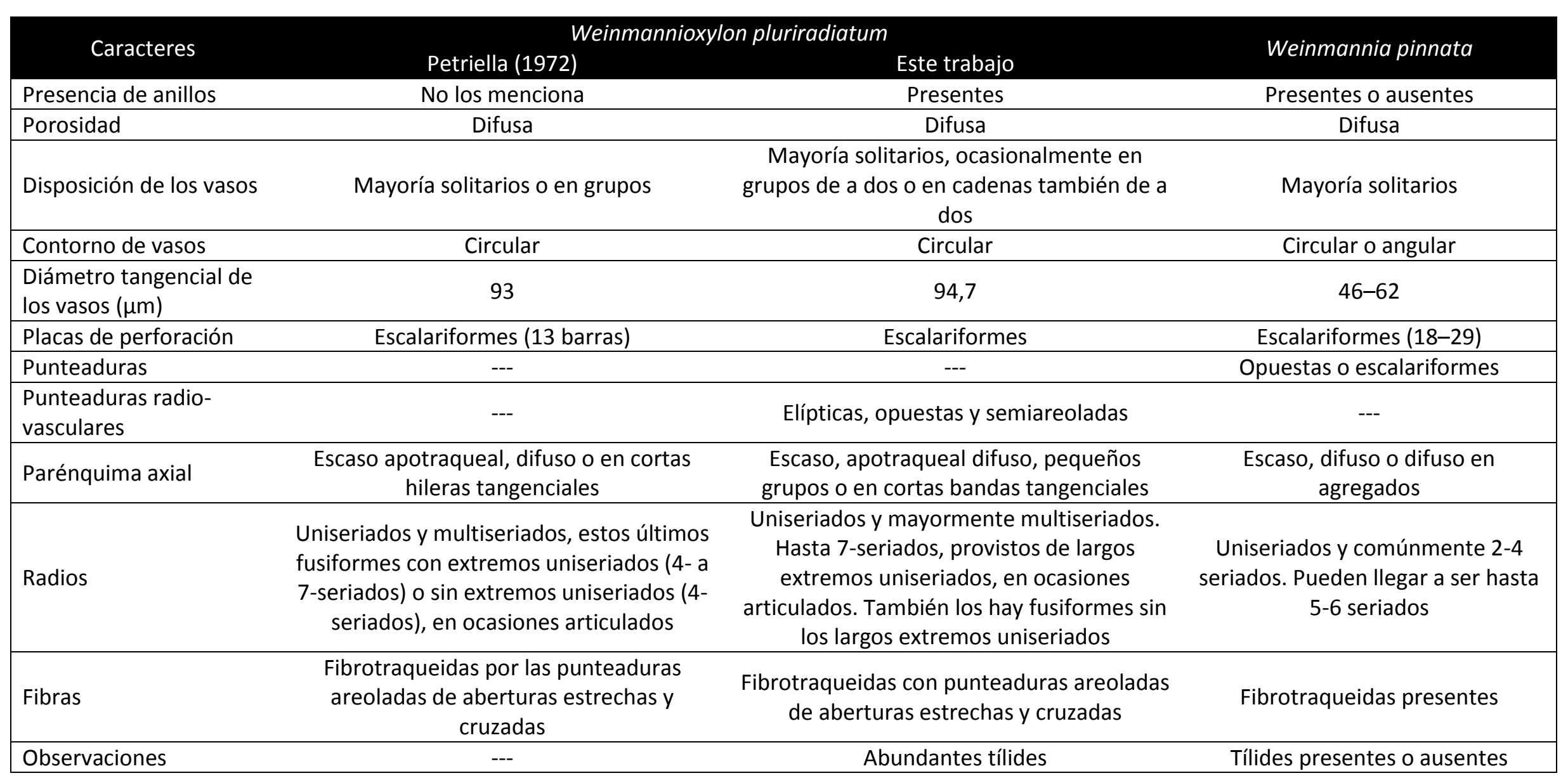

Tabla 4.9: tabla comparativa entre Weinmannioxylon pluriradiatum y su pariente vivo más cercano. 


\begin{tabular}{|c|c|c|c|}
\hline \multirow{2}{*}{ Caracteres } & \multicolumn{2}{|c|}{ Weinmannioxylon multiperforatum } & \multirow{2}{*}{ Weinmannia pinnata } \\
\hline & Petriella (1972) & Este trabajo & \\
\hline Presencia de anillos & No los menciona & Presentes & Presentes o ausentes \\
\hline Porosidad & Difusa & Difusa & Difusa \\
\hline Disposición de los vasos & $\begin{array}{c}\text { Mayoría agrupados, también solitarios y en } \\
\text { cadena }\end{array}$ & $\begin{array}{c}\text { Mayoría solitarios, ocasionalmente en } \\
\text { grupos de a dos o en cadenas también de a } \\
\text { dos }\end{array}$ & Mayoría solitarios \\
\hline Contorno de vasos & Circular & Circular & Circular o angular \\
\hline $\begin{array}{l}\text { Diámetro tangencial de } \\
\text { los vasos }(\mu \mathrm{m})\end{array}$ & 83,5 & 85,6 & $46-62$ \\
\hline Placas de perforación & Escalariformes (promedio 21 barras) & Escalariformes & Escalariformes (18-29) \\
\hline Punteaduras & Opuestas o escalariformes & Opuestas o escalariformes & Opuestas o escalariformes \\
\hline $\begin{array}{l}\text { Punteaduras radio- } \\
\text { vasculares }\end{array}$ & $\begin{array}{c}\text { Simples amplias elípticas, generalmente } \\
\text { opuestas }\end{array}$ & Elípticas, opuestas y semiareoladas & ( \\
\hline Parénquima axial & $\begin{array}{c}\text { Escaso, apotraqueal difuso o formando } \\
\text { pequeños grupos de pocas células } \\
\text { circulares o lineares }\end{array}$ & $\begin{array}{l}\text { Escaso, apotraqueal difuso, pequeños } \\
\text { grupos o en cortas bandas tangenciales }\end{array}$ & $\begin{array}{l}\text { Escaso, difuso o difuso en } \\
\text { agregados }\end{array}$ \\
\hline Radios & $\begin{array}{c}\text { Uniseriados y mayormente multiseriados. } \\
\text { Hasta 4-seriados, provistos de largos } \\
\text { extremos uniseriados, en ocasiones } \\
\text { articulados }\end{array}$ & $\begin{array}{l}\text { Uniseriados y mayormente multiseriados. } \\
\text { Hasta 5-seriados, provistos de largos } \\
\text { extremos uniseriados, en ocasiones } \\
\text { articulados. También los hay fusiformes sin } \\
\text { los largos extremos uniseriados }\end{array}$ & $\begin{array}{l}\text { Uniseriados y comunmente 2- a 4- } \\
\text { seriados. Pueden llegar a ser hasta } \\
\text { 5-a 6-seriados }\end{array}$ \\
\hline Fibras & $\begin{array}{l}\text { Podrían tratarse de fibrotraqueidas pero } \\
\text { no se ven las punteaduras }\end{array}$ & $\begin{array}{c}\text { Fibrotraqueidas con punteaduras areoladas } \\
\text { de aberturas estrechas y cruzadas. De } \\
\text { paredes muy gruesas }\end{array}$ & Fibrotraqueidas presentes \\
\hline Observaciones & Vasos con apéndices & Vasos con apéndices. Abundantes tílides & Tílides presentes o ausentes \\
\hline
\end{tabular}

Tabla 4.10: tabla comparativa entre Weinmannioxylon multiperforatum y su pariente vivo más cercano. 
Caracteres

Petriella (1972)

Elaeocarpoxylon sloaneoides

\begin{tabular}{|c|c|c|c|}
\hline 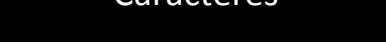 & Petriella (1972) & Este trabajo & \\
\hline Presencia de anillos & $\begin{array}{l}\text { Presentes por disminución del diámetro de } \\
\text { las fibras }\end{array}$ & $\begin{array}{l}\text { Presentes por disminución del diámetro de } \\
\text { las fibras }\end{array}$ & Presentes \\
\hline Porosidad & Difusa & Difusa & Difusa \\
\hline Disposición de los vasos & $\begin{array}{l}\text { Solitarios o radiales múltiples de } 3 \text { ó hasta } \\
\qquad 9 \text { células }\end{array}$ & $\begin{array}{c}\text { Solitarios o radiales múltiples de } 2 \text { a } 9 \\
\text { células }\end{array}$ & $\begin{array}{l}\text { Radiales múltiples de } 4 \text { o más } \\
\text { células }\end{array}$ \\
\hline Contorno de vasos & Circular o elíptico & Circular o elíptico & --- \\
\hline $\begin{array}{l}\text { Diámetro tangencial de } \\
\text { los vasos }(\mu \mathrm{m})\end{array}$ & 82 & 72,4 & $50-200$ \\
\hline Placas de perforación & Simples (una escalariforme) & Simples o escalariformes & $\begin{array}{c}\text { Simples u ocasionalmente } \\
\text { escalariformes }\end{array}$ \\
\hline Punteaduras & $\begin{array}{c}\text { Escalariformes u opuestas (de tipo } \\
\text { transicional) }\end{array}$ & $\begin{array}{c}\text { Escalariformes u opuestas (de tipo } \\
\text { transicional) }\end{array}$ & Opuestas o escalariformes \\
\hline $\begin{array}{l}\text { Punteaduras radio- } \\
\text { vasculares }\end{array}$ & Opuestas o escalariformes, semiareoladas & Opuestas o escalariformes, semiareoladas & $\begin{array}{c}\text { Escalariformes a verticales, } \\
\text { semiareoladas }\end{array}$ \\
\hline Parénquima axial & Escasamente paratraqueal & Escasamente paratraqueal & Extremadamente raro o ausente \\
\hline Radios & $\begin{array}{l}\text { Uniseriados y multiseriados (2- a 5- } \\
\text { seriados), estos últimos fusiformes con } \\
\text { extremos uniseriados, y articulados. } \\
\text { Heterogéneos tipo II }\end{array}$ & $\begin{array}{l}\text { Uniseriados y multiseriados (2- a 5- } \\
\text { seriados), estos últimos fusiformes con } \\
\text { extremos uniseriados, y articulados. } \\
\text { Heterogéneos tipo II }\end{array}$ & $\begin{array}{c}\text { Radios anchos (4- a } 10 \text {-seriados), } \\
\text { algunos con extremos uniseriados, } \\
\text { heterogéneos }\end{array}$ \\
\hline Fibras & Septadas & Septadas & Septadas \\
\hline Observaciones & --- & --- & --- \\
\hline
\end{tabular}

Tabla 4.11: tabla comparativa entre Elaeocarpoxylon sloaneoides y su pariente vivo más cercano.
Vallea sp.

Presentes

u ocasionalmente

puestas o escalariformes

riformes a verticales, semiareoladas 


\begin{tabular}{|c|c|c|c|}
\hline \multirow{2}{*}{ Caracteres } & \multicolumn{2}{|c|}{ Euxylophoroxylon chiquichanense } & \multirow{2}{*}{ Euxylophora paraensis } \\
\hline & Petriella (1972) & Este trabajo & \\
\hline Presencia de anillos & Presentes & Presentes, poco demarcados & Poco demarcados o ausentes \\
\hline Porosidad & Difusa & Difusa & Difusa \\
\hline Disposición de los vasos & $\begin{array}{c}\text { Radiales múltiples de } 2 \text { ó } 3 \text { células y } \\
\text { solitarios }\end{array}$ & $\begin{array}{c}\text { Radiales múltiples cortos de } 2 \text { ó } 3 \text { células y } \\
\text { solitarios }\end{array}$ & Radiales múltiples y solitarios \\
\hline Contorno de vasos & Elíptico o circular & Elíptico o circular & Elíptico o circular \\
\hline $\begin{array}{l}\text { Diámetro tangencial de } \\
\text { los vasos }(\mu \mathrm{m})\end{array}$ & 150 & 157,5 & $100-200$ \\
\hline Placas de perforación & Simples & Simples & Simples \\
\hline Punteaduras & --- & --- & Alternas \\
\hline $\begin{array}{l}\text { Punteaduras radio- } \\
\text { vasculares }\end{array}$ & --- & --- & Con bordes distintivos \\
\hline Parénquima axial & Escasamente paratraqueal & Escasamente paratraqueal & Escasamente paratraqueal \\
\hline Radios & $\begin{array}{l}\text { Exclusivamente multiseriados, 4- a 6- } \\
\text { seriados }\end{array}$ & $\begin{array}{l}\text { Exclusivamente multiseriados, 2- a 6- } \\
\text { seriados }\end{array}$ & Radios hasta 10 seriados \\
\hline Fibras & No septadas & No septadas & No septadas \\
\hline Observaciones & Células secretoras en los radios & Células secretoras en los radios & $\begin{array}{c}\text { Células oleíferas o mucilaginosas } \\
\text { asociadas a los radios }\end{array}$ \\
\hline
\end{tabular}

Tabla 4.12: tabla comparativa entre Euxylophoroxylon chiquichanense y su pariente vivo más cercano. 


\begin{tabular}{|c|c|c|c|}
\hline \multirow{2}{*}{ Caracteres } & \multicolumn{2}{|c|}{ Bridelioxylon americanum } & \multirow{2}{*}{ Ocotea } \\
\hline & Petriella (1972) & Este trabajo & \\
\hline Presencia de anillos & Presentes & Presentes & Presentes \\
\hline Porosidad & Difusa & $\begin{array}{r}\text { Difusa } \\
\end{array}$ & Difusa \\
\hline Disposición de los vasos & $\begin{array}{c}\text { Mayormente radiales múltiples de } 2 \text { a } 4 \\
\text { células, también solitarios y en menor } \\
\text { medida agrupados }\end{array}$ & $\begin{array}{l}\text { Mayormente radiales múltiples de } 2-3(4) \\
\text { células, también solitarios y en menor } \\
\text { medida agrupados }\end{array}$ & Solitarios o radiales múltiples \\
\hline Contorno de vasos & Circular & Circular & Circular \\
\hline $\begin{array}{l}\text { Diámetro tangencial de } \\
\text { los vasos }(\mu \mathrm{m})\end{array}$ & 109,5 & 139,8 & Variable \\
\hline Placas de perforación & Simples & Simples & $\begin{array}{l}\text { Mayormente simples, puede haber } \\
\text { escalariformes }\end{array}$ \\
\hline Punteaduras & Alternas & Alternas & Alternas \\
\hline $\begin{array}{l}\text { Punteaduras radio- } \\
\text { vasculares }\end{array}$ & 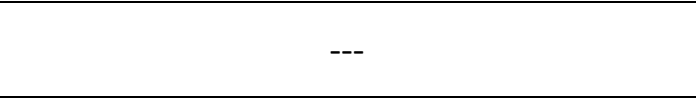 & --- & --- \\
\hline Parénquima axial & $\begin{array}{l}\text { Escaso paratraqueal. Apotraqueal difuso en } \\
\text { cortas líneas radiales }\end{array}$ & $\begin{array}{l}\text { Escasamente paratraqueal y apotraqueal } \\
\text { difuso, prácticamente ausente }\end{array}$ & Vasicéntrico \\
\hline Radios & $\begin{array}{l}\text { 3- a 4- seriados, uniseriados escasos. } \\
\text { Heterogéneos }\end{array}$ & $\begin{array}{l}\text { 3- a 4-seriados fusiformes y en algunos } \\
\text { casos articulados. Heterogéneos }\end{array}$ & $\begin{array}{l}\text { 1- a 4-seriados, puede haber } \\
\text { articulados por partes } \\
\text { uniseriadas. Heterogéneos }\end{array}$ \\
\hline Fibras & Septos muy poco numerosos & $\begin{array}{c}\text { Septos muy poco numerosos, mayormente } \\
\text { no septadas }\end{array}$ & Septadas y no septadas \\
\hline Observaciones & Punteaduras ornadas & $\begin{array}{c}\text { Las punteaduras no se observan lo } \\
\text { suficientemente bien para asegurar que } \\
\text { son ornadas. Tílides. Células oleíferas en } \\
\text { los radios }\end{array}$ & $\begin{array}{l}\text { Células oleíferas presentes en los } \\
\text { radios. Puede haber tilosis }\end{array}$ \\
\hline
\end{tabular}

Tabla 4.13: tabla comparativa entre Bridelioxylon americanum y su pariente vivo más cercano. 


\begin{tabular}{|c|c|c|}
\hline \multirow{2}{*}{ Caracteres } & \multicolumn{2}{|c|}{ Rhizophoroxylon spallettii } \\
\hline & Petriella (1972) & Este trabaio \\
\hline Presencia de anillos & Presentes, poco visibles & Presentes, poco visibles \\
\hline Porosidad & Difusa & Difusa \\
\hline Disposición de los vasos & Solitarios & $\begin{array}{l}\text { Mayormente solitarios, también radiales } \\
\text { cortos de } 2-3 \text { células }\end{array}$ \\
\hline Contorno de vasos & Circular & Circular \\
\hline $\begin{array}{l}\text { Diámetro tangencial de } \\
\text { los vasos }(\mu \mathrm{m})\end{array}$ & 112 & 114,8 \\
\hline Placas de perforación & Escalariformes (5-10 barras) & Escalariformes (más de 10 barras) \\
\hline Punteaduras & Opuestas o transicionales a alternas & Transicionales a alternas \\
\hline $\begin{array}{l}\text { Punteaduras radio- } \\
\text { vasculares }\end{array}$ & ( & --- \\
\hline Parénquima axial & Escaso, apotraqueal difuso & Escaso, apotraqueal difuso \\
\hline Radios & $\begin{array}{l}\text { Uniseriados y mayormente multiseriados, } \\
\text { fusiformes, 2- a 5- seriados. Heterogéneos }\end{array}$ & $\begin{array}{c}\text { Multiseriados, fusiformes, generalmente } 4 \\
\text { seriados (2-7). Heterogéneos }\end{array}$ \\
\hline Fibras & Pared gruesa, no están bien preservadas & $\begin{array}{c}\text { Pared muy gruesa. Algunas con } \\
\text { punteaduras circulares y muy pequeñas }\end{array}$ \\
\hline Observaciones & --- & Escasa tilosis (de paredes delgadas) \\
\hline
\end{tabular}

Tabla 4.14: tabla comparativa entre los caracteres de Rhizophoroxylon spallettii observados por Petriella (1972) y en el presente trabajo de tesis. 
Como resultado de la aplicación del método del Coexistence Approach se obtuvo una temperatura media anual de entre $25,5^{\circ} \mathrm{C}$ y $26,7^{\circ} \mathrm{C}$ y precipitaciones medias anuales de alrededor de $200 \mathrm{~cm}$ anuales (Fig. 4.4).

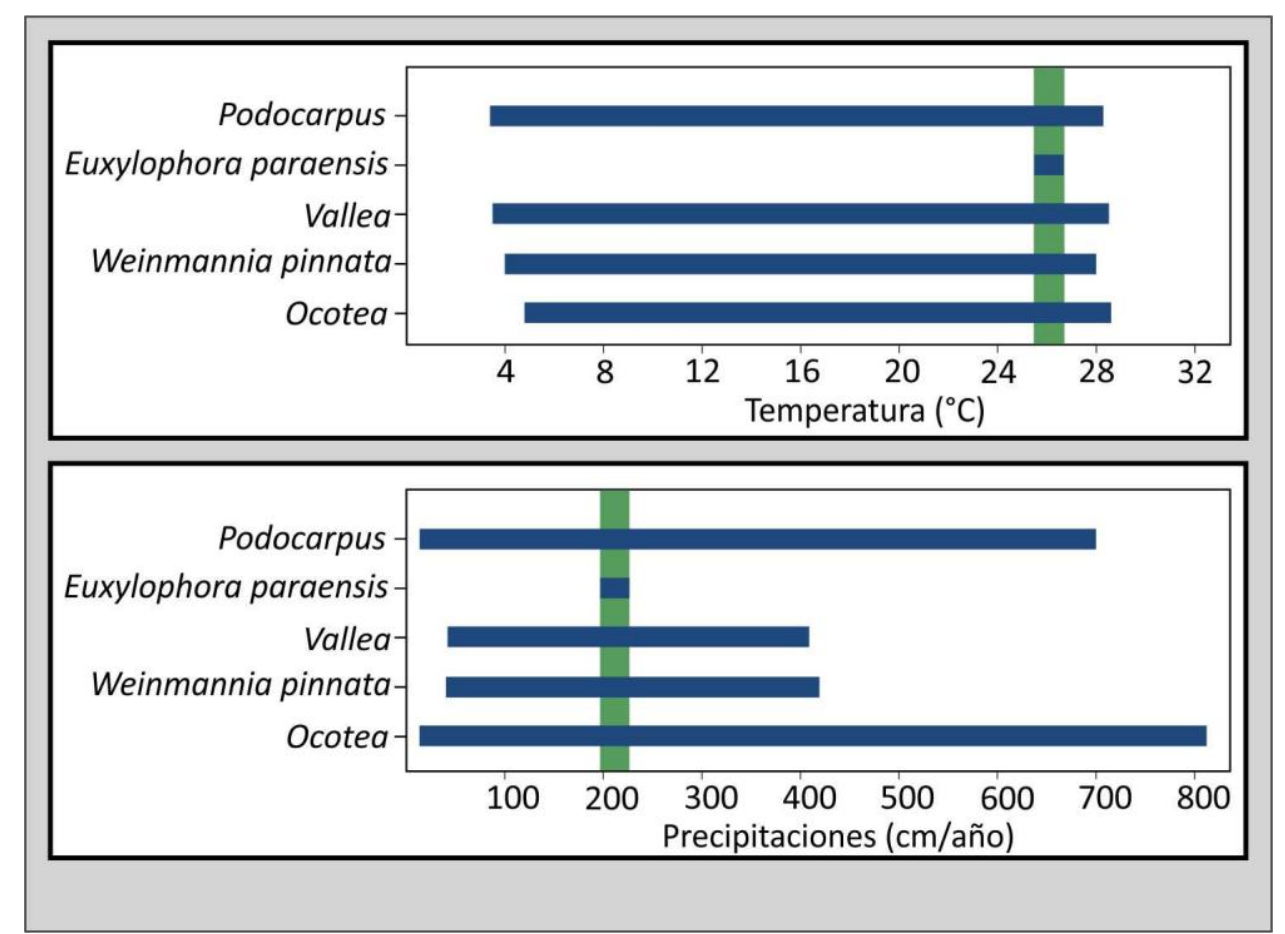

Fig. 4.4. Gráficos de MAT y MAP según el método del Coexistence Approach.

\subsection{Caracteres eco-xilológicos}

Ninguno de los ejemplares presenta porosidad circular, ni patrones de distribución de vasos oblicua o dendrítica, actualmente asociados a climas templadocálidos (Wheeler \& Baas, 1991, 1993; Baas \& Wheeler, 2011).

Los vasos poseen un gran diámetro tangencial, con un valor promedio de 110,6 $\mu \mathrm{m}(72,4-157,2)$ (Tabla 4.7). Esto señala un ambiente templado cálido a cálido (Baas \& Xinying, 1986; Wheeler \& Baas, 1991, 1993; Carlquist, 2001; Baas \& Wheeler, 2011).

El largo de los elementos de vaso es muy variable, tres de las especies presentan valores cercanos o menores a los $500 \mu \mathrm{m}$, y otras tres presentan valores por sobre los $1000 \mu \mathrm{m}$ (Tabla 4.7). Según Baas \& Xinying $(1986)$ y Carlquist $(1975,2012)$ el largo de los vasos en zonas húmedas es mayor y son más cortos en zona más secas.

La frecuencia de vasos es muy baja, con valores desde los 9 a los 33 vasos por $\mathrm{mm}^{2}$, algo típico de regiones tropicales (Van der Graaff \& Baas, 1974; Baas \& Xinying, 1986; Wheeler \& Baas, 1991, 1993; Baas \& Wheeler, 2011). 
Tres de las especies presentan placas de perforación simples, lo cual se correlaciona con ambientes cálidos y húmedos, mientras que las de tipo escalariformes se dan en lugares templados fríos o tropicales pero de alta montaña (Baas \& Schweingruber, 1987; Baas, 1982; Wheeler \& Baas, 1991, 1993). Las tres especies restantes tienen placas de perforación escalariformes con un alto número de barras, lo cual según Baas (1982), indicaría un ambiente húmedo.

Ninguno de los ejemplares presenta engrosamientos helicoidales, característicos de zonas templado-frías y/o secas (Van der Graaff \& Baas, 1974; Baas \& Xinying, 1986; Baas \& Schweingruber, 1987; Wheeler \& Baas, 1991, 1993; Carlquist, 2012).

En los casos de elementos imperforados con punteaduras, éstas son areoladas, típico de zonas con alto grado de humedad (Carlquist, 2001). La presencia de septos en las fibras también se relaciona con floras tropicales (Baas \& Schweingruber, 1987; Wheeler \& Baas, 1991).

El parénquima axial es escaso en todos los taxa analizados, en la mayoría es escasamente paratraqueal y en otros casos es apotraqueal difuso o agrupado. Según Wheeler \& Baas (1991) y Morris et al. (2015), la distribución y la cantidad de parénquima se relacionan con la temperatura, siendo mayormente paratraqueal y más abundante en lugares tropicales.

Ninguno de los ejemplares tiene estructura estratificada, la cual está presente en climas templado-cálidos (Wheeler \& Baas, 1991). 
3. FORMACIÓN SALAMANCA

\subsection{Sistemática paleobotánica}

Orden Araucariales Gorozhankin, 1904

Familia Podocarpaceae Endl., 1847

Género Podocarpoxylon Gothan, 1905

Especie tipo Podocarpoxylon juniperoides Gothan, in Gagel 1906

Podocarpoxylon multiparenchymatosum Pujana et Ruiz, 2017

Figuras: 4.5 y 4.6 .

Material estudiado: MPEF-Pb 8385 y MPEF-Pb 8386.

Localidad: Estancia Las Violetas, provincia del Chubut, Argentina.

Horizonte estratigráfico: Formación Salamanca. Paleoceno.

Descripción: madera de tipo coniferoide, homoxilica y picnoxílica. Los anillos de crecimiento son apenas delimitables por 1 o 2 hileras de traqueidas de leño tardío, con una transición abrupta entre éste y el leño temprano. Las traqueidas presentan una sección oval a cuadrangular (Fig. 4.5 A,B). El diámetro tangencial de las mismas es de $20,3(11,4-30) \mu \mathrm{m}$ y el radial es de $21,8(13,4-31) \mu \mathrm{m}$ en el leño temprano, mientras que en el leño tardío es de $7,2(3,2-11,7) \mu \mathrm{m}$. El grosor de las paredes en las traqueidas es $2,5(1,4-4,0) \mu \mathrm{m}$. El parénquima axial es abundante $\mathrm{y}$ en sección transversal es difuso y/o en bandas tangenciales (Fig. 4.5 A,B). Los radios están separados entre sí por 4 (1-8) traqueidas.

Las punteaduras radiales de las traqueidas siguen un plan abietinoide, es decir son areoladas, circulares, uniseriadas y espaciadas (Fig. 4.5 C,D). Estas punteaduras tienen un diámetro radial de $13,9(8,9-18,9) \mu \mathrm{m}$ y vertical de $13,2(9,4-17,5) \mu \mathrm{m}$; las aperturas tienen un diámetro radial de $2,4(1,7-3,3) \mu \mathrm{m}$ y vertical de $2,2(1,6-3,0) \mu \mathrm{m}$. Los radios son homocelulares y las células parenquimáticas que los conforman tienen sus paredes lisas, tanto las horizontales como las terminales. Los campos de cruzamiento cuentan con 1 (2) oculiporos por campo, con un diámetro de 6,0 (3,8-6,5) $\mu \mathrm{m}$. Los mismos son del tipo taxodiode (o "podocarpoide", ver Pujana \& Ruiz, 2017) de bordes delgados y amplia apertura de extremos ahusados, inclinada de forma oblicua a vertical (Figs. 4.5 E,F y $4.6 \mathrm{~A}, \mathrm{~B}$ ). 

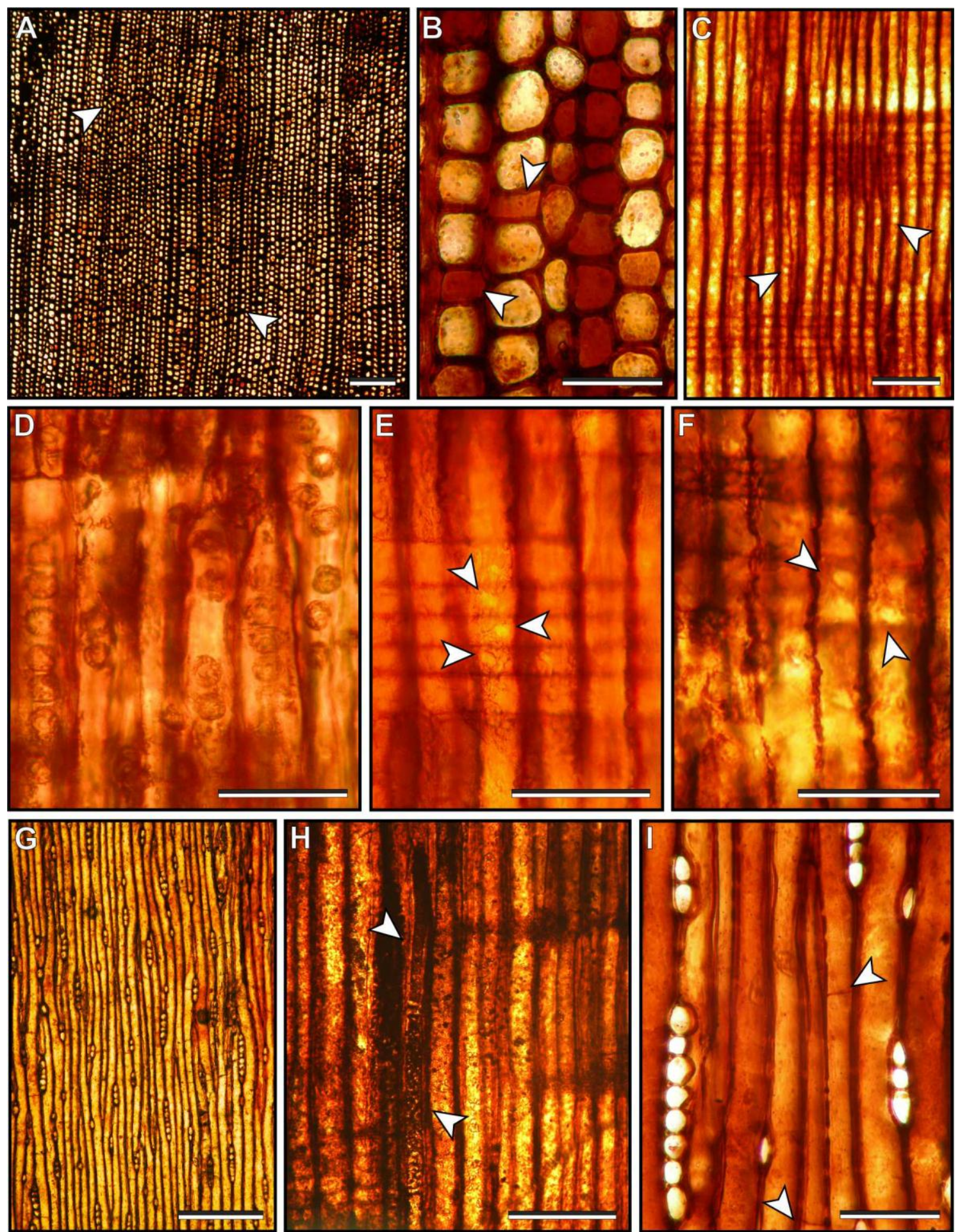

Figura 4.5. Podocarpoxylon multiparenchymatosum. MPEF-Pb 8386. A. ST. Parénquima axial en bandas tangenciales (flechas). B. ST. Detalle del parénquima axial (flechas). C. SLR. Punteaduras radiales uniseriadas y espaciadas (flechas). D. SLR. Detalle de las punteaduras radiales. E, F. SLR. Campos de cruzamiento con punteaduras taxodioides (flechas). G. SLT. Radios uniseriados. H. SLT. Parénquima axial (flechas). I. SLT. Traqueidas septadas (flechas). Escalas. A,G: $200 \mu \mathrm{m}$; C,H: $100 \mu \mathrm{m}$; B,D-F,I: $50 \mu \mathrm{m}$. 
En corte longitudinal tangencial se observa la presencia de traqueidas septadas (Fig. 4.5 I). El parénquima axial posee paredes terminales lisas (Fig. $4.5 \mathrm{H}$ ). Los radios son exclusivamente uniseriados con 4 (1-15) células de alto (Fig. 4.5 G,I). Dichos radios miden $56,3(19,0-138,5) \mu m$ de alto y $6,5(3,1-12,6) \mu m$ de ancho. En vista tangencial las células radiales son ovales, midiendo $13,6(8,1-24,1) \mu \mathrm{m}$ de alto y $7,1(4,3-11,2) \mu \mathrm{m}$ de ancho. La pared de las mismas tiene $1,0(0,6-1,7) \mu \mathrm{m}$ de espesor.
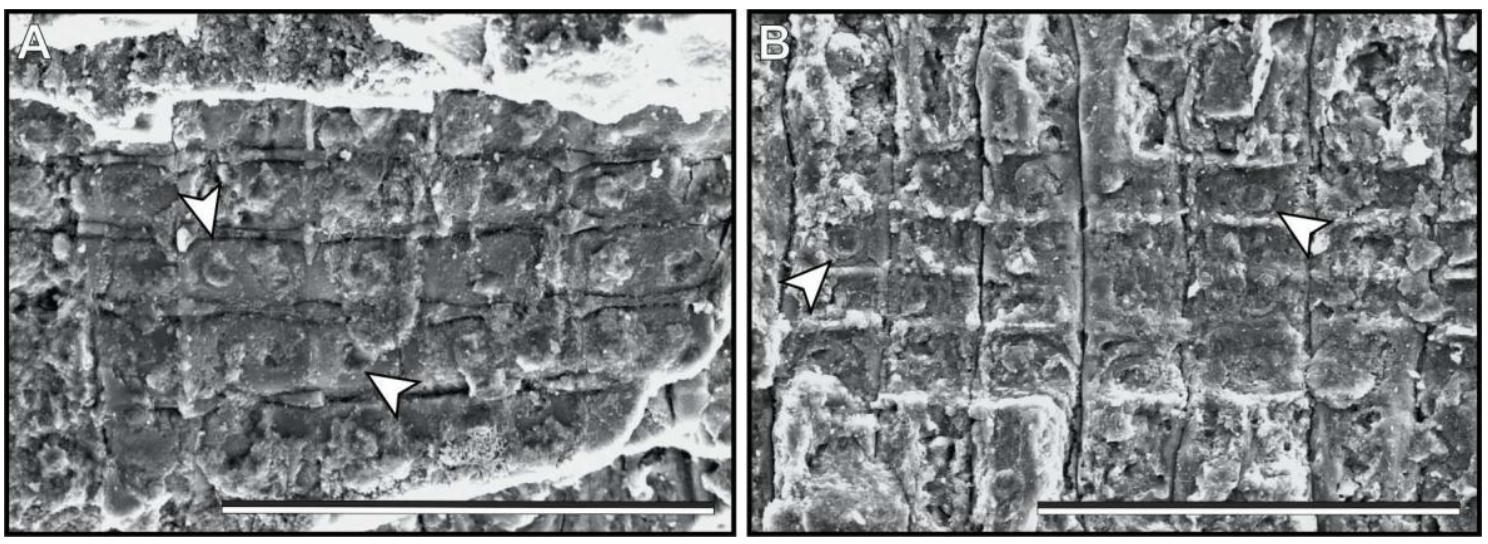

Figura 4.6. Podocarpoxylon multiparenchymatosum. MPEF-Pb 8386 A y B. SLR. Campos de cruzamiento con campos taxodioides (flechas). Escalas. $100 \mu \mathrm{m}$.

Comparaciones y comentarios: el material fue asignado al género Podocarpoxylon de acuerdo con las siguientes características: punteaduras radiales de tipo abietinoide, ausencia de canales resiníferos y engrosamientos espiralados, campos de cruzamiento con menos de 4 oculiporos con bordes delgados y aberturas no horizontales, en algunos casos ordenadas en filas (sensu Philippe \& Bamford, 2008). De las especies correspondientes a este género en Sudamérica, las únicas con presencia de parénquima axial y punteaduras exclusivamente uniseriadas son $P$. multiparenchymatosum, P. palaeoandinum Nishida y P. palaeosalignum Nishida. Dado que estas dos últimas tienen punteaduras en los campos de cruzamiento de tipo pinoide o phyllocladoide en vez de taxodioide, se asigna el fósil aquí estudiado a $P$. multiparenchymatosum (Nishida, 1984b; Pujana \& Ruiz, 2017; Ruiz et al., 2017).

En la actualidad hay una enorme cantidad de especies asignables a las Podocarpaceae y que comparten similitudes con el fósil descripto. Una de las más parecidas por poseer radios exclusivamente uniseriados, es Podocarpus salignum Don, cabe destacar que esta especie actualmente habita en los bosques andino-patagónicos 
(Tortorelli, 1956; Rancusi et al., 1987) (para más comparaciones ver Pujana \& Ruiz, 2017).

\section{Orden Araucariales Gorozhankin, 1904}

Familia Cupressaceae sensu stricto (sensu Pilger, 1926) o Podocarpaceae Endl., 1847 Género Cupressinoxylon Göpert, 1850 nom. cons. prop. Especie tipo Cupressinoxylon gothanii Kräusel, 1920

\section{Cupressinoxylon austrocedroides Nishida, 1984a}

Figuras: 4.7 y 4.8 .

Material estudiado: MPEF-Pb 8387

Localidad: Estancia Las Violetas, provincia del Chubut, Argentina.

Horizonte estratigráfico: Formación Salamanca. Paleoceno.

Descripción: se trata de una madera coniferoide, homoxílica y picnoxílica. En corte transversal se aprecian anillos de crecimiento, la mayoría de ellos con sólo 1 o 2 hileras de células de leño tardío, aunque en otros casos el porcentaje de leño tardío es mayor llegando a alcanzar 11 hileras de células (Fig. 4.7 A). En el primer caso la transición entre leño temprano y tardío es abrupta, mientras que en el último caso es de forma gradual. En sección transversal las traqueidas son de forma circular a poligonal y se observan espacios intercelulares de forma triangular o cuadrangular (Fig. 4.7 A,B). Las traqueidas tienen un diámetro tangencial de $20,0(6,1-28,1) \mu m$ con una pared de $3,7(2,6-5,9) \mu \mathrm{m}$ de espesor. El diámetro radial de las traqueidas varía entre $19,0(8,3-33,7) \mu \mathrm{m}$ en el leño temprano y $5,2(2,0-10,0) \mu \mathrm{m}$ en el leño tardío. El parénquima axial es difuso (Fig. 4.7 B). Los radios están separados entre sí por 3 (1-6) filas de traqueidas.

En vista longitudinal radial, las punteaduras de las traqueidas siguen un típico plan abietinoide, circulares, bien espaciadas y uniseriadas (muy excepcionalmente biseriadas opuestas) (Figs. 4.7 C y 4.8 A,B). Las punteaduras miden $12,7(10,4-16,7) \mu \mathrm{m}$ radialmente y $11,8(8,7-15,0) \mu \mathrm{m}$ verticalmente, en cuanto a los poros, los mismos poseen un diámetro radial de $2,3 \mu \mathrm{m}(1,6-3,0)$ y vertical de $2,6(1,9-3,4) \mu \mathrm{m}$ en vertical. Los radios son homocelulares, con las paredes terminales de las células parenquimáticas lisas. La mayoría de las paredes horizontales son también lisas pero algunas presentan engrosamientos nodulares (Fig. 4.7 D). Los campos de cruzamiento 
contienen un oculiporo de tipo cupresoide, de bordes gruesos y abertura inclinada (Figs. 4.7 E,F y 4.8 C,D) con un diámetro vertical de $5,5(4,1-7,2) \mu \mathrm{m}$. Se observan hifas septadas dentro de algunos de los radios mientras que otros presentan contenidos (Fig. 4.7 F).

En el corte longitudinal tangencial se observan radios uniseriados, con 6 (1-21) células y $111,1(20,6-362,4) \mu \mathrm{m}$ de alto y $16(8,6-31,6) \mu \mathrm{m}$ de ancho (Fig. $4.7 \mathrm{G}-1)$. Las células radiales poseen una sección circular, exceptuando las terminales que son ovaladas. El diámetro horizontal de dichas células parenquimáticas es de 14,2 (7,3$28,6) \mu \mathrm{m}$ y el vertical es $15,1(8-35) \mu \mathrm{m}$, con paredes de $1,9(1,3-3,0) \mu \mathrm{m}$ de espesor. Las paredes terminales del parénquima axial son lisas (Fig. $4.7 \mathrm{H}, \mathrm{I}$ ).

Comparaciones y comentarios: la madera se asigna como Cupressinoxylon de acuerdo a Göppert (ver Philippe \& Bamford, 2008), por el leño tardío usualmente con células comprimidas y de paredes gruesas, el leño temprano con células más anchas y de paredes delgadas, las punteaduras radiales abietinoides, el parénquima axial, los radios homogéneos, bajos y uniseriados, compuestos de parénquima con punteaduras, y los campos de cruzamiento usualmente ordenados en filas y columnas. Si lo comparamos con otras especies de Cupressinoxylon de Sudamérica vemos que se diferencia claramente de C. hallei Kräusel, C. mochaense Nishida y Cupressinoxylon sp. de Pujana et al. (2015) porque éstos tienen mayor número de punteaduras por campo de cruzamiento (Kräusel, 1924; Nishida, 1984b). También se distingue de C. zamunerae Bodnar, Ruiz, Artabe, Morel et Ganuza y C. patagonicum Conwentz debido a que estos tienen punteaduras radiales en parte biseriadas (Conwentz, 1885; Bodnar et al., 2015).

Los campos cupresoides pueden ser encontrados actualmente no solo en las Cupresaceae, sino también en las Podocarpaceae (IAWA committee, 2004; Vázquez Correa et al., 2010; Pujana et al., 2014), por lo que las maderas de Cupressionoxylon pueden ser afines a cualquiera de estas dos familias. En este caso, como notó el mismo Nishida (1984a) al describir la especie, C. austrocedroides se asemeja mucho a la Cupressaceae Austrocedrus chilensis (Don) Florin et Bou, a la cual debe su nombre y con la cual no tiene notables diferencias anatómicas. 

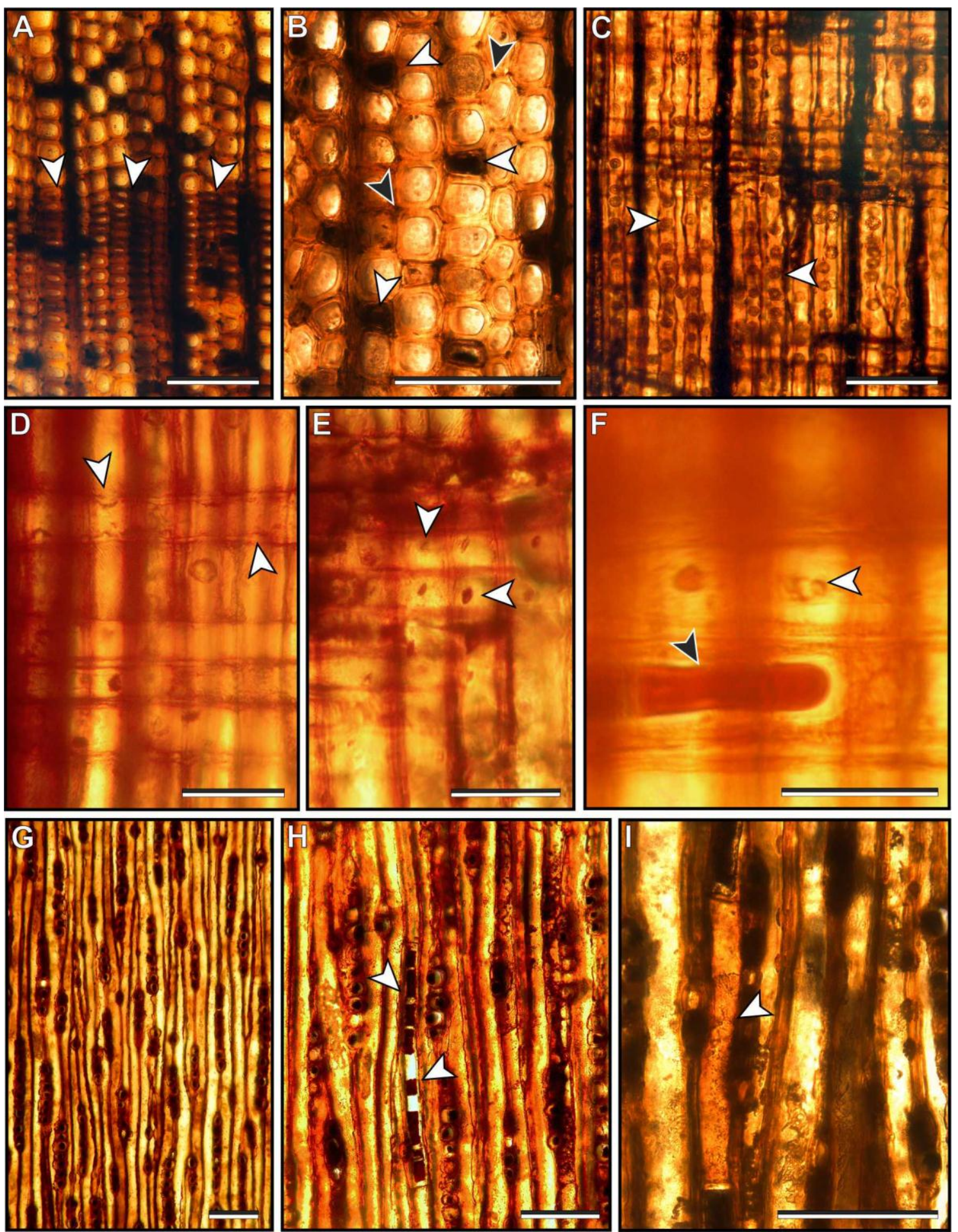

Figura 4.7. Cupressinoxylon austrocedroides. MPEF-Pb 8387. A. ST. Límite de un anillo de crecimiento (flechas). B. ST. Detalle del parénquima axial (flechas blancas) y espacios intercelulares (flechas negras). C. SLR. Punteaduras radiales uniseriadas y espaciadas (flechas). D. SLR. Engrosamientos nodulares. E. SLR. Campos de cruzamiento (flechas blancas). F. STR. Detalle de las punteaduras de los campos de cruzamiento (flechas bancas) y parénquima axial con contenidos (flecha negra). G. SLT. Radios uniseriados. H. SLT. Parénquima axial (flechas). I. SLT. Detalle de parénquima axial (flecha). Escalas. A-C,G-I: $100 \mu \mathrm{m}$; D-E: $50 \mu \mathrm{m}$; F: $25 \mu \mathrm{m}$. 

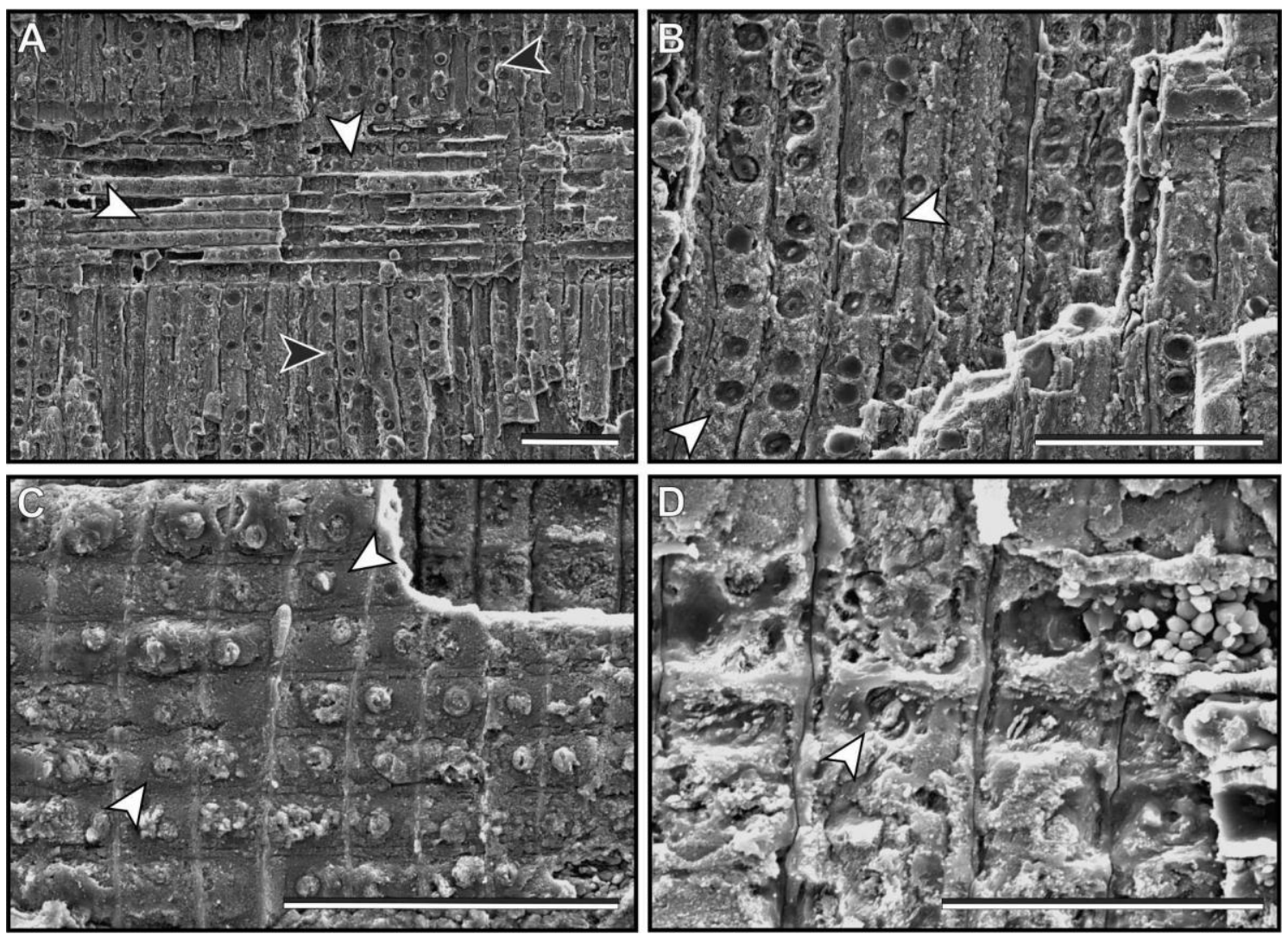

Figura 4.8. Cupressinoxylon austrocedroides. MPEF-Pb 8387. A. SLR. Vista general de los campos de cruzamiento (flechas blancas) y de las punteaduras radiales de las traqueidas (flechas negras). B. SLR. Detalle de las punteaduras radiales mayormente uniseriadas y muy raramente biseriadas (flechas). C. SLR. Campos de cruzamiento con punteaduras cupresoides (flechas). D. SLR. Detalle punteaduras cupresoides en el campo de cruzamiento (flecha).

Escalas. A-C: $100 \mu \mathrm{m}$; D: $50 \mu \mathrm{m}$.

\section{Cupressinoxylon artabeae Ruiz, Brea, Raingemborn et Matheos, 2017}

Figuras: 4.9 y 4.10 .

Material estudiado: MPEF-Pb 8388.

Localidad: Estancia Las Violetas, provincia del Chubut, Argentina.

Horizonte estratigráfico: Formación Salamanca. Paleoceno.

Descripción: madera de tipo coniferoide, homoxílica y picnoxílica. Los anillos de crecimiento son demarcados, con 1-3 hileras de traqueidas de leño tardío. La transición entre leño temprano y tardío es abrupta (Fig. 4.9 A,B). Las traqueidas son rectangulares en vista transversal y entre ellas suele haber espacios intercelulares (Fig. 4.9 A,B). Las traqueidas tienen $22,7(12,5-22,7) \mu \mathrm{m}$ de diámetro tangencial y 24,2 $(11,4-36,2) \mu \mathrm{m}$ y $18,2(8,7-23,7) \mu \mathrm{m}$ de diámetro radial en el leño temprano y en el tardío respectivamente. El espesor de la pared celular es de 5,9 $(3,2-9,5) \mu \mathrm{m}$. No hay 
parénquima axial o es extremadamente escaso. Un número de 4 (2-6) traqueidas separan los radios.

En vista longitudinal radial se observa que las punteaduras de las traqueidas son abietinoides, mayormente uniseriadas y espaciadas (Figs. $4.9 \mathrm{C}$ ), pero en ocasiones también biseriadas opuestas y parcialmente contiguas (Fig. 4.9 D). Crásulas presentes (Fig. 4.9 C,D). El diámetro radial de las punteaduras es de $18,1(13,4-22,1) \mu \mathrm{m}$ y el de las aberturas es $2,7(1,7-4,6) \mu \mathrm{m}$; y el diámetro vertical mide $14,9(11,1-17,4) \mu \mathrm{m}$ en la areola y $2,7 \mu \mathrm{m}(1,9-3,4)$ en la abertura. Los radios son homocelulares, compuestos por células parenquimáticas de paredes horizontales y terminales lisas. Hay 1(2) oculiporos en cada campo de cruzamiento, en su mayoría cupresoides con la abertura inclinada más angosta que los bordes (Figs. 4.9 E,G y 4.10 B). También las hay taxodioides ("podocarpoides") con la abertura más amplia y forma de ojal inclinado formando un amplio ángulo con la horizontal. La areola, que no llega a los extremos de la abertura, es muy delgada (Fig. 4.9 F,H). El diámetro vertical promedio de estas punteaduras es de $10,8(9,4-12) \mu \mathrm{m}$.

Los radios son únicamente uniseriados y poseen un alto de 8 (1-29) células y 138,8 (40,7-464,0) $\mu \mathrm{m}$ (Fig. 4.9 I,J). El parénquima radial consta de un lumen ovalado en vista tangencial, que mide en promedio $14,9(8,2-23,3) \mu \mathrm{m}$ de alto y $8,9(5,3-12,9)$ $\mu \mathrm{m}$ de ancho, con un espesor de pared de 1,3 $(0,9-1,8) \mu \mathrm{m}$.

Comparaciones y comentarios: este ejemplar fue asignado como Cupressinoxylon de acuerdo a los mismos caracteres mencionados anteriormente en $C$. austrocedroides. La presencia de crásulas lo hace fácilmente distinguible de las restantes especies de Cupressinoxylon presentes en Sudamérica. C. mochaense Nishida (del Mioceno de Chile) es la única especie con este carácter, pero a diferencia del fósil estudiado en esta tesis, tiene punteaduras radiales exclusivamente uniseriadas, tres o más punteaduras por campo y carece de anillos de crecimiento (Nishida, 1984b). Debido a esto y a la presencia de punteaduras en los campos de notable tamaño (11 $\mu \mathrm{m})$ se estableció la nueva especie $C$. artabeae en una reciente publicación producto en parte de esta tesis doctoral (Ruiz et al., 2017). 

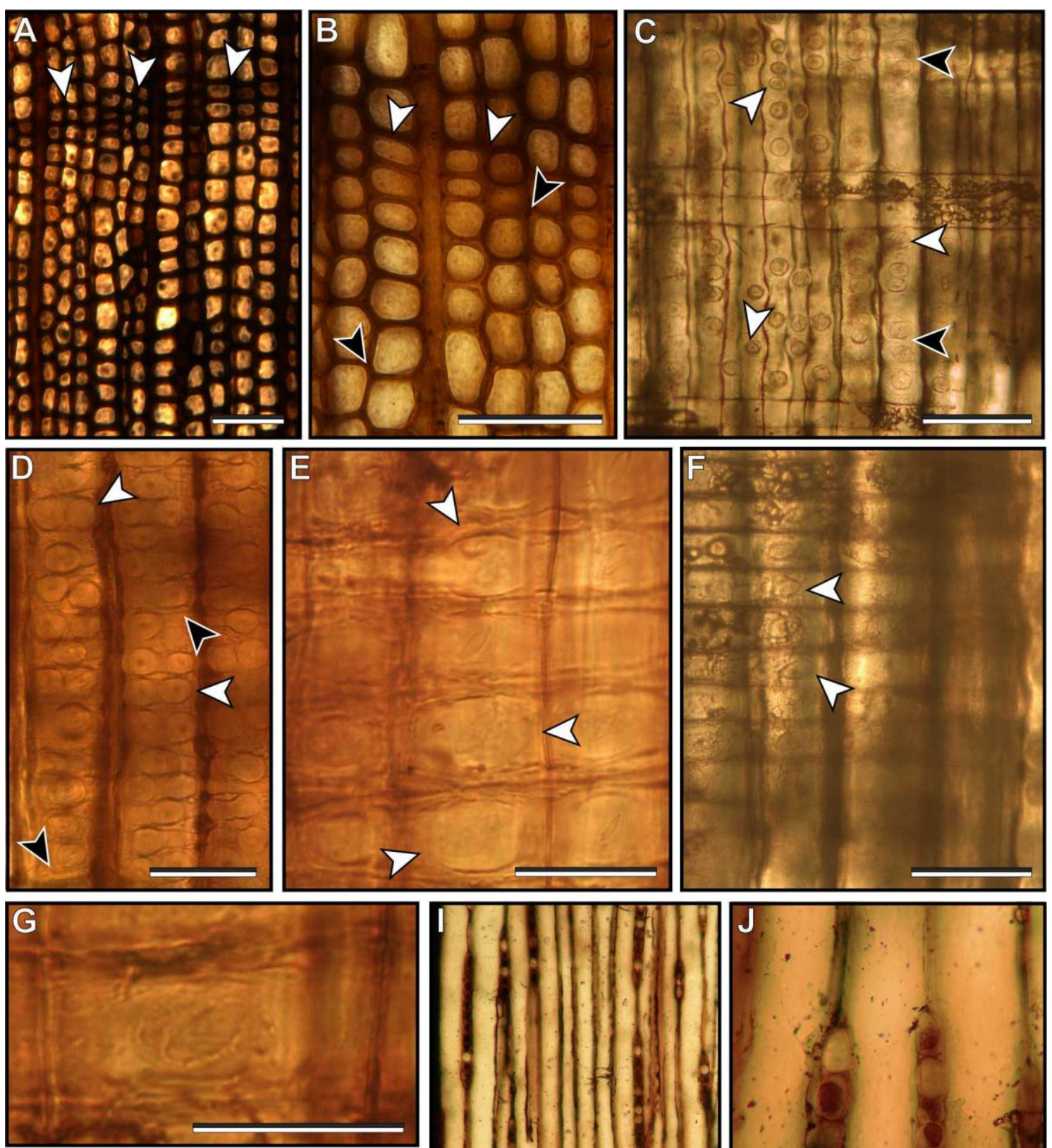

$\mathrm{H}$
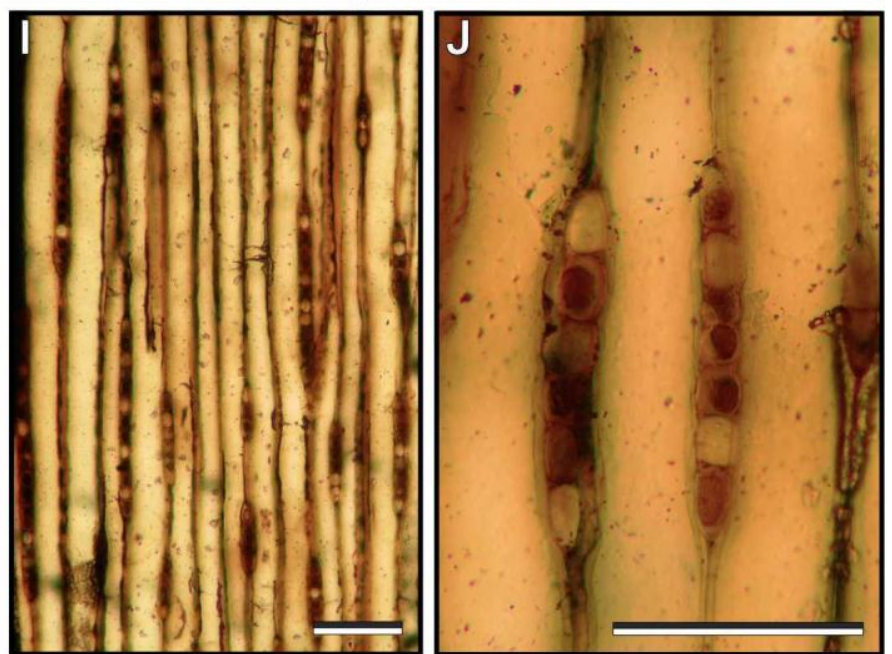

Figura 4.9. Cupressinoxylon artabeae. MPEF-Pb 8388. A. ST. Límite del anillo de crecimiento

(flechas). B. ST. Detalle del límite de anillo (flechas blancas) y espacios intercelulares (flechas negras). C. SLR. Punteaduras radiales uniseriadas y espaciadas (flechas blancas) y crásulas (flechas negras). D. SLR. Punteaduras radiales biseriadas opuestas y contiguas (flechas blancas) y crásulas (flechas negras). E, G. SLR. Campos de cruzamientos con punteaduras cupresoides. F,H. SLR. Campos de cruzamiento con punteaduras taxodioides. I, J. SLT. Radios uniseriados.

Escalas. A-C, I: $100 \mu \mathrm{m} ; \mathrm{D}, \mathrm{F}, \mathrm{J}: 50 \mu \mathrm{m}$; E-H: $25 \mu \mathrm{m}$. 

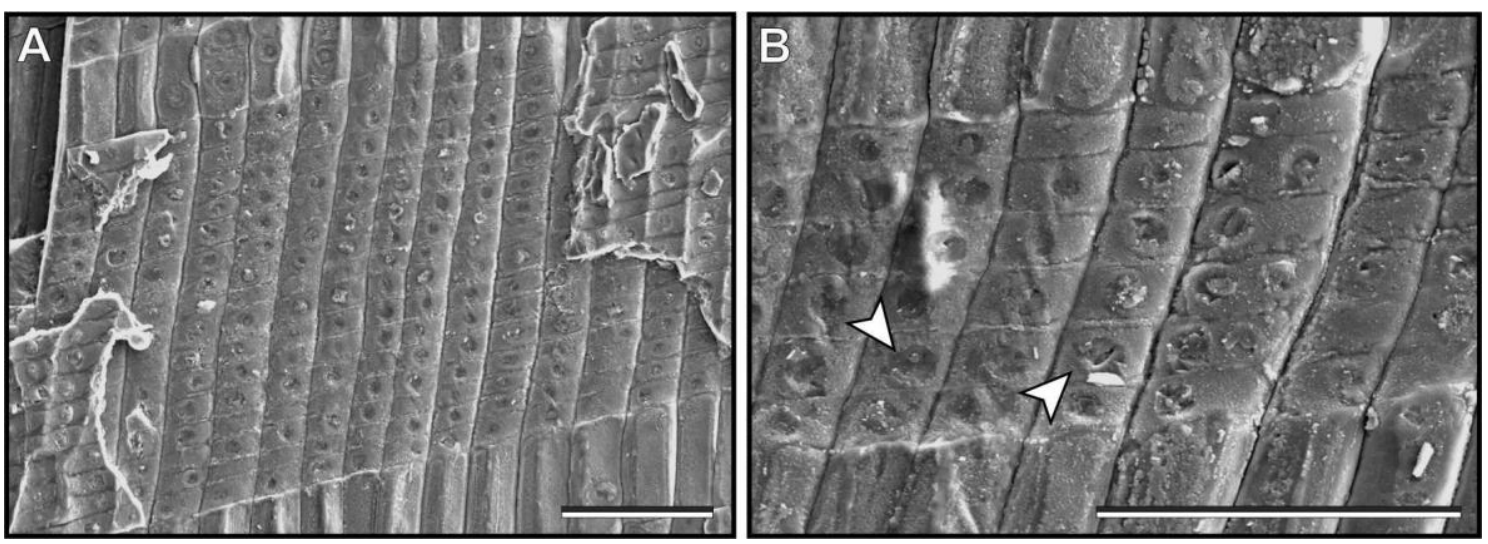

Figura 4.10. Cupressinoxylon artabeae. MPEF-Pb 8388. A, B. SLR. Campos de cruzamiento con punteaduras cupresoides (flechas). Escalas. $100 \mu \mathrm{m}$.

Como ya se mencionó previamente, las características de las maderas de Cupressinoxylon las acercan tanto a las Podocarpaceae como a las Cupressaceae, ambas familias bien representadas en los bosques andino-patagónicos. Dentro de las Podocarpaceae Podocarpus parlatorei Pilg. es muy parecido al ejemplar fósil con la diferencia de poseer abundante parénquima (Tortorelli, 1956). En cuanto a las Cupressaceae, $C$. artabeae se asemeja más a especies australianas, ya que las de Sudamérica tienen mayor número de punteaduras por campo y las mismas son más pequeñas (Tortorelli, 1956; Rancusi et al., 1987). Neocallitropsis Florin es el género más afín, con punteaduras radiales que pueden ser biseriadas, presencia de crásulas y 1-2(4-6) punteaduras por campo de cruzamiento, las mismas de 7-13 $\mu \mathrm{m}$ de diámetro y de tipo cupresoide o podocarpoide (Greguss, 1955).

\section{cf. Cupressinoxylon}

Figuras: 4.11 y 4.12 .

Material estudiado: MPEF-Pb 8389 y MPEF-Pb 8390.

Localidad: Estancia Las Violetas, provincia del Chubut, Argentina.

Horizonte estratigráfico: Formación Salamanca. Paleoceno.

Descripción: madera de tipo coniferoide, homoxílica y picnoxílica. Los anillos de crecimiento están demarcados y también se observan falsos anillos (Fig. 4.11 A). Hay 1-4 hileras de traqueidas en el leño tardío y la transición entre el leño temprano y el tardío es abrupta. El diámetro tangencial de traqueidas es de $10,4(3,1-17,1) \mu \mathrm{m}$ y las paredes tienen un espesor de $5,1(3,6-7,0) \mu \mathrm{m}$. En el leño temprano las traqueidas 
presentan un diámetro radial de $7,9(2,7-16,9) \mu \mathrm{m}$, mientras que en el tardío es de 5,6 $(1,3-8,9) \mu \mathrm{m}$. La sección transversal de las traqueidas es circular a oval (Fig. $4.11 \mathrm{~A}, \mathrm{~B})$.

En vista radial se observan punteaduras de tipo abietinoide en las traqueidas, es decir son circulares, areoladas, uniseriadas y contiguas o espaciadas (Figs. 4.11 C,D y 4.12 A). Estas punteaduras tienen un diámetro radial de $11,7(8,6-16,4) \mu m$ y un diámetro vertical de $11,3(7,3-15,4) \mu \mathrm{m}$; las aberturas de las punteaduras tienen 2,4 $(1,7-3,4) \mu \mathrm{m}$ de diámetro radial y $2,8(1,4-2,8) \mu \mathrm{m}$ de diámetro vertical. Los radios son homocelulares, con las paredes del parénquima radial lisas. Hay 1-2 punteaduras por campo de cruzamiento, del tipo cupresoide, pero éstas no se observan con mucha claridad (Figs. $4.11 \mathrm{E}, \mathrm{F}$ y $4.12 \mathrm{~B})$.

Los radios son uniseriados, de 50,1 (12,6-122,9) $\mu \mathrm{m}$ y $3(1-10)$ células de altura (Fig. $4.11 \mathrm{G}, \mathrm{H}$ ). En vista tangencial las células radiales poseen $10,6(6,6-14,7) \mu \mathrm{m}$ de alto y 6,6 (3,3-12,9) $\mu \mathrm{m}$ de ancho, con una pared de 1,4 (1,0-2,0) $\mu \mathrm{m}$. Hay hifas de hongos en el interior de algunos radios (Fig. 4.11 E). Parénquima axial presente con paredes terminales lisas y con contenidos oscuros (Fig. $4.11 \mathrm{G}, \mathrm{H}$ ). Fibras septadas y no septadas.

Comparaciones y comentarios: probablemente se trate de un leño afín al género Cupressinoxylon pero los campos de cruzamiento no se pueden ver con suficiente detalle como para poder precisar la identificación. 

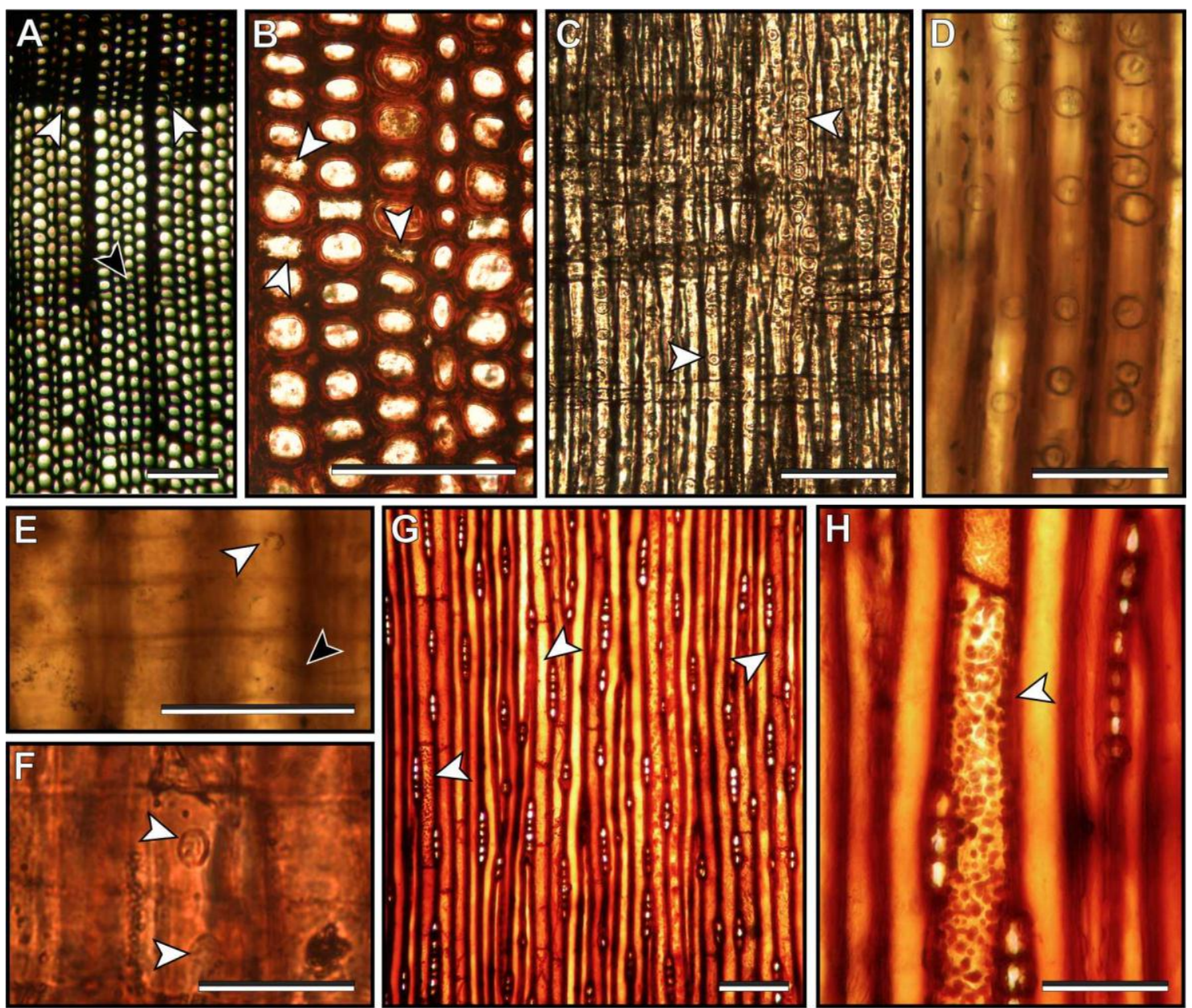

Figura 4.11. cf. Cupressinoxylon. MPEF-PB 8389. A. ST. Límite de un anillo de crecimiento (flechas blancas) y un falso anillo (flechas negras). B. ST. Parénquima axial (flechas). C. SLR.

Punteaduras radiales uniseriadas y espaciadas (flechas). D. SLR. Detalle de punteaduras radiales uniseriadas. E. SLR. Campos de cruzamientos con punteaduras cupresoides (flechas blancas) e hifas de hongos (flecha negra) F. SLR. Campos de cruzamientos con punteaduras cupresoides (flechas blancas). G. SLR. Parénquima axial (flechas). H. SLT. Detalle del parénquima axial con contenidos. Escalas. A-C, G: $100 \mu \mathrm{m} ; \mathbf{D}, \mathbf{E}, \mathbf{H}: 50 \mu \mathrm{m} ; \mathbf{F}: 25 \mu \mathrm{m}$.
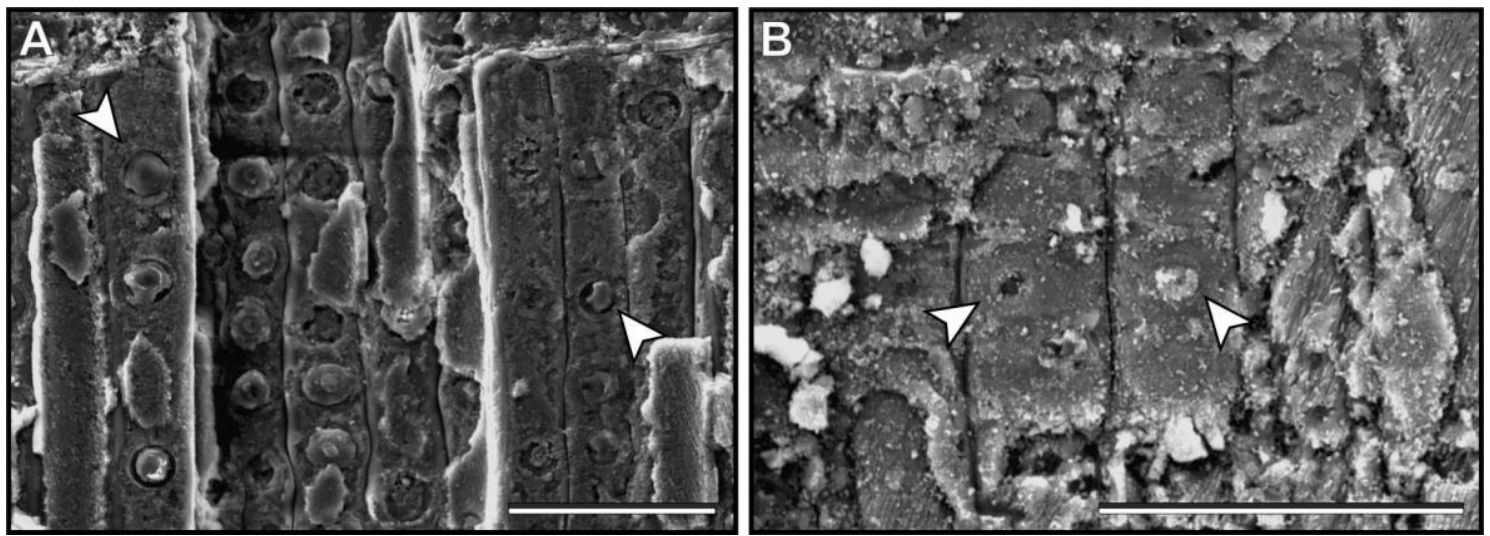

Figura 4.12. cf. Cupressinoxylon. MPEF-PB 8389. A. SLR. Punteaduras radiales. B. SLR. Campos de cruzamiento cupresoides. Escalas. A,B: $50 \mu \mathrm{m}$. 


\section{Xilotipo 1}

Afinidad: Angiospermae.

Figura: 4.13.

Material estudiado: MPEF-Pb 8391.

Localidad: Estancia Las Violetas, provincia del Chubut, Argentina.

Horizonte estratigráfico: Formación Salamanca. Paleoceno.

Descripción: madera angiospérmica, picnoxílica y heteroxílica. Anillos de crecimiento ausentes. La porosidad es difusa y los vasos son exclusivamente solitarios, con una densidad de 37 (25-60) vasos por $\mathrm{mm}^{2}$ (Fig. $4.13 \mathrm{~A}, \mathrm{~B}$ ). Los elementos de vaso tienen un contorno circular y miden en promedio $33,5(19,3-57,1) \mu \mathrm{m}$ de diámetro tangencial y $52(25,2-79) \mu \mathrm{m}$ de diámetro radial; con $274,5(209,3-393,9) \mu \mathrm{m}$ de largo. Las placas de perforación son simples (Fig. $4.13 \mathrm{C}$ ) y las punteaduras de los elementos de vaso son escalariformes a opuestas (Fig. 4.13 D), con un diámetro vertical de 6,2 $(4,1-10,5) \mu \mathrm{m}$.

El parénquima axial se presenta en bandas tangenciales de 2-3 células, tendiendo a una disposición de tipo reticulado, más claro en algunas zonas que en otras (Fig. 4.13 A,B). Las células parenquimáticas miden 82,3 (63,7-112) $\mu \mathrm{m}$ de largo (Fig. $4.13 \mathrm{G}$ ).

Las fibras son paredes muy gruesas, de $3,8(2,2-5,6) \mu \mathrm{m}$ y un pequeño lumen de $4,5(2,3-7,7) \mu m$ de diámetro tangencial.

Los radios son de forma ahusada y en su mayoría biseriados, aunque también los hay uni y triseriados (Fig. 4.13 E,F). Los mismos son heterogéneos, con células procumbentes y algunas cuadradas generalmente a los márgenes (Fig. 4.13 C). Presentan estratificación (Fig. 4.13 E,F). Hay 15 (12-17) radios por mm y tienen un promedio de $10(8-12)$ células de alto. Miden $265,1(205,8-383,1) \mu \mathrm{m}$ de alto y 35 $(17,2-57,3) \mu \mathrm{m}$ de ancho. 

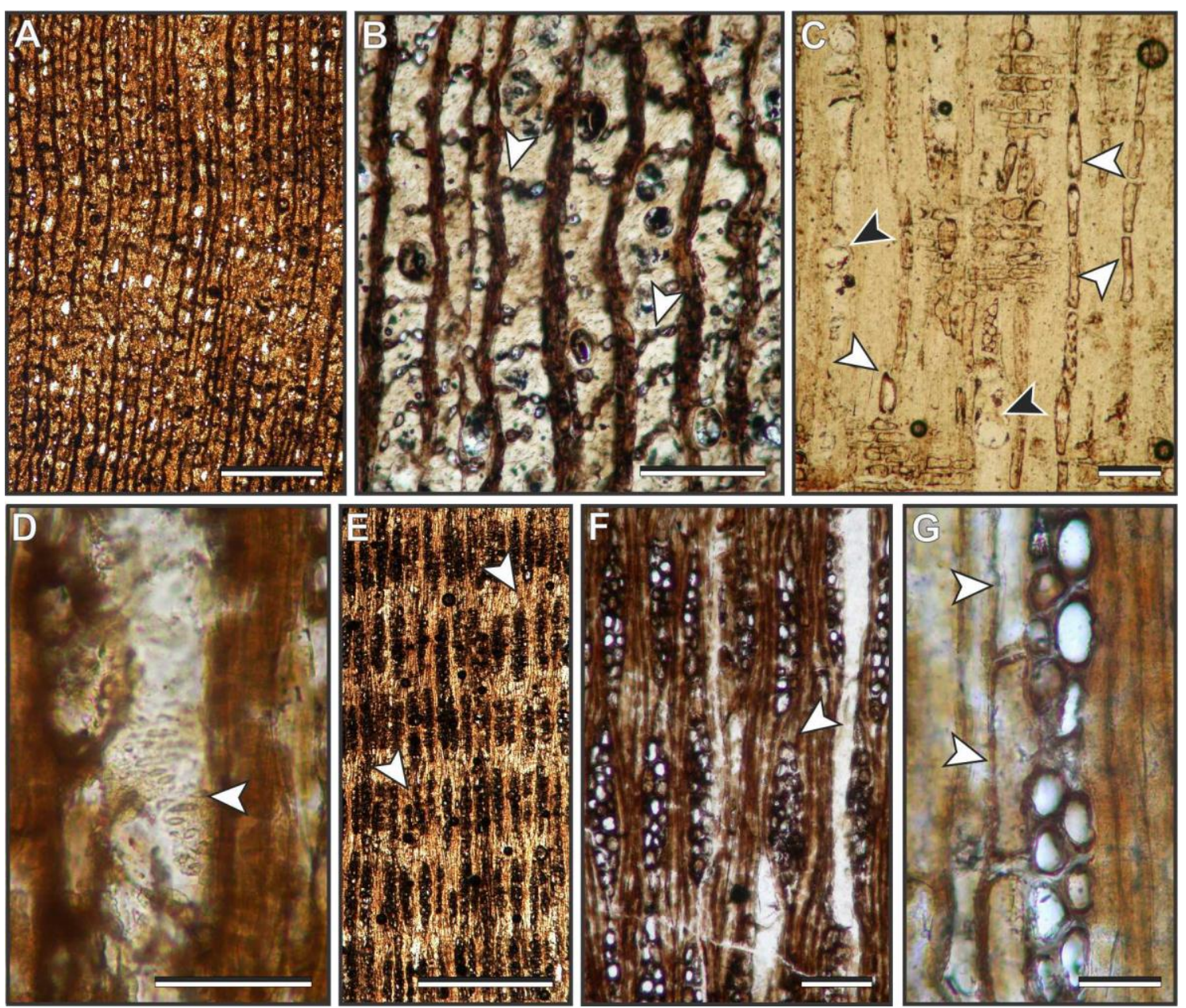

Figura 4.13. Xilotipo 1. MPEF-PB 8391. A. ST. Vista general mostrando la distribución de los vasos y el parénquima axial. B. ST. Parénquima axial en cortas bandas tangenciales (flechas). C. SLR. Radios heterogéneos, placas simples (fechas negras) y parénquima axial (flechas blancas).

D. SLR. Elemento de vaso con punteaduras escalariformes a opuestas (flecha). E. SLT. Vista general de los radios estratificados (flechas). F. SLT. Detalle de los radios estratificados (flecha). G. SLT. Parénquima axial (flechas). Escalas. A,E: $500 \mu \mathrm{m}$; B: $200 \mu \mathrm{m}$; C,F: $100 \mu \mathrm{m}$; D,G: $50 \mu \mathrm{m}$.

Comparaciones y comentarios: la estructura estratificada en los radios es una característica muy distintiva presente solo en algunas familias. Este carácter combinado con vasos exclusivamente solitarios y placas de perforación simples se da en varias familias (e.g. Bignoniaceae, Bombacaceae, Fabaceae, Moraceae, Burseraceae, Ulmaceae, Zygophyllaceae). Las Bignoniaceae se distinguen por tener punteaduras intervasculares alternas y parénquima paratraqueal desde vasicéntrico hasta confluente. Mientras que las Bombacaceae se diferencian por presentan punteaduras alternas y algunos radios 4-10 seriados (o incluso más) que no están estratificados. Las Fabaceae también cuentan con punteaduras alternas, comúnmente ornadas y parénquima paratraqueal muy abundante. Las Moraceae por otro lado, 
también se diferencian del fósil por el tipo de parénquima (paratraqueal). Algunos géneros de las Burseraceae y las Ulmaceae también tienen radios estratificados como el fósil estudiado, pero no es un carácter común y además poseen parénquima paratraqueal. Finalmente, las Zygophyllaceae son similares en la mayoría de los caracteres, incluido el parénquima que puede ser apotraqueal en bandas uniseriadas, pero sigue difiriendo del Xilotipo 1 por poseer punteaduras intervasculares alternas además de la presencia de fibrotraqueidas (Metcalfe \& Chalk, 1950).

En lo que refiere al registro fósil, no son muchos los taxones que presentan radios estratificados, de hecho este es uno de los primeros registros de este tipo de estructura en maderas paleocenas del hemisferio sur. La mayoría de los registros datan del Mioceno de Europa y Asia y son asignados como leguminosas, en su mayoría Papilonoideae. Se diferencian de la especie aquí descripta en general por más de un carácter, siendo los más comunes: la presencia de gran cantidad de vasos dispuestos en radiales múltiples, punteaduras intervasculares alternas y en muchos casos ornadas, patrones más elaborados de parénquima axial, muy abundante y casi siempre incluyendo parénquima paratraqueal y estratificación de otros elementos además de los radios (InsideWood, 2004 en adelante). Dadas las notables diferencias de estas familias con el Xilotipo 1 , el material probablemente debe ser publicado como un nuevo morfogénero de afinidad incierta.

Orden Myrtales Juss. ex Bercht. et J. Presl, 1820

Familia Myrtaceae Juss., 1789

Género Myrceugenellites Nishida, Nishida et Nasa, 1988

Especie tipo Myrceugenellites maytenoides Nishida, H. Nishida et Nasa, 1988

\section{Myrceugenellites sp.}

Figura: 4.14 .

Material de referencia: MPEF-Pb 8393.

Otros materiales estudiados: MPEF-Pb 8392, MPEF-Pb 8394, MPEF-Pb 8395, MPEF-Pb 8396, MPEF-Pb 8397, MPEF-Pb 8398.

Localidad: Estancia Las Violetas, provincia del Chubut, Argentina.

Horizonte estratigráfico: Formación Salamanca. Paleoceno. 
Descripción: leño picnoxílico, heteroxílico. Los anillos de crecimiento están demarcados por el achatamiento radial de las fibras y una leve reducción del diámetro de los elementos de vaso (Fig. 4.14 A). La porosidad es difusa, con 15 (9-20) vasos por $\mathrm{mm}^{2}$. Los vasos son solitarios $(96 \%)$, raramente en pares tangenciales $(2,3 \%)$, agrupados $(1,1 \%)$ y en series radiales mayormente de dos (0,9\%) (Fig. 4.14 A). Los elementos de vaso son de sección redondeada y miden: 144,6 $(61,6-193,8) \mu \mathrm{m}$ de diámetro tangencial, $133,9(43,1-189,3) \mu m$ de diámetro radial y 1261,0 (790,8-1943) $\mu \mathrm{m}$ de largo. Algunos de los ejemplares tienen contornos ovalados, más alargados en sección transversal pero esto probablemente se debe a deformación de las muestras post mortem. Las placas de perforación son de tipo escalariforme, con 34 (24-44) barras (Fig. 4.14 C,D), también se encontraron placas con partes fenestriformes (Fig. 4.14 E). Los elementos de vaso presentan apéndices en sus extremos. Las punteaduras intervasculares son circulares y opuestas, en ocasiones tendiendo a escalariformes (Fig. 4.14 F,G) y miden 5,5 (4,0-6,7) $\mu \mathrm{m}$ de diámetro vertical. Hay escasa tilosis.

El parénquima axial es escasamente paratraqueal y posee pequeñas punteaduras circulares y opuestas (Fig. $4.14 \mathrm{~B}, \mathrm{~J}, \mathrm{~L}$ ).

Las fibrotraqueidas tienen un diámetro tangencial de $28,1(15,3-43,3) \mu \mathrm{m}$, con punteaduras areoladas de $8,1(6,5-9,7) \mu \mathrm{m}$ de diámetro vertical y aberturas alargadas (Fig. 4.14 J-L). En ocasiones se observa la presencia de septos (Fig. $4.14 \mathrm{~K}$ ).

Los radios son en su mayoría uniseriados, homogéneos y de células erectas. También hay heterogéneos en parte bi- o triseriados, con largos extremos uniseriados iguales a los radios uniseriados (Fig. 4.14 C,I-L). Hay 12 (10-15) radios por mm y son muy altos, con más de $4,0(0,6-5,0) \mathrm{mm}$ y $18(4-18)$ células. Con un ancho de 32,3 $(14,5-59,3) \mu \mathrm{m}$. Las punteaduras radiovasculares son areoladas, circulares y opuestas, similares a las punteaduras intervasculares (Fig. 4.14 C,H), con un diámetro tangencial de $6,1(3,9-8,3) \mu \mathrm{m}$.

Comparaciones y comentarios: la porosidad difusa con vasos solitarios, las placas de perforación escalariforme con numerosas barras, las punteaduras intervasculares de escalariformes a opuestas, las punteaduras radio-vasculares pequeñas, el parénquima escasamente paratraqueal, el tipo de radios (uni-triseriados, 
con partes hasta triseriadas y largos extremos uniseriados) y la presencia de fibrotraqueidas en ocasiones septadas hacen a esta madera afín a las Myrtaceae.
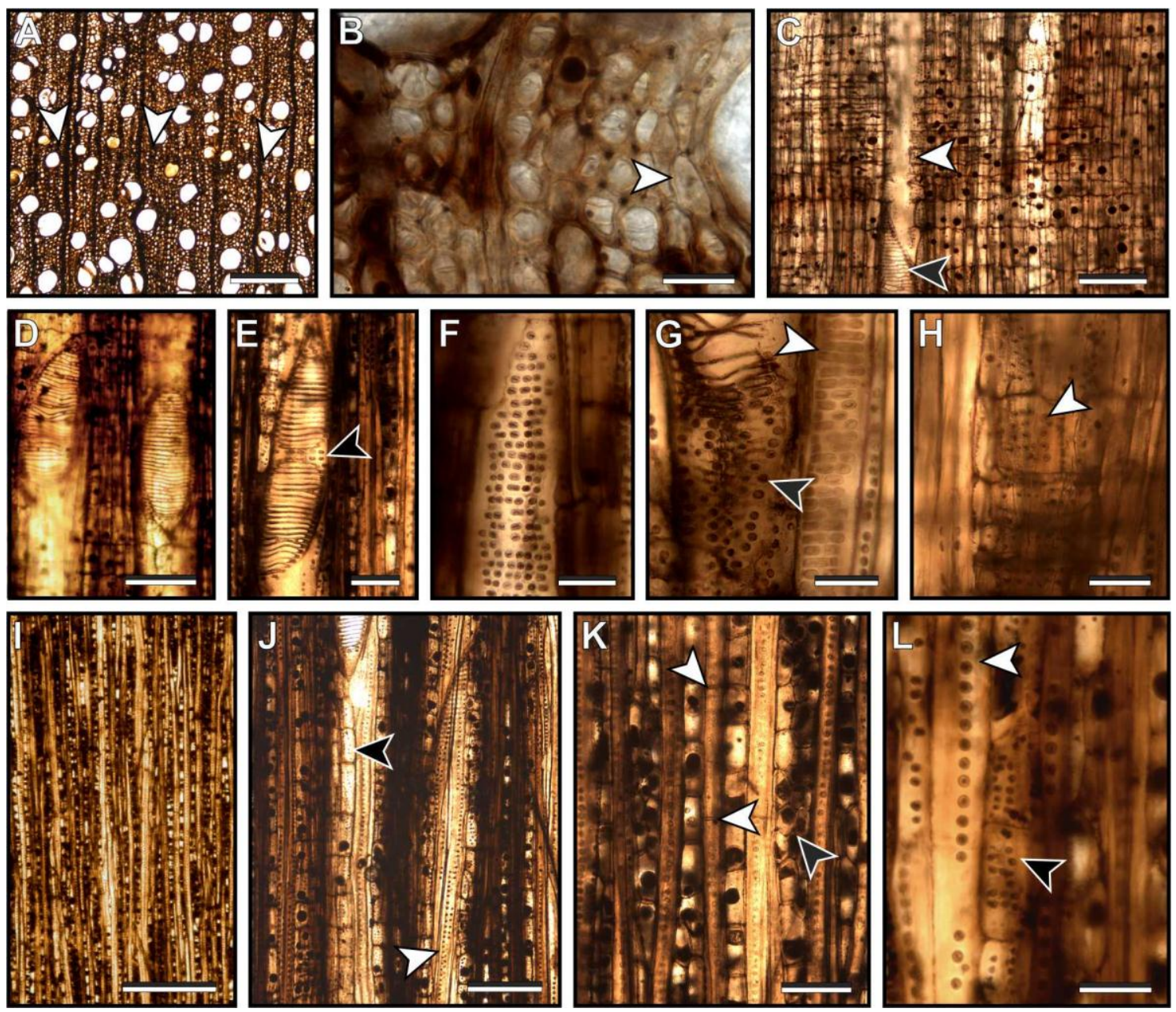

Figura 4.14. Myrceugenellites. MPEF-PB 8393. A. ST. Vista general mostrando la distribución de los vasos y el límite de un anillo de crecimiento (flechas). B. ST. Detalle de las fibras y el parénquima axial paratraqueal (flecha). C. SLR. Radios heterogéneos, placa escalariforme (fecha negra) y punteaduras radiovasculares (flecha blanca). D. SLR. Placas escalariformes. E.

SLT. Placa escalariforme con parte fenestriforme (flecha). F. SLT. Elemento de vaso con punteaduras opuestas. G. SLR. Elementos de vaso con punteaduras opuestas (flecha negra) y tendiendo a escalariformes (flecha blanca). H. SLR. Detalle de las punteaduras radiovasculares (flecha). I. SLT. Vista general mostrando forma y disposición de los radios. J. SLT. Parénquima escasamente paratraqueal (flecha negra) y fibrotraqueidas rodeando los elementos de vaso

(flecha blanca). K. SLT. Fibrotraqueidas septadas (flechas blancas) y células radiales con contenidos oscuros (flecha negra). L. SLT. Detalle del parénquima axial (flecha negra) y las punteaduras areoladas de las fibrotraqueidas (flecha blanca). Escalas. A,I: $500 \mu \mathrm{m}$;

$$
\text { C,J: } 200 \mu \mathrm{m} ; \mathrm{D}, \mathrm{E}, \mathrm{K}: 100 \mu \mathrm{m} ; \mathbf{B}, \mathbf{F}-\mathrm{H}, \mathrm{L}: 50 \mu \mathrm{m} \text {. }
$$

Dentro de los géneros fósiles asociados a las Myrtaceae, el que presenta mayores similitudes con el fósil aquí estudiado es Myrceugenellites Nishida, siendo las únicas diferencias el número de vasos por $\mathrm{mm}^{2}$ y el tipo de parénquima (Nishida et al., 
1988). Hay actualmente dos especies dentro de este morfogénero: Myrceugenellites maytenoides Nishida y M. oligocenum Pujana, ambas con vasos mucho más numerosos (más de 200 por $\mathrm{mm}^{2}$ ), de notablemente menor diámetro (menos de $100 \mu \mathrm{m}$ ) y con distinta distribución del parénquima axial (apotraqueal difuso en la primera y ausente en la segunda) (Nishida et al., 1988; Pujana, 2009a).

\section{Orden Laurales Juss. ex Bercht. et J. Presl, 1820}

Familia Lauraceae Juss., 1789

\section{Xilotipo 2}

Figura: 4.15 .

Material estudiado: MPEF-Pb 8399.

Localidad: Estancia Las Violetas, provincia del Chubut, Argentina.

Horizonte estratigráfico: Formación Salamanca. Paleoceno.

Descripción: leño picnoxílico, heteroxílico. Los anillos de crecimiento son levemente marcados o ausentes. La porosidad es difusa. La mayoría de los vasos son solitarios $(71 \%)$, pero también hay un alto porcentaje de radiales cortos mayoritariamente de 2 elementos (18\%) y más excepcionalmente radiales largos (4\%), agrupados (6,3\%) y pares tangenciales (0,6\%) (Fig. 4.15 A,B). Hay 29 (16-51) vasos por $\mathrm{mm}^{2}$. Los vasos tienen un contorno circular a ovalado con un diámetro tangencial de $60,4(18,5-104,0) \mu \mathrm{m}$ y un diámetro radial de $86,4(44,0-137,0) \mu \mathrm{m}$. El largo de los elementos de vaso es de $497,4(347,3-735,5)$ um y además tienen apéndices. Estos vasos presentan placas de perforación inclinadas de tipo escalariforme con un promedio de 9 (4-16) barras (Fig. 4.15 C,D). Las punteaduras intervasculares son escalariformes a opuestas y opuestas a alternas (Fig. 4.14 E,F), con un diámetro vertical de 6,3 (4,6-8,0) $\mu \mathrm{m}$. Hay abundantes tílides (Fig. $4.15 \mathrm{~J})$.

El parénquima axial es escasamente paratraqueal (Fig. 4.15 B,J).

Las fibrotraqueidas están algo degradadas por lo que no es posible medir con claridad el lumen ni la pared de las mismas. Presentan punteaduras de 5,3 (4,2-6,2) $\mu \mathrm{m}$ de diámetro vertical con una abertura elíptica (Fig. $4.15 \mathrm{~K}$ ).

Los radios son fusiformes, mayormente homogéneos aunque hay también de tipo heterogéneo con una hilera de células erectas en los extremos además de las 
procumbentes (Fig. 4.15 C,G). Hay 7 (6-8) radios por $\mathrm{mm}$. Tienen un ancho promedio de $4(3-7)$ células y $77,7 \mu \mathrm{m}(44,06-138,85)$ y un alto de $28(9-78)$ células y 1,2 mm (0,3-2,7) (Fig. $4.15 \mathrm{H}$ ). Incluidas en los radios, o bien a los márgenes de éstos, hay grandes células oleíferas con contenidos (Fig. 4.15 B,H,I). Las punteaduras radiovasculares son de tipo escalariforme y semiareoladas, con un diámetro vertical de 9,0 $(3,8-14,0) \mu \mathrm{m}$ (Fig. $4.15 \mathrm{G})$.
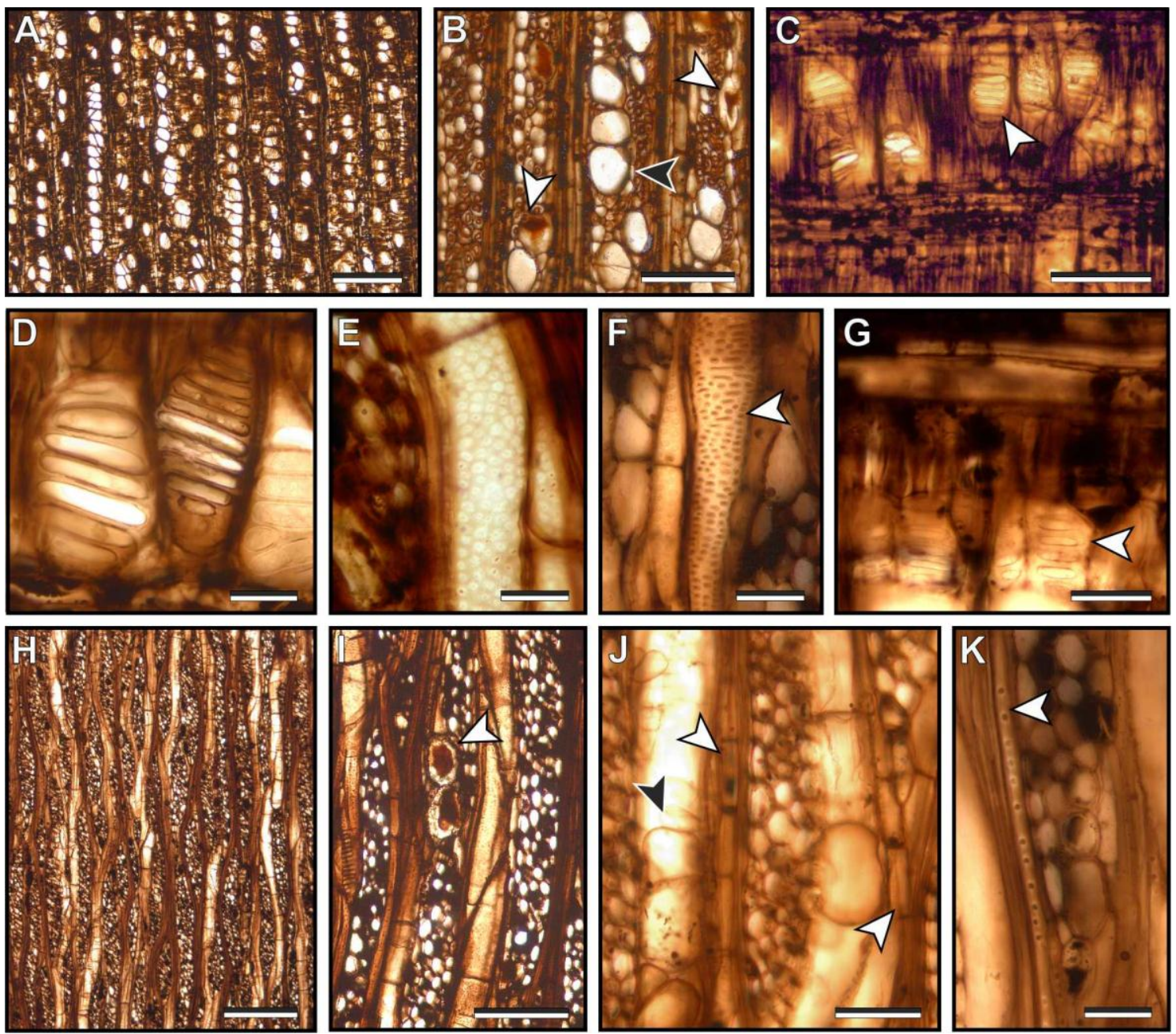

Figura 4.15. Xilotipo 2. MPEF-PB 8399. A. ST. Vista general mostrando la distribución de los

vasos. B. ST. Detalle de células con contenido (flecha blanca) y el parénquima axial escasamente paratraqueal (flecha negra). C. SLR. Radios mayormente homogéneos y placas estratificadas (flecha). D. SLR. Placas de perforación estratificadas. E. SLT. Elemento de vaso con punteaduras opuestas a alternas. F. SLT. Elemento de vaso con punteaduras escalariformes a opuestas (flecha). G. SLR. Punteaduras radiovasculares escalariformes (flecha). H. SLT. Vista general de los radios. I. SLT. Células con contenidos entre los radios (flecha). J. SLT. Parénquima axial paratraqueal (flechas blancas) y tílides en el interior de los vasos (flecha negra). K. SLT. Detalle de las punteaduras en las fibrotraqueidas (flecha). Escalas.

A,H: $500 \mu \mathrm{m} ; \mathbf{B}, \mathbf{C}, \mathrm{I}: 200 \mu \mathrm{m}$; J:100 $\mu \mathrm{m} ; \mathrm{D}-\mathbf{G}, \mathrm{K}: 50 \mu \mathrm{m}$. 
Comparaciones y comentarios: las familias actuales que presentan la combinación de los caracteres placas de perforación escalariformes y células con contenidos oleíferos o mucilaginosos son pocas. Entre ellas se encuentran las Canellaceae, donde los vasos son exclusivamente solitarios o raramente de a pares, las placas tienen de 10 a 60 barras, y los radios son más angostos que en el Xilotipo 2; Dilleniaceae también con vasos exclusivamente solitarios o raramente de a pares, comúnmente con ráfides y radios de dos tamaños distintos; Magnoliaceae que tiene parénquima en bandas y marginal, radios marcadamente heterogéneos y radios 3-4 seriados; Monimiaceae con vasos solitarios en su mayoría, más de 20 barras por placa de perforación y parénquima apotraqueal; y Myristicaceae de radios 1-3 seriados (muchos exclusivamente uniseriados) y tubos taníferos. Por último, la familia que concuerda con una gran mayoría de los caracteres presentes en el Xilotipo 2 son las Lauraceae. Esta familia puede tener vasos dispuestos en radiales múltiples largos y cortos además de solitarios, hay parénquima escasamente paratraqueal, punteaduras radiovasculares escalariformes, tilosis común, radios de 4-8 seriados, las fibras pueden tener punteaduras areoladas y cuando es así no suelen ser septadas y, si bien es más habitual la presencia de placas de perforación simples, también aparecen placas escalariformes esporádicamente en algunos géneros (Metcalfe \& Chalk, 1950). La única diferencia notable encontrada con el fósil estudiado es que las Lauraceae poseen punteaduras intervasculares exclusivamente alternas, de cualquier manera, el Xilotipo 2 presenta punteaduras desde algo escalariformes a opuestas e incluso tendiendo a alternas. Dado que esta transición encontrada en el fósil podría deberse a la antigüedad del mismo (Paleoceno temprano), podría decirse que el fósil es afín a las Lauraceae.

Comparando con el registro fósil vemos que las mayores similitudes también se dan con especies asignadas a las Lauraceae pero ninguna presenta placas exclusivamente escalariformes (InsideWood, 2004 en adelante; Cevallos-Ferriz et al., 2016). Si las hay con placas tanto simples como escalariformes (Cinnamomoxylon limagnense (Privé-Gill et Pelletier) Gottwald, C. seemannianum (Mädel) Gottwald, Laurinoxylon chalatenangensis Cevallos-Ferriz, Cerón-López et Flores-Rocha, L. diluviale (Unger) Felix, L. mueller-stolli Süss et Mädel, L. naginimariense Awasthi et 
Mehrotra, L. tertiarum Prakash et Tripathi), pero que además presentan otras diferencias notables con el Xilotipo 2, como ser fibras septadas, parénquima vasicéntrico a confluente y radios hasta triseriados (Süss \& Mädel, 1958; Prakash \& Tripathi, 1972; Awasthi \& Mehrotra, 1989; Gottwald, 1997; Dupéron et al., 2008; Cevallos-Ferriz et al., 2016). En Sudamérica el registro de maderas de Lauraceae fósiles incluye a: Beilschmiedioxylon parataubernium Ramos del Pleistoceno tardío de Entre Ríos, Argentina, Curtiembrexylon poledrii Franco del Plioceno de Argentina, Laurinoxylon atlanticum (Romero) Dupéron-Laudoueneix et Dupéron del Eoceno de Argentina, L. chubutense (Brea) Dupéron-Laudoueneix et Dupéron del Cenozoico inferior de Chubut, Argentina L. artabeae (Brea) Dupéron-Laudoueneix et Dupéron y L. mucilaginosum (Brea) Dupéron-Laudoueneix et Dupéron (Romero, 1970; Brea, 1995, 1998b; Ramos et al., 2012; Franco, 2012) todas ellas con placas simples como la principal diferencia con el Xilotipo 2. El Xilotipo 2 deberá asignarse entonces como un nuevo taxón dentro de las Lauraceae.

\section{Orden Gentialales Juss. ex Bercht. et J. Presl, 1820}

Familia Apocynaceae Juss., 1789

\section{Xilotipo 3}

Figura: 4.16.

Material de referencia: MPEF-Pb 8400.

Otro material estudiado: MPEF-Pb 8401.

Localidad: Estancia Las Violetas, provincia del Chubut, Argentina.

Horizonte estratigráfico: Formación Salamanca. Paleoceno.

Descripción: anillos de crecimiento ausentes. La porosidad es difusa con 14 (919) vasos por $\mathrm{mm}^{2}$. La disposición de los vasos es mayormente solitaria (67\%) y en radiales múltiples cortos de dos o tres elementos (32\%), asimismo hay un pequeño porcentaje de radiales largos de más de cuatro vasos $(3,6 \%)$ y pares tangenciales $(0,8 \%)$. En sección transversal los elementos de vaso presentan un contorno circular (Fig. 4.16 A,B). Las medidas de los mismos son: 136,6 $(75,6-183,3) \mu m$ de diámetro tangencial, $121,2(66,9-191,9) \mu \mathrm{m}$ de diámetro radial y $485,6(286,2-726,1) \mu \mathrm{m}$ de largo. Las placas de perforación son simples (Fig. 4.16 D). Las punteaduras son 
circulares, de opuestas a alternas y ornadas (Fig. 4.14 E-G), con un diámetro tangencial de $9,9(7,0-12,7) \mu \mathrm{m}$. Hay abundantes tílides.

Las fibras son septadas (Fig. $4.16 \mathrm{~K}$ ), con un diámetro tangencial promedio de $18,7 \mu \mathrm{m}(7,7-26,4)$ y una pared de $3(1,7-5,0) \mu \mathrm{m}$.

El parénquima axial es escasamente paratraqueal (Fig. 4.16 F,L).

La mayor parte de los radios son heterogéneos y heterocelulares, fusiformes y multiseriados (Fig. $4.16 \mathrm{C}, \mathrm{J}-\mathrm{L}$ ). Éstos van desde los $160 \mu \mathrm{m}$ hasta más de 2,8 mm de altura (promedio de $956 \mu \mathrm{m})$. Suelen tener $4(2-8)$ células y $88,2 \mu \mathrm{m}(26,3-157,0)$ de ancho. Algunos tienen extremos uniseriados conformados por células erectas, normalmente en número de uno o dos, aunque pueden llegar a siete. También los hay articulados por medio de estas porciones uniseriadas o por porciones más angostas que el resto del radio. A parte de los radios multiseriados, en mucha menor proporción, hay radios uniseriados de 1-11 células de alto, de igual apariencia a los extremos uniseriados de los radios multiseriados. Las punteaduras radiovasculares son fenestriformes (Fig. 4.6 I), de 24,6 (10,8-29,2) $\mu \mathrm{m}$.

Algunas de las células son de mayor tamaño y tienen un gran contenido de color anaranjado que ocupa el lumen celular casi por completo, probablemente se traten de células oleíferas o mucilaginosas (Fig. 4.16 B,C,H,K). Estas se ubican mayormente en los radios ya sea en los extremos, en las partes uniseriadas que articulan dos radios o en los márgenes de las porciones multiseriadas. Más raramente se las encuentra también de forma aislada entre fibras. Además algunas de las células parenquimáticas que componen los radios presentan otro tipo de contenidos a modo de "gotitas oscuras" (Fig. 4.16I). 

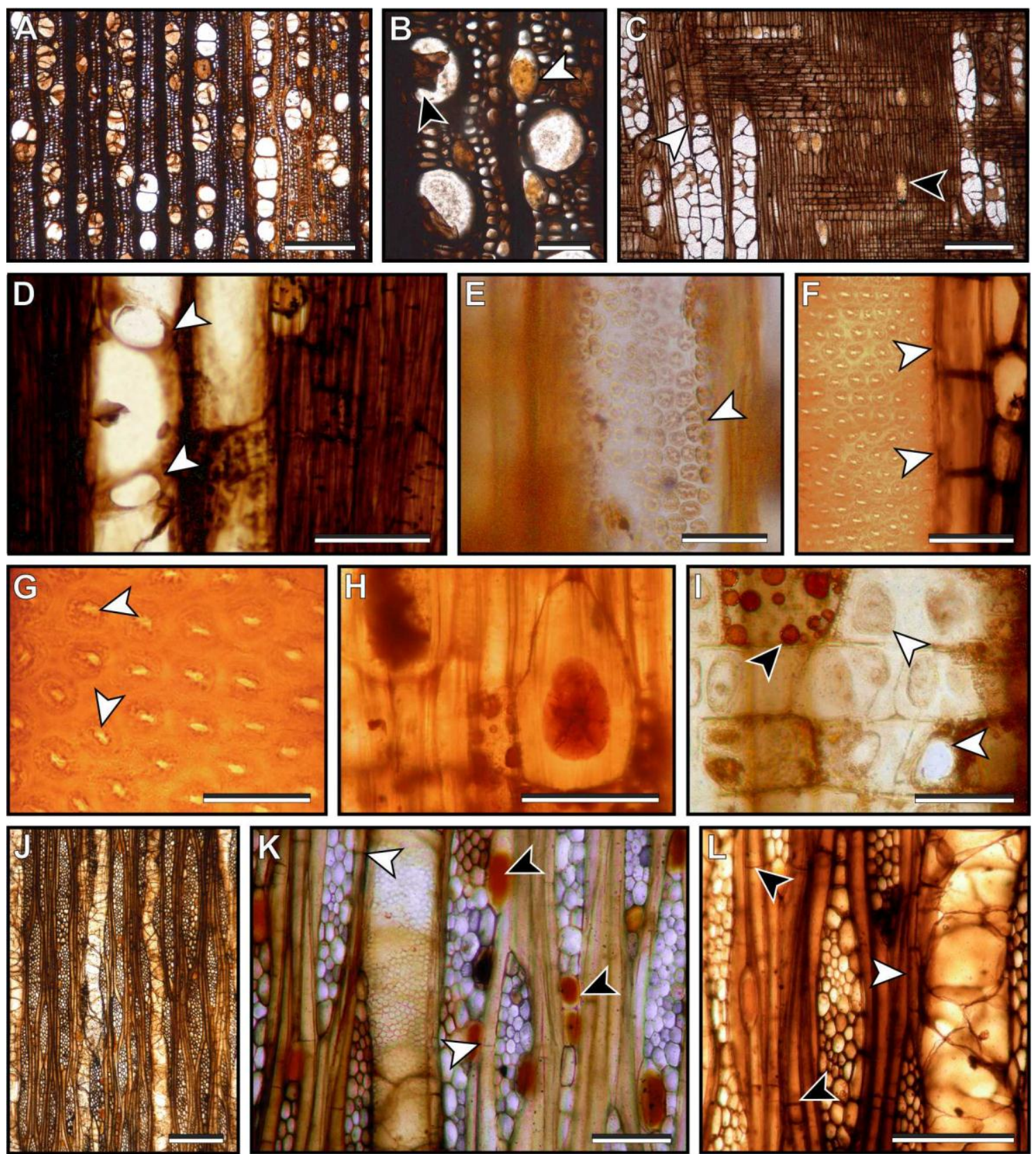

Figura 4.16. Xilotipo 3. MPEF-PB 8400. A. ST. Vista general mostrando la distribución de los vasos. B. ST. Detalle de vasos con tílides (flecha negra) y células oleíferas (flecha blanca). C. SLR. Radios heterogéneos, placa de perforación simple (flecha blanca) y células oleíferas (flecha negra). D. SLR. Placas de perforación simples (flechas). E. SLT. Elemento de vaso con punteaduras opuestas a alternas ornadas (flecha). F. SLT. Elemento de vaso con punteaduras

opuestas a alternas y parénquima axial paratraqueal (flechas). G. SLR. Detalle de las punteaduras intervasculares ornadas (flecha). H. SLR. Detalle de las células oleiferas. I. SLT. Punteaduras radiovasculares fenestriformes (flechas blancas) y gotitas de contenido en el parénquima radial (flecha negra). J. SLT. Vista general de los radios. K. SLT. Células oleíferas (flechas negras) y fibras septadas (flechas blancas). L. SLT. Fibras septadas (flechas negras) y parénquima paratraqueal (flecha blanca). Escalas. A,C,J: $500 \mu \mathrm{m} ; \mathbf{D}, \mathbf{K}, \mathrm{L}: 200 \mu \mathrm{m} ; \mathbf{B}, \mathbf{H}: 100 \mu \mathrm{m}$;

E,F,I: $50 \mu \mathrm{m} ; \mathbf{G :} 25 \mu \mathrm{m}$. 
Comparaciones y comentarios: la presencia de células oleíferas o mucilaginosas y las punteaduras ornadas son caracteres bastante distintivos pero no suelen encontrarse juntos. Dentro de las familias actuales se pueden encontrar en las Apocynaceae que además también presentan vasos solitarios o múltiples radiales, placas de perforación simples, pueden tener parénquima escasamente paratraqueal y tilosis y las hay con radios uniseriados y multiseriados (Metcalfe $\&$ Chalk, 1950). Sin embargo, esta familia presenta punteaduras radio-vasculares similares a las intervasculares, pequeñas y alternas, mientras que en el fósil son solo una o dos muy amplias de tipo fenestriforme.

\subsection{Ecuaciones propuestas por Wiemann et al. $(1998,1999)$}

El número de angiospermas encontradas es muy bajo (4) como para aplicar este estudio.

\subsection{Anillos de crecimiento}

Los anillos de crecimiento están muy bien marcados en las coníferas pero no así en las angiospermas, donde la única que presenta anillos levemente marcados es Myrceugenellites sp., pero el número de los mismos es muy bajo para realizar las mediciones correspondientes.

\begin{tabular}{|lcccccccccc|}
\hline Ejemplar & $\begin{array}{c}\text { № } \\
\text { anillos }\end{array}$ & $\begin{array}{c}\text { № } \\
\text { falsos } \\
\text { anillos }\end{array}$ & $\begin{array}{c}\text { № anillos } \\
\text { de } \\
\text { heladas }\end{array}$ & $\begin{array}{c}\text { Ancho } \\
\text { medio }\end{array}$ & $\begin{array}{c}\text { Ancho } \\
\text { máx. }\end{array}$ & $\begin{array}{c}\text { Ancho } \\
\text { mín. }\end{array}$ & $\begin{array}{c}\text { Desv. } \\
\text { Est. }\end{array}$ & SA & SM \\
\hline MPEF-Pb 8385 & 14 & 0 & 0 & 1,59 & 3,00 & 0,26 & 0,79 & $0,00-1,54$ & 0,41 \\
\hline MPEF-Pb 8386 & 7 & 0 & 0 & 2,25 & 3,55 & 1,32 & 0,87 & --- & --- \\
\hline MPEF-Pb 8387 & 8 & 0 & 0 & 3,75 & 5,20 & 0,86 & 1,51 & --- & -- \\
\hline MPEF-Pb 8388 & 21 & 3 & 0 & 0,80 & 1,42 & 0,27 & 0,33 & $0,01-1,01$ & 0,26 \\
\hline MPEF-Pb 8389 & 9 & 1 & 0 & 2,16 & 2,91 & 0,87 & 0,76 & --- & --- \\
\hline MPEF-Pb 8390 & 11 & 0 & 0 & 2,67 & 4,17 & 1,57 & 0,81 & $0,01-0,46$ & 0,20 \\
\hline Promedio & & & & 2,20 & 3,75 & 0,86 & 0,84 & $0,01-1,00$ & 0,29 \\
\hline
\end{tabular}

Tabla 4.15: datos de los anillos de crecimiento medidos. Valores de ancho en $\mathrm{mm}$.

Podocarpoxylon multiparenchymatosum (MPEF-Pb 8385, 8386), Cupressinoxylon austrocedroides (MPEF-Pb 8387), Cupressinoxylon artabeae (MPEF-Pb 8388) y cf.

Cupressinoxylon (MPEF-Pb 8389, 8390).

Se midieron seis secuencias sumando un total de 70 anillos, todas ellas muy cortas, siendo la más larga de tan solo 21 anillos. Tres de las secuencias no llegaban al mínimo de 10 anillos sugerido para efectuar los cálculos de sensibilidad anual y media, 
sin embargo si se midieron los demás parámetros estadísticos, ya que son estas secuencias las que denotan el notable grosor que presentan los anillos de esta localidad. Los anillos tienen $2,20(0,80-3,75) \mathrm{mm}$ de espesor, el grosor mínimo promedio es de 0,86 $(0,26-1,57) \mathrm{mm}$ y el espesor máximo promedio es de 3,75(1,425,20 ) (Tabla 4.15 y Fig. 4.17). Todas las secuencias presentaban anillos de más de 30 células de espesor (a excepción de Cupressinoxylon artabeae) con lo cual se pudo aplicar el método de Creber \& Chaloner (1984b) para calcular el porcentaje de leño temprano y tardío. Podocarpoxylon multiparenchymatosum fue el más variable con solo $6,7 \%$ de leño tardío en uno de los ejemplares y $21,6 \%$ en el otro, Cupressinoxylon austrocedroides presenta $15 \%$ de leño tardío y el cf. Cupressinoxylon también varía entre $6,9 \%$ y $13 \%$ de leño tardío (Tabla 4.16). Más allá de la variación en valores, los porcentajes de leño tardío de todos los ejemplares medidos son bajos. Los dos ejemplares de Cupressinoxylon donde se pudo calcular la sensibilidad anual (SA) y media (SM) muestran valores bajos de SA pero bastante distintos a pesar de tener valores de SM prácticamente iguales $(0,26$ y 0,20). Esto indica que aunque ambos leños eran complacientes, el ejemplar MPEF-Pb 8388, que tiene valores de SA de hasta 1, pudo sufrir eventos climáticos extremos (Tabla 4.15 y Figs. 4.17). Podocarpoxylon multiparenchymatosum en cambio, muestra valores de SA que llegan a los 1,5 y una SM de 0,41, tratándose entonces de un leño sensitivo (Tabla 4.15 y Figs. 4.17). Este ejemplar probablemente se encontraba en las lindes del bosque, es decir más expuesto. 

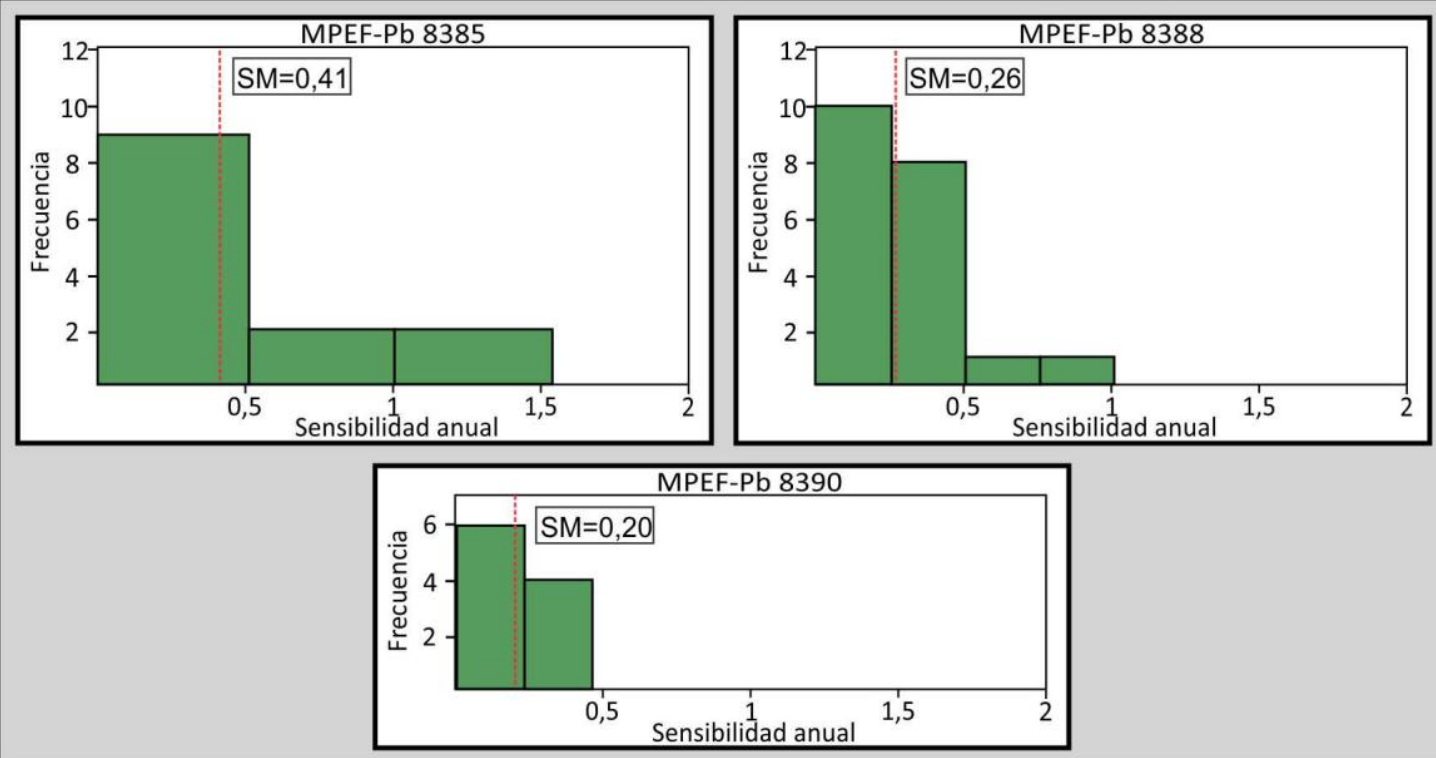

Fig. 4.17. Histogramas de Sensibilidad Anual (SA). Las líneas punteadas en rojo indica la Sensibilidad Media (SM). Podocarpoxylon multiparenchymatosum (MPEF-Pb 8385), Podocarpoxylon artabeae (MPEF-Pb 8388), cf. Cupressinoxylon (MPEF-Pb 8390).

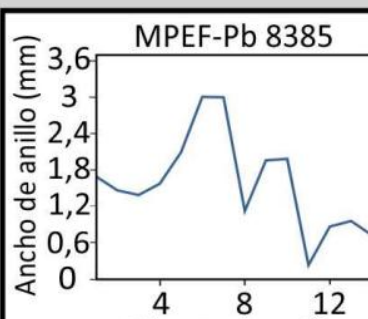

Número de anillo
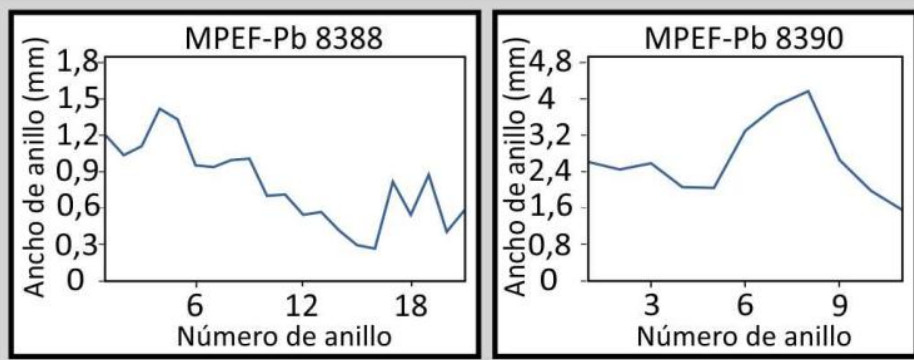

Fig. 4.18. Curvas de espesores de los anillos de crecimiento analizados. Podocarpoxylon multiparenchymatosum (MPEF-Pb 8385), Podocarpoxylon artabeae (MPEF-Pb 8388) y cf. Cupressinoxylon (MPEF-Pb 8390).

\begin{tabular}{|cccccc|}
\hline Ejemplar & \% leño temprano & \% de leño tardío & Skew & \% de disminución & RMI \\
\hline MPEF-Pb 8385 & $93,33 \%$ & $6,67 \%$ & $20,00 \%$ & $79,87 \%$ & 5,32 \\
\hline MPEF-Pb 8386 & $78,43 \%$ & $21,57 \%$ & $13,72 \%$ & $70,61 \%$ & 15,23 \\
\hline MPEF-Pb 8387 & $85,04 \%$ & $14,96 \%$ & $135,29 \%$ & $89,78 \%$ & 14,96 \\
\hline MPEF-Pb 8389 & $93,10 \%$ & $6,90 \%$ & $12,64 \%$ & $57,91 \%$ & 3,99 \\
\hline MPEF-Pb 8390 & $86,36 \%$ & $13,64 \%$ & $34,54 \%$ & $71,93 \%$ & 9,80 \\
\hline
\end{tabular}

Tabla 4.16: resumen de los datos tomados de los anillos de crecimiento. Podocarpoxylon multiparenchymatosum (MPEF-Pb 8385, 8386), Cupressinoxylon austrocedroides (MPEF-Pb 8387) y cf. Cupressinoxylon (MPEF-Pb 8389, 8390). 


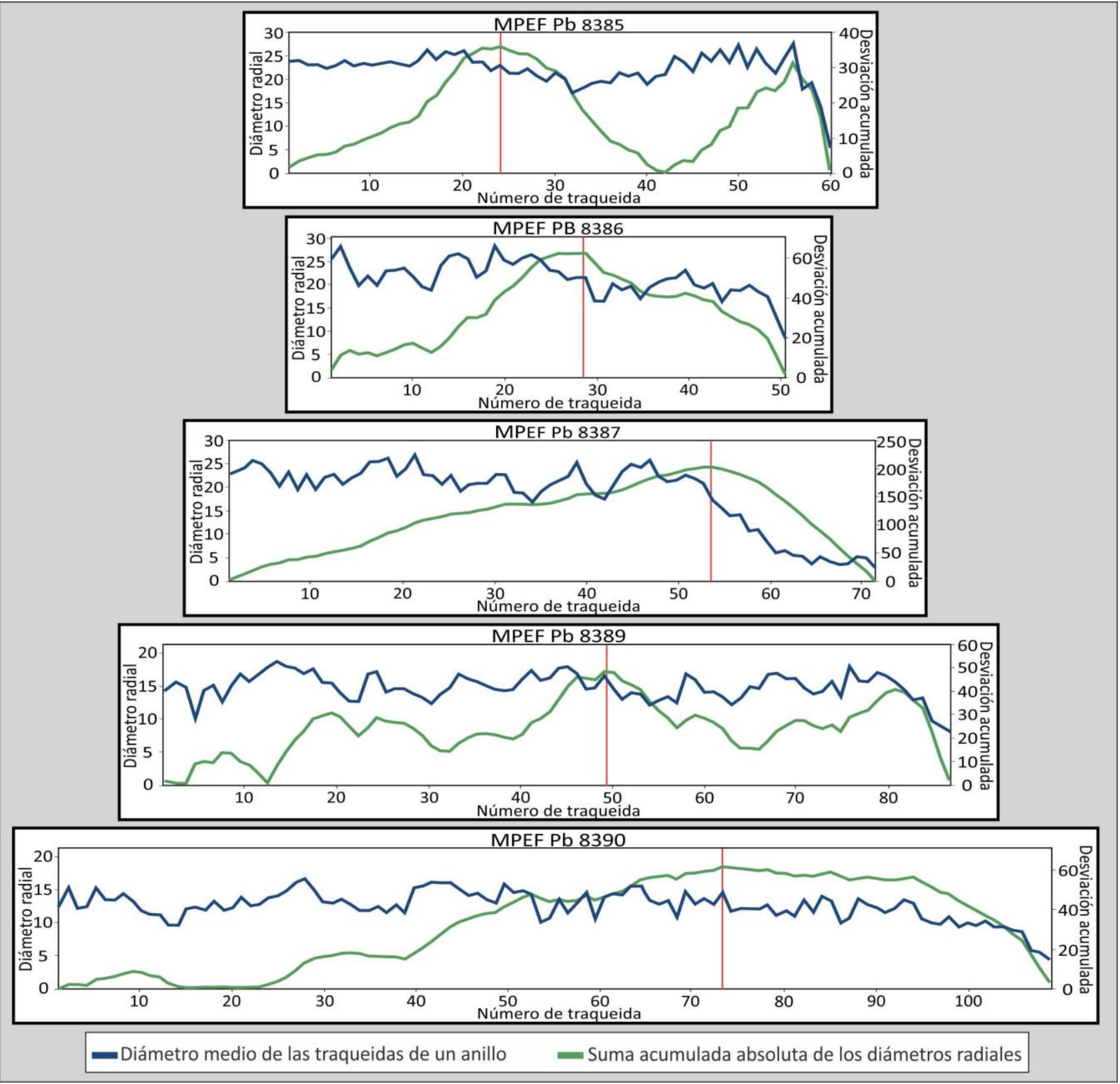

Fig. 4.19. Curvas CSDM. Podocarpoxylon multiparenchymatosum (MPEF-Pb 8385, 8386), Cupressinoxylon austrocedroides (MPEF-Pb 8387) y cf. Cupressinoxylon (MPEF-Pb 8389, 8390).

Los anillos son casi todos del tipo D (MPEF-PB 8386, 8387, 8390) según la clasificación de Creeber \& Chaloner (1984b) (Fig. 4.19). Los anillos tipo D indican que la temporada de crecimiento fue relativamente uniforme pero con un evento terminal que provocó el cese de la actividad cambial. El ejemplar MPEF-Pb 8389 presenta anillos tipo $E$, este tipo de anillo es similar al $D$ solo que con el límite de anillo mucho menos marcado, casi imperceptible. Por otro lado, el ejemplar MPEF-Pb 8385 parece ser un caso particular porque comienza siendo aparentemente del tipo D pero luego la curva vuelve a subir y baja abruptamente como en los anillos de tipo E. Además, las sumas 
acumuladas muestran una curva bimodal lo que sugeriría que hubo un nuevo aporte de agua hacia el final del período de crecimiento.

El cf. Cupressinoxylon presenta un falso anillo de crecimiento (Fig. 4.12) y el C. artabeae tres, todos ellos marcados por traqueidas cuyos diámetros radiales decrecen y vuelven a crecer de forma paulatina. Esto marcaría un nuevo aporte de agua antes de que se llegue a interrumpir el crecimiento.

Los altos valores de skew, todos superiores a 12 (Tabla 4.16), indican que las cuatro especies eran perennifolias (Falcon-Lang, 2000a). El índice de demarcación de anillo (RMI) de todos los ejemplares en donde se pudo aplicar el estudio, da valores por debajo de 15 (Tabla 4.16). Esto indicaría una retención foliar de 3 a 15 años como la actual Araucaria araucana. El bajo porcentaje de leño tardío (Tabla 4.16) también se corresponde con este resultado. Por otro lado, el porcentaje de disminución toma valores más elevados (Tabla 4.16), los cuales se corresponden con especies actuales que van desde deciduas hasta 6 años de retención foliar, pero no con los porcentajes de Araucaria araucana que son menores a 50 \% (Falcon-Lang, 2000b). Consensuando todos los resultados podemos decir que las coníferas de la Formación Salamanca aquí estudiadas eran perennifolias con una retención foliar aproximada de entre tres y seis años.

\section{4. Índices de Vulnerabilidad y Mesomorfía}

Los valores de vulnerabilidad y mesomorfía obtenidos son altos, 0,90-9,75 y 248,53-12156,04 respectivamente (Tabla 4.17), señalando un ambiente marcadamente mesomórfico libre de heladas y/o sequías.

\begin{tabular}{|lccccc|} 
& Diam. vasos & № vasos por $\mathrm{mm}^{2}$ & Largo de elem. de vasos & Vulnerabilidad & Mesomorfía \\
\hline Xilotipo 1 & 33,5 & 37 & 274,5 & 0,90 & 248,53 \\
\hline Myrceugenellites & 144,6 & 15 & 1261 & 9,64 & 12156,04 \\
\hline Xilotipo 2 & 60,4 & 29 & 497,4 & 2,09 & 1039,39 \\
\hline Xilotipo 3 & 136,6 & 14 & 485,6 & 9,75 & 4738,07 \\
\hline
\end{tabular}

Tabla 4.17: datos utilizados para calcular el índice de vulnerabilidad y el de mesomorfía. Medidas en $\mu \mathrm{m}$.

\subsection{Método del Coexistence Approach (CA) o del pariente vivo más cercano}

Este método tampoco pudo ser aplicado con las maderas de esta formación dado que varias son de afinidad incierta, incluso a nivel familia (Xilotipos 1 a 3). Las 
restantes, además de representar un bajo número de taxones (5), son afines a familias que actualmente tienen una tolerancia climática bastante amplia (i.e. Podocarpaceae y/o Cupressaceae).

\subsection{Caracteres eco-xilológicos}

La porosidad es difusa en todos los taxones estudiados. Esto no es de extrañar ya que la porosidad circular (comúnmente asociada a climas templados cálidos) no aparece sino hasta el Eoceno y en el hemisferio sur es poco común aún hasta en la actualidad (Wheeler \& Baas, 1991, 1993; Wheeler et al., 2007; Baas \& Wheeler, 2011).

El diámetro tangencial promedio de los vasos es bajo en dos de los taxones y notablemente mayor en los otros dos (Myrceugenellites y el Xilotipo 3). Los vasos anchos son característicos de zonas tropicales y también de zonas templadas de montaña (Baas \& Xinying; 1986; Schweingruber, 1988; Wheeler \& Baas, 1991; Carlquist, 2001).

La baja frecuencia de vasos por $\mathrm{mm}^{2}$, como la que se encuentra presente en las cuatro angiospermas de la Formación Salamanca aquí estudiadas, es común en regiones tropicales (Van der Graaff \& Baas, 1974; Baas \& Xinying, 1986; Schweingruber, 1988; Wheeler \& Baas, 1991, 1993; Baas \& Wheeler, 2011).

Dos de los taxones presentan placas de perforación escalariformes (Myrceugenellites sp. y Xilotipo 2), mientras que los otros dos poseen placas simples (Xylotipo 1 y 3 ). Las placas escalariformes si bien suelen ser indicativas de lugares templado-fríos hasta polares, también son características de tropicales alta montaña y lugares con humedad estable (Baas \& Schweingruber, 1987; Wheeler \& Baas, 1991, 1993; Baas, 1982; Wheeler et al., 2007; Carlquist, 2012).

No hay engrosamientos espiralados los cuales son poco frecuentes en lugares tropicales y húmedos, de cualquier manera este carácter por el momento no fue registrado hasta el Eoceno (Van der Graaff \& Baas, 1974; Baas \& Xinying, 1986; Baas \& Schweingruber, 1987; Wheeler \& Baas, 1991, 1993; Wheeler et al., 2007; Carlquist, 2001, 2012). 
Uno de los taxones (Xilotipo 3) presenta punteaduras ornadas, comunes en climas fríos o tropicales de montaña (Baas \& Wheeler, 2011).

En tres de los taxones se observan claramente fibras de punteaduras areoladas (fibrotraqueidas). Estas son menores o ausentes en lugares secos (Carlquist, 2001). Además, dos de los taxones (Myrceugenellites sp. y el Xilotipo 3) presentan septos en las fibras lo cual actualmente es más común en floras tropicales (Schweingruber, 1988; Baas \& Schweingruber, 1987; Wheeler \& Baas, 1991 Wheeler et al., 2007).

Únicamente el Xilotipo 1 tiene fibras de paredes muy gruesas y pequeño lumen, un carácter habitual en leños adaptados a la sequía (Baas \& Wheeler, 2011).

A excepción del Xilotipo 1, los demás taxones presentan muy poco parénquima escasamente paratraqueal, lo cual evidenciaría temperaturas no muy elevadas (Morris et al. 2015, Plavcova et al., 2016). Hay que destacar que patrones más elaborados de distribución parenquimática y la mayor abundancia del mismo no son reportados hasta el Eoceno, por lo cual no son marcadores climáticos fiables para el Paleoceno (Wheeler \& Baas, 1991, 1993). 


\section{FORMACIÓN RÍO TURBIO}

El material de la Formación Río Turbio fue en parte previamente descripto (Pujana, 2008; Pujana \& Ruiz, 2017) y los taxones allí estudiados se mencionan en la tabla 4.18.

\begin{tabular}{|l|l|}
\hline \multirow{3}{*}{ Gimnospermas } & Phyllocladoxylon sp. A de Pujana 2008 (S) \\
\cline { 2 - 2 } & $\begin{array}{l}\text { Podocarpoxylon multiparenchymatosum Pujana \& Ruiz (I) } \\
\text { (=Podocarpoxylon sp. B de Pujana, 2008) }\end{array}$ \\
\hline Angiospermas & Xilotipo 2 de Pujana 2008 (aquí cf. Caldcluvioxylon)(I) \\
\hline
\end{tabular}

Tabla 4.18: lista de taxones analizados descriptos previamente. La letra entre paréntesis indica el miembro donde fueron hallados, (I) inferior y (S) superior.

Posteriormente se colectaron y describieron nuevos ejemplares detallados a continuación en la sección 4.1 ("Sistemática Paleobotánica"). Los mismos cuentan con un estado de preservación regular, con lo cual en algunos ejemplares solo se pudieron efectuar breves descripciones, ya que no fue posible observar todos los caracteres diagnósticos y/o llevar a cabo mediciones precisas. Otros ejemplares pudieron ser identificados solo como Angiospermae indet o Gimnospermae indet (ver Apéndice II).

\subsection{Sistemática paleobotánica}

Orden Araucariales Gorozhankin, 1904

Familia Podocarpaceae Endl., 1847

Género Phyllocladoxylon Gothan, 1905

Especie tipo Phyllocladoxylon muelleri (Schenk, en Schimper \& Schenk, 1890)

Gothan, 1905.

\section{Phyllocladoxylon antarcticum Gothan, 1908}

Figura: 4.20 .

Material estudiado: MPM PB 2231.

Localidad: RT1, Río Turbio, provincia de Santa Cruz, Argentina.

Horizonte estratigráfico: Formación Río Turbio, Miembro Inferior. Eoceno.

Descripción: madera de tipo coniferoide, homoxílica y picnoxílica. Los anillos de crecimiento están bien marcados por el achatamiento radial de las últimas 1-4 hileras de traqueidas, con una transición gradual entre el leño temprano y el leño tardío (Fig. 4.20 A,B). Las traqueidas son de forma redondeada a cuadrangular (Fig. 4.20 B), con un 
diámetro tangencial de $19,9(13,5-28,6) \mu \mathrm{m}$ y radial de $14,3(4,4-25,6) \mu \mathrm{m}$ en el leño temprano. Las paredes de las traqueidas presentan un grosor de 3,6 $(1,9-5,4) \mu \mathrm{m}$.

Las punteaduras radiales de las traqueidas siguen un plan abietinoide y son exclusivamente uniseriadas (Fig. 4.20 C,D). Las punteaduras miden 12,6 (8,7-17,2) $\mu \mathrm{m}$ de diámetro vertical y $12,7(9,6-16,7) \mu \mathrm{m}$ de diámetro radial, con poros de 3,0 $(2,2-$ 4,6) $\mu \mathrm{m}$ de diámetro. Los radios son homocelulares y las células parenquimáticas que los conforman tienen todas sus paredes lisas (Fig. 4.20 D,E). Los campos de cruzamiento cuentan con uno o raramente dos punteaduras simples (ooporos), en ocasiones con un delgado borde (Fig. 4.20 D,E). La punteaduras son ovales a circulares, con un diámetro vertical de $9,7(7,0-13,8) \mu \mathrm{m}$.

Los radios son uniseriados, homocelulares, con 5 (1-9) células de alto. No se observa parénquima axial.
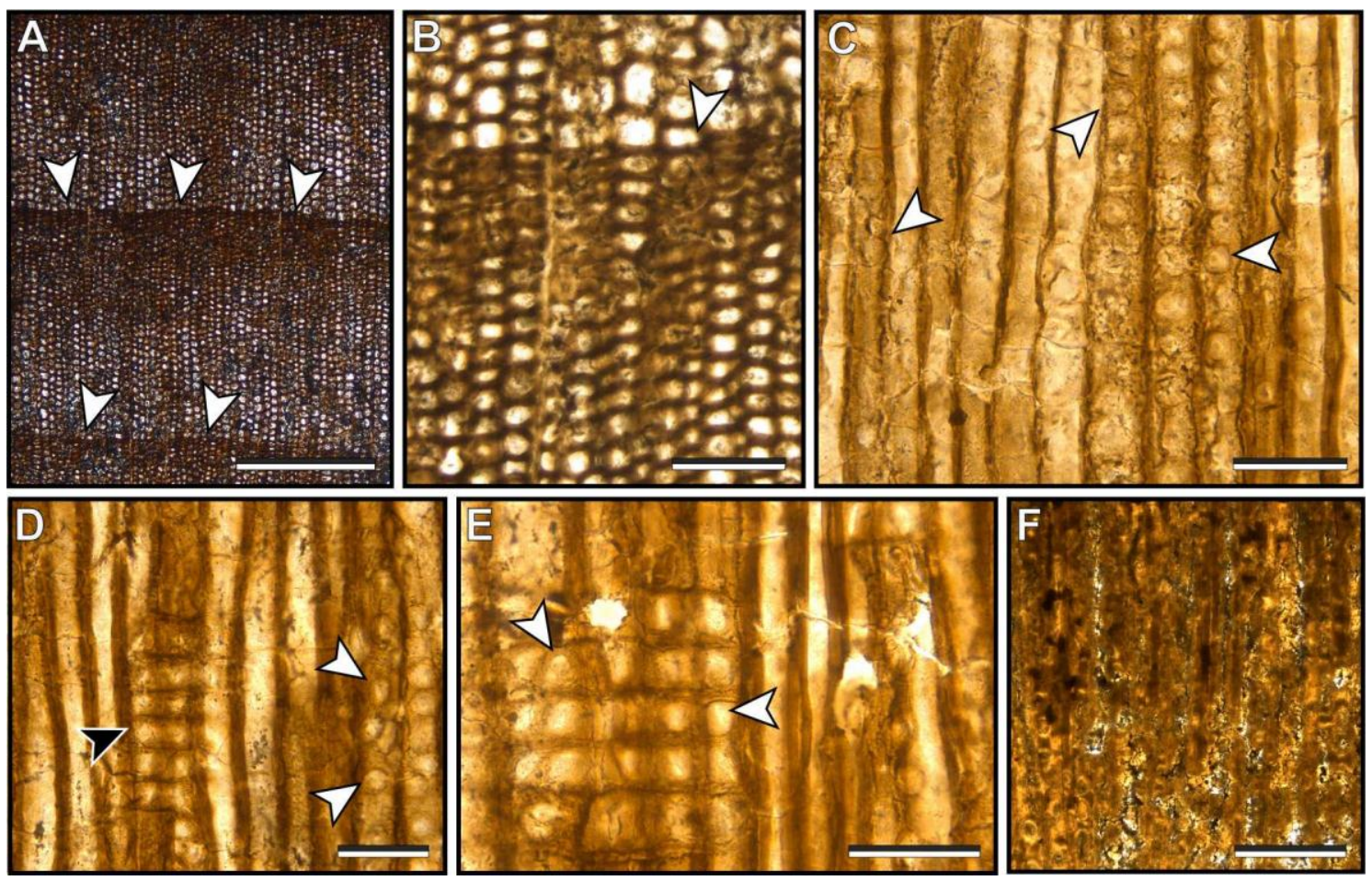

Figura 4.20. cf. Phyllocladoxylon antarcticum. MPM PB 2231. A,B. ST. Vista transversal de las traqueidas y los anillos de crecimiento bien marcados (flechas). C. SLR. Punteaduras radiales de las traqueidas abietinoides (flechas). D. SLR. Punteaduras radiales de las traqueidas abietinoides (flechas blancas) y campos de cruzamiento (flecha negra). E. SLR. Campos de cruzamiento con ooporos ovales o circulares (flechas). F. SLT. No se encuentra bien preservado. Escalas. A: $500 \mu \mathrm{m}$; B: $100 \mu \mathrm{m}$; C-E: $50 \mu \mathrm{m}$; F: $200 \mu \mathrm{m}$. 
Comparaciones y comentarios: Phyllocladoxylon antarcticum es caracterizada por anillos de crecimiento marcados, el tipo de campo de cruzamiento, las punteaduras uniseriadas abietinoides, los radios uniseriados y la ausencia de parénquima axial. La especie fue anteriormente registrada en Patagonia (Kräusel, 1924; Nishida et al., 1990) y es particularmente abundante en el Eoceno de Antártida (Pujana et al., 2014).

\section{cf. Phyllocladoxylon}

Figura: 4.21.

Material estudiado: MPM PB 17938 y MPM PB 17939.

Localidad: RT16, Río Turbio, provincia de Santa Cruz, Argentina.

Horizonte estratigráfico: Formación Río Turbio, Miembro Superior. Oligoceno.

Descripción: las muestras consisten en astillas carbonizadas. Las punteaduras en las paredes radiales de las traqueidas son difíciles de ver, pero parecieran seguir un plan abietinoide, exclusivamente uniseridas y espaciadas (Fig. 4.21 A,B). Las punteaduras radiales son circulares $11,11(8,6-12,6) \mu \mathrm{m}$ en diámetro vertical y 11 $(8,3-13,0) \mu \mathrm{m}$ en diámetro radial. Los campos de cruzamiento tienen una o dos punteaduras grandes, simples o con un borde delgado (Fig. 4.21 C,D). Las punteaduras son circulares a ovales, con un diámetro vertical de 9,3 $(6,4-12,0) \mu \mathrm{m}$. Las paredes horizontales y verticales del parénquima radial son lisas (Fig 4.21 C,D) y los radios son homocelulares con 4 (2-7) células de alto.

Comparaciones y comentarios: estos ejemplares fueron preservados como carbonizaciones, los cuales además eran de pequeño tamaño, por lo cual solo se pudieron estudiar mediante microscopio electrónico de barrido, y muchos de sus caracteres no pudieron ser observados y medidos (por ejemplo presencia de anillos o de parénquima axial). De cualquier manera, los campos de cruzamiento y las punteaduras radiales de las traqueidas señalan una afinidad con el género Phyllocladoxylon. 

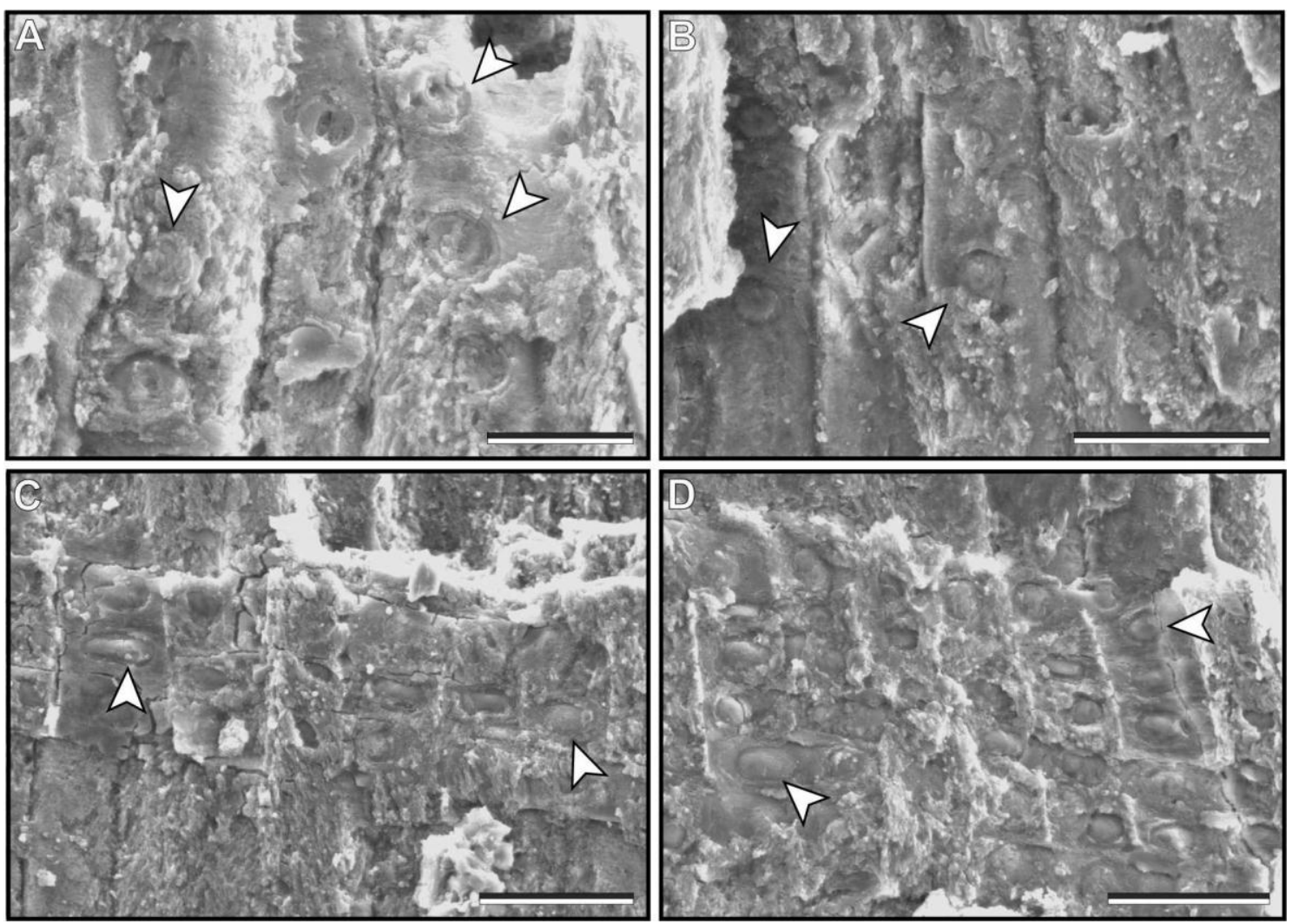

Figura 4.21. cf. Phyllocladoxylon. MPM PB 17939. A,B. SLR. Punteaduras radiales de las traqueidas con plan abietinoide (flechas). C,D. SLR. Campos de cruzamiento con punteaduras fenestriformes (flechas). Escalas. A: $25 \mu \mathrm{m}$; B-C: $50 \mu \mathrm{m}$.

Orden Araucariales Gorozhankin, 1904

Familia Araucariaceae Henkel et Hochst, 1865

Género Agathoxylon Hartig, 1848

Especie tipo Agathoxylon cordaiatum Hartig, 1848

aff. Agathoxylon antarcticus (Poole \& Cantrill, 2001) Pujana, Santillana et Marenssi, 2014

Figuras: 4.22 y 4.23 .

Material estudiado: MPM PB 2256, MPM PB 17927, MPM PB 17931, MPM PB 17932, MPM PB 17933, MPM PB 17934, MPM PB 17936.

Localidades: RT9 y RT15, Río Turbio, provincia de Santa Cruz, Argentina.

Horizonte estratigráfico: Formación Río Turbio, Miembro Superior. Oligoceno.

Descripción: madera de tipo coniferoide, homoxílica y picnoxilica. Los anillos de crecimiento están levemente marcados por el achatamiento radial de las últimas hileras de traqueidas y solo se observan en algunos ejemplares. Las traqueidas presentan una sección redondeada a cuadrangular (Fig. 4.22 A). El diámetro tangencial 
de las traqueidas es de $16,3(10,8-25,4) \mu \mathrm{m}$, el radial de $10,2(7,8-12,6) \mu \mathrm{m}$ y las paredes son de $3,6(2,3-5,7) \mu \mathrm{m}$ de espesor.

En vista radial se observa que las punteaduras de las traqueidas se disponen según un plan araucarioide, predominantemente uniseriadas aunque también biseriadas, contiguas y alternas cuando son biseriadas (Figs. 4.22 B y 4.23 A). Estas punteaduras son hexagonales a circulares con un diámetro vertical de $9,6(7,0-11,7)$ $\mu \mathrm{m}$ y radial de 9,6 (7-12) $\mu \mathrm{m}$. Los radios son homocelulares y están compuestos por células parenquimáticas de paredes horizontales y verticales lisas (Fig. 4.23 A,B). Los campos de cruzamiento son de tipo araucarioide con 3 (1-6) punteaduras areoladas (oculiporos) por campo. Las mismas están a veces comprimidas entre ellas, son circulares y tienen un diámetro vertical de 7,6 (5,2-10,2) $\mu \mathrm{m}$ (Fig. 4.23 A,B).

Los radios son exclusivamente uniseriados, con una altura de 8 (1-21) células y $186,5(28-533,3) \mu \mathrm{m}$. Tienen una frecuencia de $8(5-10)$ radios por $\mathrm{mm}$. Las células radiales tienen un lumen tangencial de $6,4(3,0-13,2) \mu \mathrm{m}$ y uno vertical de $14,3(6,1-$ $28,8) \mu \mathrm{m}$, con una pared de $3,2(2,1-4,8) \mu \mathrm{m}$ (Fig. $4.22 \mathrm{C}$ ).
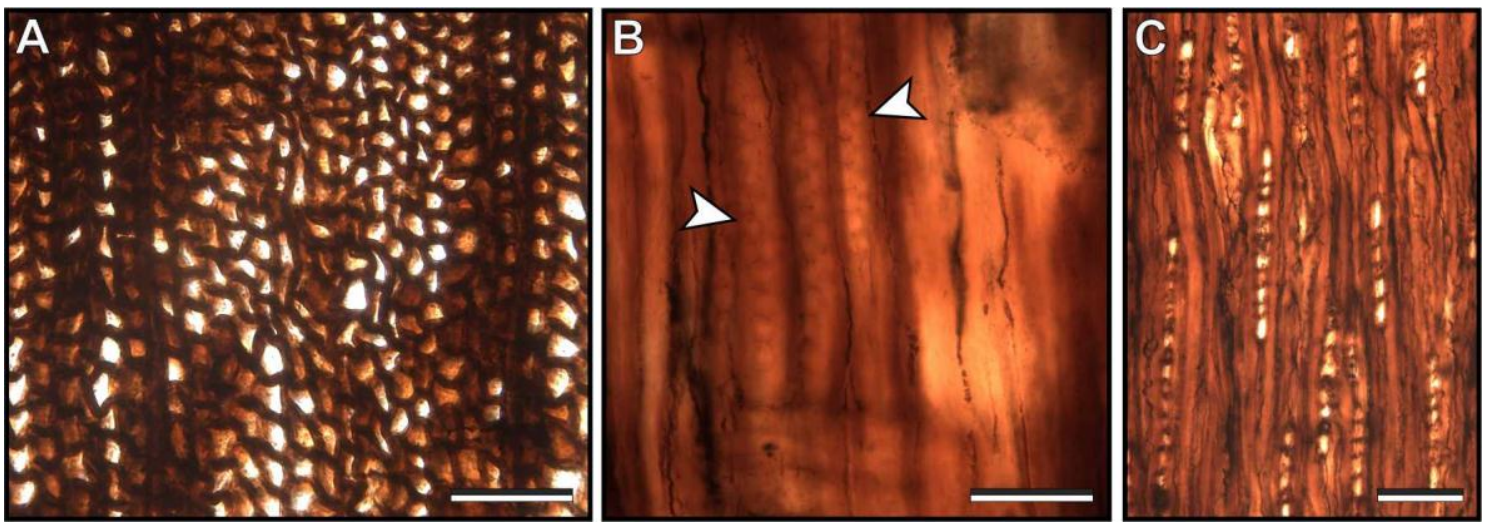

Figura 4.22. aff. Agathoxylon antarcticus. MPM PB 17927. A. ST. Vista general de las traqueidas. B. SLR. Punteaduras radiales de las traqueidas con plan araucarioide (flechas). C. SLT. Vista general de los radios en sección transversal. Escalas. A,C: $100 \mu \mathrm{m}$; B: $50 \mu \mathrm{m}$. 

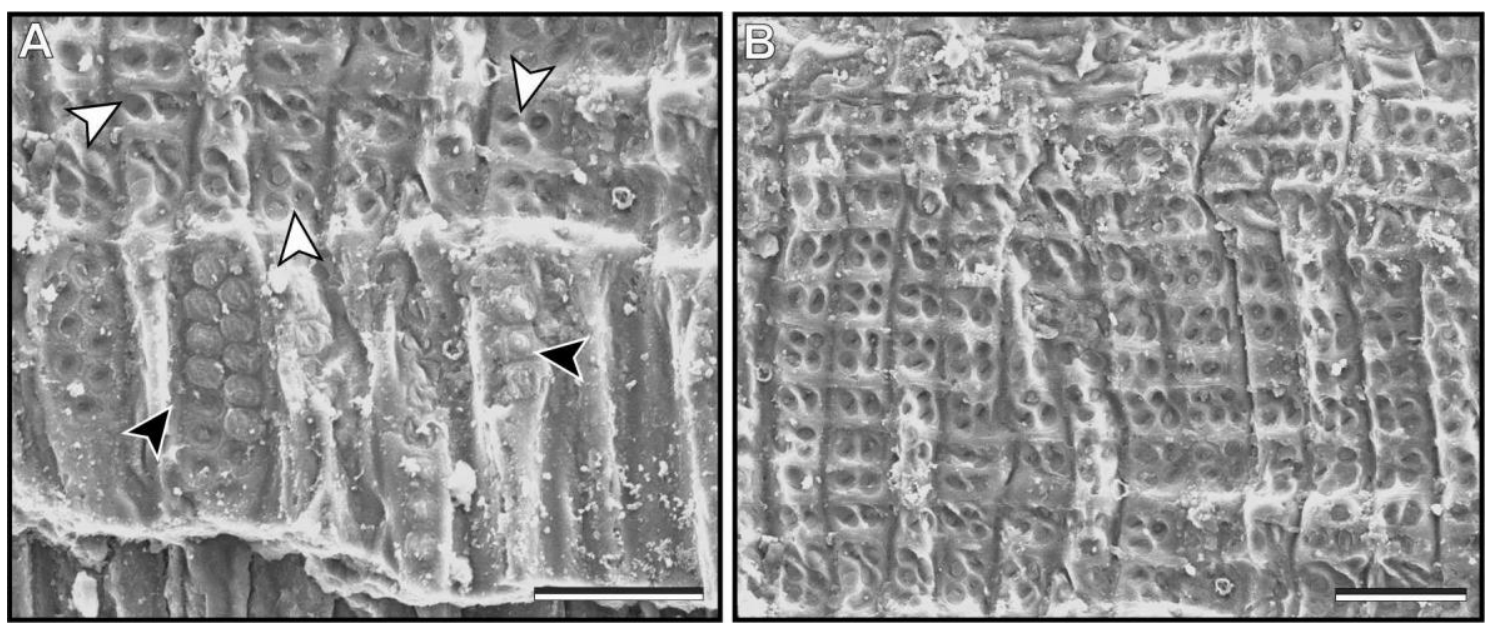

Figura 4.23. aff. Agathoxylon antarcticus. MPM PB 17927. A. SLR. Punteaduras radiales de las traqueidas con plan araucarioide (flechas negras) y campos de cruzamiento con punteaduras araucarioides (flechas blancas). B. SLR. Campos de cruzamiento con punteaduras araucarioides. Escalas. A,B: $50 \mu \mathrm{m}$.

Comparaciones y comentarios: la especie $A$. antarcticus se caracteriza por presentar anillos de crecimiento levemente marcados, punteaduras radiales uni o biseriadas del tipo araucarioide, campos de cruzamiento araucarioides, radios uniseriados, ausencia de resin-plugs y de parénquima axial (Pujana et al., 2014, 2015; Mirabelli et al., 2018).

Las muestras tienen las características anatómicas típicas del género Araucaria Juss., como por ejemplo Araucaria araucana (Molina) K. Koch, que vive actualmente en la Patagonia. Si bien no todos los Agathoxylon son asignables a las Araucariaceae, dada la edad y la anatomía del fósil, es certero afirmar que este ejemplar es afín a dicha familia.

Orden Oxalidales Bercht. et J.Presl, 1820

Familia Cunoniaceae Brown, 1814

Género Caldcluvioxylon Zhang et Wang, 1994

Especie tipo Caldcluvioxylon collinsense Zhang et Wang, 1994

\section{Caldcluvioxylon sp.}

Figuras: 4.24 .

Material estudiado: MPM PB 2236

Localidad: RT2, Río Turbio, provincia de Santa Cruz, Argentina.

Horizonte estratigráfico: Formación Río Turbio, Miembro Inferior. Eoceno. 
Descripción: leño picnoxílico y heteroxílico. Los anillos de crecimiento están demarcados por el achatamiento radial de las fibras y una leve reducción del diámetro de los elementos de vaso (Fig. 4.24 A,B). La porosidad es difusa, con 79 (68-90) vasos por $\mathrm{mm}^{2}$. Los vasos son solitarios (95\%), raramente en pares tangenciales (4,5\%), (Fig. 4.24 A-C). Los vasos son de sección redondeada y miden $50,1(27,7-68,2) \mu \mathrm{m}$ de diámetro tangencial y $61,6(22,1-89,7) \mu \mathrm{m}$ de diámetro radial. Las placas de perforación son de tipo escalariforme, con 18 (12-29) barras (Fig. 4.24 D). Las punteaduras presentes en los elementos de vaso son escalariformes a opuestas (Fig. $4.24 \mathrm{E})$ y miden $3,2(2,3-4,2)$ de diámetro vertical.

El parénquima axial es apotraqueal difuso y muy escaso (Fig. 4.24 C,J).

Las fibrotraqueidas tienen una pared de $6,5(3,7-10,0)$, con punteaduras areoladas y de abertura alargada que poseen un diámetro vertical de $4,5(2,9-6,0)$ (Fig. $4.24 \mathrm{~K})$.

Los radios son, en su mayoría, uniseriados y homogéneos, de células erectas. También se observan escasos radios heterogéneos (Fig. 4.24 G), en parte biseriados, con extremos uniseriados de 3 (1-9) células (Fig. 4.24 H,I). Se observan 11 (9-16) radios por mm y tienen una altura de $367,0(61,2-967,3) \mu m$ y $8(1-18)$ células. Con un ancho de $13,7(6,4-27,42) \mu \mathrm{m}$. Las punteaduras radiovasculares son escalariformes a transicionales con un diámetro vertical de 4,1 (2,8-5,7) $\mu \mathrm{m}$ (Fig. 4.24 F).

Comparaciones y comentarios: este ejemplar es el mismo descripto en el trabajo de tesis de Pujana (2008) como Xilotipo 2. Aquí se lo identifica como perteneciente al género Caldcluvioxylon. Este género fue inválidamente publicado por Torres (1990), luego Zhang \& Wang (1994) describen la especie C. collinsense Zhang et Wang. Esta especie es muy similar al fósil aquí estudiado, compartiendo casi la totalidad de caracteres, a excepción de los anillos que están más marcados en $C$. collinsense y los radios son algo más bajos y generalmente uniseriados en el ejemplar aquí descripto. 

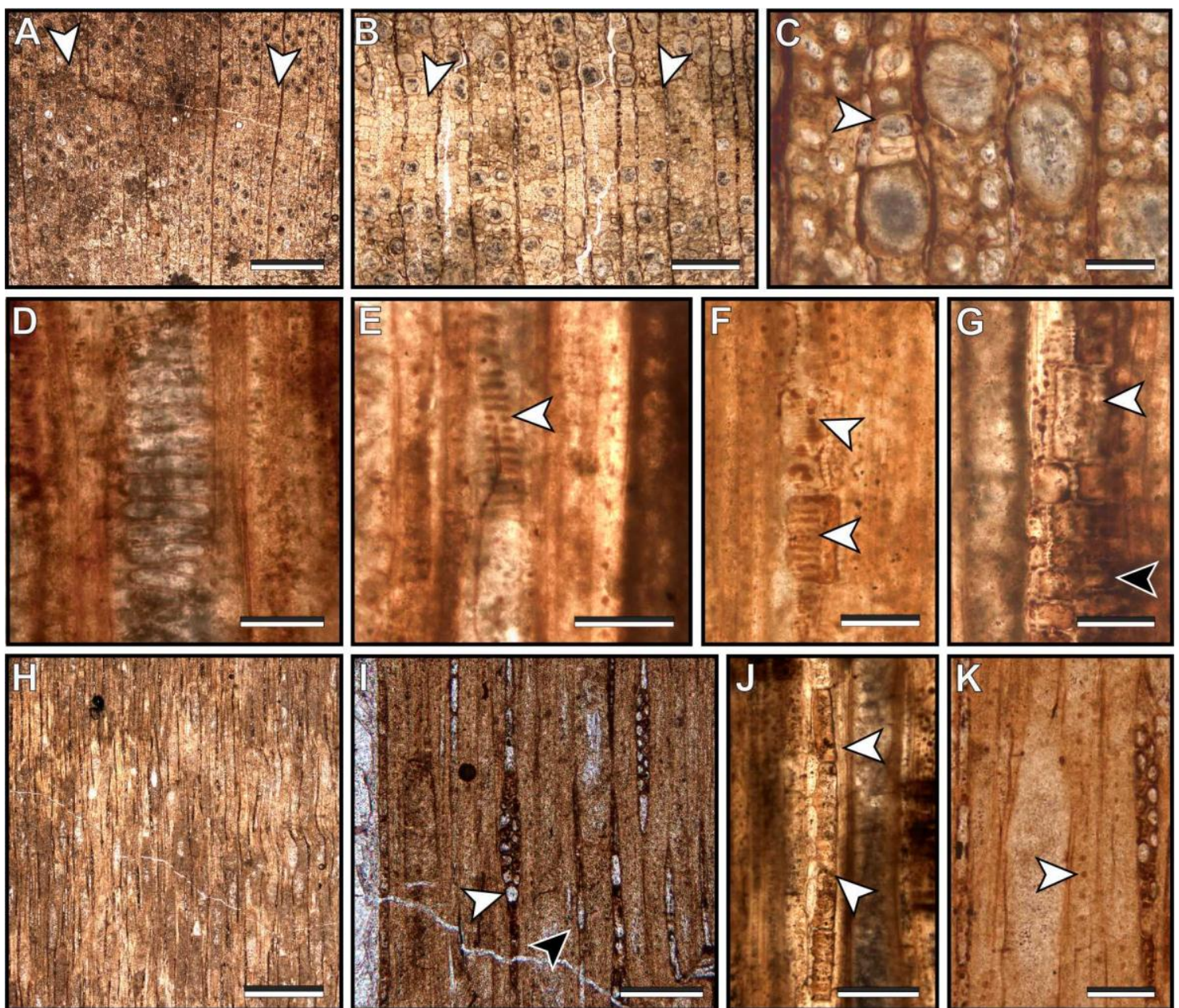

Figura 4.24. cf. Caldcluvioxylon. MPM PB 2236. A,B. ST. Porosidad tendiendo a semicircular con vasos solitarios. Límite de anillo de crecimiento poco marcado (flechas) C. ST. Detalle de la sección transversal. Parénquima axial difuso y muy escaso (flecha). D. SLR. Placa de perforación escalariforme. E. SLR. Punteaduras de los vasos escalariformes a opuestas (flecha). F. SLR. Punteaduras radio-vasculares escalariformes (flechas). G. SLR. Radios heterogéneos con células erectas (flecha blanca) y procumbentes (flecha negra). H. SLT. Vista general de los radios en sección tangencial. I. SLT. Radios heterogéneos biseriados con extremos uniseriados

(flecha blanca) y radios homogéneos uniseriados (flecha negra). J. SLR. Parénquima axial (flechas). K. SLT. Fibras con punteaduras (flecha). Escalas. A,H: $500 \mu \mathrm{m}$; B: $200 \mu \mathrm{m}$; I,J: $100 \mu \mathrm{m}$; C,E-G,K: $50 \mu \mathrm{m} ; \mathrm{D}: 25 \mu \mathrm{m}$

\section{Xilotipo 4}

Afinidad: Angioespermae.

Figura: 4.25 .

Material estudiado: MPM PB 17953

Localidad: RT 28, Río Turbio, provincia de Santa Cruz, Argentina.

Horizonte estratigráfico: Formación Río Turbio, Miembro Inferior. Eoceno. 
Descripción: los anillos de crecimiento están delimitados por la disminución en el diámetro radial de las últimas hileras de fibras (Fig. $4.25 \mathrm{~A}-\mathrm{C}$ ). Las porosidad es circular y hay $21(18-26)$ vasos por $\mathrm{mm}^{2}$. Los vasos se disponen mayormente de forma solitaria aunque también hay series radiales de hasta cuatro vasos (Fig. $4.25 \mathrm{~A}-\mathrm{C}$ ) y tienen un diámetro tangencial de $68,2(31,6-111,9) \mu \mathrm{m}$. Los radios son homogéneos uni o biseriados, aunque hay zonas con radios de mayor seriación hasta 7-seriados y agregados (esto bien podría tratarse de una ramificación) (Fig. 4.25 D,E). Se observan 8 (6-10) radios por $\mathrm{mm}$ y tienen $15(2-24)$ células y $326,9(82-630,8) \mu \mathrm{m}$ de altura y 24,7 $(13,1-34,9) \mu \mathrm{m}$ de ancho.

Comentarios: este ejemplar tampoco cuenta con una buena preservación, solo se presentan algunas zonas en los preparados donde pueden observarse claramente algunos de los caracteres.

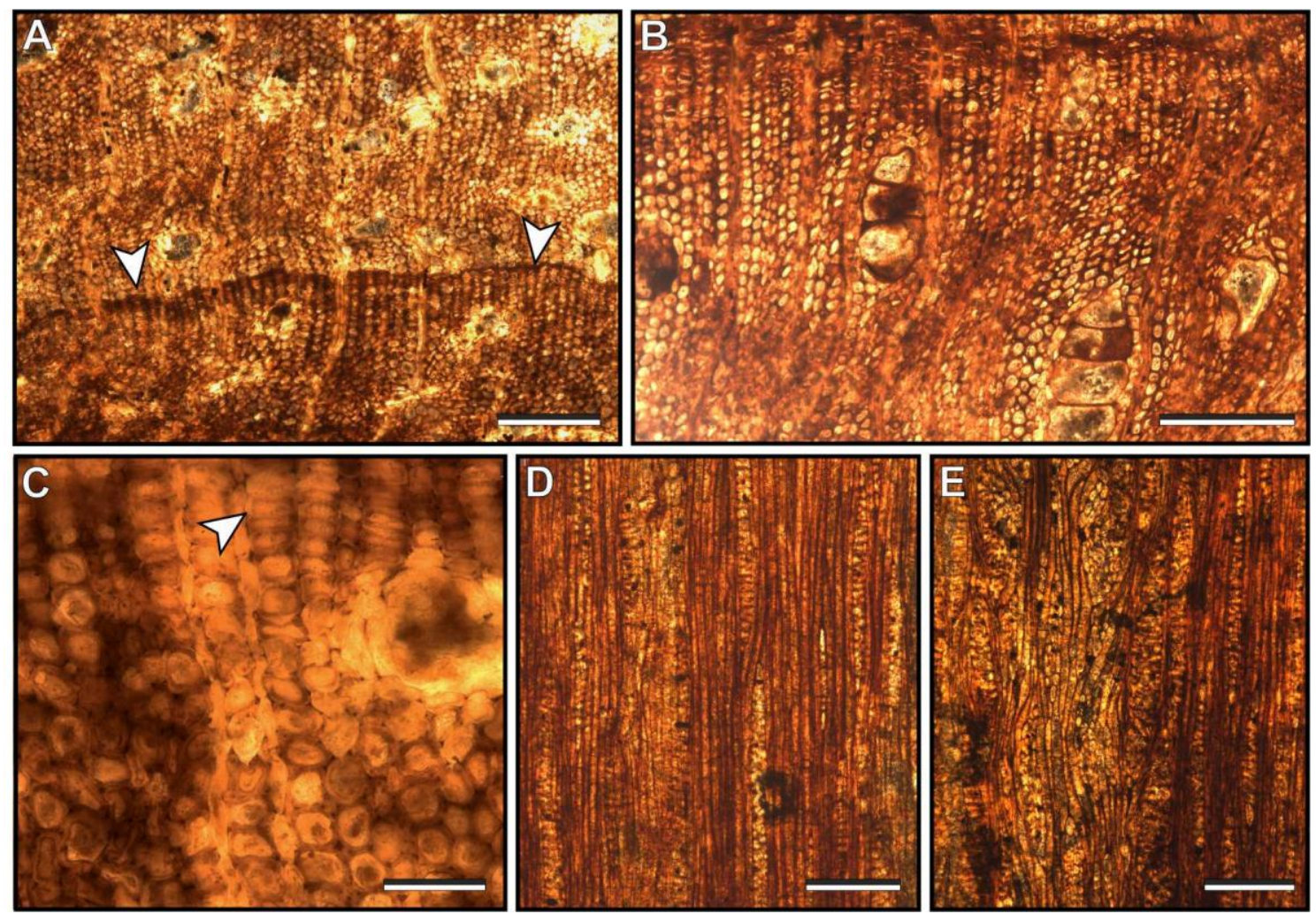

Figura 4.25. Xilotipo 4. MPM PB 17953. A-C. ST. Porosidad es difusa, vasos dispuestos de forma solitaria o en múltiples radiales y anillos de crecimiento (flechas). D,E. SLT. Radios homogéneos. C,D. SLT. Radios uni y pluriseriados. Escalas. A,D,F: $200 \mu \mathrm{m}$; B: $100 \mu \mathrm{m}$; C: $50 \mu \mathrm{m}$. 
Orden Fagales Engler, 1892

Familia Nothofagaceae Kuprianova, 1962

Género Nothofagoxylon Gothan, 1908

Especie tipo Nothofagoxylon scalariforme Gothan, 1908

\section{aff. Nothofagoxylon sp. 1}

Figura: 4.26 .

Material estudiado: MPM PB 17951

Localidad: RT 24, Río Turbio, provincia de Santa Cruz, Argentina.

Horizonte estratigráfico: Formación Río Turbio, Miembro Inferior. Eoceno.

Descripción: la porosidad es difusa y los vasos se disponen de forma solitaria o en series radiales de hasta cuatro vasos (Fig. 4.26 A). Se observa una media de 31 vasos por $\mathrm{mm}^{2}$. Los elementos de vaso miden $72,0(32,7-115,3) \mu \mathrm{m}$ de diámetro tangencial y poseen una longitud de $371,1(220,9-585,5) \mu \mathrm{m}$. Las placas de perforación son simples y las punteaduras intervasculares son opuestas a alternas (Fig. 4.26 C,D). Los radios son bi- o triseriados (Fig 4.26 E,F) y parecieran ser homogéneos, con punteaduras radiovasculares escalariformes (Fig. 4.26 B). En vista longitudinal tangencial se observa parénquima axial, aparentemente apotraqueal difuso, aunque es difícil asegurarlo ya que no se lo distingue claramente en vista transversal.
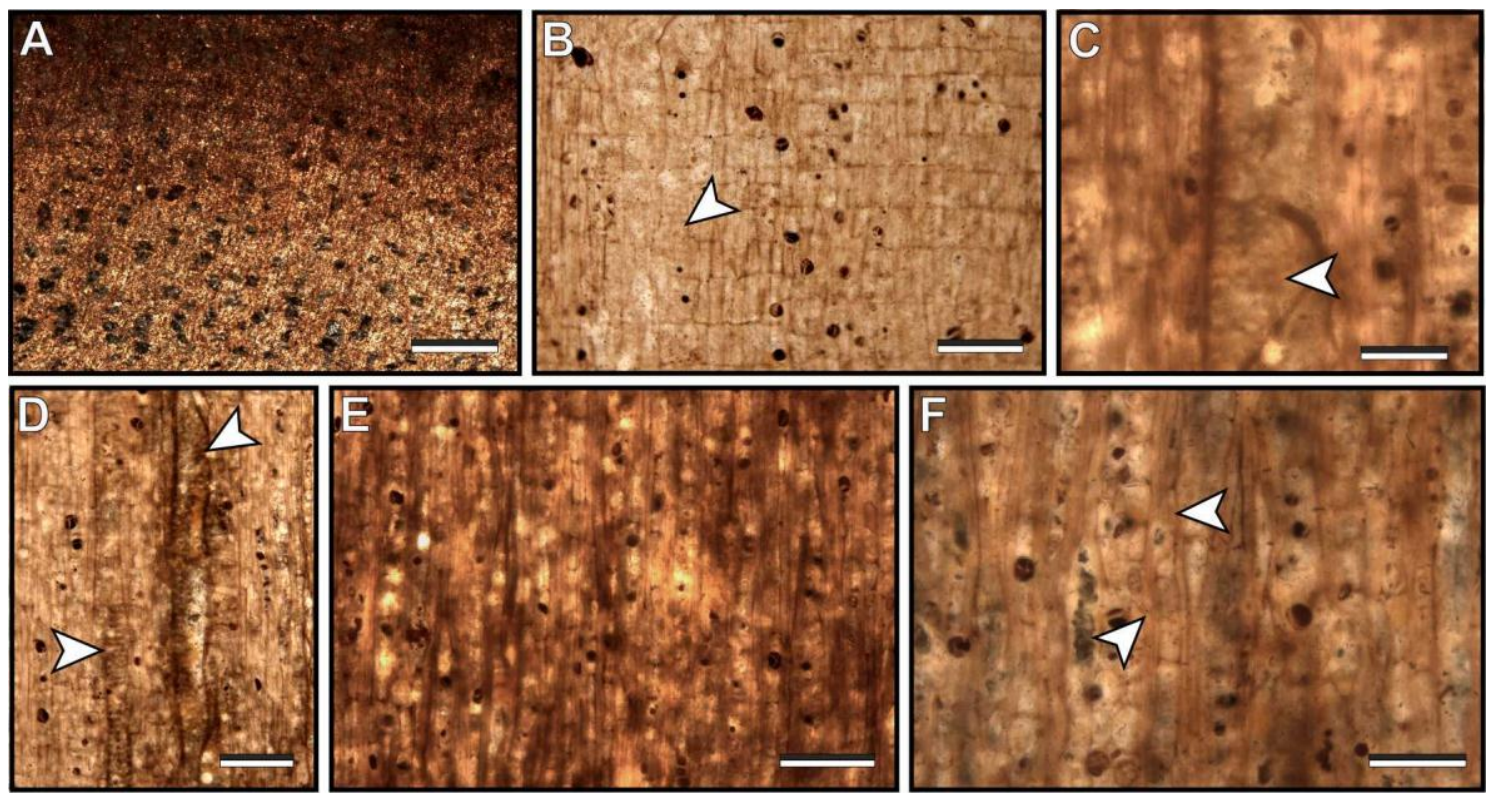

Figura 4.26. aff. Nothofagoxylon sp. 1. MPM PB 17951. A. ST. Porosidad es difusa y vasos dispuestos de forma solitaria o en múltiples radiales. B. SLR. Radios homogéneos, con punteaduras radiovasculares escalariformes (flecha). C,D. SLT. Punteaduras intervasculares opuestas a alternas (flechas). E,F. SLT. Radios bi- o triseriados y parénquima axial (flechas).

Escalas. A: $500 \mu \mathrm{m}$; B,D,E: $100 \mu \mathrm{m}$; C,F: $50 \mu \mathrm{m}$. 
Comentarios: la muestra no está lo suficientemente bien preservada como para permitir una descripción más detallada, sin embargo es comparable a la especie Nothofagoxylon ruei Salard (=Nothofagoxylon paraprocera Ancibor) descripta por Ancibor (1984) en esta formación.

\section{aff. Nothofagoxylon sp. 2}

Figura: 4.27 .

Material estudiado: MPM PB 17952

Localidad: RT 27, Río Turbio, provincia de Santa Cruz, Argentina.

Horizonte estratigráfico: Formación Río Turbio, Miembro Superior. Eoceno.

Descripción: los anillos de crecimiento están bien marcados por el menor diámetro radial de las últimas dos o tres hileras de fibras (Fig. 4.27 A). La porosidad es difusa con 35 (21-45) vasos por $\mathrm{mm}^{2}$. Los vasos se disponen mayormente en múltiples radiales cortos y largos de hasta cinco vasos, también los hay solitarios y más raramente agrupados (Fig. 4.27 A,B). Los mismos tienen un diámetro tangencial de 42,4 $(19,5-68,5) \mu \mathrm{m}$. Las placas de perforación parecen ser simples. Las punteaduras intervasculares se observan con dificultad, siendo en apariencia alternas (Fig. 4.27 F). Ocasionalmente se observan tílides. Los radios son homogéneos, en su mayoría uniseriados aunque también los hay parcialmente biseriados (Fig. 4.27 C,E). Se presentan $20(16-25)$ radios por $\mathrm{mm}$, con unas 6 (2-13) células de alto. Los radios miden $256,2(112,4-502,5) \mu \mathrm{m}$ de alto y $26,4(13,95-44,49) \mu \mathrm{m}$ de ancho. Las punteaduras radiovasculares son opuestas a escalariformes (Fig. 4.27 C).

Comentarios: al igual que con los Xilotipos 4 y el Nothofagoxylon sp. 1, este ejemplar cuenta con una mala preservación, lo cual imposibilitó efectuar una descripción detallada y comparaciones más completas. 

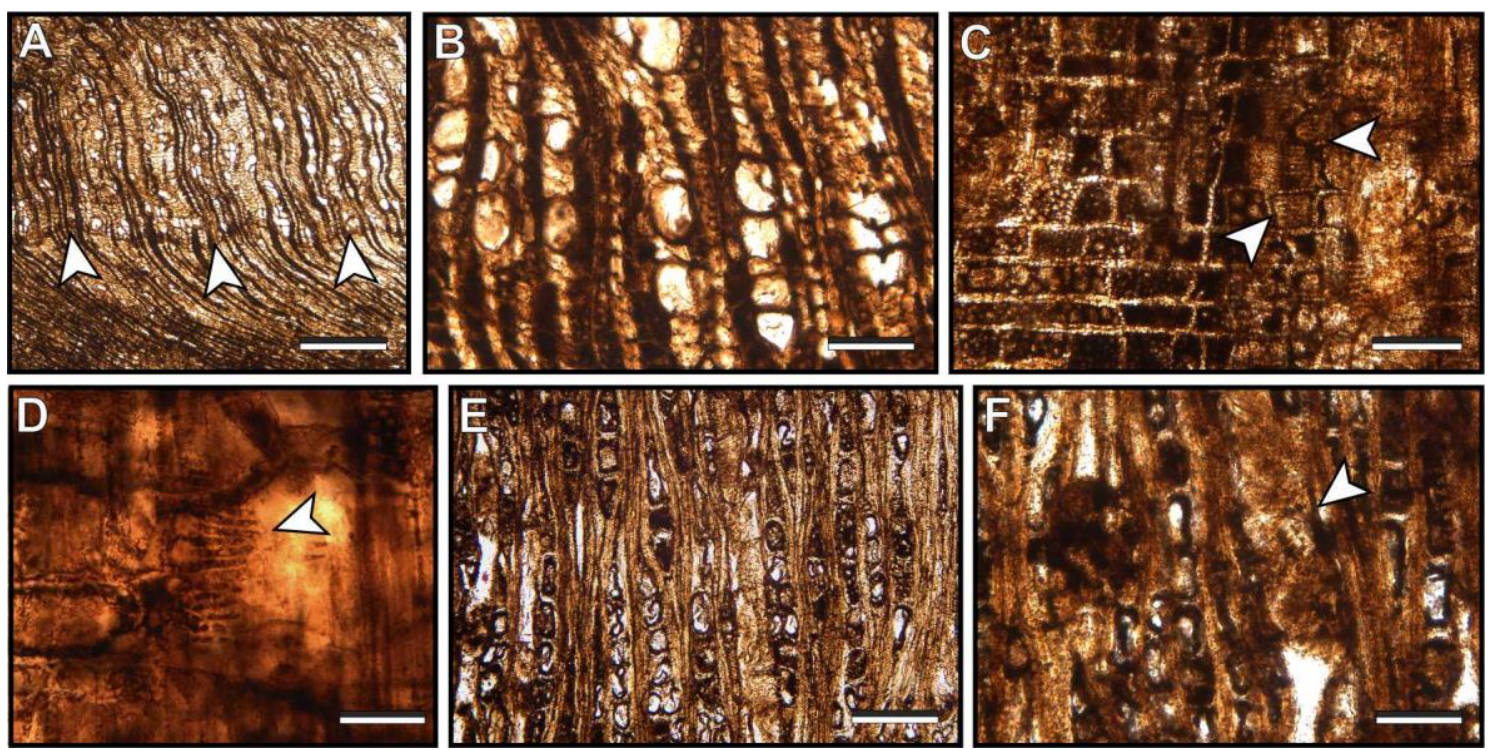

Figura 4.27. aff. Nothofagoxylon sp.2. MPM PB 17952. A,B. ST. Porosidad difusa, vasos dispuestos en múltiples radiales cortos y largo o solitarios. Anillos de crecimiento (flechas).

C,D. SLR: radios homogéneos con punteaduras radiovasculares opuestas a escalariformes

(flechas). E. SLT. Radios uniseriados y parcialmente biseriados. F. SLT. Punteaduras intervasculares alternas. Escalas. A: $500 \mu \mathrm{m}$; B,C,E: $100 \mu \mathrm{m}$; D,F: $50 \mu \mathrm{m}$.

\subsection{Ecuaciones propuestas por Wiemann et al. $(1998,1999)$}

Dada la escasa diversidad de angiospermas, sumado a su mal estado de preservación, no se pudieron aplicar las ecuaciones propuestas por Wiemann et al. (1998, 1999).

\subsection{Anillos de crecimiento}

Ejemplares procedentes tanto del miembro inferior como del miembro superior de la Formación Río Turbio cuentan con anillos de crecimiento marcados. Dado el amplio rango temporal entre ellos se los analizó por separado más allá de pertenecer a una única unidad estratigráfica. 


\begin{tabular}{|lccccccccc|}
\hline \multicolumn{1}{|c}{ Ejemplar } & $\begin{array}{c}\text { № } \\
\text { anillos }\end{array}$ & $\begin{array}{c}\text { № } \\
\text { falsos } \\
\text { anillos }\end{array}$ & $\begin{array}{c}\text { № anillos } \\
\text { de } \\
\text { heladas }\end{array}$ & $\begin{array}{c}\text { Ancho } \\
\text { medio }\end{array}$ & $\begin{array}{c}\text { Ancho } \\
\text { máx. }\end{array}$ & $\begin{array}{c}\text { Ancho } \\
\text { mín. }\end{array}$ & $\begin{array}{c}\text { Desv. } \\
\text { Est. }\end{array}$ & SA & SM \\
\hline MPM PB 2230 & 15 & 0 & 0 & 0,45 & 0,69 & 0,27 & 0,14 & $0,03-0,61$ & 0,24 \\
\hline MPM PB 2231 & 22 & 0 & 0 & 0,77 & 1,12 & 0,23 & 0,22 & $0-0,78$ & 0,22 \\
\hline MPM PB 17956 & 24 & 0 & 0 & 0,88 & 2,12 & 0,21 & 0,56 & $0,02-0,93$ & 0,39 \\
\hline $\begin{array}{l}\text { Promedio miemb. } \\
\text { inferior }\end{array}$ & & & & 0,70 & 1,31 & 0,24 & 0,30 & $0,02-0,77$ & 0,28 \\
\hline MPM PB 2242 & 51 & 0 & 0 & 0,36 & 0,55 & 0,13 & 0,96 & $0-0,68$ & 0,21 \\
\hline MPM PB 2244 & 24 & 1 & 0 & 0,74 & 1,34 & 0,15 & 0,38 & $0-1,12$ & 0,30 \\
\hline MPM PB 2245 & 44 & 0 & 0 & 0,40 & 0,57 & 0,16 & 0,10 & $0-0,75$ & 0,25 \\
\hline MPM PB 2246 & 39 & 0 & 0 & 0,56 & 1,20 & 0,10 & 0,28 & $0,02-1,28$ & 0,35 \\
\hline MPM PB 2248 & 71 & 0 & 0 & 0,31 & 0,84 & 0,04 & 0,19 & $0,07-1,36$ & 0,33 \\
\hline MPM PB 17928 & 131 & 0 & 0 & 0,23 & 0,58 & 0,06 & 0,11 & $0-1,07$ & 0,30 \\
\hline MPM PB 17929 & 45 & 2 & 0 & 0,71 & 1,55 & 0,18 & 0,28 & $0,01-0,87$ & 0,33 \\
\hline MPM PB 17930 & 93 & 2 & 0 & 0,34 & 0,67 & 0,12 & 0,88 & $0-0,94$ & 0,20 \\
\hline $\begin{array}{l}\text { Promedio miemb. } \\
\text { superior }\end{array}$ & & & & 0,46 & 0,91 & 0,12 & 0,40 & $0,01-1,01$ & 0,28 \\
\hline
\end{tabular}

Tabla 4.19: datos de los anillos de crecimiento analizados. Miembro inferior: Angiospermae indet. (MPM PB 2230), Phyllocladoxylon antarcticum (MPMPB 2231) y cf.

Phyllocladoxylon/Podocarpoxylon (MPM PB 17956). Miembro superior: Phyllocladoxylon sp. A (MPMPB 2242, 2244, 2245, 2246, 2248, 17928, 17929, 17930). Valores de ancho en mm.

Miembro inferior:
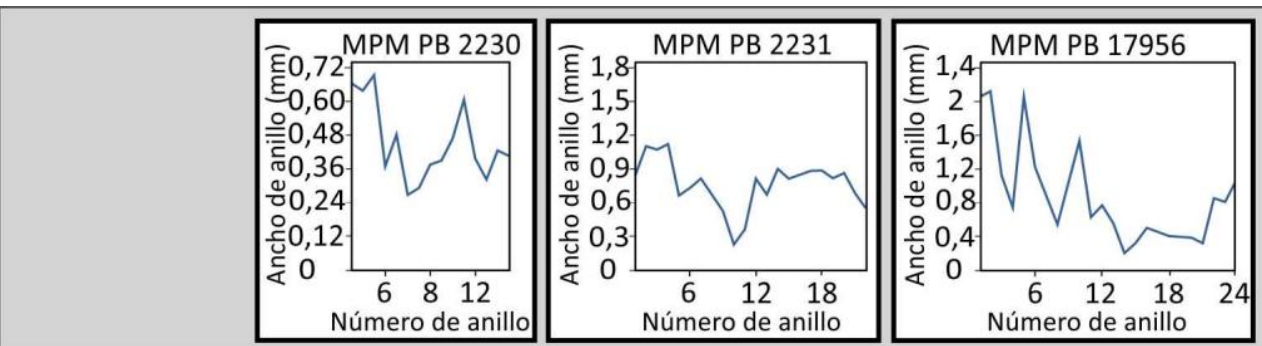

Fig. 4.28. Curvas de espesores de los anillos de crecimiento analizados del miembro inferior de la Fm. Río Turbio. Angiospermae indet. (MPM PB 2230), Phyllocladoxylon antarcticum (MPMPB-2231) y cf. Phyllocladoxylon/Podocarpoxylon (MPM PB 17956).

En total se midieron 559 anillos. En el miembro inferior se pudieron medir tres secuencias de anillos que corresponden a una angiosperma indeterminada (MPMPB 2230) con anillos bien marcados por achatamiento de las últimas hileras de fibras y reducción en el número y tamaño de vasos (porosidad semicircular), un ejemplar de Phyllocladoxylon antarcticum (MPMPB 2231) y otra conífera probablemente afín a los géneros Phyllocladoxylon o Podocarpoxylon (MPM PB 17956). Podocarpoxylon multiparenchymatosum también presenta anillos de crecimiento, aunque muy levemente marcados y notablemente más anchos. Sin embargo, en $P$. multiparenchymatosum, no se pudieron estimar los parámetros estadísticos y la sensibilidad anual y media, debido al escaso número de anillos por preparado (1-2) y al 
grado de deformación en algunas muestras. Por otra parte, sí fue posible en algunos casos, realizar estudios de hábito foliar utilizando el método de Falcon-Lang (2000a,b) (Tabla 4.20). También se presentan angiospermas indeterminadas con los anillos claramente marcados por el menor diámetro de las últimas 1-4 hileras de fibras (aff. Nothofagoxylon sp. 2) y otras también por presentar vasos de mayor tamaño en el leño temprano.

Las tres secuencias analizadas suman un total de 61 anillos que van desde los 15 a los 24 anillos. En promedio tienen un espesor de 0,70 $(0,45-0,88) \mathrm{mm}$ (Fig. 4.28), con un promedio mínimo de $0,24 \mathrm{~mm}$ y un máximo promedio de $1,31 \mathrm{~mm}$. El anillo más angosto es de 0,21 mm y el más ancho de 2,12 mm (Tabla 4.19).

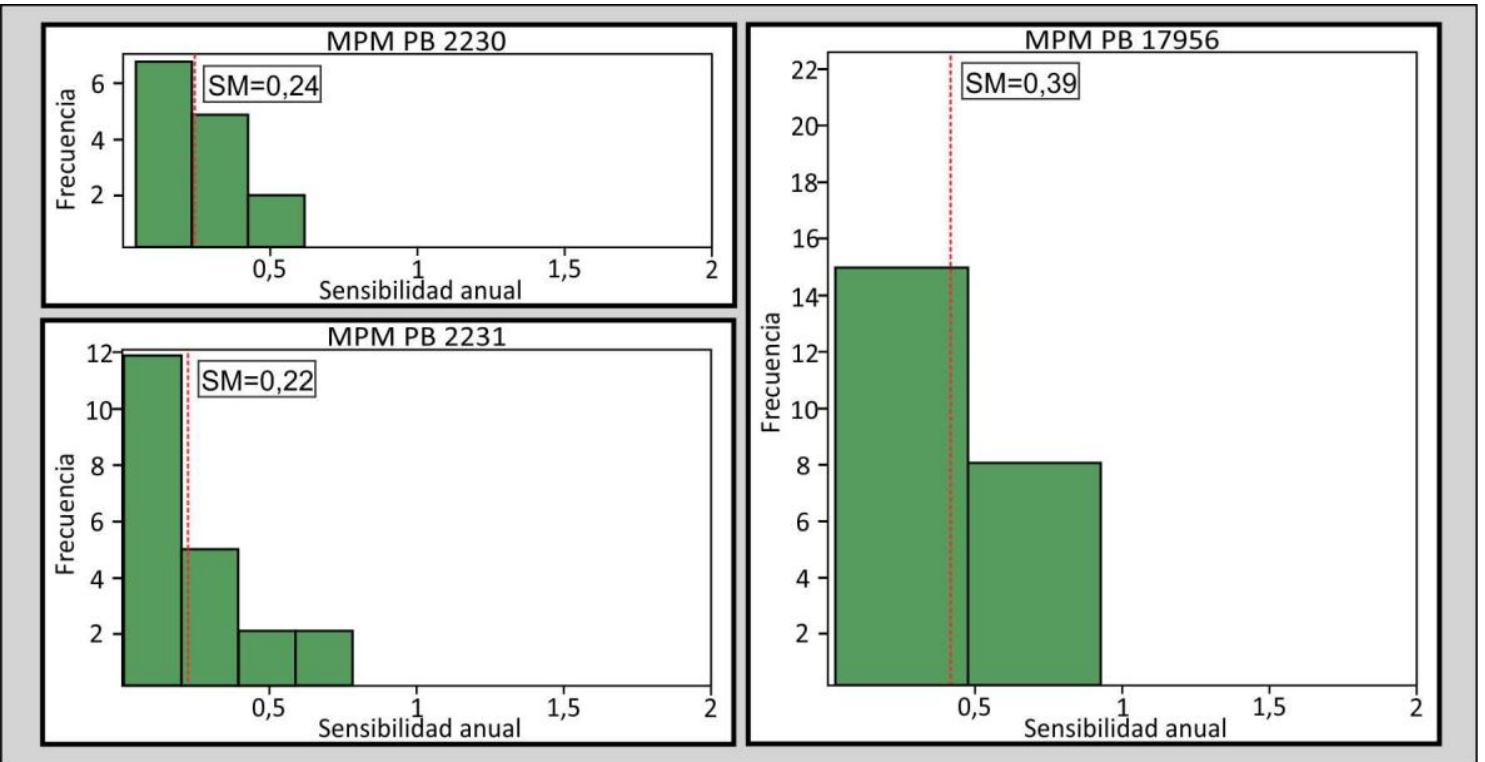

Fig. 4.29. Histogramas de Sensibilidad Anual (SA) de las muestras del miembro inferior de la Fm. Río Turbio. Las líneas punteadas en rojo indica la Sensibilidad media (SM). Angiospermae indet. (MPM PB 2230), Phyllocladoxylon antarcticum (MPM PB 2231) y cf. Phyllocladoxylon/Podocarpoxylon (MPM PB 17956).

La sensibilidad anual varía entre 0 y 1,28 , con una media de entre 0,02 y 0,77 (Tabla 4.19 y Fig. 4.29). La sensibilidad media es de 0,28 en promedio, mostrando que los árboles eran complacientes. Sólo una de las muestras dio un valor mayor a 0,30 (sensitivo). Por consiguiente, se podría sugerir que las condiciones climáticas eran en general estables, aunque pudo haber ocasionales momentos con temperaturas bajas extremas. De cualquier manera el número de secuencias de anillos analizados (3) es 
muy bajo y las condiciones reales podrían estar sesgadas por, entre otros motivos, la falta de material.

Los anillos de los ejemplares de Podocarpoxylon multiparenchymatosum estudiados son de tipo D o E del esquema clasificatorio de Creber \& Chaloner (1984b) (Fig. 4.33). Estos tipos de anillos son similares e indican una temporada de crecimiento relativamente uniforme con un evento terminal que marca el receso de la actividad cambial. En los de tipo E los anillos son tan poco marcados que casi pasan desapercibidos. Existen Podocarpaceae actuales que tienden a variar entre estos dos tipos de anillos según las circunstancias (Creber \& Chaloner, 1984b).

Se observa un posible falso anillo en un ejemplar de Podocarpoxylon multiparenchymatosum (MPM PB 2249) (Fig. 4.30 A).

Podocarpoxylon multiparenchymatosum presenta entre un $5,4 \%$ y un $27,6 \%$ de leño tardío, un porcentaje de disminución de $66 \%$ a 75,6\%, y un índice de demarcación de anillo (RMI) de 4,15 a 19,53\%. Estos porcentajes señalan una retención de las hojas entre tres y seis años (Falcon-Lang, 2000a). El porcentaje de skew varía entre $27,7 \%$ y $76,2 \%$, valores similares a los de las Podocarpaceae que habitan actualmente en Nueva Zelanda (Falcon-Lang, 2000b). Por tanto, la especie fósil aquí estudiada sería perennifolia con un índice de retención foliar comprendido entre los tres y seis años.

\section{Miembro superior:}

En el miembro superior las ocho secuencias analizadas suman un total de 498 anillos que corresponden todos a Phyllocladoxylon sp. A (MPM PB 2242, 2244, 2245, $2246,2248,17928,17929,17930)$. También hay una angiosperma indeterminada que tiene anillos marcados por disminución en el diámetro radial de las últimas hileras de fibras y una leve reducción en el tamaño de vasos hacia el leño tardío, pero cuyo grado de deformación no permitió realizar las mediciones correspondientes para calcular los parámetros estadísticos. Phyllocladoxylon sp. A (MPM PB 2258) fue el único ejemplar con algunos anillos lo suficientemente anchos para realizar los estudios de hábito foliar propuestos por Falcon-Lang $(2000 a, b)$. 

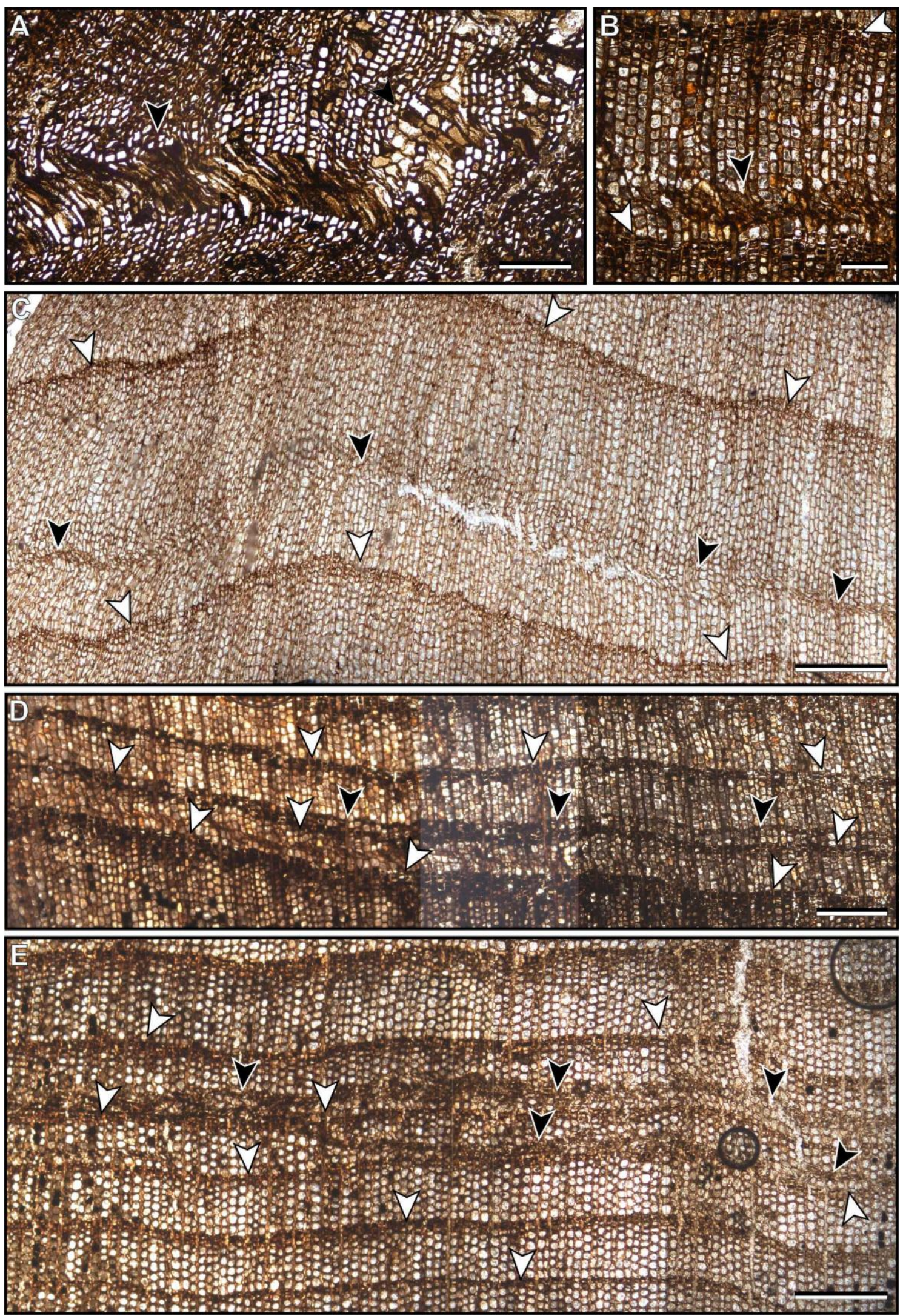

Figura 4.30. Leños con falsos anillos. Límite de anillo verdadero (flechas blancas), límite de falso anillo (flechas negras). A. Podocarpoxylon multiparenchymatosum (MPM PB 2249). B-E.

Phyllocladoxylon sp. A. B. MPM PB 17929. C. MPM PB 2244. D. MPM PB 17929. E. MPM PB 17930. Escalas. A-C: $500 \mu \mathrm{m} ; \mathrm{D}, \mathrm{E}: 200 \mu \mathrm{m}$. 


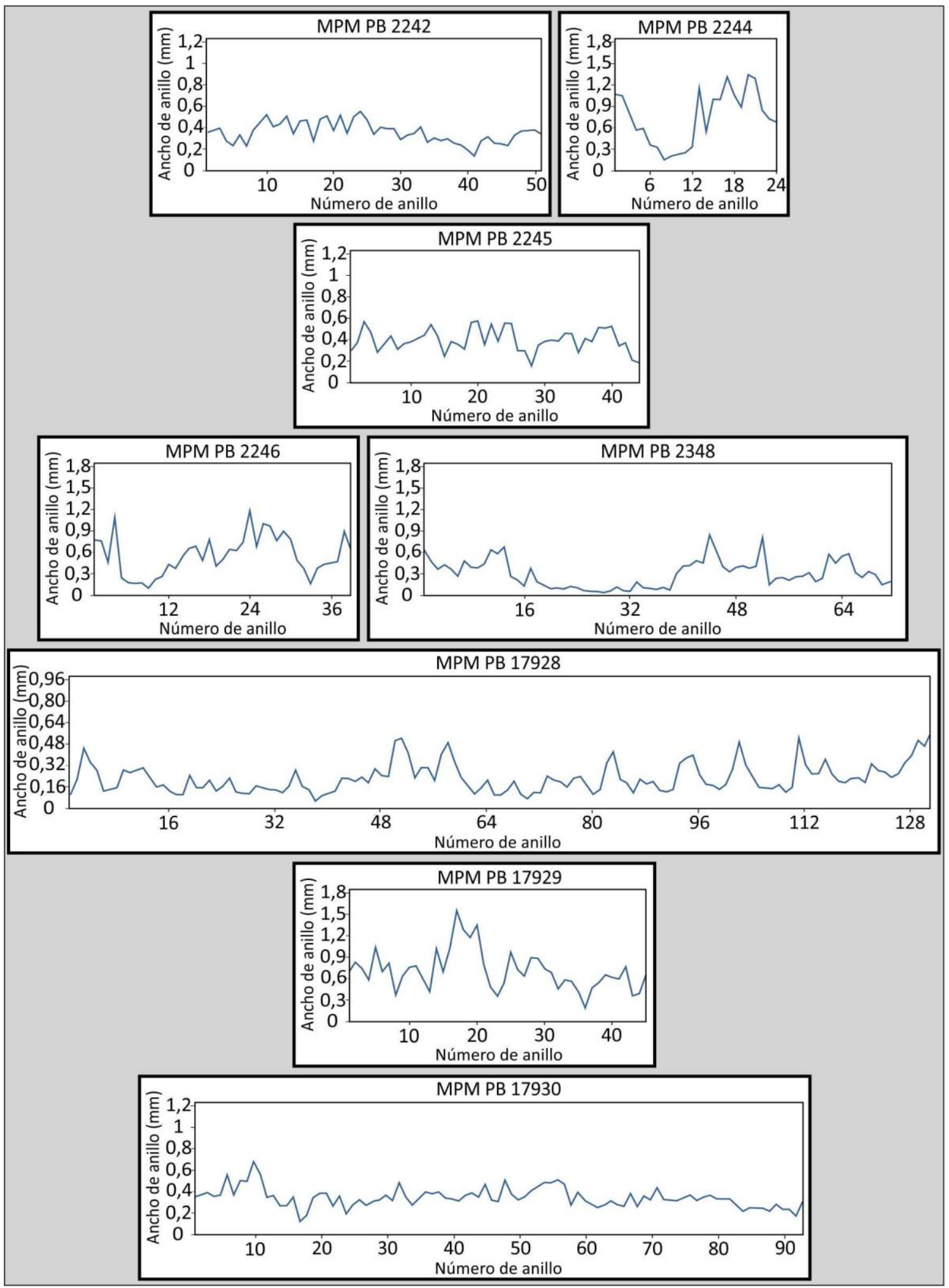

Fig. 4.31. Curvas de espesores de los anillos de crecimiento analizados del miembro superior de la Fm. Río Turbio. Todos correspondientes a Phyllocladoxylon sp. A.

Los anillos no llegan a ser muy anchos, siendo la media $0,46(0,23-0,74) \mathrm{mm}$, el anillo más angosto es de apenas 0,04 mm y el más ancho de 1,55 mm (Tabla 4.19 y Fig. 
4.31). Estos valores en los anillos indicarían que el crecimiento de los troncos era lento lo que puede deberse a factores ambientales poco favorables.

La sensibilidad anual arrojó valores entre 0,01-1,01 y la sensibilidad media 0,28 (Tabla 4.19 y Fig. 4.32). Esto indica que los leños eran complacientes con algún evento climático extremo aislado.

En tres de las secuencias de anillos analizadas en Phyllocladoxylon sp. A (MPM PB 2244, 17929, 17930) del miembro superior se observaron falsos anillos (Tabla 4.19 y Fig. 4.30 B-E).

El ejemplar MPM PB 2258 (Phyllocladoxylon sp. A), tiene anillos que superan las 30 células de espesor $y$, por consiguiente, se pudieron aplicar los análisis de hábito foliar propuestos por Falcon-Lang (2000a, b). El ejemplar cuenta con $20 \%$ de leño tardío, $76 \%$ de porcentaje de disminución y $15,20 \%$ de índice de demarcación de anillo (Tabla 4.20). Estos valores son similares a los del actual Cedrus libani que tiene una retención foliar de tres a seis años (Falcon-Lang 2000a). El porcentaje de skew de 60 (Tabla 4.20) se corresponde con las actuales Araucaria araucana (3-15 años) (FalconLang 2000b). Por lo tanto, estos resultados permiten inferir que se trataría de una especie perennifolia con una retención foliar de tres a seis años. 


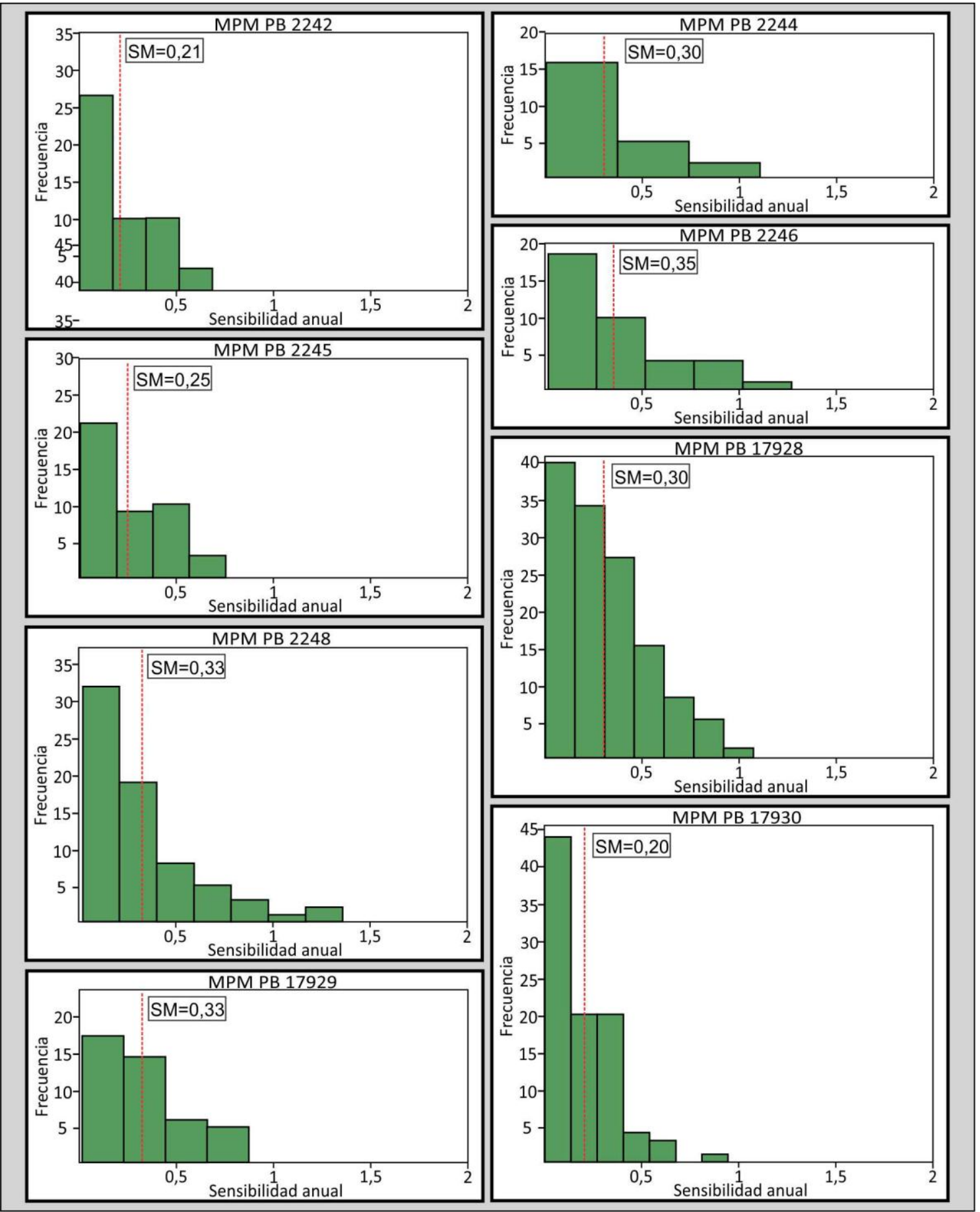

Fig. 4.32. Histogramas de Sensibilidad Anual (SA) de las muestras del miembro superior de la Fm. Río Turbio. La línea punteada en rojo indica la Sensibilidad Media (SM). Todos los ejemplares corresponden a Phyllocladoxylon sp. A. 


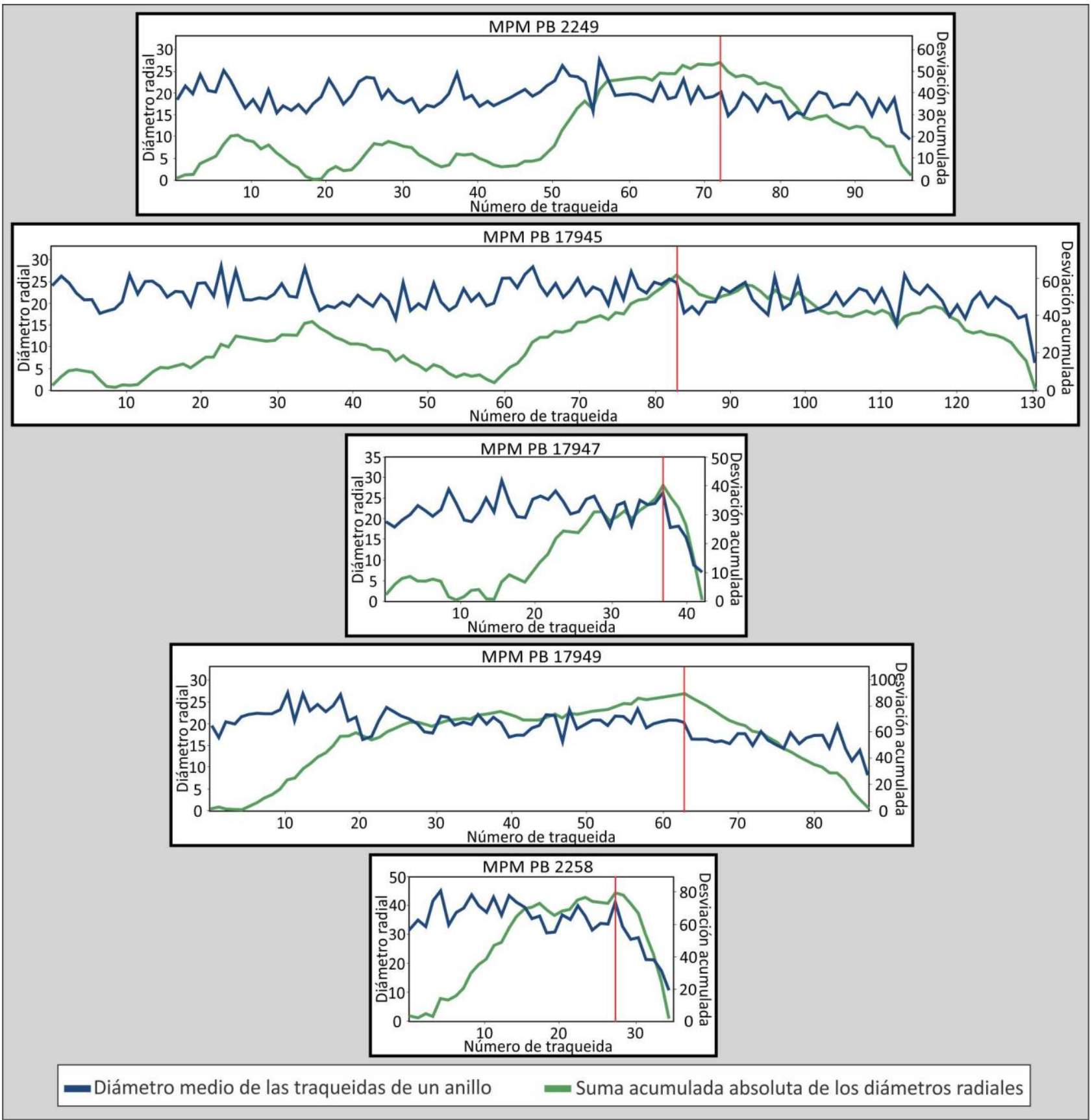

Fig. 4.33. Curvas CSDM. Podocarpoxylon multiparenchymatosum (MPMPB 2249, 17945, 17947, 17949) (miembro inferior); Phyllocladoxylon sp. A (MPMPB 2258) (miembro superior).

\begin{tabular}{|cccccc|}
\hline Ejemplar & \% leño temprano & \% de leño tardío & Skew & \% de disminución & RMI \\
\hline MPMPB 2249 & $92,86 \%$ & $7,14 \%$ & $48,98 \%$ & 66,01 & 4,71 \\
\hline MPMPB 17945 & $94,62 \%$ & $5,38 \%$ & $27,69 \%$ & $77,04 \%$ & 4,15 \\
\hline MPMPB 17947 & $88,10 \%$ & $11,90 \%$ & $76,19 \%$ & $75,63 \%$ & 9 \\
\hline MPMPB 17949 & $72,41 \%$ & $27,59 \%$ & $44,83 \%$ & $70,81 \%$ & 19,53 \\
\hline MPMPB 2258 & $80 \%$ & $20 \%$ & $60 \%$ & $76 \%$ & 15,20 \\
\hline
\end{tabular}

Tabla 4.20: resumen de los datos tomados de los anillos de crecimiento. Podocarpoxylon multiparenchymatosum (MPMPB 2249, 17945, 17947, 17949) (miembro inferior); Podocarpoxylon sp. A (MPMPB 2258) (miembro superior). 


\section{4. Índices de Vulnerabilidad y Mesomorfía}

Al igual que con las ecuaciones de Wiemann et al. $(1998,1999)$, los índices de vulnerabilidad y mesomorfía prácticamente no pudieron ser aplicados dado el estado de preservación de los ejemplares. Solo en el caso de Nothofagoxylon sp. 1 (miembro inferior de la formación) se pudo obtener medidas de los tres caracteres necesarios. Los resultados indican que se trataba de una especie mesomórfica, es decir que contaba con abundante aporte hídrico para su desarrollo (Tabla 4.21).

Diam. vasos № vasos por $\mathrm{mm}^{2}$ Largo elem. de vasos Vulnerabilidad Mesomorfía

\begin{tabular}{llllll}
$\begin{array}{l}\text { Nothofagoxylon } \\
\text { sp. } 1\end{array}$ & 72 & 31 & 371 & 2,32 & 11501 \\
\hline
\end{tabular}

Tabla 4.21: Datos utilizados para calcular el índice de vulnerabilidad y el de mesomorfía. Medidas en $\mu \mathrm{m}$.

\subsection{Método del Coexistence Approach (CA) o del pariente vivo más cercano}

Nuevamente, la aplicación de este método se vio limitada en parte por la mala preservación del material que impidió establecer una similitud estrecha con los taxones actuales que indicaran algún tipo de parentesco. Por otro lado, al separar los taxones según los miembros, la diversidad presente se ve muy disminuida, contando en el miembro inferior con cinco taxones y en el superior con cuatro. Además, los parientes cercanos relacionados con las coníferas tienen una gran plasticidad en cuanto a tolerancias tanto de temperatura como de humedad.

\subsection{Caracteres eco-xilológicos}

La mayoría de las angiospermas leñosas de la formación fueron colectadas en el miembro inferior (Caldcluvioxylon sp., Xilotipo 4, y aff. Nothofagoxylon sp. 1) siendo la especie aff. Nothofagoxylon sp. 2 la única angiosperma correspondiente al miembro superior.

\section{Miembro inferior:}

Ninguno de los ejemplares presenta porosidad circular, ni vasos con patrones oblicuo o dendrítico, caracteres asociados actualmente a climas templados a subtropicales. Hay que tener en cuenta que la porosidad circular es un carácter que aparece en el Eoceno y aún hasta la actualidad sigue siendo poco común en las 
maderas nativas del Hemisferio Sur (Wheeler \& Baas, 1991, 1993; Wheeler et al., 2007; Baas \& Wheeler, 2011).

Los tres taxones de angiospermas tienen vasos con un diámetro de 50 a $70 \mu \mathrm{m}$, llegando a superar los $100 \mu \mathrm{m}$ en algunos casos (Xilotipo 4 y aff. Nothofagoxylon sp. 1). Dado que los vasos anchos $(>100 \mu \mathrm{m})$ son indicativos de zonas templado-cálidas (Baas \& Xinying, 1986; Schweingruber, 1988; Wheeler \& Baas, 1991, 1993; Carlquist, 2001; Wheeler et al., 2007; Baas \& Wheeler, 2011; Morris et al., 2018), estos valores sugerirían temperaturas mesotérmicas.

En cuanto a la densidad de vasos, ésta es muy baja en las tres especies, no superando en promedio los 35 vasos por $\mathrm{mm}^{2}$. Esto puede estar relacionado con altas temperaturas o con una gran disponibilidad de agua (Van der Graaff \& Baas, 1974; Baas \& Xinying, 1986; Schweingruber, 1988; Wheeler \& Baas, 1991, 1993; Baas \& Wheeler, 2011).

Calcluvioxylon sp. tiene placas de perforación escalariformes con numerosas barras, mientras que las otras dos especies (Nothofagoxylon sp. 1 y el Xilotipo 4) parecieran tener placas simples. Según varios autores las placas escalariformes de dan habitualmente en lugares tanto templado-fríos hasta polares, como así también en zonas tropicales de alta montaña, hallándose en menor medida en zonas templadas y áridas (Baas \& Schweingruber, 1987; Wheeler \& Baas, 1991, 1993; Baas, 1982; Wheeler et al., 2007). Baas (1982) sugiere que cuanto más seco es el ambiente menor es el número de barras de las placas, mientras que Carlquist (2012) afirma que las placas escalariformes se dan en lugares con humedad estable.

Otros caracteres tales como, engrosamientos espiralados o punteaduras ornadas no se observan en ninguno de los taxones. Dichos caracteres son comunes en climas templado-fríos o en zonas secas (Van der Graaff \& Baas, 1974; Baas \& Xinying, 1986; Baas \& Schweingruber, 1987; Wheeler \& Baas, 1991, 1993; Wheeler et al., 2007; Carlquist, 2001, 2012).

Las areolas en las fibras son menores o están ausentes en lugares secos (Carlquist, 2001), por lo que la presencia de las mismas en Caldcluvioxylon sp. sería un indicador de condiciones más húmedas. Lamentablemente la preservación de las otras 
dos especies no es lo suficientemente buena para determinar si había fibras de punteaduras areoladas.

El escaso parénquima axial observado señala que las temperaturas no eran muy altas (Schweingruber, 1988; Wheeler \& Baas, 1991; Wheeler et al., 2007; Soffiatti et al. 2016; Morris et al., 2018).

No se observaron cristales, cuya presencia aumenta desde climas templados a más tropicales y es mayor en condiciones xéricas (Wheeler et al., 2007).

\section{Miembro superior:}

La única especie descripta de este miembro tampoco presenta porosidad circular o patrones elaborados de distribución de vasos (como ser el dendrítico o el oblicuo), siendo que ambos caracteres son indicadores de altas temperaturas (Wheeler \& Baas, 1991, 1993; Wheeler et al., 2007; Baas \& Wheeler, 2011).

El diámetro de los elementos de vaso del Nothofagoxylon sp. 2 fue de los más bajos registrados, con una media que no supera los $50 \mu \mathrm{m}$ y con valores máximos que no superan los $70 \mu \mathrm{m}$. Estos valores son menores que los de las especies del miembro inferior y notablemente menores que los de las especies paleocenas. Siendo que mayores tamaños de vasos indican mayores temperaturas (Baas \& Xinying, 1986; Schweingruber, 1988; Wheeler \& Baas, 1991, 1993; Carlquist, 2001; Wheeler et al., 2007; Baas \& Wheeler, 2011; Morris et al., 2018), estos pequeños tamaños indicarían un clima probablemente microtérmico.

La densidad de vasos es muy baja, de tan solo 35 vasos por $\mathrm{mm}^{2}$. Como se citó anteriormente, esta proporción se relaciona con altas temperaturas o con una gran disponibilidad de agua (Van der Graaff \& Baas, 1974; Baas \& Xinying, 1986, Schweingruber, 1988; Wheeler \& Baas, 1991, 1993; Baas \& Wheeler, 2011).

Tampoco se observan en el taxón del miembro superior caracteres comunes de climas templado-fríos o de zonas secas, como ser los engrosamientos espiralados y las punteaduras ornadas (Van der Graaff \& Baas, 1974; Baas \& Xinying, 1986; Baas \& Schweingruber, 1987; Wheeler \& Baas, 1991, 1993; Wheeler et al., 2007; Carlquist, 2001, 2012). Hay que tener en cuenta que el estado de preservación de este ejemplar 
no es bueno y la aparente ausencia de dichos caracteres podría ser por la preservación. Lo mismo ocurre con la ausencia de fibrotraqueidas o de fibras septadas, ambos caracteres comunes de climas actualmente tropicales (Baas \& Schweingruber, 1987; Schweingruber, 1988; Wheeler \& Baas, 1991; Carlquist, 2001; Wheeler et al., 2007).

Tampoco se observa correctamente el grosor de la pared de las fibras (indicador de sequía sensu Baas \& Wheeler, 2011), ni el parénquima axial (indicador de temperaturas sensu Schweingruber, 1988; Wheeler \& Baas, 1991; Wheeler et al., 2007; Soffiatti et al. 2016; Morris et al., 2018).

Al igual que en el miembro inferior, no se observaron cristales, cuya presencia como se indicó se incrementa desde climas templados a más tropicales y es mayor aún en lugares xéricos (Wheeler et al., 2007). 


\section{FORMACIÓN RÍO GUILLERMO}

Los materiales de la Formación Río Guillermo no cuentan con una buena preservación. La mayoría del material solo puede ser identificado a grandes rasgos como angiospermas o coníferas según la presencia o no de vasos, pero en otros casos ni siquiera se llega a ese punto (ver apéndice). Los únicos taxones que lograron ser claramente identificados fueron Agathoxylon y dos especies de Nothofagoxylon ( $N$. scalariforme Gothan y N. kraeuseli Boureau et Salard). Debido a la mala preservación de la mayor parte del material, sumado a la baja diversidad de aquellos que sí pudieron ser descriptos e identificados previamente (Pujana, 2008), no fue posible aplicar la mayoría de los métodos propuestos en la presente tesis. Por tal motivo, solo se estudiaron los anillos de crecimiento, el índice de vulnerabilidad y mesomorfía y se tuvieron consideraciones generales de las tres especies reconocidas.

\subsection{Anillos de crecimiento}

\begin{tabular}{|lccccccccc|}
\hline Ejemplar & $\begin{array}{c}\text { № } \\
\text { anillos }\end{array}$ & $\begin{array}{c}\text { № } \\
\text { falsos } \\
\text { anillos }\end{array}$ & $\begin{array}{c}\text { № anillos } \\
\text { de } \\
\text { heladas }\end{array}$ & $\begin{array}{c}\text { Ancho } \\
\text { medio }\end{array}$ & $\begin{array}{c}\text { Ancho } \\
\text { máx. }\end{array}$ & $\begin{array}{c}\text { Ancho } \\
\text { mín. }\end{array}$ & $\begin{array}{c}\text { Desv. } \\
\text { Est. }\end{array}$ & SA & SM \\
\hline MPM PB-2279 & 20 & 0 & 0 & 0,64 & 0,81 & 0,39 & 0,10 & $0,02-0,67$ & 0,18 \\
\hline MPM PB-2285 & 12 & 0 & 0 & 1,47 & 2,40 & 0,38 & 0,62 & $0,06-1,12$ & 0,41 \\
\hline MPM PB-2286 & 16 & 0 & 0 & 1,92 & 3,25 & 1,19 & 0,56 & $0,02-0,83$ & 0,30 \\
\hline MPM PB-2288 & 5 & 0 & 0 & 3,31 & 5,15 & 2,02 & 1,16 & --- & --- \\
\hline MPM PB-2289 & 15 & 0 & 0 & 1,39 & 2,03 & 0,92 & 0,38 & $0,01-0,60$ & 0,23 \\
\hline MPM PB-2297 & 14 & 0 & 0 & 1,27 & 1,79 & 0,63 & 0,37 & $0-0,95$ & 0,33 \\
\hline MPM PB-2324 & 16 & 0 & 0 & 1,35 & 2,17 & 0,35 & 0,55 & $0,05-1,08$ & 0,43 \\
\hline MPM PB-2342 & 33 & 0 & 0 & 0,35 & 0,88 & 0,14 & 0,19 & $0-1,22$ & 0,43 \\
\hline MPM PB-2345 & 16 & 0 & 0 & 0,85 & 1,18 & 0,36 & 0,24 & $0,01-0,85$ & 0,38 \\
\hline MPM PB-2346 & 12 & 0 & 0 & 0,77 & 1,34 & 0,39 & 0,29 & $0,01-0,48$ & 0,26 \\
\hline MPM PB-2349 & 34 & 0 & 0 & 0,64 & 1,65 & 0,20 & 0,35 & $0,03-0,65$ & 0,27 \\
\hline MPM PB-2352 & 25 & 0 & 0 & 1,07 & 1,78 & 0,30 & 0,35 & $0,01-1,02$ & 0,28 \\
\hline MPM PB 17957 & 12 & 0 & 0 & 1,98 & 2,86 & 1,21 & 0,53 & $0,07-0,81$ & 0,25 \\
\hline MPM PB 17959 & 4 & 0 & 0 & 4,38 & 5,91 & 3,46 & 1,10 & --- & --- \\
\hline Promedio & & & & 1,53 & 2,37 & 0,85 & 0,48 & $0,02-0,86$ & 0,31 \\
\hline
\end{tabular}

Tabla 4.22: datos de los anillos de crecimiento medidos. Valores de ancho en $\mathrm{mm}$.

Agathoxylon sp. A (MPM PB 2279); Nothofagoxylon sp. (MPM PB 2285, 2286, 2289, 2346,

17957); Conífera indet. (MPM PB 2297); Nothofagoxylon scalariforme (MPM PB 2324); Nothofagoxylon kraeuseli (MPM PB 2342). Angiosperma indet; (MPM PB 2345, 2349, 2352). 

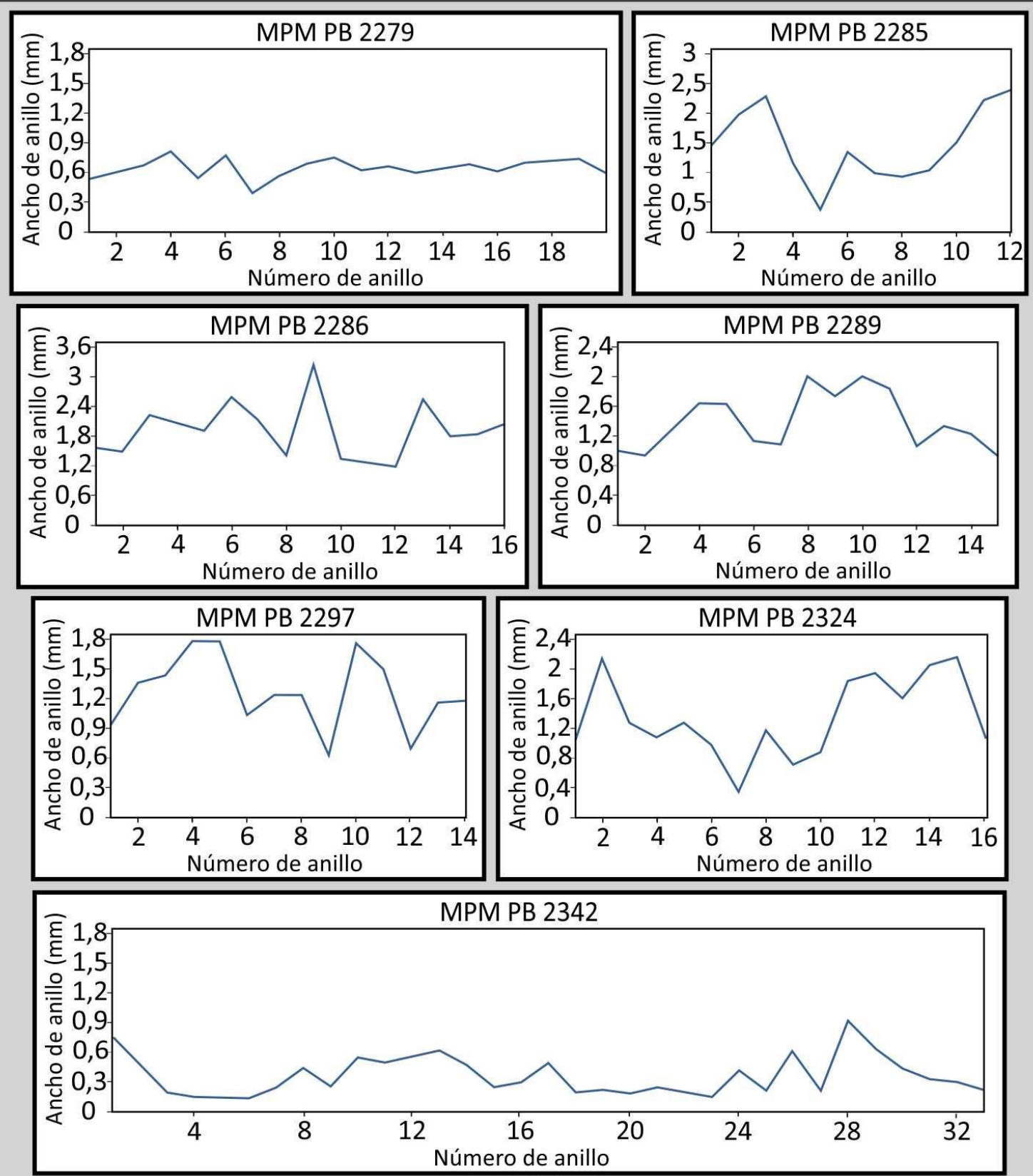

Fig. 4.34. Curvas de espesores de los anillos de crecimiento analizados en la Fm. Río Guillermo. Agathoxylon sp. A (MPM PB 2279); Nothofagoxylon sp. (MPM PB 2285, 2286, 2289); Conífera indet. (MPM PB 2297); Nothofagoxylon scalariforme (MPM PB 2324); Nothofagoxylon kraeuseli (MPM PB 2342).

Se midieron 14 secuencias de entre 4 y 34 anillos, sumando 234 anillos en total. Las dos secuencias con menos de 10 anillos solo se incluyeron para los cálculos estadísticos generales ya que presentan los anillos más anchos, pero no se las utilizó para el cálculo de sensibilidad anual y media (Tabla 4.22). En Agathoxylon sp. y las gimnospermas indeterminadas los anillos están demarcados por la disminución del diámetro radial las últimas hileras de traqueidas. En el caso de los ejemplares de 
Nothofagoxylon, los anillos están marcados por el menor diámetro radial de las fibras y también por la reducción gradual en el tamaño de los elementos de vaso. El ancho promedio es de $1,56(0,64-4,38) \mathrm{mm}$, siendo el más angosto de $0,14 \mathrm{~mm}$ y el más ancho de 5,91 mm (Tabla 4.22 y Figs. 4.34 y 4.35 ).

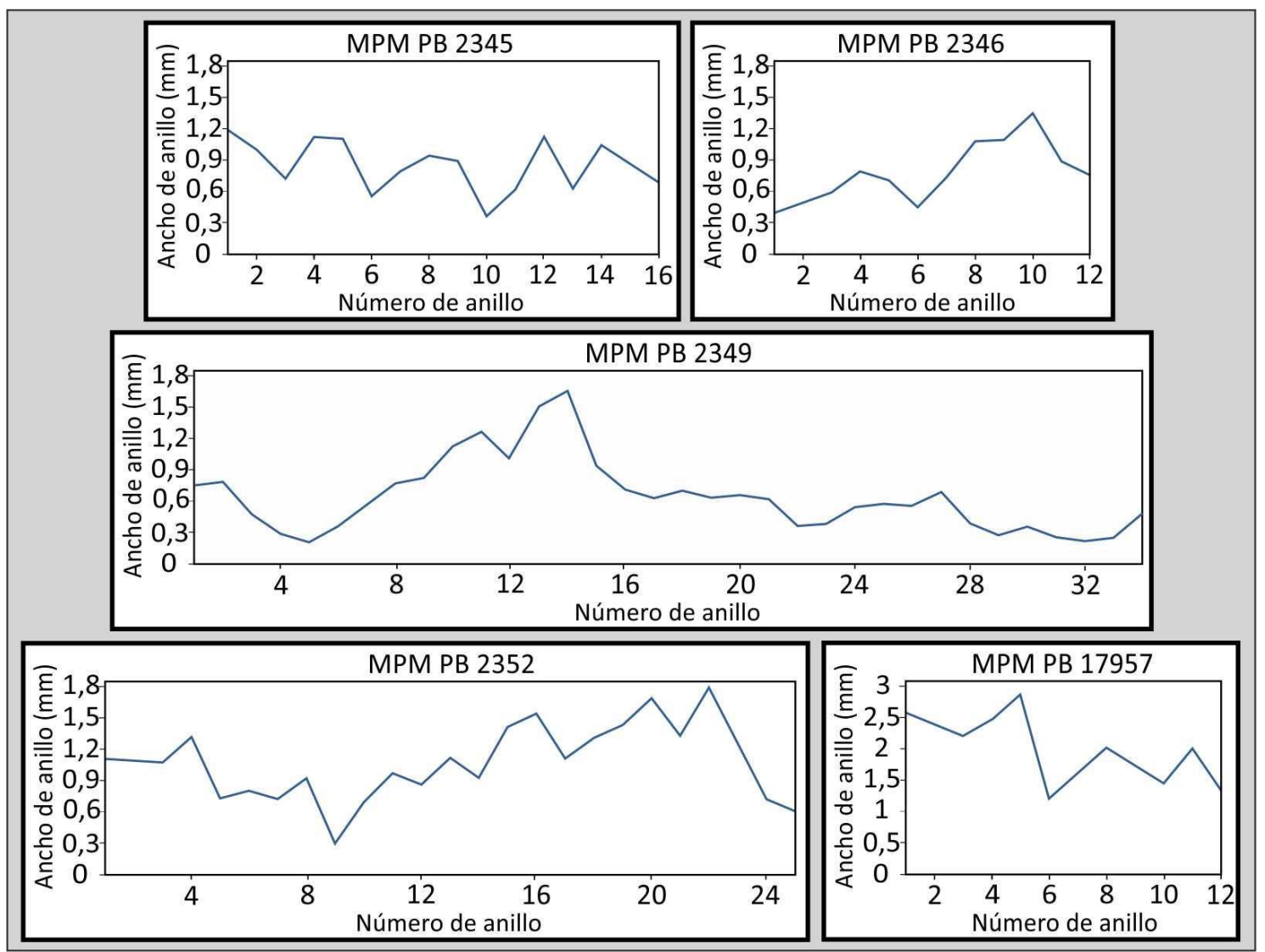

Fig. 4.35. Curvas de espesores de los anillos de crecimiento analizados en la Fm. Río Guillermo. Angiosperma indet. (MPM PB 2345, 2349, 2352); Nothofagoxylon sp. (MPM PB 2346, 17957).

No se registraron falsos anillos, ni anillos de heladas, por lo que se infiere que no habría habido grandes perturbaciones climáticas y/o ambientales.

La SA mostró valores entre 0-1,22, uniformemente distribuidos alrededor de la media por lo que no se habrían detectado eventos climáticos extremos (Tabla 4.22 y Figs. 4.36 y 4.37). La SM promedio es de 0,31 , con valores entre 0,18 y 0,43 . Dado que la mitad son sensitivos y la mitad complacientes, estaríamos ante un ambiente con áreas más protegidas con microclimas más uniformes y áreas más expuestas y extremadamente sensibles a los abruptos cambios (Tabla 4.22 y Figs. 4.36 y 4.37 ). 

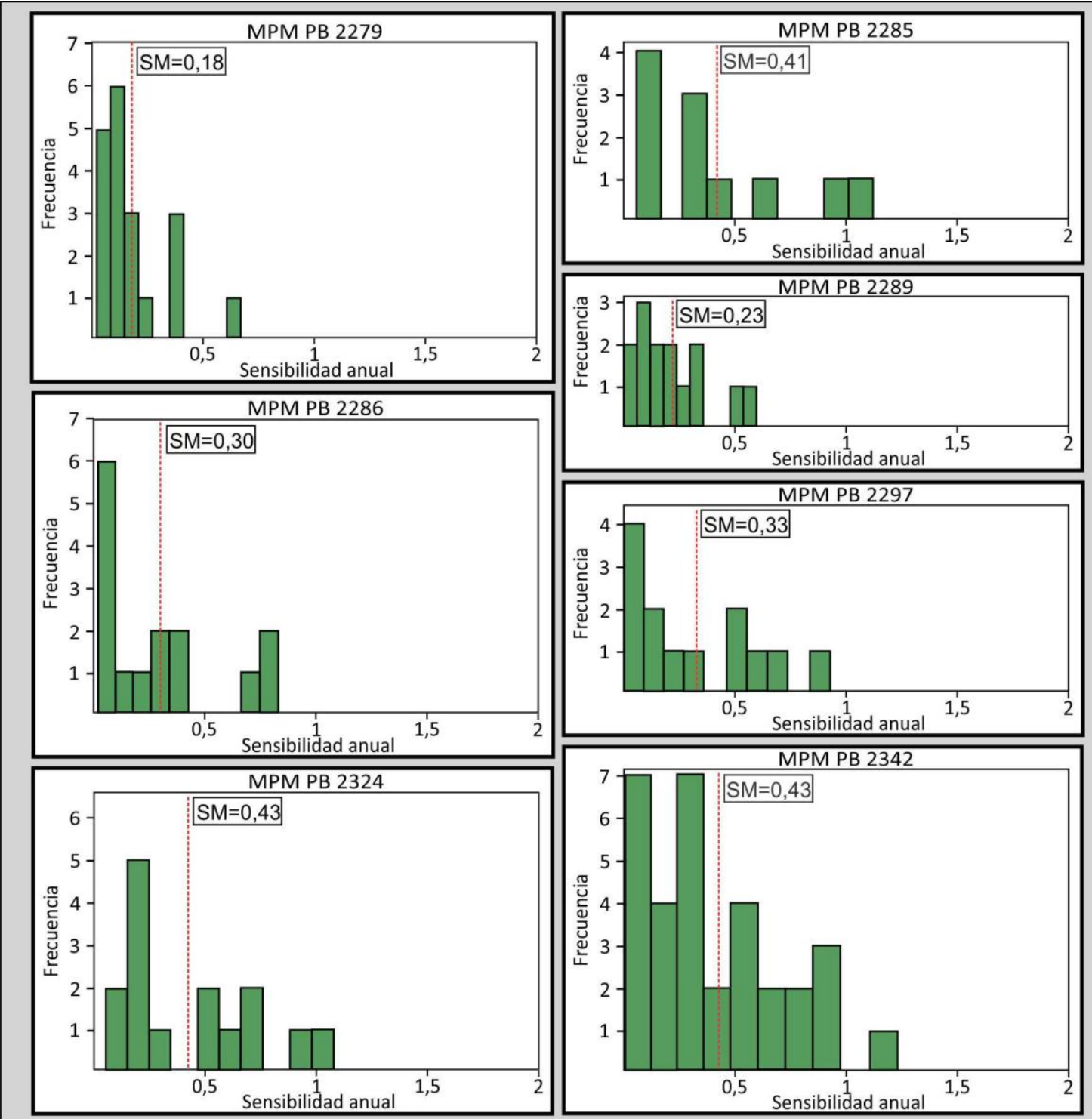

Fig. 4.36. Histogramas de Sensibilidad Anual (SA) de las muestras de la Fm. Río Guillermo. Las líneas punteadas en rojo indican la Sensibilidad media (SM). Agathoxylon sp. A (MPM PB 2279); Nothofagoxylon sp. (MPM PB 2285, 2286, 2289); Conifera indet. (MPM PB 2297); Nothofagoxylon scalariforme (MPM PB 2324); Nothofagoxylon kraeuseli (MPM PB 2342).

No se registraron leños gimnospérmicos con anillos de más de 30 células de espesor o que las mismas estuvieran lo suficientemente bien preservadas como para graficar curvas CSDM. Por consiguiente no se pudo identificar el tipo de anillo según Creber \& Chaloner (1984b) ni aplicar los cálculos de hábito foliar de Falcon-Lang (2000a, b). 


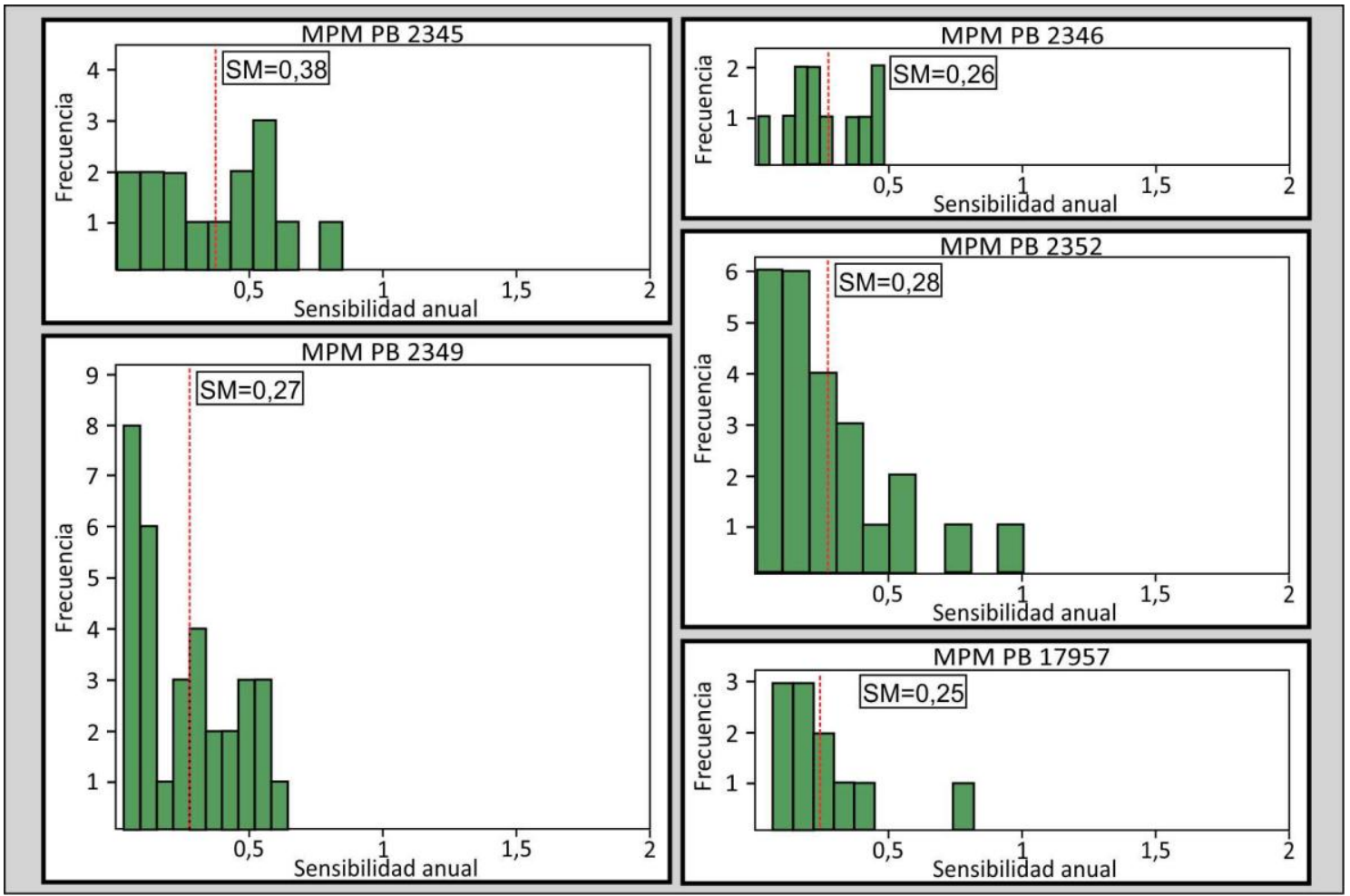

Fig. 4.37. Histogramas de Sensibilidad Anual (SA) de las muestras de la Fm. Río Guillermo. Las líneas punteadas en rojo indican la Sensibilidad media (SM). Angiosperma indet. (MPM PB 2345, 2349, 2352); Nothofagoxylon sp. (MPM PB 2346, 17957).

\section{2. Índices de Vulnerabilidad y Mesomorfía}

Tanto el índice de vulnerabilidad como el de mesomorfía arroja valores muy bajos en las dos especies identificadas, esto indicaría que el agua no era abundante en la zona y las plantas habrían estado adaptadas para sufrir sequías (Tabla 4.23).

\begin{tabular}{|lccccc|} 
& $\begin{array}{c}\text { Diám. } \\
\text { vasos }\end{array}$ & $\begin{array}{c}\text { № vasos por } \\
\mathrm{mm}^{2}\end{array}$ & $\begin{array}{r}\text { Largo de elem. } \\
\text { de vasos }\end{array}$ & Vulnerabilidad & Mesomorfía \\
\hline $\begin{array}{l}\text { Nothofagoxylon } \\
\text { scalariforme }\end{array}$ & 53 & 178 & 143 & 0,3 & 42,58 \\
\hline $\begin{array}{l}\text { Nothofagoxylon } \\
\text { kraeuseli }\end{array}$ & 56 & 137 & 207 & 0,4 & 84,61 \\
\hline
\end{tabular}

Tabla 4.23: datos utilizados para calcular los índices de vulnerabilidad y de mesomorfía. Medidas en $\mu \mathrm{m}$.

\subsection{Consideraciones generales}

Las escasas especies identificadas en la Fm. Guillermo se corresponden con algunas de las encontradas en la Fm. Río Leona (ver a continuación). La concordancia en cuanto a ubicación espacio temporal de ambas formaciones y la coincidencia en el registro fósil (ver más adelante), hace pensar que se trataba de una misma flora donde los elementos dominantes eran Nothofagaceae acompañadas de coníferas. 
También es de destacar que estas floras tienen una gran similitud con los bosques andino-patagónicos actuales, los cuales están restringidos a la porción montañosa cordillerana y zonas aledañas de la Patagonia, en donde habitan varias especies de Nothofagus, relacionadas con las especies fósiles de Nothofagoxylon y también de Araucaria araucana afín a las especies fósiles de Agathoxylon. 


\section{FORMACIÓN RÍO LEONA}

El material proveniente de la Formación Río Leona comprende coníferas y diversas angiospermas, cuya anatomía y sistemática fue estudiada previamente por Pujana (Pujana 2007, 2008, 2009a, b) (Tabla 4.24).

\begin{tabular}{|l|l|}
\hline \multirow{5}{*}{ Gimnospermas } & Agathoxylon sp. \\
\cline { 2 - 2 } & Podocarpoxylon sp. A \\
\hline \multirow{5}{*}{ Angiospermas } & Scalarixylon patagonicum Pujana \\
\cline { 2 - 2 } & Scalarixylon grandiradiatum Pujana \\
\cline { 2 - 2 } & Maloidoxylon cesariae Pujana \\
\cline { 2 - 2 } & Nothofagoxylon scalariforme Gothan \\
\cline { 2 - 2 } & Nothofagoxylon triseriatum Torres et Lemoige \\
\cline { 2 - 2 } & Nothofagoxylon kraeuseli Boureau et Salard \\
\cline { 2 - 2 } & Nothofagoxylon ruei Salard \\
\cline { 2 - 2 } & Nothofagoxylon aggregatum Pujana \\
\cline { 2 - 2 } & Myrceugenellites oligocenum Pujana \\
\cline { 2 - 2 } & Laurelites doroteaensis Nishida, H. Nishida et Nasa. \\
\cline { 2 - 2 } & Doroteoxylon vicente-perezii Nishida, H. Nishida et Oshawa \\
\cline { 2 - 2 } & Resinaxylon schinusoides Pujana \\
\cline { 2 - 2 } & Xilotipo 3 de Pujana 2008 \\
\hline
\end{tabular}

Tabla 4.24: lista de taxones analizados.

\subsection{Ecuaciones propuestas por Wiemann et al. $(1998,1999)$}

En este caso, al tratarse de una formación relativamente reciente (Mioceno), ya se encontraban presentes todos los caracteres anatómicos que encontramos en la actualidad necesarios para aplicar todas las ecuaciones propuestas por Wiemann et al. $(1998,1999)$ (Tabla 4.25). Los resultados son detallados a continuación en la tabla 4.26 . 


\begin{tabular}{|c|c|c|c|c|c|c|c|c|c|c|c|c|c|}
\hline & \multicolumn{13}{|c|}{ Caracteres anatómicos de la madera } \\
\hline & $\operatorname{tang}$ & RP & mult & spir & $\begin{array}{l}<100 \\
\text { um }\end{array}$ & sept & $>10$ ser & het4+ & homo & stor & abs & marg & para \\
\hline $\begin{array}{l}\text { Scalarixylon } \\
\text { patagonicum }\end{array}$ & 1 & 0 & 0 & 0 & 1 & 0 & 1 & 0 & 0 & 0 & 0 & 0 & 1 \\
\hline $\begin{array}{l}\text { Scalarixylon } \\
\text { grandiradiatum }\end{array}$ & 1 & 0 & 0 & 0 & 1 & 0 & 1 & 0 & 1 & 0 & 0 & 0 & 1 \\
\hline $\begin{array}{l}\text { Maloidoxylon } \\
\text { cesariae }\end{array}$ & 0 & 0 & 0 & 0 & 1 & 0 & 0 & 0 & 0 & 0 & 0 & 0 & 0 \\
\hline $\begin{array}{l}\text { Nothofagoxylon } \\
\text { scalariforme }\end{array}$ & 0 & 0 & 0,5 & 0 & 1 & 0 & 0 & 0 & 0 & 0 & 1 & 0 & 0 \\
\hline $\begin{array}{l}\text { Nothofagoxylon } \\
\text { triseriatum }\end{array}$ & 0 & 0 & 0,5 & 0 & 1 & 0 & 0 & 0 & 0 & 0 & 1 & 0 & 0 \\
\hline $\begin{array}{l}\text { Nothofagoxylon } \\
\text { kraeuseli }\end{array}$ & 0 & 0 & 0,5 & 0 & 1 & 0 & 0 & 0 & 0 & 0 & 1 & 0 & 0 \\
\hline $\begin{array}{l}\text { Nothofagoxylon } \\
\text { ruei }\end{array}$ & 0 & 0 & 0 & 0 & 1 & 0 & 0 & 0 & 0 & 0 & 1 & 0 & 0 \\
\hline $\begin{array}{l}\text { Nothofagoxylon } \\
\text { aggregatum }\end{array}$ & 0 & 0 & 0 & 0 & 1 & 0 & 0 & 0 & 0 & 0 & 1 & 0 & 0 \\
\hline $\begin{array}{l}\text { Myrceugenellites } \\
\text { oligocenum }\end{array}$ & 0 & 0 & 1 & 0 & 1 & 1 & 0 & 0 & 0 & 0 & 1 & 0 & 0 \\
\hline $\begin{array}{l}\text { Laurelites } \\
\text { doroteaensis }\end{array}$ & 0 & 0 & 1 & 0 & 1 & 0 & 0 & 0 & 0 & 0 & 0 & 0 & 0 \\
\hline $\begin{array}{l}\text { Doroteoxylon } \\
\text { vicente-perezii }\end{array}$ & 1 & 1 & 0 & 1 & --- & 1 & 1 & 0 & 0 & 0 & 0 & 0 & 1 \\
\hline $\begin{array}{l}\text { Resinaxylon } \\
\text { schinusoides }\end{array}$ & 0 & 0 & 0 & 0 & 1 & 1 & 0 & 0 & 0 & 0 & 1 & 0 & 1 \\
\hline Xylotipo 3 & 1 & 0 & 0 & 1 & 0 & 0 & 0 & 0 & 0 & 0 & 0 & 0 & 1 \\
\hline
\end{tabular}

Tabla 4.25: matriz de datos empleada para aplicar las ecuaciones de Wiemann et al. (1998, 1999).

\begin{tabular}{|c|c|c|c|}
\hline Ecuación & Resultado & Ecuación & Resultado \\
\hline MAT & $4,96{ }^{\circ} \mathrm{C}$ & $\mathbf{7}$ & $8,74{ }^{\circ} \mathrm{C}$ \\
\hline MART & $18,72{ }^{\circ} \mathrm{C}$ & $\mathbf{8}$ & $28,21^{\circ} \mathrm{C}$ \\
\hline CMMT & $-6,86^{\circ} \mathrm{C}$ & $\mathbf{9}$ & $-1,18^{\circ} \mathrm{C}$ \\
\hline MAP & $525,77 \mathrm{Cm}$ & $\mathbf{1 0}$ & $21,70{ }^{\circ} \mathrm{C}$ \\
\hline DRY & $-1,17$ meses & $\mathbf{1 1}$ & $25,30{ }^{\circ} \mathrm{C}$ \\
\hline $\mathbf{1}$ & $14,40^{\circ} \mathrm{C}$ & $\mathbf{1 2}$ & $22,84^{\circ} \mathrm{C}$ \\
\hline $\mathbf{2}$ & $21,31^{\circ} \mathrm{C}$ & $\mathbf{1 3}$ & $16,16^{\circ} \mathrm{C}$ \\
\hline $\mathbf{3}$ & $3,92{ }^{\circ} \mathrm{C}$ & $\mathbf{1 4}$ & $28,2{ }^{\circ} \mathrm{C}$ \\
\hline $\mathbf{4}$ & $11,50^{\circ} \mathrm{C}$ & $\mathbf{1 5}$ & $15,60{ }^{\circ} \mathrm{C}$ \\
\hline $\mathbf{5}$ & $22,95^{\circ} \mathrm{C}$ & $\mathbf{1 6}$ & $8,13^{\circ} \mathrm{C}$ \\
\hline $\mathbf{6}$ & $6,14{ }^{\circ} \mathrm{C}$ & & \\
\hline
\end{tabular}

Tabla 4.26: resultados de las ecuaciones propuestas por Wiemann et al. $(1998,1999)$.

\subsection{Anillos de crecimiento}

Un total de 140 secuencias de anillos fueron medidas, las más cortas de 4 anillos y las más largas de 84 anillos, sumando 681 anillos en total (Tabla 4.27). La sensibilidad anual y media solo se calculó para aquellas secuencias de más de 10 anillos, pero también se midieron secuencias más cortas para calcular el resto de los parámetros estadísticos, ya que estas secuencias cortas registraban los mayores espesores. 
Las dos especies de coníferas presentaban anillos, ambas con una transición gradual entre leño temprano y tardío, con 2 a 3 células de espesor en éstos últimos. En los anillos con más de 30 traqueidas de espesor fue posible aplicar el método propuesto por Creber \& Chaloner (1984b) obteniendo como resultado un $81 \%$ de leño temprano y un $19 \%$ de leño tardío (Tabla 4.28). En cuanto a las angiospermas los tipos de anillos varían ligeramente según el género: en las dos especies determinadas como Scalarixylon, los anillos están marcados por la reducción en la distancia entre bandas de vasos, un ligero ensanchamiento de los radios multiseriados y una leve reducción en el tamaño de vasos; mientras que en los ejemplares de Maloidoxylon, Myrceugellenites, Laurelites, Resinaxylon los anillos están marcados por el achatamiento radial de las ultimas 2-3 fibras; en los ejemplares asignados a Nothofagoxylon los anillos están marcados por el menor diámetro radial de las últimas fibras y también por la reducción gradual en el tamaño de los elementos de vaso (exceptuando en N. kraeuseli), siendo mayor el número de fibras de leño tardío en $N$. triseriatum (15-20). Los ejemplares de Doroteoxylon tienen porosidad circular con vasos grandes y solitarios en el leño temprano y agrupamiento de los vasos menores en el tardío, además hay una reducción en el diámetro radial en las últimas hileras de fibras.

En resumen, hay anillos en todos los taxones presentes y en la mayoría muy bien demarcados, indicando una clara estacionalidad. Analizando todos los anillos medidos se ve que el espesor medio promedio es de $1,2 \mathrm{~mm}$, mientras que el espesor mínimo promedio es de 0,6 $\mathrm{mm}$ y el espesor máximo promedio es de 2,1 $\mathrm{mm}$. El anillo más angosto es de 0,05 $\mathrm{mm}$ y el más ancho de $6,6 \mathrm{~mm}$, pero estos extremos son raros y la mayoría de los ejemplares se aproximan más a la media (Tabla 4.27).

La sensibilidad anual va entre 0 y 1,42 con un promedio de $0,02-0,91$. Esto señalaría que los eventos climáticos extremos eran relativamente comunes. La sensibilidad media promedio es de 0,27, con un mínimo de 0,08 y un máximo de 0,90. Si bien este promedio marca que los leños habrían sido complacientes, analizando los resultados de forma individual se aprecia que hay un importante número de ejemplares marcadamente sensitivos (Tabla 4.27). Los ejemplares con sensibilidades 
altas podrían reflejar que estos árboles crecieron cerca del borde los bosques o cerca de los límites climáticos determinados para su distribución.

\begin{tabular}{|c|c|c|c|c|c|c|c|c|c|}
\hline Ejemplar & $\begin{array}{c}\text { № } \\
\text { anillos }\end{array}$ & $\begin{array}{c}\text { № } \\
\text { falsos } \\
\text { anillos }\end{array}$ & $\begin{array}{c}\text { № anillos } \\
\text { de } \\
\text { heladas }\end{array}$ & $\begin{array}{l}\text { Ancho } \\
\text { medio }\end{array}$ & $\begin{array}{l}\text { Ancho } \\
\text { máx. }\end{array}$ & $\begin{array}{c}\text { Ancho } \\
\text { mín. }\end{array}$ & $\begin{array}{c}\text { Desv. } \\
\text { Est. }\end{array}$ & SA & SM \\
\hline MPM PB 1954 & 26 & 0 & 0 & 0,54 & 1,40 & 0,20 & 0,26 & $0-0,93$ & 0,37 \\
\hline MPM PB 1955 & 34 & 0 & 0 & 1,10 & 2,01 & 0,17 & 0,39 & $0-1,51$ & 0,26 \\
\hline MPM PB 1956 & 13 & 2 & 0 & 1,17 & 2,09 & 0,43 & 0,48 & $0,07-0,95$ & 0,48 \\
\hline MPM PB 1962 & 30 & 0 & 0 & 1,28 & 3,17 & 0,32 & 0,81 & $0,02-1,25$ & 0,46 \\
\hline MPM PB 1964 & 31 & 0 & 0 & 0,70 & 1,40 & 0,38 & 0,26 & $0-0,81$ & 0,29 \\
\hline MPM PB 1965 & 37 & 0 & 0 & 0,54 & 1,19 & 0,17 & 0,27 & $0,01-0,92$ & 0,34 \\
\hline MPM PB 1968 & 19 & 0 & 0 & 1,04 & 1,78 & 0,34 & 0,47 & $0,02-0,57$ & 0,20 \\
\hline MPM PB 1971 & 24 & 0 & 0 & 0,88 & 1,79 & 0,28 & 0,41 & $0,07-1,10$ & 0,43 \\
\hline MPM PB 1972 & 60 & 0 & 0 & 0,58 & 1,50 & 0,18 & 0,30 & $0,01-0,81$ & 0,26 \\
\hline MPM PB 1973 & 84 & 0 & 0 & 0,37 & 1,46 & 0,93 & 0,24 & $0,03-1,30$ & 0,51 \\
\hline MPM PB 1975 & 26 & 0 & 0 & 0,58 & 1,28 & 0,20 & 0,28 & $0,01-0,77$ & 0,33 \\
\hline MPM PB 1977 & 27 & 0 & 0 & 1,12 & 2,17 & 0,69 & 0,28 & $0-0,72$ & 0,23 \\
\hline MPM PB 1979 & 66 & 0 & 0 & 0,33 & 0,78 & 0,12 & 0,16 & $0-1,16$ & 0,29 \\
\hline MPM PB 1980 & 26 & 0 & 0 & 1,36 & 3,34 & 0,13 & 1,05 & $0,03-1,72$ & 0,54 \\
\hline MPM PB 1983 & 27 & 0 & 0 & 0,75 & 1,12 & 0,46 & 0,18 & $0-0,38$ & 0,16 \\
\hline MPM PB 1984 & 14 & 0 & 0 & 1,88 & 4,09 & 1,27 & 0,70 & $0-1,02$ & 0,29 \\
\hline MPM PB 1986 & 21 & 0 & 0 & 1,52 & 2,50 & 0,44 & 0,56 & $0-0,85$ & 0,31 \\
\hline MPM PB 1994 & 21 & 0 & 0 & 0,61 & 0,99 & 0,19 & 0,24 & $0,02-0,69$ & 0,22 \\
\hline MPM PB 1995 & 24 & 0 & 0 & 0,19 & 0,29 & 0,11 & 0,55 & $0,01-0,64$ & 0,24 \\
\hline MPM PB 1999 & 10 & 0 & 0 & 2,13 & 3,26 & 0,58 & 0,82 & $0,01-0,95$ & 0,31 \\
\hline MPM PB 2101 & 23 & 0 & 0 & 1,40 & 2,59 & 0,45 & 0,64 & $0,02-1$ & 0,31 \\
\hline MPM PB 2105 & 14 & 0 & 0 & 2,08 & 3,14 & 1,37 & 0,48 & $0,05-0,34$ & 0,17 \\
\hline MPM PB 2108 & 12 & 0 & 0 & 1,47 & 2,79 & 0,72 & 0,53 & $0,05-0,62$ & 0,31 \\
\hline MPM PB 2116 & 10 & 0 & 0 & 1,86 & 2,62 & 0,56 & 0,70 & $0-0,77$ & 0,34 \\
\hline MPM PB 2118 & 42 & 0 & 0 & 0,66 & 1,48 & 0,20 & 0,33 & $0,01-1,2$ & 0,33 \\
\hline MPM PB 2119 & 24 & 0 & 0 & 1,00 & 2,01 & 0,35 & 0,40 & $0,01-1,05$ & 0,27 \\
\hline MPM PB 2124 & 34 & 0 & 0 & 0,97 & 3,64 & 0,28 & 0,77 & $0-0,97$ & 0,41 \\
\hline MPM PB 2128 & 13 & 0 & 0 & 1,69 & 2,04 & 1,26 & 0,28 & $0-0,22$ & 0,08 \\
\hline MPM PB 2135 & 15 & 0 & 0 & 2,91 & 3,99 & 1,19 & 0,75 & $0,01-0,56$ & 0,16 \\
\hline MPM PB 2136 & 10 & 1 & 0 & 3,35 & 4,92 & 2,36 & 0,94 & $0,03-0,55$ & 0,22 \\
\hline MPM PB 2137 & 13 & 0 & 0 & 1,92 & 2,70 & 1,23 & 0,44 & $0-0,45$ & 0,20 \\
\hline MPM PB 2138 & 33 & 0 & 0 & 1,07 & 2,70 & 0,17 & 0,53 & $0,04-1,24$ & 0,40 \\
\hline MPM PB 2141 & 16 & 0 & 0 & 1,71 & 2,35 & 1,17 & 0,35 & $0,07-0,43$ & 0,90 \\
\hline MPM PB 2142 & 26 & 0 & 0 & 1,55 & 3,54 & 3,56 & 0,95 & $0,01-1,36$ & 0,47 \\
\hline MPM PB 2143 & 28 & 0 & 0 & 0,86 & 1,22 & 0,42 & 0,21 & $0,01-0,76$ & 0,26 \\
\hline MPM PB 2146 & 15 & 0 & 0 & 1,13 & 2,41 & 0,56 & 0,44 & $0,01-0,65$ & 0,33 \\
\hline MPM PB 2148 & 34 & 0 & 0 & 0,88 & 1,61 & 0,42 & 0,30 & $0,01-0,75$ & 0,27 \\
\hline MPM PB 2149 & 31 & 0 & 0 & 1,07 & 1,52 & 0,51 & 0,28 & $0-0,53$ & 0,22 \\
\hline MPM PB 2151 & 37 & 0 & 0 & 0,67 & 1,15 & 0,35 & 0,20 & $0-0,64$ & 0,22 \\
\hline MPM PB 2153 & 26 & 0 & 0 & 0,76 & 1,92 & 0,29 & 0,40 & $0,01-1,16$ & 0,44 \\
\hline MPM PB 2156 & 19 & 0 & 0 & 0,79 & 1,11 & 0,49 & 0,17 & $0,01-0,62$ & 0,19 \\
\hline MPM PB 2160 & 19 & 0 & 0 & 0,14 & 0,37 & 0,06 & 0,08 & $0,02-0,89$ & 0,37 \\
\hline MPM PB 2161 & 23 & 0 & 0 & 1,10 & 1,74 & 0,25 & 0,46 & $0-0,91$ & 0,21 \\
\hline MPM PB 2170 & 55 & 0 & 0 & 0,40 & 0,87 & 0,10 & 0,19 & $0,01-1,19$ & 0,42 \\
\hline MPM PB 2171 & 31 & 0 & 0 & 0,42 & 1,16 & 0,10 & 0,25 & $0,01-1,27$ & 0,38 \\
\hline MPM PB 2174 & 42 & 0 & 0 & 0,57 & 1,22 & 0,15 & 0,24 & $0,01-1,36$ & 0,31 \\
\hline MPM PB 2177 & 12 & 0 & 0 & 2,68 & 4,84 & 0,44 & 1,19 & $0,01-1,55$ & 0,58 \\
\hline MPM PB 2181 & 59 & 0 & 0 & 0,30 & 0,59 & 0,09 & 0,11 & $0-1,27$ & 0,31 \\
\hline MPM PB 2182 & 38 & 0 & 0 & 0,84 & 1,49 & 0,37 & 0,30 & $0,02-0,68$ & 0,28 \\
\hline MPM PB 2184 & 37 & 1 & 0 & 0,49 & 1,59 & 0,07 & 0,34 & $0-1,22$ & 0,45 \\
\hline MPM PB 2185 & 47 & 0 & 0 & 0,76 & 1,56 & 0,35 & 0,28 & $0,01-0,58$ & 0,25 \\
\hline MPM PB 2187 & 32 & 0 & 0 & 0,80 & 1,81 & 0,31 & 0,36 & $0-0,69$ & 0,28 \\
\hline
\end{tabular}




\begin{tabular}{|c|c|c|c|c|c|c|c|c|c|}
\hline Ejemplar & $\begin{array}{c}\text { № } \\
\text { anillos }\end{array}$ & $\begin{array}{c}\text { № } \\
\text { falsos } \\
\text { anillos }\end{array}$ & $\begin{array}{c}\text { № anillos } \\
\text { de } \\
\text { heladas }\end{array}$ & $\begin{array}{l}\text { Ancho } \\
\text { medio }\end{array}$ & $\begin{array}{l}\text { Ancho } \\
\text { máx. }\end{array}$ & $\begin{array}{c}\text { Ancho } \\
\text { mín. }\end{array}$ & $\begin{array}{c}\text { Desv. } \\
\text { Est. }\end{array}$ & SA & SM \\
\hline MPM PB 2198 & 32 & 0 & 0 & 1,31 & 3,07 & 0,56 & 0,64 & $0,01-1,17$ & 0,38 \\
\hline MPM PB 2199 & 27 & 0 & 0 & 1,15 & 4,12 & 0,20 & 0,93 & $0,04-1,29$ & 0,40 \\
\hline MPM PB 2200 & 13 & 0 & 0 & 1,75 & 2,99 & 0,74 & 0,73 & $0,01-0,73$ & 0,30 \\
\hline MPM PB 2202 & 7 & 0 & 0 & 5,31 & 6,55 & 4,29 & 0,74 & --- & +-- \\
\hline MPM PB 2204 & 4 & 0 & 0 & 4,14 & 4,52 & 3,74 & 0,35 & --- & --- \\
\hline MPM PB 2207 & 13 & 0 & 0 & 2,73 & 3,62 & 1,50 & 0,66 & $0,01-0,56$ & 0,26 \\
\hline MPM PB 2211 & 71 & 0 & 0 & 0,26 & 0,65 & 0,11 & 0,11 & $0,02-0,94$ & 0,28 \\
\hline MPM PB 2212 & 27 & 0 & 0 & 1,43 & 2,87 & 0,45 & 0,61 & $0-1,20$ & 0,33 \\
\hline MPM PB 2215 & 27 & 0 & 0 & 1,55 & 3,21 & 0,87 & 0,49 & $0,03-0,97$ & 0,27 \\
\hline MPM PB 2216 & 15 & 0 & 0 & 1,30 & 2,43 & 0,67 & 0,49 & $0,13-0,91$ & 0,42 \\
\hline MPM PB 2220 & 18 & 0 & 0 & 1,15 & 1,59 & 0,72 & 0,26 & $0,01-0,49$ & 0,21 \\
\hline MPM PB 2221 & 15 & 0 & 0 & 1,73 & 2,56 & 0,97 & 0,50 & $0,05-0,90$ & 0,28 \\
\hline MPM PB 2271 & 10 & 0 & 0 & 1,74 & 3,30 & 0,51 & 0,75 & $0,04-1,24$ & 0,54 \\
\hline MPM PB 2272 & 43 & 0 & 0 & 0,66 & 1,66 & 0,07 & 0,47 & $0,01-1,26$ & 0,49 \\
\hline MPM PB 2273 & 20 & 0 & 0 & 0,88 & 1,31 & 0,54 & 0,23 & $0,01-0,47$ & 0,17 \\
\hline MPM PB 2277 & 33 & 0 & 0 & 0,87 & 1,71 & 0,25 & 0,37 & $0,02-1,05$ & 0,31 \\
\hline MPM PB 2278 & 25 & 0 & 0 & 0,70 & 1,10 & 0,20 & 0,22 & $0-1,33$ & 0,38 \\
\hline MPM PB 14382 & 19 & 2 & 0 & 1,51 & 2,40 & 0,19 & 0,50 & $0,01-1,56$ & 0,31 \\
\hline MPM PB 14393 & 33 & 0 & 0 & 0,74 & 2,17 & 0,21 & 0,55 & $0,01-0,77$ & 0,29 \\
\hline MPM PB 14396 & 20 & 0 & 0 & 0,83 & 1,92 & 0,47 & 0,32 & $0,05-0,82$ & 0,36 \\
\hline MPM PB 14398 & 44 & 0 & 0 & 0,44 & 1,14 & 0,09 & 0,25 & $0,02-1,54$ & 0,48 \\
\hline MPM PB 14400 & 51 & 0 & 0 & 0,70 & 1,43 & 0,16 & 0,28 & $0,01-1,17$ & 0,31 \\
\hline MPM PB 14401 & 36 & 1 & 0 & 0,54 & 1,94 & 0,22 & 0,33 & $0,03-0,99$ & 0,33 \\
\hline MPM PB 14402 & 21 & 0 & 0 & 1,44 & 2,24 & 0,49 & 0,42 & $0-1,02$ & 0,27 \\
\hline MPM PB 14404 & 13 & 0 & 0 & 0,79 & 1,24 & 0,46 & 0,22 & $0-0,59$ & 0,25 \\
\hline MPM PB 14405 & 18 & 0 & 0 & 0,69 & 1,08 & 0,41 & 0,20 & $0,04-0,47$ & 0,28 \\
\hline MPM PB 14407 & 6 & 0 & 0 & 3,31 & 4,83 & 2,23 & 0,96 & --- & --- \\
\hline MPM PB 14410 & 49 & 0 & 0 & 0,39 & 0,90 & 0,16 & 0,16 & $0,03-1,21$ & 0,41 \\
\hline MPM PB 14411 & 7 & 0 & 0 & 2,08 & 2,59 & 1,69 & 0,31 & --- & --- \\
\hline MPM PB 14412 & 22 & 0 & 0 & 0,72 & 1,18 & 0,38 & 0,24 & $0,01-0,65$ & 0,26 \\
\hline MPM PB 14413 & 20 & 0 & 0 & 0,91 & 2,25 & 0,26 & 0,52 & $0,02-0,95$ & 0,38 \\
\hline MPM PB 14416 & 15 & 0 & 0 & 1,62 & 2,41 & 1,13 & 0,44 & $0,01-0,67$ & 0,35 \\
\hline MPM PB 14419 & 16 & 0 & 0 & 1,04 & 1,80 & 0,46 & 0,37 & $0,04-0,94$ & 0,33 \\
\hline MPM PB 14420 & 34 & 0 & 0 & 0,89 & 2,15 & 0,25 & 0,53 & $0,06-0,87$ & 0,32 \\
\hline MPM PB 14421 & 24 & 0 & 0 & 0,97 & 1,32 & 0,46 & 0,28 & $0-0,80$ & 0,27 \\
\hline MPM PB 14423 & 37 & 0 & 0 & 0,50 & 1,31 & 0,23 & 0,22 & $0,02-1,05$ & 0,32 \\
\hline MPM PB 14424 & 28 & 0 & 0 & 0,93 & 1,41 & 0,45 & 0,25 & $0,02-1,02$ & 0,24 \\
\hline MPM PB 14425 & 18 & 0 & 0 & 0,85 & 1,60 & 0,31 & 0,38 & $0,03-1,01$ & 0,32 \\
\hline MPM PB 14426 & 13 & 0 & 0 & 1,05 & 1,51 & 0,61 & 0,33 & $0,01-0,66$ & 0,24 \\
\hline MPM PB 14428 & 8 & 0 & 0 & 3,39 & 4,35 & 1,89 & 0,87 & --- & --- \\
\hline MPM PB 14429 & 33 & 0 & 0 & 0,74 & 1,18 & 0,33 & 0,21 & $0-0,61$ & 0,26 \\
\hline MPM PB 14430 & 31 & 0 & 0 & 0,71 & 1,76 & 0,21 & 0,35 & $0,01-0,94$ & 0,26 \\
\hline MPM PB 14431 & 70 & 0 & 0 & 0,37 & 0,88 & 0,09 & 0,20 & $0-1,09$ & 0,41 \\
\hline MPM PB 14437 & 26 & 0 & 0 & 0,68 & 1,21 & 0,26 & 0,27 & $0,03-1,04$ & 0,32 \\
\hline MPM PB 14439 & 29 & 0 & 0 & 0,37 & 0.92 & 0,10 & 0,21 & $0,01-0,81$ & 0,29 \\
\hline MPM PB 14447 & 28 & 0 & 0 & 0,38 & 0,73 & 0,16 & 0,13 & $0-0,91$ & 0,25 \\
\hline MPM PB 14448 & 10 & 0 & 0 & 1,08 & 1,87 & 0,35 & 0,44 & $0,03-0,99$ & 0,46 \\
\hline MPM PB 14450 & 54 & 0 & 0 & 0,44 & 1,33 & 0,17 & 0,23 & $0-1,33$ & 0,35 \\
\hline MPM PB 14456 & 12 & 0 & 0 & 1,81 & 5,52 & 0,59 & 1,40 & $0,01-1,60$ & 0,58 \\
\hline MPM PB 14461 & 45 & 0 & 0 & 0,49 & 1,24 & 0,24 & 0,18 & $0-0,65$ & 0,23 \\
\hline MPM PB 14465 & 15 & 0 & 0 & 2,31 & 3,81 & 1,10 & 0,81 & $0,18-1,10$ & 0,43 \\
\hline MPM PB 14468 & 16 & 0 & 0 & 1,30 & 2,25 & 0,77 & 0,46 & $0,04-0,57$ & 0,22 \\
\hline MPM PB 14469 & 23 & 1 & 0 & 1,18 & 1,79 & 0,37 & 0,43 & $0,01-0,82$ & 0,25 \\
\hline MPM PB 14954 & 19 & 0 & 0 & 1,34 & 2,14 & 0,88 & 0,36 & $0,07-0,80$ & 0,23 \\
\hline MPM PB 14956 & 36 & 0 & 0 & 0,65 & 1,23 & 0,32 & 0,31 & $0,03-0,68$ & 0,25 \\
\hline MPM PB 14968 & 8 & 0 & 0 & 3,20 & 5,29 & 1,23 & 1,35 & --- & $\begin{array}{l}-- \\
\end{array}$ \\
\hline MPM PB 14969 & 24 & 0 & 0 & 1,15 & 1,68 & 0,66 & 0,33 & $0,06-0,75$ & 0,32 \\
\hline
\end{tabular}




\begin{tabular}{|c|c|c|c|c|c|c|c|c|c|}
\hline Ejemplar & $\begin{array}{c}\text { № } \\
\text { anillos }\end{array}$ & $\begin{array}{c}\text { № } \\
\text { falsos } \\
\text { anillos }\end{array}$ & $\begin{array}{c}\text { № anillos } \\
\text { de } \\
\text { heladas }\end{array}$ & $\begin{array}{l}\text { Ancho } \\
\text { medio }\end{array}$ & $\begin{array}{l}\text { Ancho } \\
\text { máx. }\end{array}$ & $\begin{array}{c}\text { Ancho } \\
\text { mín. }\end{array}$ & $\begin{array}{c}\text { Desv. } \\
\text { Est. }\end{array}$ & SA & SM \\
\hline MPM PB 14970 & 18 & 0 & 0 & 1,13 & 2,91 & 0,22 & 0,66 & $0-1,13$ & 0,33 \\
\hline MPM PB 14980 & 18 & 2 & 0 & 0,74 & 1,25 & 0,29 & 0,28 & $0-0,98$ & 0,32 \\
\hline MPM PB 14985 & 20 & 0 & 0 & 0,93 & 2,24 & 0,50 & 0,54 & $0,01-1,21$ & 0,30 \\
\hline MPM PB 17993 & 14 & 0 & 0 & 1,71 & 2,84 & 1,05 & 0,47 & $0,04-0,85$ & 0,27 \\
\hline MPM PB 18003 & 21 & 0 & 0 & 0,78 & 1,69 & 0,36 & 0,30 & $0-0,67$ & 0,27 \\
\hline MPM PB 18004 & 7 & 0 & 0 & 1,79 & 2,19 & 1,45 & 0,24 & --- & +-- \\
\hline MPM PB 18005 & 15 & 0 & 0 & 0,76 & 1,37 & 0,29 & 0,32 & $0,02-1,21$ & 0,41 \\
\hline MPM PB 18007 & 17 & 0 & 0 & 1,20 & 2,25 & 0,35 & 0,57 & $0,01-1,10$ & 0,29 \\
\hline MPM PB 18009 & 84 & 0 & 0 & 0,30 & 0,83 & 0,05 & 0,15 & $0-1,11$ & 0,32 \\
\hline MPM PB 18014 & 12 & 0 & 0 & 2,09 & 4,39 & 1,41 & 0,80 & $0,09-1,03$ & 0,35 \\
\hline MPM PB 18015 & 45 & 0 & 0 & 0,43 & 0,78 & 0,07 & 0,17 & $0,01-1,42$ & 0,30 \\
\hline MPM PB 18017 & 30 & 0 & 0 & 0,77 & 1,67 & 0,20 & 0,28 & $0-0,85$ & 0,32 \\
\hline MPM PB 18022 & 8 & 0 & 0 & 2,86 & 3,37 & 2,27 & 0,41 & --- & --- \\
\hline MPM PB 18024 & 29 & 0 & 0 & 0,85 & 1,52 & 0,48 & 0,24 & $0,03-0,56$ & 0,22 \\
\hline MPM PB 18035 & 19 & 0 & 0 & 2,20 & 3,44 & 0,86 & 0,79 & $0,03-1,11$ & 0,38 \\
\hline MPM PB 18042 & 14 & 0 & 0 & 1,60 & 2,72 & 1,03 & 0,49 & $0,03-0,32$ & 0,16 \\
\hline MPM PB 18044 & 39 & 0 & 0 & 0,49 & 0,80 & 0,22 & 0,15 & $0,02-0,86$ & 0,36 \\
\hline MPM PB 18056 & 39 & 0 & 0 & 0,43 & 0,74 & 0,17 & 0,14 & $0,01-0,77$ & 0,26 \\
\hline MPM PB 18057 & 21 & 0 & 0 & 0,79 & 1,49 & 0,37 & 0,32 & $0,05-0,70$ & 0,31 \\
\hline MPM PB 18064 & 16 & 0 & 0 & 1,26 & 1,97 & 0,52 & 0,51 & $0,03-0,72$ & 0,25 \\
\hline MPM PB 18072 & 30 & 0 & 0 & 0,56 & 1,82 & 0,16 & 0,37 & $0,02-1$ & 0,30 \\
\hline MPM PB 18073 & 12 & 0 & 0 & 2,09 & 3,30 & 1,37 & 0,70 & $0,04-0,66$ & 0,29 \\
\hline MPM PB 18074 & 35 & 0 & 0 & 0,82 & 1,55 & 0,25 & 0,40 & $0,02-0,74$ & 0,22 \\
\hline MPM PB 18093 & 21 & 0 & 0 & 0,71 & 1,16 & 0,45 & 0,19 & $0-0,50$ & 0,18 \\
\hline MPM PB 18119 & 14 & 0 & 0 & 2,99 & 4,24 & 1,64 & 0,79 & $0,06-0,88$ & 0,30 \\
\hline MPM PB 18122 & 23 & 0 & 0 & 1,30 & 2,73 & 0,63 & 0,56 & $0,02-0,73$ & 0,27 \\
\hline MPM PB 18142 & 28 & 0 & 0 & 0,49 & 1,32 & 0,19 & 0,31 & $0-1,42$ & 0,37 \\
\hline MPM PB 18143 & 18 & 0 & 0 & 1,21 & 3,60 & 0,75 & 0,62 & $0,03-0,84$ & 0,23 \\
\hline MPM PB 18151 & 25 & 0 & 0 & 0,52 & 0,78 & 0,28 & 0,14 & $0,01-0,69$ & 0,27 \\
\hline MPM PB 18156 & 7 & 0 & 0 & 2,19 & 2,88 & 1,31 & 0,54 & --- & --- \\
\hline Promedio & & & & 1,20 & 2,10 & 0,05 & 0,43 & $0,02-0,91$ & 0,27 \\
\hline
\end{tabular}

Tabla 4.27: datos de los anillos de crecimiento medidos. Valores de ancho en $\mathrm{mm}$. En negrita los valores de SM muy elevados.

Debido a lo fragmentario del material observado y la alteración factible de producirse con el proceso de fosilización en muchos casos fue difícil establecer la presencia de falsos anillos o anillos de heladas. Aun así se observaron al menos 10 falsos anillos (Tabla 4.27 y Fig. 4.38).

Los anillos de crecimiento de las coníferas estudiadas son todos del "tipo D" según Creeber \& Chaloner (1984b) (Figs. 4.39 y 4.40). Estos anillos señalan un evento terminal que cesó la actividad cambial luego de una temporada de crecimiento relativamente uniforme. 

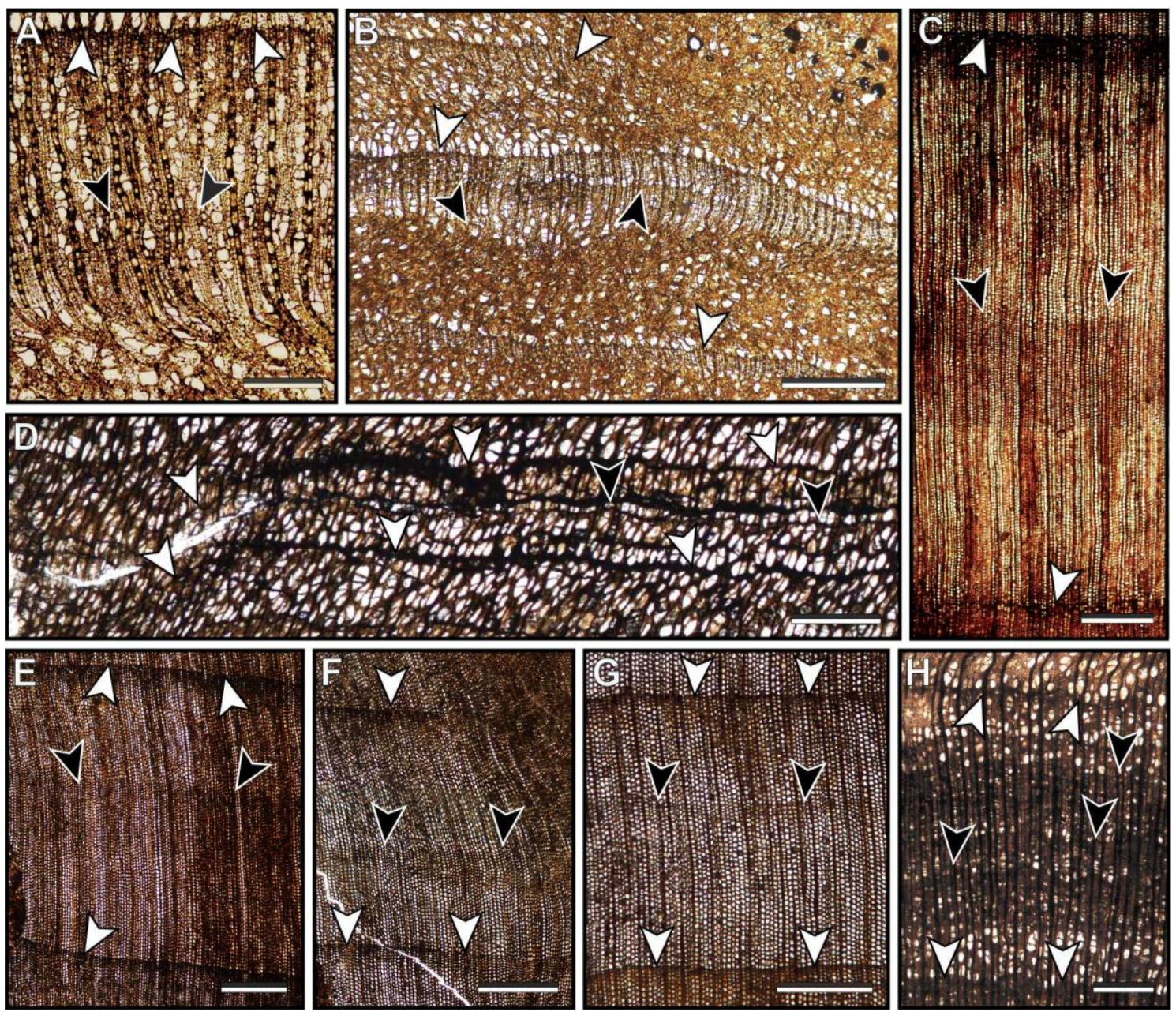

Figura 4.38. Falsos anillos. En vista transversal. Límites de anillos verdaderos (flechas blancas), límites de falsos anillos (flechas negras). A,B. MPM PB 1956. C. MPM PB 2136. D. MPM PB 14401. E,F. MPM PB 14382. G. MPM PB 14469. H. MPM PB 14980.

Escalas. A,C-H: $200 \mu \mathrm{m}$; B: $500 \mu \mathrm{m}$.

\begin{tabular}{|lccccc|}
\hline Ejemplar & \% leño temprano & \% de leño tardío & Skew & \% de disminución & RMI \\
\hline MPM PB 1977 & $80 \%$ & $20 \%$ & $60 \%$ & $83 \%$ & 17 \\
\hline MPM PB 1999 & $65 \%$ & $35 \%$ & $4 \%$ & $81 \%$ & 28 \\
\hline MPM PB 2136 & $84 \%$ & $16 \%$ & $67 \%$ & $85 \%$ & 14 \\
\hline MPM PB 2137 & $85 \%$ & $15 \%$ & $69 \%$ & $93 \%$ & 14 \\
\hline MPM PB 14382 & $86 \%$ & $14 \%$ & $71 \%$ & $80 \%$ & 12 \\
\hline MPM PB 14383 & $84 \%$ & $16 \%$ & $37 \%$ & $77 \%$ & 12 \\
\hline MPM PB 14386 & $86 \%$ & $14 \%$ & $72 \%$ & $64 \%$ & 9 \\
\hline MPM PB 14402 & $85 \%$ & $15 \%$ & $47 \%$ & $82 \%$ & 12 \\
\hline MPM PB 14469 & $84 \%$ & $16 \%$ & $67 \%$ & $79 \%$ & 13 \\
\hline MPM PB 18016 & $75 \%$ & $25 \%$ & $50 \%$ & $77 \%$ & 19 \\
\hline MPM PB 18064 & $73 \%$ & $27 \%$ & $4 \%$ & $88 \%$ & 23 \\
\hline MPM PB 18143 & $82 \%$ & $18 \%$ & $64 \%$ & $69 \%$ & 12 \\
\hline MPM PB 18156 & $90 \%$ & $10 \%$ & $80 \%$ & $77 \%$ & 7 \\
\hline
\end{tabular}

Tabla 4.28: resumen de los datos tomados de los anillos de crecimiento. Conífera indet. (MPM

PB 1977, 14382, 14383, 14386, 18143, 18156); Agathoxylon sp. A (MPM PB 1999);

Podocarpoxylon sp. A (MPM PB 2136, 2137); Cf. Podocarpoxylon (MPM PB 14402, 14469);

Agathoxylon sp. (MPM PB 18016, 18064). 


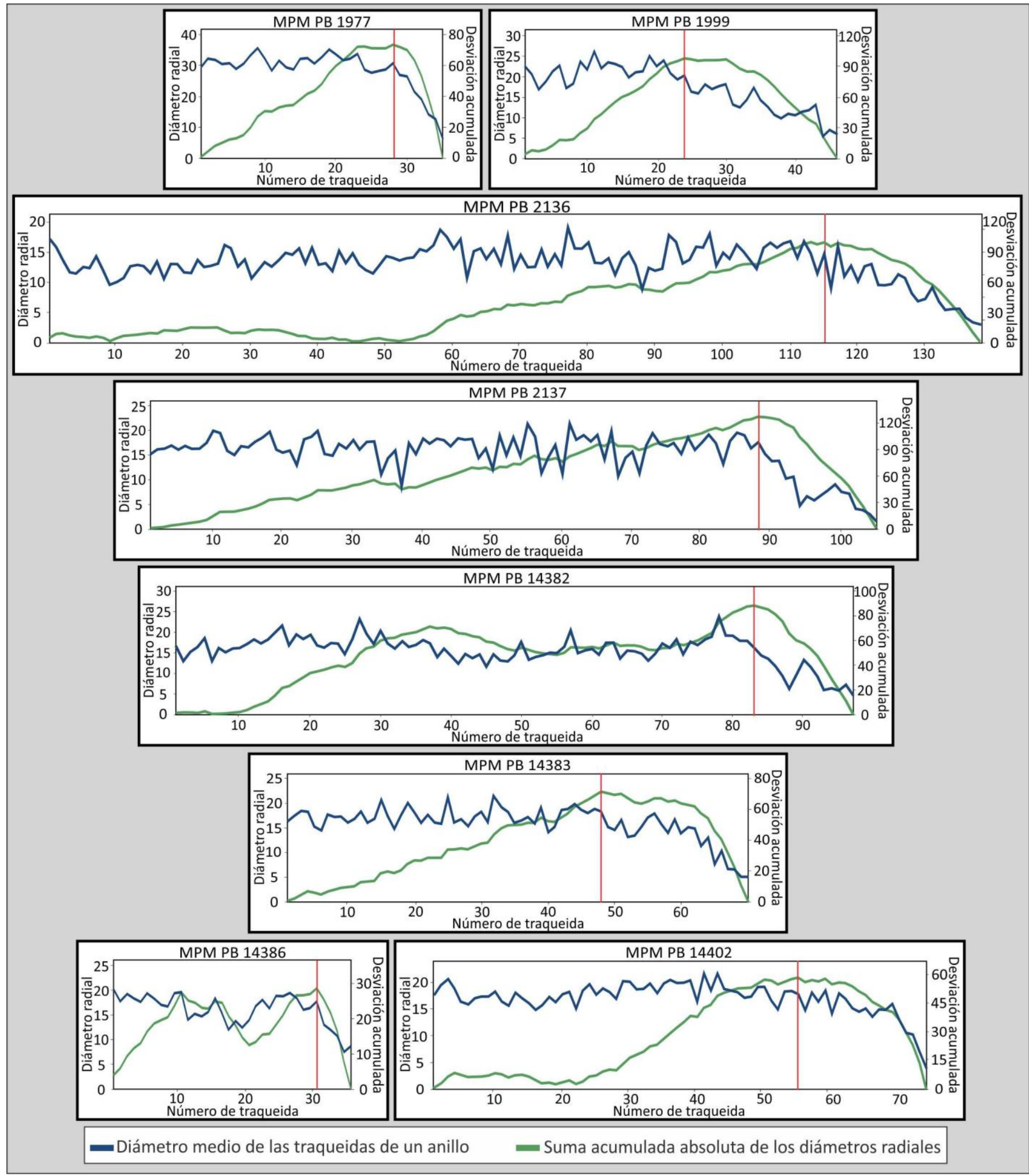

Fig. 4.39. Curvas CSDM. Conífera indeterminada (MPM PB 1977, 14383, 14386), Agathoxylon sp. (MPM PB 1999), Podocarpoxylon (MPM PB 2136, 2137, 14402). 


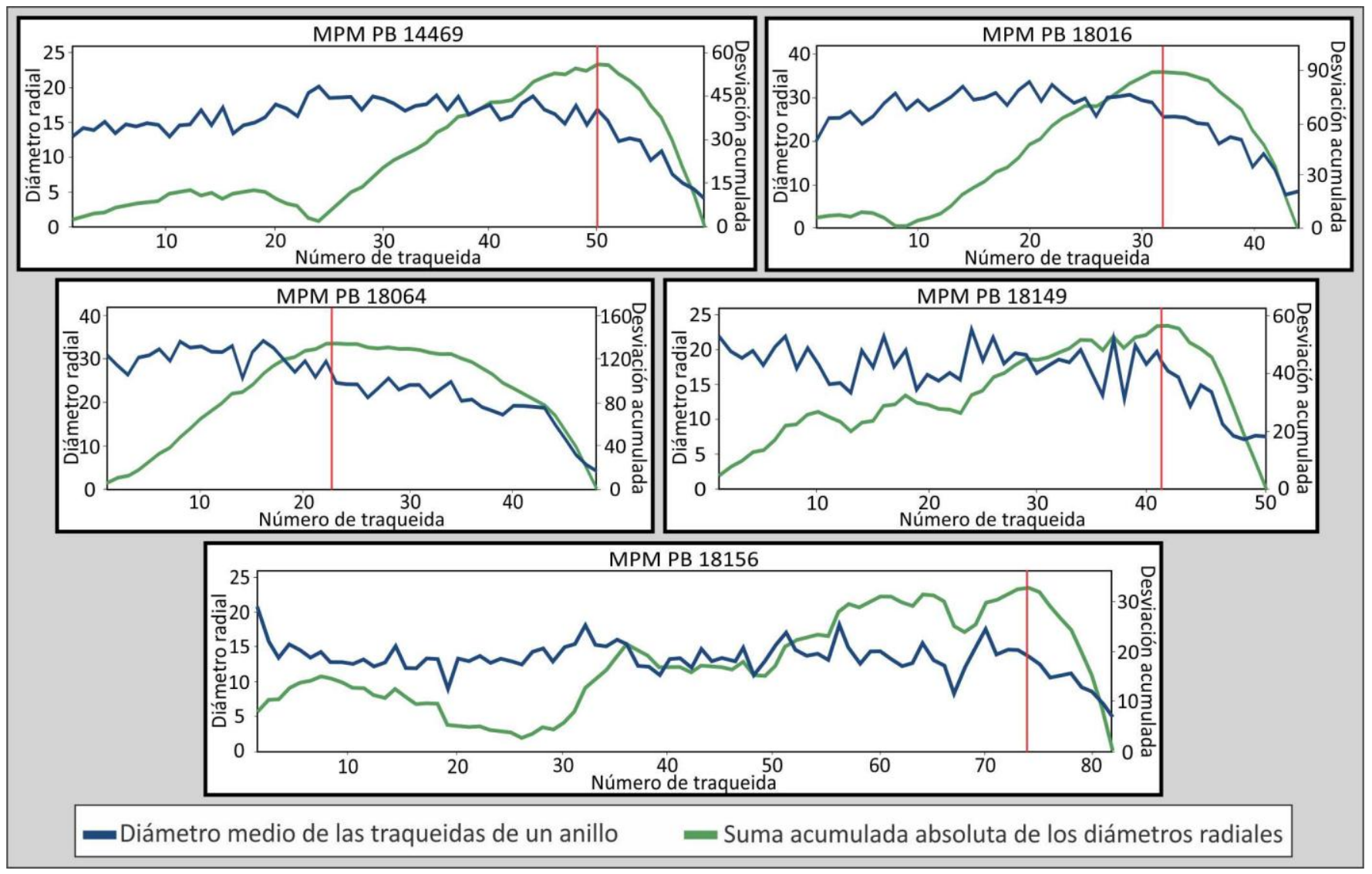

Fig. 4.40. Curvas CSDM de un Podocarpoxylon (MPM PB 14469), Agathoxylon (MPM PB 18016, 18064), coníferas indeterminadas (MPM PB 18149, 18156).

Los porcentajes de leño tardío y el Ring Markedness Index (RMI) de todos los ejemplares analizados se corresponden con especies perennes como la actual Araucaria araucana o como Cedrus libani (Falcon-Lang, 2000b). El alto porcentaje de skew de la mayoría de las muestras también se correspondería con el de Araucaria araucana, indicando 3 a 15 años de retención foliar (Falcon-Lang, 2000a) (Tabla 4.28 y Figs. 4.39 y 4.40$)$.

\section{3. Índices de Vulnerabilidad y Mesomorfía}

Las dos especies de Scalarixylon y la especie Doroteoxylon vicente-perezii no pueden ser incluidas en este análisis ya que presentan variación en el diámetro de los vasos y en la densidad de los mismos entre el leño temprano y el leño tardío. 


\begin{tabular}{|lccccc|}
\hline & $\begin{array}{c}\text { Diám. } \\
\text { vasos }\end{array}$ & $\begin{array}{c}\text { No vasos } \\
\text { por mm }{ }^{2}\end{array}$ & $\begin{array}{c}\text { Largo de elem. } \\
\text { de vasos }\end{array}$ & Vulnerabilidad & Mesomorfía \\
\hline Maloidoxylon cesariae & 16 & 436 & 150 & 0,04 & 5,50 \\
\hline Nothofagoxylon scalariforme & 53 & 178 & 143 & 6,30 & 2,58 \\
\hline Nothofagoxylon triseriatum & 80 & 40 & 207 & 0,40 & 84,61 \\
\hline Nothofagoxylon kraeuseli & 56 & 137 & 550 & 0,20 & 105,32 \\
\hline Nothofagoxylon ruei & 45 & 235 & 275 & 0,44 & 120,9 \\
\hline Nothofagoxylon aggregatum & 51 & 116 & 590 & 0,12 & 68,44 \\
\hline Myrceugenellites oligocenum & 29 & 250 & 469 & 0,08 \\
\hline Laurelites doroteaensis & 47 & 139 & 37,52 \\
\hline
\end{tabular}

Tabla 4.29: datos utilizados para calcular el índice de vulnerabilidad y el de mesomorfía.

Medidas en $\mu \mathrm{m}$.

Exceptuando a Nothofagoxylon triseriatum con un índice de vulnerabilidad de 2 , el resto de las especies presentan un índice de vulnerabilidad extremadamente bajo indicando que son muy capaces de soportar estrés hídrico y/o congelamiento. Lo mismo ocurre con el índice de mesomorfía que, exceptuando el valor 1300 de $N$. triseriatum, el resto se corresponde con ambientes de baja disponibilidad de agua (Tabla 4.29).

\subsection{Método del Coexistence Approach (CA) o del pariente vivo más cercano}

Afinidad sistemática

Agathoxylon sp. - Es afín a las Araucariaceae principalmente por las punteaduras hexagonales en las paredes radiales de las traqueidas, el tipo de campo de cruzamiento y la ausencia de parénquima axial. Las especies más australes de esta familia en Sudamérica son Araucaria angustifolia (Bert.) O.K. y Araucaria araucana (Mol.) De estas dos especies, se considera a A. araucana como la más afín al fósil estudiado ya que tiene el mismo tipo de punteaduras radiales en las traqueidas (mayormente uniseriadas) (Tabla 4.30) (Tortorelli, 1956; Rancusi et al., 1987).

Podocarpoxylon sp. A - Sería afín a las Podocarpaceae, pero podría estar relacionada con varios géneros, dado que presentan caracteres anatómicos muy similares que no permiten una clara delimitación genérica. Por este motivo y sumado a que el estado de preservación de los campos de cruzamiento no es óptimo, no se consideró esta especie para el estudio del CA.

Scalarixylon patagonicum - Se asigna a las Proteaceae y se asemeja a las especies de esta familia actualmente presentes en la Patagonia, tales como: Guevina avellana Mol., Lomatia hirsuta (Lam.) Diels, L. dentata R. Br., L. ferruginea R. Br. y en 
especial a Embothrium coccineum J.R. Forst et G. Forst. Esta última especie es la que, al igual que S. patagonicum, presenta caracteres semejantes como ser bandas tangenciales de 2-3 vasos de ancho (Tabla 4.31) (Wagemann, 1948; Tortorelli, 1956; Rancusi et al., 1987).

Scalarixylon grandiradiatum - Al igual que la especie anterior, S. grandiradiatum también es afín a las Proteaceae nativas de Patagonia, sobre todo a Lomatia R. Br. y Guevina avellana las cuales poseen bandas de 1-2 vasos de ancho. Guevina avellana se distingue de $S$. grandiradiatum debido a que posee engrosamientos espiralados y radios más altos. Dentro de las especies de Lomatia, la más similar es L. ferruginea, ya que L. dentata puede tener placas de perforación escalariformes (además de las simples) y L. hirsuta en la disposición de los vasos (hay vasos en bandas diagonales) (Tabla 4.32) (Wagemann, 1948; Tortorelli, 1956; Rancusi et al., 1987).

Maloidoxylon cesariae - La especie es afín a la familia Rosaceae, pero dada la gran cantidad de especies dentro de la familia y el escaso estudio de las mismas (en especial de los arbustos de Patagonia) se prefiere dejarla fuera de este análisis ya que no es certera su afinidad con las especies actuales.

Nothofagoxylon scalariforme - Tiene afinidad con todas las especies del género Nothofagus subgénero Nothofagus: N. antárctica (G. Forst.) Oerst., N. pumilio (Poepp. et Endl.) Krasser, N. dombeyi (Mirb.) Bl., N. nitida (Phil.) Krasser y N. betuloides (Mirb.) Oerst. (Tabla 4.33) (Tortorelli, 1956; Rancusi et al., 1987; Rivera, 1988;).

Nothofagoxylon triseriatum - Los radios bi o triseriados relacionan a esta especie con el actual subgénero Lophozonia Turcz. de Nothofagus. Dentro del subgénero se consideran como más cercanas las especies $N$. alpina (Poepp. ex A. DC.) Oerst., N. glauca (Phil.) Krasser y N. oblicua (Mirb.) Oerst. ya que son las especies presentes en América del Sur. De estas especies, Nothofagoxylon triseriatum presenta mayor similitud con $N$. glauca y con $N$. oblicua, ya que $N$. alpina prácticamente no presenta radios triseriados y las punteaduras vasculares son en ocasiones escalariformes pero no alternas (Tabla 4.34) (Tortorelli, 1956; Rancusi et al., 1987; Rivera, 1988). 
Nothofagoxylon kraeuseli - Esta especie también tiene similitudes con las tres especies sudamericanas del género Nothofagus subgénero Lophozonia pero, al no presentar radios triseriados, se asemeja más a $N$. oblicua y $N$. alpina (Tabla 4.35) (Tortorelli, 1956; Rancusi et al., 1987; Rivera, 1988).

Nothofagoxylon ruei - De las especies de Nothofagus actuales, solo $N$. alessandri Espinosa, N. leoni Espinosa y, en ocasiones, N. oblicua y N. procera (Poepp. et Endl.) Oesrt. presentan punteaduras intervasculares alternas como las de N. ruei. De las mencionadas especies, la que presenta mayor porcentaje de radios uniseriados es N. alessandri por lo que se considera a esta especie como el pariente más próximo (Tabla 4.36) (Rancusi et al., 1987).

Nothofagoxylon aggregatum - También presenta afinidad con el subgénero Lophozonia de Nothofagus y, de las tres especies de este subgénero presentes en Sudamérica, la que más se asemeja es $N$. glauca por ser la especie donde los radios triseriados son más abundantes (Tabla 4.37) (Rancusi et al., 1987).

Myrceugenellites oligocenum - Es una Myrtaceae afín al género Luma A. Gray. Las especias más australes de este género son Luma apiculata (D.C) Burret y Luma chequen (Mol.) A. Gray. L. chequen se diferencia de la especie fósil por poseer placas simples, fibras no-septadas y radios ocasionalmente triseriados, por otra parte carece de tílides y de engrosamientos espiralados (Rancusi et al., 1987). Por lo tanto L. apiculata sería la especie más emparentada al fósil ya que posee la más caracteres en común (Tabla 4.38).

Laurelites doroteaensis - Esta especie tiene afinidad con la familia Atherospermataceae. Los representantes de dicha familia que habitan actualmente en la Patagonia son: Laureliopsis philippiana (Looser) Schodde y Laurelia sempervirens Tul. Ambas especies se diferencian muy poco entre sí, únicamente por caracteres cuantitativos, ya que las mismas son muy similares a la especie fósil Laurelites doroteaensis (Tabla 4.39).

Doroteoxylon vicente-perezii - Es muy similar a algunas especies de los géneros Gleditsia L. y Robinia L. (Caesalpinoideae) del hemisferio norte y su relación con el fósil es poco plausible. En la región hay arbustos de leguminosas pero lamentablemente su 
anatomía aún no ha sido estudiada en detalle, por lo que se excluirá esta especie del análisis de CA.

Resinaxylon schinusoides - El fósil se asemeja a las maderas de Anacardiaceae como Schinus L., presente en Patagonia, pero a diferencia de éstas, carece de engrosamientos espiralados en los elementos de vaso. Dada que la diferencia en este carácter puede ser justamente debida a diferencias ecológicas o climáticas, no se considera prudente incluirlo en el CA.

\begin{tabular}{|ccc|}
\hline Caracteres & Agathoxylon sp. & Araucaria araucana \\
\hline Presencia de anillos & Presentes, de transición gradual & $\begin{array}{c}\text { Presentes, de transición } \\
\text { gradual }\end{array}$ \\
\hline $\begin{array}{c}\text { Contorno de las } \\
\text { traqueidas }\end{array}$ & Redondeado & Cuadrado o redondeado \\
\hline Punteaduras radiales & $\begin{array}{c}\text { Uniseriadas con zonas biseriadas, } \\
\text { contiguas y circulares a } \\
\text { hexagonales }\end{array}$ & $\begin{array}{c}\text { Uniseriadas, ocasionalmente } \\
\text { biseriadas, en estos casos } \\
\text { alternas y de forma poligonal }\end{array}$ \\
\hline Radios & $\begin{array}{c}\text { Uniseriados, raramente porciones } \\
\text { biseriadas. 2 a 16 células de alto }\end{array}$ & $\begin{array}{c}\text { Uniseriados. De entre } 5 \text { y } 10 \\
\text { células de alto }\end{array}$ \\
\hline Campos de cruzamiento & 3 a 6 punteaduras contiguas & $\begin{array}{c}1 \text { a 10 punteaduras por } \\
\text { campo en dos o tres hileras. }\end{array}$ \\
\hline Traqueidas septadas & Ausente & Ausente \\
\hline Parénquima axial & Ausente & Escaso o ausente \\
\hline
\end{tabular}

Tabla 4.30: tabla comparativa entre Agathoxylon sp. y su pariente vivo más cercano. 


\section{Caracteres}

Presencia de anillos

Porosidad

\section{Scalarixylon patagonicum}

Presentes, marcados por la disminución de la distancia entre bandas de vasos, ampliación de los radios multiseriados y una escasa reducción en el tamaño de los vasos Porosidad circular

Disposición de los vasos Bandas tangenciales (2-3 vasos de ancho), algo curvadas

\section{Embothrium coccineum}

Presentes, se distinguen por la reducción del tamaño de los poros y la distancia entre las bandas de poros

\begin{tabular}{|c|c|c|}
\hline Contorno de vasos & Algo elípticos, radialmente elongados & Radialmente elongados o algo angulares \\
\hline $\begin{array}{l}\text { Diámetro tangencial de } \\
\text { los vasos }(\mu \mathrm{m})\end{array}$ & $47(22-75)$ & $40(10-78)$ \\
\hline Placas de perforación & Simples & Simples \\
\hline Punteaduras & Alternas & Alternas u opuestas \\
\hline $\begin{array}{l}\text { Punteaduras radio- } \\
\text { vasculares }\end{array}$ & Dispersas, dispuestas al azar & --- \\
\hline Parénquima axial & $\begin{array}{l}\text { En bandas paratraqueales escalariformes, asociadas } \\
\text { unilateralmente al lado externo de las bandas de vasos }\end{array}$ & Paratraqueal unilateral \\
\hline Radios & $\begin{array}{l}\text { Uniseriados y multiseriados. Los multiseriados de hasta } 20 \\
\text { células de espesor y hasta } 2,5 \text { mm de altura, rara vez con } \\
\text { extensiones uniseriadas. Son homogéneos a heterogéneos } \\
\text { compuestos de células procumbentes en el centro y } \\
\text { cuadradas en los extremos. Los uniseriados llegan a } 9 \text { células } \\
\text { de altura y son heterogéneos }\end{array}$ & $\begin{array}{l}\text { Uniseriados y multiseriados. Los multiseriados tienen en } \\
\text { promedio } 10 \text { células de ancho. Los uniseriados son de } 6 \text { (1- } \\
\text { 12) células de alto. Son homogéneos a heterogéneos }\end{array}$ \\
\hline Fibras & De pared delgada, de sección subrectangular a circular & De sección hexagonal, con punteaduras \\
\hline Observaciones & $\begin{array}{c}+- \\
\end{array}$ & --- \\
\hline
\end{tabular}

Tabla 4.31: tabla comparativa entre Scalarixylon patagonicum y su pariente vivo más cercano. 


\section{Caracteres}

Presencia de anillos

Porosidad

Disposición de los vasos

Contorno de vasos

Diámetro tangencial de

los vasos $(\mu \mathrm{m})$

Placas de perforación

Punteaduras

Punteaduras radiovasculares

Parénquima axial

Radios

\begin{tabular}{|l} 
\\
\hline Fibras \\
\hline
\end{tabular}

Observaciones
Scalarixylon grandiradiatum

Apenas marcados por la disminución de la distancia entre bandas de vasos y la ampliación de los radios multiseriados Difusa

En bandas tangenciales, algo curvadas (1 o 2 vasos de espesor)

Circular, escasamente alargados de forma radial $43(25-65)$

Lomatia ferruginea

Presentes. Marcados por la disminución de la distancia entre bandas de vasos y reducción del tamaño de poros Circular

En bandas tangenciales, algo curvadas Circular, escasamente alargados de forma radial

$44(20-75)$

Simples

Alternas

Alternas, a veces opuestas

Parecieran ser similares a las punteaduras intervasculares aunque más pequeñas

Redondeadas, pequeñas y simples

En bandas paratraqueales escalariformes, asociadas unilateralmente al lado externo de las bandas de vasos

Paratraqueal

Uniseriados y multiseriados. Los multiseriados de hasta 20

células de espesor y hasta $5 \mathrm{~mm}$ de altura, rara vez con

extensiones uniseriadas. Son homogéneos a heterogéneos compuestos de células procumbentes en el centro y

cuadradas en los extremos. Los uniseriados llegan a 7 células de altura y son heterogéneos

De pared delgada, de sección subrectangular a circular y con Pared medianamente engrosada, de sección circular a punteaduras hexagonal y con punteaduras. No septadas

Uniseriados y multiseriados. Multiseriados de 10 (6-17)

células de espesor y hasta $5 \mathrm{~mm}$ de altura (promedio 1,5 ). Radios uniseriados de 6 (1-15) células de altura. Heterogéneos

punteaduras

Tabla 4.32: tabla comparativa entre Scalarixylon grandiradiatum y su pariente vivo más cercano. 


\section{Caracteres}

Presencia de anillos

\section{Porosidad}

Disposición de los vasos

Contorno de vasos

Diámetro tangencial de los vasos $(\mu \mathrm{m})$

Placas de perforación
Nothofagoxylon scalariforme

Presentes. Marcados por una reducción del tamaño de vasos y del diámetro radial, de

1-3 hileras de fibras del leño tardío

$$
\text { Difusa a semicircular }
$$

Solitarios o en series radiales de hasta 4

$$
\text { vasos }
$$

Circular, elongado

$$
53 \text { (13-118) }
$$

$40(25-63) ; 2) 51(25-80)$;
1)Nothofagus antarctica; 2) N. pumilio; 3)N. nitida;4) N. betuloides; 5) N. dombeyi

\begin{tabular}{|c|c|c|}
\hline Placas de perforacion & leño tardío & Simples \\
\hline Punteaduras & $\begin{array}{c}\text { Escalariformes a opuestas, raramente } \\
\text { alternas }\end{array}$ & Opuesta a escalariforme \\
\hline $\begin{array}{l}\text { Punteaduras radio- } \\
\text { vasculares }\end{array}$ & $\begin{array}{c}\text { Circulares a horizontalmente elongadas } \\
\text { con un arreglo de opuestas a } \\
\text { escalariformes }\end{array}$ & $\begin{array}{l}1 ; 3 ; 4) \text { Opuestas o escalariformes; 2) Opuestas, escalariformes u irregulares; } \\
\text { 5) opuestas }\end{array}$ \\
\hline Parénquima axial & $\begin{array}{c}\text { Difuso, su abundancia varía según el } \\
\text { ejemplar }\end{array}$ & Difuso. Escaso \\
\hline Radios & $\begin{array}{l}\text { Uniseriados o parcialmente biseriados. } \\
\text { Heterogéneos, normalmente con una } \\
\text { hilera de células erectas a cuadradas en los } \\
\text { extremos }\end{array}$ & $\begin{array}{l}\text { Heterogéneos, con células procumbentes y células erectas en ambos márgenes. } \\
\begin{array}{l}\text { 1;2) Uniseriados o biseriados. 3;5) Uniseriados o parcialmente biseriados; } \\
\text { 4) exclusivamente uniseriados }\end{array}\end{array}$ \\
\hline Fibras & No septadas & Septadas \\
\hline Observaciones & Cristales en el parénquima axial & Cristales en el parénquima \\
\hline
\end{tabular}

\section{Presentes}

Difusa

Tabla 4.33: tabla comparativa entre Nothofagoxylon scalariforme y su pariente vivo más cercano. 


\section{Caracteres}

Presencia de anillos

Porosidad

Disposición de los vasos

Contorno de vasos

Diámetro tangencial de

los vasos $(\mu \mathrm{m})$

Placas de perforación

Punteaduras

Punteaduras radio-

vasculares

Parénquima axial

Radios

Triseriados o biseriados, heterogéneos con una hilera de células marginales cuadradas o erectas

Presentes. Marcados por una reducción del tamaño de vasos

y del diámetro radial de 15-20 hileras de fibras del leño tardío

$$
\text { Semicircular }
$$

Solitarios o series radiales de 2-3 vasos (hasta 6 en el leño tardío)

Elípticos, radialmente elongados

$$
80(45-115)
$$

Simples, raramente escalariformes en el leño tardío

Opuestas a alternas

Circulares

1) Opuestas; 2) Opuestas a alternas

Solitarios, de a pares, o en series radiales de 4-6 poros

Ovales

1) Opuestas a escalariformes; 2) Alternas a irregulares

Fibras

De pared delgada

Observaciones 


\section{Caracteres}

Presencia de anillos

Porosidad

Disposición de los vasos

Contorno de vasos

Diámetro tangencial de

los vasos ( $\mu \mathrm{m})$

Placas de perforación

Punteaduras

Punteaduras radio-

vasculares

Parénquima axial

Radios

Fibras

Observaciones
Nothofagoxylon kraeuseli

Presentes, marcados por la reducción del diámetro radial de las últimas 3-8 fibras de leño tardío

Difusa a semicircular Solitarios o series radiales de hasta 5 vasos Circular a elíptico

$$
56 \text { (25-100) }
$$

1)N. obliqua; 2) N. alpina

Presentes

Difusa y semicircular Solitarios, de a pares, o en series radiales de 4-6 poros

Ovales

1) $43(29-69)$; 2) $75(40-120)$

Simples

1) Opuestas a alternas; 2) Opuestas, algunas veces

escalariformes

Opuestas a alternas, raramente escalariformes

1) Opuestas a escalariformes; 2) Alternas a irregulares; Opuestas

Difuso

Heterogéneos.

Típicamente biseriados, pero también uniseriados con

porciones biseriadas. Heterogéneos

1) Uni y biseriado, raramente triseriado; 2) Uni o biseriados No septadas Septadas

Tabla 4.35: tabla comparativa entre Nothofagoxylon kraeuseli y su pariente vivo más cercano. 


\section{Caracteres}

Presencia de anillos

Porosidad

Disposición de los vasos

Contorno de vasos

Diámetro tangencial de

los vasos $(\mu \mathrm{m})$

Placas de perforación

Punteaduras

Punteaduras radio-

vasculares

Parénquima axial

Radios

Fibras

Observaciones
Nothofagoxylon ruei

Presentes. Marcados por una reducción del tamaño de vasos y del diámetro radial de 5-10 hileras de fibras del leño tardío

$$
\text { Semicircular }
$$

Nothofagus alessandri

Presentes

Difusa

Solitarios o series radiales de 4 vasos, raramente de más o en

grupos

Solitarios o en series radiales de 2 a 4 vasos, o en ocasiones

hasta 8

Ovalado

Circular a cuadrangula

$46(25-75)$

$45(22-78)$

Simples

Simples

Alternas

Alternas, raramente opuestas

Transicionales a circulares

Circulares

Difuso

Uniseriados, en ocasiones localmente biseriados. Heterogéneos, con una hilera de células erectas marginales

Mayormente uniseriados, también biseriados. Heterogéneos Pared delgada

Paredes delgadas

Tabla 4.36: tabla comparativa entre Nothofagoxylon ruei y su pariente vivo más cercano. 


\section{Caracteres}

Presencia de anillos

Porosidad
Nothofagoxylon aggregatum

Presentes. Marcados por una reducción del tamaño de vasos y del diámetro radial de 3-5 hileras de fibras del leño tardío
Nothofagus glauca

Presentes
Radiales múltiples de hasta 9 vasos y ocasionalmente en

Disposición de los vasos agrupados de a 6-10 vasos en el leño tardío. Los vasos tienen una tendencia al arreglo diagonal en el leño tardío

\begin{tabular}{|c|c|c|}
\hline Contorno de vasos & Circular & Ovales \\
\hline $\begin{array}{l}\text { Diámetro tangencial de } \\
\text { los vasos }(\mu \mathrm{m})\end{array}$ & $51(27-88)$ & $50(37-69)$ \\
\hline Placas de perforación & Simples & Simples \\
\hline Punteaduras & $\begin{array}{c}\text { Alternas y también opuestas a escalariformes hacia la porción } \\
\text { terminal de los vasos }\end{array}$ & Opuestas \\
\hline $\begin{array}{l}\text { Punteaduras radio- } \\
\text { vasculares }\end{array}$ & Opuestas a escalariformes & Opuestas a escalariformes \\
\hline Parénquima axial & Difuso & Difuso \\
\hline Radios & $\begin{array}{c}\text { Radios usualmente triseriados, raramente uni-biseriados o } \\
\text { parcialmente 4-seriados. Heterogéneos, con una hilera de } \\
\text { células cuadradas o erectas }\end{array}$ & Heterogéneos. Uni, bi o triseriados \\
\hline Fibras & De pared delgada & No septadas \\
\hline Observaciones & Tilosis abundante & --- \\
\hline
\end{tabular}

Tabla 4.37: tabla comparativa entre Nothofagoxylon aggregatum y su pariente vivo más cercano.

Solitarios, de a pares, o en series radiales de $4-6$ poros Ovales

\section{Difusa}




\section{Caracteres}

Presencia de anillos

Porosidad

Disposición de los vasos

Contorno de vasos

Diámetro tangencial de

los vasos ( $\mu \mathrm{m})$

Placas de perforación

Punteaduras

Punteaduras radio-

vasculares

Parénquima axial

Radios

Fibras

Observaciones

\section{Myrceugenellites oligocenum}

Presentes, marcados por la reducción del diámetro radial de las últimas 2-3 hileras de fibras en el leño tardío

$$
\text { Difusa }
$$

Solitarios o en pares tangenciales

Angular a oval

Luma apiculata

Presentes, marcados por la reducción del diámetro radial de las últimas 2-3 hileras de fibras en el leño tardío

$$
\text { Difusa }
$$

Mayoría solitarios, raramente agrupados

Circulares u ovalados

$29(15-52)$

$$
29(15-38)
$$

Escalariformes (21-37 barras) Escalariforme a alterna

Opuestas a escalariforme

Apotraqueal difuso escaso

---

Uniseriados y parcialmente biseriados. Heterogéneos parcialmente biseriados. Heterogéneos

Fibrotraqueidas, en ocasiones septadas

Fibrotraqueidas septadas

Tilosis. Células radiales con uno o dos contenidos oscuros circulares

Tilosis

Tabla 4.38: tabla comparativa entre Myrceugenellites oligocenum y su pariente vivo más cercano. 


\section{Caracteres}

Presencia de anillos

Porosidad

Disposición de los vasos

Contorno de vasos

Diámetro tangencial de

los vasos $(\mu \mathrm{m})$

Placas de perforación

Punteaduras

Punteaduras radio-

vasculares

Parénquima axial

Radios

Fibras

Observaciones
Laurelites doroteaensis

Presentes, marcados por la reducción del diámetro radial de 1-2 hileras de fibras en el leño tardío

Difusa

1) Laureliopsis philippiana; 2) Laurelia sempervirens

Presentes, delimitados por la compresión radial de fibras y la disminución del tamaño de poros

$$
\text { Difusa }
$$

\section{Mayormente solitarios, en ocasiones también de agrupados Mayormente solitarios, en ocasiones también de agrupados de}

de a pares

a pares

Angular a ova

Oval a angular

$$
47(25-75)
$$

1) 32 (14-50); 2) 46 (31-62)

scalariformes (20-45 barras)

Opuestas a escalariformes

Escalariformes (1) 25-70 barras; 2) 11-21)

Escalariformes

Escalariformes

Escalariformes

Escasamente visible. Difuso

Multiseriados, de 3-4(6) células de ancho. Heterogéneos, con Uni-, bi- y triseriados. Heterogéneos. Con 1-3 (6) células

1-3 hileras de células cuadradas a erectas en los extremos marginales

No septadas, de paredes gruesas y con punteaduras tanto en las caras radiales como en la tangenciales

No septadas, con punteaduras $--$

Tabla 4.39: tabla comparativa entre Laurelites doroteaensis y su pariente vivo más cercano. 

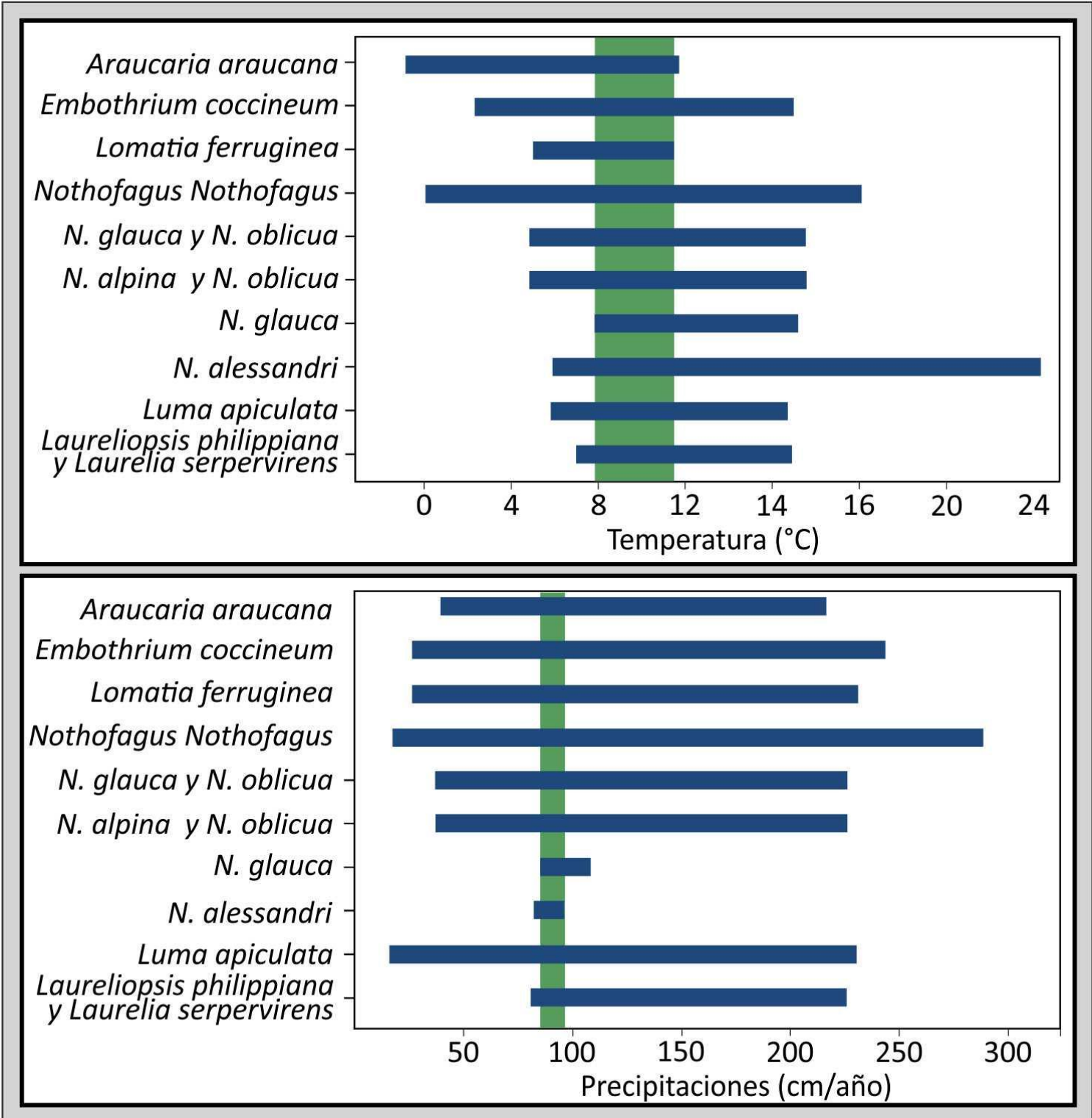

Fig. 4.41. Gráficos de MAT y MAP según el método del Coexistence Approach.

Como resultado de la aplicación del método del Coexistence Approach se obtuvo una temperatura media anual (MAT) de entre $8^{\circ}$ y $11,6^{\circ} \mathrm{C}$ y precipitaciones medias anuales (MAP) de entre 84,4 y $96,3 \mathrm{~cm}$ anuales (Fig. 4.41).

\subsection{Caracteres eco-xilológicos}

La porosidad es claramente difusa en todas las especies a excepción de las Nothofagaceae y del Xilotipo 3 (Pujana, 2008), que tienen una tendencia a la porosidad semicircular y de Doroteoxylon vicente-perezii, que presenta porosidad circular. Además, las dos especies de Scalarixylon, si bien de porosidad difusa por definición, presentan una mayor concentración de elementos de vaso en el leño temprano y están 
casi desprovistas de ellos en el tardío, lo que funcionalmente la asemeja bastante al leño con porosidad semicircular. La porosidad circular está asociada normalmente a climas templados (Wheeler \& Baas, 1991, 1993; Wheeler et al., 2007; Baas \& Wheeler, 2011).

En cuanto a la disposición de los vasos, Maloidoxylon cesariae los tiene solitarios mientras que las Nothofagaceae y Resinaxylon schinusoides los tienen solitarios o en series radiales, $R$. schinusoides con una tendencia al arreglo diagonal. Myrceugenellites oligocenum y Laurelites doroteaensis tienen vasos solitarios o en pares tangenciales. Sacalarixylon patagonicum presenta bandas tangenciales de vasos (2-3) con un patrón festoneado y en ocasiones conectadas entre ellas radialmente. Lo mismo ocurre con Scalarixylon grandiradiatum, solo que las bandas son más angostas (1-2 vasos). El Xilotipo 3 (Pujana, 2008) presenta vasos solitarios, en series radiales y tangenciales cortas en el leño temprano, mientras que en el tardío presenta bandas diagonales a tangenciales. Doroteoxylon vicente-perezii con porosidad circular tiene vasos solitarios o en pares tangenciales en el leño temprano y agrupados en el leño tardío. Tanto las bandas de vasos diagonales como los agrupados se suelen asociar a climas subtropicales a templados (Baas \& Xinying, 1986; Wheeler \& Bass, 1993; Wheeler et al., 2007.)

El diámetro tangencial medio de los elementos de vaso es menor a $100 \mu \mathrm{m}$ en todos los casos, excepto en el Xilotipo 3 (Pujana, 2008), esto es común en áreas templado-frías o templadas de montaña (Baas \& Xinying, 1986; Schweingruber, 1988; Wheeler \& Baas, 1991; Carlquist, 2001).

El largo de los miembros de vasos es muy variable, con valores entre 143 y 650 $\mu \mathrm{m}$, por lo que este dato no sería muy significativo.

La frecuencia de vasos también es variable, rondando desde 200 vasos por $\mathrm{mm}^{2}$, con frecuencias excepcionalmente mínimas de 40 vasos por $\mathrm{mm}^{2}$ y llegando hasta 430 vasos por $\mathrm{mm}^{2}$. Una alta frecuencia de vasos es común en regiones templado-frías a polares o tropicales de alta montaña, así como también en regiones áridas (Van der Graaff \& Baas, 1974; Baas \& Xinying, 1986, Schweingruber, 1988; Wheeler \& Baas, 1991; Baas \& Wheeler, 2011). 
Del total de 13 especies, ocho presentan placas de perforación simples, tres tienen placas simples o escalariformes ( $y$ con pocas barras cuando escalariformes) y solo dos poseen placas exclusivamente escalariformes (con numerosas barras). Por lo que el predominio de placas de perforación simples indicaría el desarrollo de un clima cálido (Baas, 1982; Baas \& Schweingruber, 1987; Wheeler \& Baas, 1991, 1993; Wheeler et al., 2007)

Doroteoxylon vicente-perezii y el Xilotipo 3 (Pujana, 2008) presentan engrosamientos espiralados en los elementos de vaso, éstos son característicos de lugares templado-fríos y también comunes en zonas secas (Van der Graaff \& Baas, 1974; Baas \& Xinying, 1986; Baas \& Schweingruber, 1987; Wheeler \& Baas, 1991, 1993; Wheeler et al., 2007; Carlquist, 2012).

Las punteaduras de los elementos de vaso tienen en la mayoría un diámetro de entre 5 y $7 \mu \mathrm{m}$, con la excepción de Maloidoxylon cesariae en donde son muy pequeñas (de $2 \mu \mathrm{m}$ ) y en el Xilotipo 3 (Pujana, 2008) en donde son notablemente más grandes (de 6 a $10 \mu \mathrm{m}$ ). Dado que el diámetro de las punteaduras sería mayor en lugares húmedos (Carlquist, 2001), se infiere que la región era muy húmeda.

Hay solo tres especies con fibras septadas: Myrceugenellites oligocenum, Doroteoxylon vicente-perezii y Resinaxylon schinusoides. Diversos autores afirman que la presencia de fibras septadas es un rasgo común en lugares tropicales (Baas \& Schweingruber, 1987; Schweingruber, 1988; Wheeler \& Baas, 1991 Wheeler et al., 2007).

Cerca de la mitad de las especies presentan fibras de paredes gruesas y la otra mitad paredes finas, por lo que este carácter es también muy variable. Siendo las fibras de paredes gruesas más comunes en zonas influenciadas por sequías (Baas \& Wheeler, 2011).

El parénquima axial es mayoritariamente escaso y difuso (i.e. Maloidoxylon y Nothofagoxylon spp.), carácter común en zonas templadas. (Schweingruber, 1988; Wheeler \& Baas, 1991; Wheeler et al., 2007; Soffiatti et al., 2016; Morris et al., 2018). 
Solo Nothofagoxylon scalariforme presenta cristales. Estas estructuras tienen actualmente mayor ocurrencia en regiones templadas a tropicales, y se incrementan en lugares xéricos (Wheeler et al., 2007). 

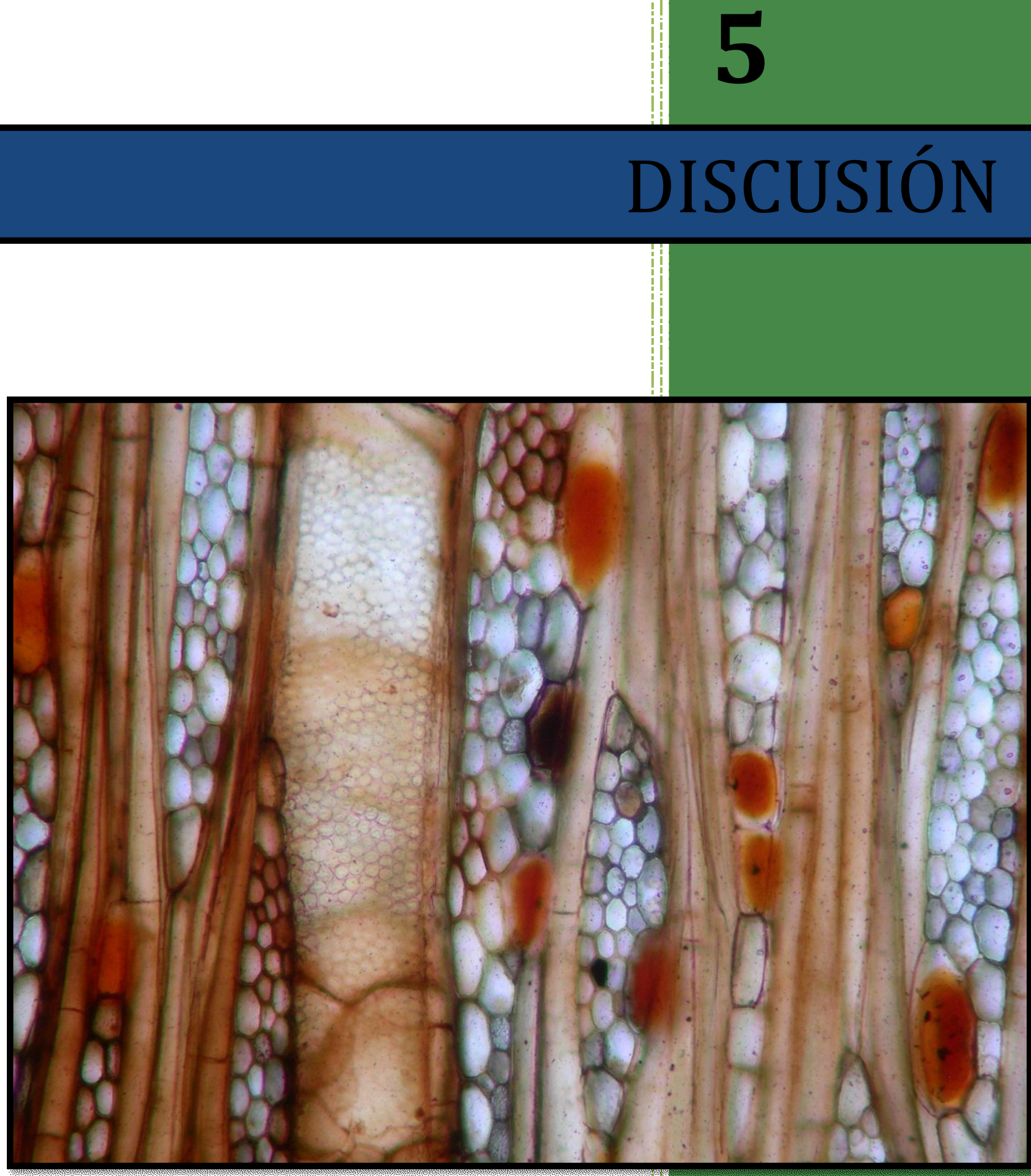

DANIELA P. RUIZ 


\section{ECUACIONES DE WIEMANN ET AL. (1998, 1999) EN MADERAS ACTUALES}

Wiemann et al. (1998) examinaron los caracteres anatómicos de la madera y su relación con la temperatura y las precipitaciones en los bosques actuales, abarcando desde climas tropicales a climas templados. Utilizaron 37 localidades para generar las ecuaciones para el cálculo de la temperatura media anual (MAT) y las precipitaciones medias anuales (MAP), pero solo cuatro localidades se ubican en el hemisferio sur y en latitudes que no superan los $19^{\circ} \mathrm{S}$. Una situación similar ocurre en el trabajo de Wiemann et al. (1999) donde generan 16 nuevas ecuaciones para el cálculo del MAT a partir de 21 localidades, de las cuales sólo tres pertenecen al hemisferio sur, nuevamente $\sin$ superar los $19^{\circ} \mathrm{S}$. Asimismo, utilizan otras 21 localidades para validar las ecuaciones y ninguna de ellas corresponde al hemisferio austral.

Si observamos los resultados obtenidos para el cálculo del MAT a partir de las ecuaciones propuestas por Wiemann et al. (1998, 1999) (Tabla 4.1 y Fig. 5.1), vemos en líneas generales que los resultados no son precisos y en su mayoría tienden a dar valores mayores que los valores reales de temperatura. Sin embargo, a pesar de que los valores absolutos no tienen una buena correlación, sí se evidencian ciertos patrones:

- Las ecuaciones proporcionan datos con mayor precisión en las localidades de bajas latitudes, coincidiendo así con las zonas más cálidas. Entre dos y siete ecuaciones estimaron valores de temperaturas ubicados dentro de los rangos de temperaturas medidos actualmente para las localidades analizadas. Esto bien podría deberse a que las localidades más australes cuentan con menos cantidad de datos por presentar una riqueza de taxones menor y a la vez, son las que están menos estudiadas en lo que su anatomía del leño respecta.

- La ecuación para el cálculo del MAT de Wiemann et al. (1998) es la que arroja los valores que mejor ajustan a las comunidades boscosas que se desarrollan en la actualidad, dando valores precisos en cinco de las ocho localidades. En los tres casos donde los resultados no eran los esperados se trató siempre de temperaturas menores. 
- Las ecuaciones 1, 2, 5 y 8 (Wiemann et al., 1999) mostraron todas temperaturas notablemente mayores a las esperadas $\left(>5^{\circ} \mathrm{C}\right)$. De cualquier manera, los valores son más bajos en las localidades al sur y más elevados al norte.

- Las ecuaciones 3 y 7 (Wiemann et al., 1999) dan en su mayoría valores menores (en general $5^{\circ}-10^{\circ} \mathrm{C}$ menos de lo esperado), pero en líneas generales se vuelve a dar que los valores son más bajos en las localidades al sur y más elevados al norte.

- La ecuación 6 proporciona valores menores a los reales en las localidades más frías de latitudes mayores, y por el contrario da valores mayores en las localidades más cálidas de latitudes menores (siempre con un desfasaje de $\pm 5-$ $\left.10^{\circ} \mathrm{C}\right)$.

- Las ecuaciones comprendidas entre la 9 y la 16 arrojan resultados que no difieren mucho entre las localidades y que varían aproximadamente en $4^{\circ} \mathrm{C}$ entre la temperatura más baja y la más alta obtenida con cada ecuación. La ecuación 9 da valores que rondan los $-4^{\circ}-1^{\circ} \mathrm{C}$, la 10 los $21^{\circ}-23^{\circ} \mathrm{C}$, la 11 los $25-$ $28^{\circ} \mathrm{C}$, la 12 los $21^{\circ}-25^{\circ} \mathrm{C}$, la 13 los $15^{\circ}-19^{\circ} \mathrm{C}$, la 14 los $27^{\circ}-31^{\circ} \mathrm{C}$, la 15 los $14^{\circ}-$ $18^{\circ} \mathrm{C}$ y la 16 los $6^{\circ}-9^{\circ} \mathrm{C}$. Estos rangos de valores indican que los resultados obtenidos con las ecuaciones de la 10 a la 15 en algunas de las localidades más cálidas estén dentro de las temperaturas esperadas, pero esto no se debería necesariamente a que la ecuación funciona correctamente, ya que claramente hay un sesgo en las temperaturas que se obtienen. Lo mismo ocurre con la ecuación 16 cuyo rango de resultados es más bajo, haciendo que los resultados coincidan en algunas de las localidades más frías, pero estén por debajo de lo esperado en las localidades más cálidas. La ecuación 9 da todos los valores por debajo de lo esperado y son los más bajos de todos, no coincidiendo ni siquiera con las temperaturas de las localidades más frías.

Fig. 5.1. Representación gráfica de las temperaturas obtenidas en cada localidad con las distintas ecuaciones propuestas por Wiemann et al., $(1998,1999)$. Entre paréntesis la temperatura real de cada localidad. 


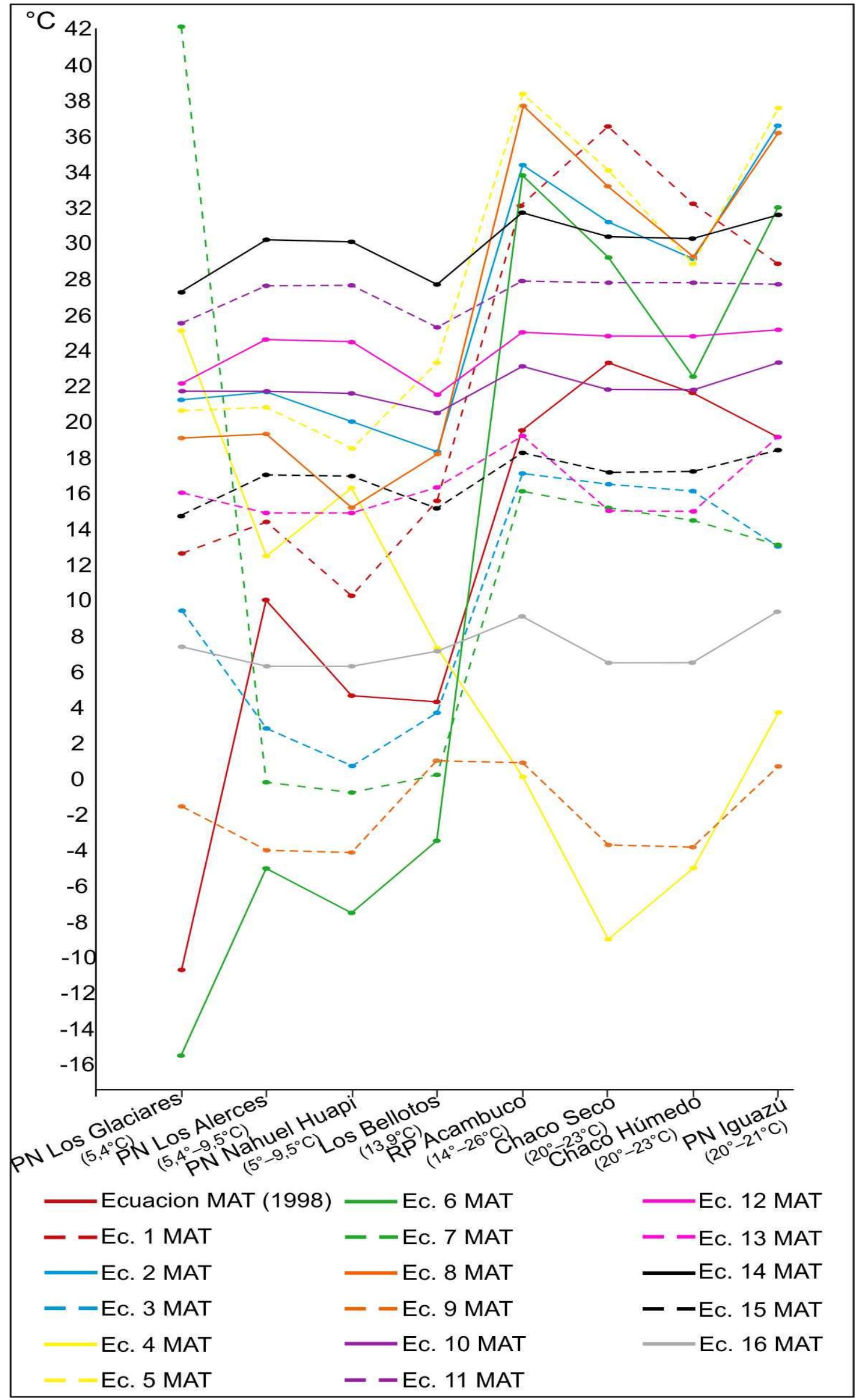


En consecuencia, se evidencia que las ecuaciones tal cual como están formuladas no dan resultados certeros con taxones que tiene una distribución en el sur de Sudamérica, a excepción de la ecuación propuesta en 1998, sobre todo en las localidades distribuidas más al norte del continente Sudamericano. De cualquier manera, las ecuaciones 1, 2, 5, 6 y 8 servirían a modo comparativo entre localidades para denotar cual es más cálida y cuál más fría pero no para obtener un valor absoluto. Asimismo, las tendencias observadas en las ecuaciones indicarían que igualmente hay una correlación entre las características de los leños y la temperatura del ambiente, pero habría que modificar las ecuaciones con valores de corrección o bien obtener nuevas ecuaciones para la región.

En cuanto al cálculo de las precipitaciones medias anuales, los resultados de la ecuación son siempre notablemente mayores que los esperados. A pesar de esto, los valores más bajos se corresponden con los lugares donde las precipitaciones son menores y los mayores con las zonas más lluviosas. Es decir que con la ecuación podemos comparar las distintas localidades y predecir con certeza cuál es más o menos lluviosa aunque no podamos calcular con exactitud la cantidad de milímetros anuales de precipitación.

\section{PALEOCENO}

\subsection{Paleoclima inferido previamente en Patagonia y Antártida en base a diferentes indicadores}

El Paleoceno cuenta con abundantes trabajos, abordado desde diferentes disciplinas, que brindan información relevante de cómo habría sido el paleoclima durante este lapso de tiempo geológico. Por ejemplo, Pascual \& Odreman Rivas (1971) hacen un aporte desde la rama de la paleontología de vertebrados, señalando la presencia de cocodrilos como indicador de un probable clima cálido y con precipitaciones pluviales anuales abundantes. Estos grandes poiquilotermos, carentes de un mecanismo regulador de la temperatura no pueden soportar temperaturas templado-frías, ni pueden encontrar refugio bajo tierra como lo hacen los pequeños poiquilotermos (Volkheimer, 1971). Simpson (1937) y Bona (2007) también mencionan la presencia de cocodrilos en la Fm. Salamanca. 
En lo referente a la sedimentología, Andreis et al., (1973) concuerdan con las evidencias paleontológicas, al decir que la Fm. Cerro Bororó se depositó bajo condiciones de clima templado-cálido y húmedo. El principal rasgo concluyente en este sentido es la abundante presencia de carbonatos. Además, hacia los sectores más altos del Miembro superior se evidencia un cambio a climas más secos. Los autores sustentan esta última conclusión en base al hallazgo de venillas de yeso, cemento de yeso y ceolitas.

Sin embargo, la mayor parte de los estudios paleoclimáticos fueron llevados a cabo por la rama de la paleobotánica, que también avala la presencia de un clima templado-cálido y húmedo durante el depósito de las formaciones de edad paleocena, incluidas las Fm. Cerro Bororó y Salamanca. Romero $(1968)$ y Arguijo $(1979,1981)$ describen tres palmeras presentes en la Fm. Salamanca (Palmoxylon patagonicum Romero) y en la Formación Cerro Bororó (Palmoxylon bororoense Arguijo y Palmoxylon vaterum Arguijo), estimando que habitaron zonas templadas a templado-cálidas dados los requerimientos térmicos de las palmeras actuales. En el presente tienen una distribución limitada por la isoterma de $18^{\circ} \mathrm{C}$ de temperatura media anual, exceptuando en Nueva Zelanda donde llega a la isoterma de $12^{\circ} \mathrm{C}$ (según Volkheimer, 1971) y en la zona del Maule en Chile con unos $15^{\circ} \mathrm{C}$ (Flores et al., 2016). Es importante destacar que en la localidad paleocena de Las Violetas estudiada en esta tesis, también se han registrado palmeras fósiles representadas por estructuras reproductivas (Futey et al., 2012) y por estípites permineralizadas (Ruiz et al., en preparación).

En el ámbito de la paleopalinología, los primeros estudios de las especies polínicas procedentes de las Fm. Cerro Bororó y Salamanca corresponden a Archangelsky (1973) y Archangelsky \& Romero (1974). En ocasiones, dichos autores hacen mención a los factores climáticos con los cuales se relacionarían las plantas productoras de los granos de polen y esporas estudiadas. Tal es el caso de las esporas de helechos con alto requerimiento de humedad, granos con probable afinidad a géneros de Olacaceae que actualmente tienen distribución tropical y granos pertenecientes a palmeras (en concordancia con lo mencionado en el párrafo anterior), algunas de ellas afines a formas actualmente restringidas a manglares (Archangelsky, 1973). Por otro lado, los registros de polen de gimnospermas 
(Podocarpaceae) indican la presencia de un régimen cálido en el Paleoceno temprano (Archangelsky \& Romero, 1974).

Recientemente Volkheimer et al. (2007) estudiaron diversas asociaciones palinológicas de la Fm. Cerro Bororó con el fin de conocer mejor las paleocomunidades de la zona. Allí también concluyen que las cinco paleocomunidades que llegan a definir, muestran condiciones climáticas subtropicales durante el Daniano de Patagonia central. La humedad habría sido variable desde la planicie costera hacia el interior, pero ésta se incrementaría en asociación con cuerpos de agua fresca muy cercanos a la costa, como así también en zonas pantanosas.

En un trabajo complementario al de Volkheimer et al. (2007), Scafati et al. (2009) describen la palinobiota lacustre del miembro inferior de la Fm. Cerro Bororó, la cual incluye algas, dinoflagelados, briofitas, pteridofitas y angiospermas. Junto con la mayoría de las descripciones, señalan las condiciones ambientales en las cuales viven actualmente dichas especies o géneros, o bien las condiciones en las cuales habitan los taxones actuales más estrechamente emparentados en caso de tratarse de especies enteramente fósiles. De esta manera, llegaron a la conclusión de que se trataba de un ambiente lacustre situado en el litoral marino por detrás de la línea de costa, junto con pantanos costeros salobres. Además, este ambiente se habría desarrollado bajo condiciones climáticas subtropicales, con calor y humedad, según lo señala el hallazgo de géneros que actualmente tienen su óptimo crecimiento alrededor de los $20^{\circ} \mathrm{C}$.

Zucol et al. (2008) dan a conocer las condiciones paleoambientales de los bosques fósiles del sur de Chubut Víctor Szlápelis y José Ormaechea (Fm. Salamanca), a partir del estudio de microfósiles silíceos. La presencia de traqueidas y vasos silicificados, fitolitos con afinidad graminoide, stegamatas de palmera y fitolitos de helechos arborescentes son indicadores de condiciones climáticas húmedas y cálidas.

Clyde et al. (2014) datan la Fm. Salamanca con distintos métodos, entre ellos el uso de palinomorfos, y allí también mencionan la presencia las esporas de taxones indicadores de ambientes templado-cálidos, no totalmente tropicales.

Otro importante indicador de paleotemperaturas son las impresiones foliares. Iglesias (2007) utiliza la técnica del análisis de márgenes foliares de 
impresiones/compresiones de hojas de angiospermas de dos localidades en donde aflora la Fm. Salamanca, para el cálculo de la temperatura media anual (MAT). Como resultado obtiene un MAT de $14,1^{\circ} \mathrm{C}\left( \pm 2,6^{\circ} \mathrm{C}\right)$ en Palacio de Los Loros y $2,1^{\circ} \mathrm{C}\left( \pm 3,52^{\circ} \mathrm{C}\right)$ en el Bosque de Ormaechea. También aplica el análisis del área foliar para el cálculo de la precipitaciones medias anuales (MAP) en las mismas localidades, obteniendo valores de $106,71(+46,10,-32,18) \mathrm{cm}$ en Palacio de Los Loros y 107,91 $(+46,60,-32,55) \mathrm{cm}$ en el Bosque de Ormaechea. Concluye que, las paleotemperaturas con mayor confidencia obtenidas del análisis de margen foliar de las floras del Paleoceno inferior estudiadas, indican valores que concuerdan con el incremento de temperaturas medias observado en el inicio del Paleoceno a escala mundial (Iglesias, 2007). Además, señala que las paleofloras estudiadas se corresponden con la paleoflora neotropical de Romero (1986) y la paleoflora subtropical gondwánica de Hinojosa (2005), pero con la salvedad de presentar hojas de Nothofagaceae que se habrían emplazado en climas mucho más cálidos, comparables a los actualmente alcanzados por la familia en el norte de Australasia. Por último, menciona que la presencia de familias termófilas como Arecaceae, Akaniaceae, Menispermaceae, Sapindaceae, probables Cunoniaceae, y hojas grandes y anchas de Podocarpaceae, que también estarían sugiriendo climas cálidos (Iglesias, 2007). Posteriormente publica un MAT de $14,1^{\circ} \mathrm{C} \pm 2,6^{\circ} \mathrm{C}$ en base a estudios del margen foliar (57,6\% de las especies dentadas) y un MAP de al menos 115 (+50/-35) cm en Palacio de los Loros (Iglesias et al., 2007).

Asimismo, existen algunos trabajos de recopilación y síntesis que compilan datos obtenidos a partir de diferentes disciplinas o especialidades en distintas formaciones a lo largo del Paleógeno. Tal es el caso de Petriella \& Archangelsky (1975) quienes reúnen la información obtenida hasta ese momento, que pudiera brindar información acerca de cómo era el ambiente y las condiciones paleoambientales durante el Paleoceno de Chubut. Principalmente, analizan la distribución geográfica y las condiciones ambientales de los taxones actuales equivalentes a los fósiles vegetales que allí mencionan. En dicho trabajo concluyen que el clima dominante debió ser del tipo subtropical húmedo.

Otros trabajos reconocidos, que reúnen las evidencias paleobotánicas obtenidas son los de Romero $(1973,1986)$. Romero diferencia las paleofloras del sur 
de Sudamérica en base a su composición taxonómica desde el Cretácico Superior, hasta el Mioceno. Las tres paleofloras resultantes fueron: la neotropical, con géneros o ancestros de taxones actualmente exclusivos de la región fitogeográfica neotropical; la antártica, con géneros o ancestros de taxones actualmente exclusivos de la región fitogeográfica antártica; y una mixta, con taxones de las anteriores coexistiendo. Según esta clasificación las floras de las Formaciones Cerro Bororó y Salamanca se ubican como "paleoflora neotropical" la cual se corresponde con un clima cálido (Romero, 1986). Si bien previamente el mismo Romero (1973) menciona granos de Nothofagidites en la Fm. Cerro Bororó y Salamanca (lo que la convertiría en una paleoflora de tipo mixto), estos son sumamente escasos (solo 4 granos en el perfil de Fm. Bororó y solo están presentes en uno de los tres perfiles estudiados de la Fm. Salamanca).

Años más tarde, Hinojosa \& Villagrán (1997) hacen una nueva revisión de los estudios paleobotánicos publicados en el cono sur, integrando los antecedentes en el marco de eventos tectónicos y climáticos que afectaron al sur de Sudamérica durante el Cenozoico. Concuerdan con los investigadores predecesores en que durante el Paleoceno de Sudamérica dominaban elementos florísticos tropicales y que en la Antártida había una mezcla de elementos tropicales y propios.

Posteriormente, Troncoso \& Romero (1998) hacen un esquema aún más detallado incluyendo 12 tipos paleoflorísticos en el extremo sur de Sudamérica, todos definidos sobre la base de la composición sistemática de los conjuntos exhumados y de las morfologías dominantes. Según este esquema, colocan a las tafofloras de las Formaciones Cerro Bororó y Salamanca como una paleoflora neotropical terciaria con Nothofagus marginal y con taxones actualmente tropicales o subtropicales de clima cálido (Troncoso \& Romero, 1998). Por consiguiente, más allá del mayor detalle en la composición paleoflorística, la conclusión arribada sigue siendo la misma que en los trabajos previos de Romero $(1973,1986)$, anteriormente explicados.

Hinojosa (2005) reformula la nomenclatura de las paleofloras cenozoicas del sur de Sudamérica en función del paleoclima y la distribución fitogeográfica de los elementos de las tafofloras. Según su esquema, el cono sur durante el Paleoceno 
estaba dominado por lo que denomina "Paleoflora Gondwanica". Esta se caracteriza por el dominio de elementos australásico, neotropicales, pantropicales, distribuídos actualmente en regiones cálidas del mundo, por lo que se habría desarrollado en condiciones climáticas tropicales, cálidas y muy húmedas. El elemento australantárctico estaba ausente.

Matheos et al. (2005) infiere las condiciones paleoecológicas y paleoambientales durante el Paleoceno de los bosques Víctor Szlápelis y José Ormaechea (Fm. Salamanca, Chubut) reuniendo datos paleopalinológicos, paleobotánicos y sedimentológicos. Concluyen que el contenido fosilífero se habría desarrollado en condiciones de un ambiente estable de clima templado-cálido y húmedo, con periodos estivales secos y primaverales lluviosos, donde la precipitación no parece haber actuado como un factor limitante en el crecimiento de la tafoflora. Asimismo, la temperatura no habría sido inferior al punto de congelamiento dado que no hay señales criogénicas en los anillos de crecimiento de los troncos.

Además de las Formaciones Cerro Bororó y Salamanca, existen otras importantes formaciones de edad paleocena en la Patagonia Argentina y la Antártida, donde numerosos estudios, principalmente paleobotánicos, han permitido realizar inferencias paleoclimáticas. Tal es el caso de la Formación Cross Valley en la Isla Seymour/Marambio (Antártida), en donde el porcentaje de hojas de margen entero (43\%) se corresponde con un bosque subtropical (Romero, 1986).

Barreda \& Palazzesi (2007) estudian el registro paleobotánico y paleopalinológico del Daniano (Paleoceno temprano) de las Formaciones Jagüel, Salamanca, Cerro Dorotea y Pedro Luro, y concuerdan en que hay una abundante presencia de taxones megatermales, asignables por ejemplo a las familias Olacaceae, Arecaceae, Pandanaceae y Symplocaceae (Barreda \& Palazzesi, 2007).

Raigemborn y colaboradores (2014) realizaron estudios sedimentológicos del Banco Negro inferior del Grupo Río Chico (Daniano-Eoceno medio). Esta sucesión epiclástica-piroclástica dentro de la Cuenca del Golfo San Jorge presenta esmectita y caolinita, las cuales sugieren que está unidad se depositó en un entorno cálido y húmedo. Además la relación entre estos minerales (S/K) junto con los análisis de facies 
sedimentarias, permitieron reconocer varios pulsos estacionales o de precipitaciones menos intensas durante la sucesión.

\subsection{Paleoclima inferido en base a maderas}

En el presente trabajo de tesis se estudiaron leños paleocenos procedentes de dos localidades ubicadas en la provincia del Chubut, donde afloran dos formaciones danianas temporalmente equivalentes (Fm. Cerro Bororó y Fm. Salamanca). Los resultados se resumen en la tabla 5.1.

\section{Formación Cerro Bororó:}

Los primeros estudios de leños de la Formación Cerro Bororó los llevó a cabo Petriella (1972). Expone que las angiospermas de esta unidad habrían habitado una zona con un régimen templado-cálido y húmedo. Por otro lado, el nivel de cicadales en la misma localidad indica que habrían estado bajo un régimen cálido y más seco. En lo que respecta al ambiente en el que habría habitado la comunidad de coníferas no se menciona ninguna inferencia paleoecológica ni paleoclimatológica. En base a la presencia de anillos de crecimiento demarcados, dicho autor deduce la existencia de un periodo más o menos seco durante el año. La comunidad, básicamente constituida por elementos australes o subantártico-trópico montanos y elementos tropicales, indicaba que el régimen de lluvias debió ser relativamente abundante, ya que todos los taxones hallados, indistintamente viven hoy en regiones con dicha característica. Propone dos escenarios posibles, la existencia de un relieve en el terreno que explicaría la convivencia de los elementos australes (que requieren un clima templado) y los tropicales (que requieren temperaturas cálidas); así mientras que los australes habrían ocupado nichos en zonas elevadas, los tropicales ocupaban las zonas bajas. La segunda propuesta, la vegetación se desarrollaría en una región llana con un clima cálido y húmedo en la cual los elementos australes habrían tenido una gran plasticidad ecológica.

Este mismo material procedente de la Fm. Cerro Bororó, colectado y estudiado por Petriella (1972), fue reestudiado a la luz de nuevas técnicas, además se incorporaron nuevas muestras, todas ellas coníferas del miembro fosilífero de las gimnospermas. 
Por medio de la aplicación de las ecuaciones de Wiemann y colaboradores $(1998,1999)$ se llegó a tres valores de $\operatorname{MAT}\left(-0,85^{\circ} \mathrm{C}, 16,56^{\circ} \mathrm{C}\right.$ y $\left.22^{\circ} \mathrm{C}\right)$. Es de notar que los resultados varían en cada una de las ecuaciones, comprendiendo temperaturas desde templado-cálidas hasta por debajo del punto de congelación. El resultado brindado por la Ecuación 5 (22ㅇ C) se toma como el más viable dado que comprende tres variables (tipos de placas de perforación, radios exclusivamente homogéneos y parénquima mayormente paratraqueal). Además, las ecuaciones 1 y 9 utilizan como única variable el parénquima paratraqueal, un carácter que si bien ya estaba presente en el Paleoceno, aún no contaba con los diseños más elaborados como ser el vasicéntrico u aliforme (Wheeler \& Baas, 1991). En los ejemplares analizados que cuentan con parénquima axial paratraqueal (i.e. Elaelocarpoxylon sloaneoides y Euxylophoroxylon chiquichanense) se trató siempre de parénquima escasamente paratraqueal pero, al ser el único tipo de parénquima presente en esos ejemplares, igual se consideró que el parénquima axial era en su mayoría de tipo paratraqueal. De cualquier manera, resulta ser una variable anatómica muy endeble en este caso como para basar exclusivamente en ella una ecuación de esta índole. Por otro lado, no debe olvidarse que a raíz de la puesta a prueba de estas ecuaciones en el hemisferio sur llevada a cabo en esta tesis, se observó que dichas ecuaciones requieren modificaciones y los resultados que otorgan deben tomarse con ciertos recaudos.

El método del Coexistence Approach (CA) indicó valores de temperatura comprendidos entre $25,5^{\circ} \mathrm{C}$ y $26,7^{\circ} \mathrm{C}$. Este valor estuvo principalmente determinado por los datos obtenidos de Euxylophora paraensis, especie actual de distribución netamente tropical.

El estudio de los caracteres eco-xilológicos también señala un ambiente megatérmico $\left(>24^{\circ}\right)$ a meso-megatérmico $\left(20^{\circ}-24^{\circ} \mathrm{C}\right)$. Esto puede inferirse por el gran diámetro tangencial de los elementos de vaso, la baja frecuencia de los mismos, la presencia de placas de perforación simples y los anillos de crecimiento escasamente demarcados (Van der Graaff \& Baas, 1974; Baas \& Xinying, 1986; Baas \& Schweingruber, 1987; Schweingruber, 1988; Wheeler \& Baas, 1991, 1993; Carlquist, 2001; Wheeler et al., 2007; Baas \& Wheeler, 2011). Algunos de los caracteres que se esperaría hallar en lugares tropicales y que no se encuentran en los taxones de la Fm. 
Cerro Bororó, son: porosidad circular, disposiciones de vasos elaboradas (e.g. oblicua o dendrítica), parénquima paratraqueal abundante y estructura estratificada (Schweingruber, 1988; Baas \& Xinying, 1986; Wheeler \& Baas, 1991, 1993; Wheeler et al., 2007; Baas \& Wheeler, 2011; Soffiatti et al., 2016; Morris et al., 2018). Sin embargo, dado que estos caracteres no han sido reportados con seguridad hasta el Eoceno en el hemisferio sur, no pueden ser utilizados como marcadores climáticos fiables en el Paleoceno (Wheeler \& Baas, 1991, 1993). La ausencia de engrosamientos helicoidales es también una característica de zonas cálidas pero este rasgo tampoco tiene registros previos al Eoceno (Wheeler \& Bass, 1993).

Los tres indicadores utilizados para estimar la temperatura coinciden entonces en que la temperatura media anual se correspondería con la de un ambiente, al menos, meso-megatérmico o incluso megatérmico, con valores de temperatura media anual probablemente por encima de los $20^{\circ} \mathrm{C}$. La ausencia de anillos con marcas de heladas (criogénicos) también avala este resultado.

El cálculo de las precipitaciones medias anuales (MAP) con la ecuación propuesta por Wiemann et al. (1998) dio un valor de 995,11 cm anuales. Hay que tener en cuenta que esta ecuación es menos confiable que aquellas para el cálculo del MAT (Wiemann et al., 1998) y que el valor exacto es exagerado en relación con los valores precipitaciones actuales, aun en las zonas más lluviosas. Aun así, si bien el valor es elevado en demasía, el hecho de que la disponibilidad de agua sea abundante concuerda con los otros métodos aplicados. El valor además se asemeja a los obtenidos en la puesta a prueba con maderas actuales de la cordillera patagónica, uno de los lugares más lluviosos de la región.

En cuanto al DRY (largo de la estación seca en meses), éste arrojó un valor de $-6,56$ meses. El valor negativo puede ser explicado por la total ausencia de una temporada seca (Poole et al., 2005).

Seis de las especies halladas en la Fm. Cerro Bororó (Podocarpoxylon mazzonii, Weinmannioxylon multiperforatum, Elaeocarpoxylon sloaneoides, Euxylophoroxylon chiquichanense, Rhizophoroxylon spallettii y Bridelioxylon americanum) presentan anillos de crecimiento. Lamentablemente, sólo en las muestras de Podocarpoxylon 
mazzonii los anillos están lo suficientemente bien delimitados y preservados como para efectuar una correcta medición y llevar a cabo los estudios correspondientes.

Creber (1977) señala que en las dicotiledóneas los anillos suelen no se tan claramente delimitables como en las coníferas. Esto se debe a que la madera es mucho más compleja en cuanto a su estructura y los límites de los anillos suelen estar marcados únicamente por unos pocos elementos comprimidos radialmente al final del periodo de crecimiento Creber (1977). Esto precisamente es lo que ocurre en las maderas fósiles aquí analizadas.

Comúnmente el porcentaje de leño temprano y tardío ha sido empleado para inferir condiciones climáticas (Creber \& Chaloner, 1984a, b). Sin embargo, Falcon-Lang $(2000 a, b)$ señala que podría ser un carácter relacionado con la retención foliar y, por lo tanto, determinado genéticamente. Ya que el porcentaje de leño tardío podría deberse entonces tanto a condiciones climáticas como genéticas, Falcon-Lang recomienda no usar este parámetro como indicador climático. De cualquier manera se puede concluir que las pocas hileras de leño tardío (1-4) por anillo, podrían deberse a: 1) la escases de agua al final de la temporada de crecimiento, 2) un final de la temporada de crecimiento fuertemente controlado por el fotoperiodo, o 3) una caída abrupta del follaje (Brea et al., 2008a). Dado que en las muestras estudiadas se obtuvo que la especie es perennifolia con una retención foliar de entre dos y seis años, la tercer opción (caída abrupta del follaje) no sería una opción viable en este caso.

Tanto los valores de SA (Sensibilidad Anual), como los de SM (Sensibilidad Media) y los tipos de anillos (sensu Creber \& Chaloner, 1984b), señalan condiciones climáticas variables. Estas habrían sido generalmente uniformes durante el periodo de crecimiento pero con eventos terminales marcados, quizás por condiciones climáticas extremas, las cuales serían las causantes del cese de la actividad cambial en muchos casos.

El índice de vulnerabilidad $(2,26-17,50)$ y el índice de mesomorfía $(1304,92-$ $7805,04)$ indican una alta disponibilidad de agua en el ambiente, lo que puede deberse a un régimen de lluvias abundantes. 
El CA arrojó valores de alrededor de $200 \mathrm{~cm}$ de precipitaciones anuales. Nuevamente este valor está principalmente determinado por la distribución actual de Euxylophora paraensis.

La presencia de ejemplares con elementos de vaso largos, placas de perforación simple o escalariforme con alto número de barras y fibrotraqueidas con punteaduras areoladas señalan un ambiente probablemente muy húmedo (Baas, 1982; Baas \& Xinying, 1986; Baas \& Schweingruber, 1987; Wheeler \& Baas, 1991, 1993; Carlquist, 2001, 2012). La ausencia de engrosamientos helicoidales también avalaría que se trata de un lugar de alta disponibilidad de agua (Van der Graaff \& Baas, 1974; Baas \& Xinying, 1986; Baas \& Schweingruber, 1987; Wheeler \& Baas, 1991, 1993; Carlquist, 2012), pero como se mencionó anteriormente, este carácter no es confiable para maderas de edad paleocena o anteriores (Wheeler \& Bass, 1993).

Tanto la ecuación de Wiemann et al. (1998) para el cálculo del MAP, como los índices de vulnerabilidad y mesomorfía, sumados a los caracteres xilológicos marcan la presencia de abundante agua en el ambiente. Esto indicaría que, al menos las angiospermas, se encontraban en un ambiente mesomórfico. En lo referente a las coníferas, se observa por un lado los anillos del tipo B (sensu Creber \& Chaloner, 1984b), que señalan un aporte de agua adecuado durante el período de crecimiento; y los anillos del tipo $D$, que marcan condiciones estables durante el periodo de crecimiento hasta un evento terminal el cual podría tratarse de una breve sequía. La escasez de agua al final del periodo de crecimiento, que puede ser mayor o menor dependiendo el año, se correspondería con los resultados obtenidos de SA y SM sumados al bajo porcentaje de leño tardío en los anillos. Se podría tratar entonces de un ambiente como el sugerido por Petriella (1972), con diferencias altitudinales, con las angiospermas en las zonas más bajas y las coníferas en las más altas con algo de pendiente. En este escenario, un breve periodo sin lluvias al final de la temporada de crecimiento podría pasar desapercibido para las angiospermas que crecen en las zonas bajas, donde la acumulación de agua habría sido permanente. Por otro lado, las sequías más o menos pronunciadas al final de la temporada de crecimiento habrían afectado en mayor o menor medida a las coníferas que crecían a mayor altura, donde las variaciones locales en el drenaje del suelo se habrían sumado a la falta de lluvias. 
Otra posibilidad es que haya habido diferentes tipos de suelos, con capacidades de retención de agua diferenciales, que generen microambientes a una misma altitud como ocurre actualmente en Entre Ríos. Para corroborar cualquiera de las dos hipótesis se requeriría de nuevos y más completos estudios de la geología del lugar.

Resumiendo, puede decirse que el Bosque de Cerro Bororó prosperó en un ambiente mesomórfico con lluvias abundantes durante casi todo el año, y con una breve estación sin lluvias más desfavorable, la que habría generado microclimas más secos en algunas regiones donde no se acumulaba el agua.

\section{Formación Salamanca:}

En lo referente al material de la Estancia Las Violetas (Fm. Salamanca), los resultados obtenidos fueron exiguos debido a la falta de diversidad de leños de angisopermas, lo que imposibilitó la aplicación de las ecuaciones propuestas por Wiemann et al. $(1998,1999)$. Por otro lado, la dificultad de relacionar algunos de los taxones descriptos (también de angiospermas) con taxones actuales también limitó la aplicación del método del CA.

Los anillos están bien marcados en las coníferas del bosque de Las Violetas, pero no así en las angiospermas leñosas. Actualmente situaciones como la falta de demarcación de los anillos en angiospermas es más común en zonas tropicales sin estacionalidad marcada (Wheeler \& Bass, 1993). En las coníferas es notable el ancho medio de anillo de alrededor de $2 \mathrm{~mm}$ y con máximos de hasta $5 \mathrm{~mm}$, denotando importantes períodos de crecimiento, con buen aporte hídrico y altas temperaturas (Brea et al., 2005a). Estos valores de espesores de anillos son muy similares a los de otros bosques de edad paleocena ya descriptos (ver a continuación en este capítulo y Tabla 5.2) Al igual que en los ejemplares de Cerro Bororó, el porcentaje de leño tardío fue bajo y esto podría deberse, entre otras causas, a un evento de sequía abrupta al final de la temporada. Los valores de sensibilidad anual y media obtenidos también concuerdan con que, a pesar de que se trataba de un bosque de maderas complacientes y que vivieron en un ambiente sin mayores cambios climáticos, eventualmente se habrían producido eventos extremos. Esta premisa se halla reforzada por los anillos de tipo D y E (de Creber \& Chaloner, 1984b) registrados, los 
cuales son típicos de zonas en donde la temporada de crecimiento es relativamente uniforme aunque pasan por un evento terminal que provoca el cese de la actividad cambial.

Analizando los caracteres anatómicos de los leños angiospérmicos presentes en la Fm. Salamanca (Bosque Las Violetas) en busca de indicadores de temperatura, se observó que no hay porosidad circular. Este carácter es un indicador común de climas templado-cálidos a cálidos, pero como se mencionó anteriormente, este carácter no aparece registrado con seguridad en el hemisferio sur hasta el Eoceno (Wheeler \& Baas, 1991, 1993; Wheeler et al., 2007; Baas \& Wheeler, 2011). Si bien dos de los taxones (Xilotipo 1 y Xilotipo 2) tienen vasos de pequeño diámetro, el diámetro tangencial promedio de los vasos es notablemente mayor en Myrceugenellites sp. y el Xilotipo $3(>100 \mu \mathrm{m})$. Estos vasos de mayor calibre, están muy expuestos a sufrir embolismo ante la falta de agua o ante temperaturas muy bajas, por lo que actualmente se presentan en zonas tropicales y también de zonas templadas de montaña con climas de tipo cálidos o templado cálido y con una abundante disponibilidad de agua (Baas \& Xinying, 1986; Schweingruber, 1988; Wheeler \& Baas, 1991; Carlquist, 2001). La baja frecuencia de vasos por $\mathrm{mm}^{2}$, hallada en las cuatro angiospermas leñosas también concuerdan con este tipo de climas (Van der Graaff \& Baas, 1974; Baas \& Xinying, 1986, Schweingruber, 1988; Wheeler \& Baas, 1991, 1993; Baas \& Wheeler, 2011). Además, dos de los taxones (Myrceugenellites sp. y Xilotipo 3) presentan septos en las fibras, lo cual actualmente es más común en floras tropicales del presente (Baas \& Schweingruber, 1987; Schweingruber, 1988; Wheeler \& Baas, 1991; Wheeler et al., 2007). Tampoco hay ejemplares con engrosamientos helicoidales, otro indicio de climas templado cálidos ya que su presencia es poco frecuente en zonas tropicales y húmedas (Van der Graaff \& Baas, 1974; Baas \& Xinying, 1986; Baas \& Schweingruber, 1987; Wheeler \& Baas, 1991, 1993; Wheeler et al., 2007; Carlquist, 2012). Con este último carácter hay que tener en cuenta lo anteriormente mencionado acerca de su primer registro recién a partir del Eoceno en el hemisferio sur, por lo cual su ausencia podría deberse más a una cuestión evolutiva que a las condiciones ambientales. Lo mismo ocurre con el parénquima axial, que es considerablemente escaso en todos los ejemplares a excepción del Xilotipo 1 (que 
además es el único que posee parénquima axial de tipo apotraqueal en vez de paratraqueal). En floras más recientes, la presencia de parénquima axial sería considerada como un marcador de bajas temperaturas (Morris et al. 2015, Plavcová et al., 2016). Sin embargo, en estas latitudes durante el Paleoceno inferior los patrones más elaborados con abundante parénquima paratraqueal no estaban aún desarrollados (Wheeler \& Baas, 1991, 1993). Aparte del tipo de parénquima axial, los únicos posibles indicadores de climas fríos hallados son la presencia de punteaduras ornadas en el Xilotipo 3 y las placas de perforación escalariformes (Myrceugenellites sp. y Xilotipo 2). Con respecto a las punteaduras ornadas, cabe destacar que también se las halla en climas tropicales de alta montaña (Baas \& Wheeler, 2011). Las placas de perforación escalariformes por otro lado, si bien pueden señalar climas templados fríos hasta polares, también son características de climas tropicales de montaña y en donde la humedad es estable (Baas, 1982; Baas \& Schweingruber, 1987; Wheeler \& Baas, 1991, 1993; Wheeler et al., 2007; Carlquist, 2012). La presencia de estratificación en los radios del Xilotipo 1 también es característica de zonas tropicales, pero como sucede con las fibras septadas y los patrones de parénquima paratraqueal, su uso para interpretar floras paleocenas no es recomendado, ya que no se generaliza hasta el Eoceno (Wheeler \& Baas, 1991, 1993).

Consensuando las evidencias que nos muestran todos estos caracteres xilológicos y teniendo en cuenta que durante el Cenozoico temprano los caracteres climáticos más sensibles del leño son los anillos de crecimiento, el diámetro tangencial de los vasos y la cantidad de vasos por $\mathrm{mm}^{2}$ (Wheeler \& Baas, 1991, 1993), se puede concluir que el clima fue meso-megatérmico. La presencia de algunos caracteres anatómicos contradictorios en algunos casos se debería meramente a que por un lado muchos de los rasgos anatómicos aún no se habían desarrollado en su totalidad en esa época, y también a que se trataban de taxones muy basales con mucha diversidad de caracteres lo cual imposibilitó su certera asignación taxonómica, incluso a nivel de familia.

En cuanto a la humedad disponible en el medio, los altos valores obtenidos con los índices de vulnerabilidad $(0,90-9,75)$ y mesomorfía $(248,53-12156,04)$ señalan un ambiente mesomórfico libre de heladas o sequías. Como ya dijimos la presencia de 
placas escalariformes en Myrceugenellites sp. y el Xilotipo 2 podrían señalar en este caso condiciones estables de humedad (Baas, 1982; Baas \& Schweingruber, 1987; Wheeler \& Baas, 1991, 1993; Wheeler et al., 2007; Carlquist, 2012). Las punteaduras areoladas (en las fibrotraqueidas) presentes en Myrceugenellites sp., Xilotipo 2 y Xilotipo 3 también son prueba de alta disponibilidad de agua, ya que las mismas están reducidas o ausentes en ambientes secos (Carlquist, 2001). El Xilotipo 1 es el único taxón sin fibrotraqueidas y con fibras de paredes muy gruesas y de pequeño lumen (carácter común en leños habituados a la sequía según Baas \& Wheeler, 2011) y además es el que presenta los valores menores en los índices de vulnerabilidad y mesomorfía (marcadamente distintos al de los demás), por lo que podría tratarse de un taxón con rangos muy amplios de tolerancia de humedad o que se desarrolló en microclimas más secos.

Los tipos de anillos mencionados previamente también concuerdan con un ambiente favorable desde el punto de vista hídrico. Los falsos anillos atestiguan posibles fluctuaciones en la disponibilidad de agua, quizás debidos a lluvias adicionales al final del periodo de crecimiento.

\section{Comparaciones con otros bosques paleocenos:}

Además de estos dos bosques analizados en la presente tesis, existen otros bosques paleocenos cuyos leños han recibido atención desde el punto de vista paleoclimático (Tabla 5.2).

Uno de ellos, muy próximos al bosque de Cerro Bororó, es el Bosque Ameghino ubicado en el Valle del Río Chubut $\left(43^{\circ} 33^{\prime} \mathrm{S}, 66^{\circ} 15^{\prime} \mathrm{W}\right)$. Este bosque se encuentra dominado por leños fósiles asignables a Podocarpoxylon mazzonii, junto con dicotiledóneas leñosas y palmeras. El análisis de los anillos de crecimiento arrojó un valor medio de grosor de anillo de 1,23 $\mathrm{mm}$ (ancho mínimo=1,11 $\mathrm{mm}$, ancho máximo= 2,69 $\mathrm{mm}$ ) y una SM promedio de 0,19. Estos datos señalan que los árboles crecieron bajo condiciones ambientales favorables y uniformes. También se realizaron curvas CSDM (Cumulative Sum of Deviation from the Mean) las cuales evidenciaron que el taxón estudiado tenía un hábito perennifolio, con largos períodos de retención foliar, de dos a seis años. El análisis sugirió que este denso bosque de hábito perennifolio se 
desarrolló bajo condiciones templado-cálidas sin importantes factores limitantes (Brea et al., 2011). Dicho bosque se encuentra casi en la misma posición paleolatitudinal y muy próximo al bosque de Cerro Bororó, siendo destacable la similitud de la composición taxonómica entre ambos (i.e Podocarpoxylon mazzonii, angiospermas leñosas y palmeras). Los resultados en las curvas CSDM y los estudios de caducidad foliar también concuerdan con los del bosque de Cerro Bororó. La diferencia más notable respecto al bosque de Cerro Bororó es que en el Bosque Ameghino los árboles eran complacientes, al igual que en el bosque Las Violetas.

Por otro lado, al sur de la provincial del Chubut, cerca de los lagos Musters y Colhué Huapi $\left(45^{\circ} 57^{\prime} \mathrm{S}, 69^{\circ} 18^{\prime} \mathrm{W}\right)$, se encuentra el bosque Víctor Szlápelis. Este bosque de edad también paleocena (Fm. Salamanca) estaba dominado exclusivamente por Aghatoxylon pseudoparenchymatosum (Gothan) Pujana et al. (Zamuner et al., 2000). Los troncos llegan a medir más de un metro de diámetro, lo que sugiere la existencia de buenas condiciones ambientales para su desarrollo. El estudio de los anillos de crecimiento señalan un ancho medio de anillo de 2,66 mm (1,31-6,03 $\mathrm{mm}$; siendo el más ancho de todos de 11,30 mm). Los valores de sensibilidad media (SM) van desde 0,39 a 1,42 (media=0,68). Estos valores demostraron que los árboles crecían en regiones con marcadas variaciones de estacionalidad, con largos períodos favorables para el crecimiento y otros períodos más restringidos de condiciones desfavorables (Brea et al., 2005a).

Muy próximo al el bosque Víctor Szlápelis, se encuentra otro bosque fósil conocido como José Ormaechea, el mismo se encuentra a unos $32 \mathrm{Km}$ de la localidad de Sarmiento en la provincia del Chubut $\left(45^{\circ} 57^{\prime} \mathrm{S}, 69^{\circ} 18^{\prime} \mathrm{W}\right)$, también perteneciente a la Fm. Salamanca. Sus maderas no cuentan con descripciones anatómicas, pero sí hay estudios de sus anillos de crecimiento. Los mismos tienen un ancho medio de 2,10 $\mathrm{mm}$, con un ancho mínimo es de 0,28 mm y un máximo de 6,59 mm. La SM varía entre 0,34 y 0,95 , siendo la media de 0,59 , señalando que los leños son sensitivos y crecieron en un ambiente variable. El leño temprano está bien desarrollado pero el leño tardío cuenta solo con 2-5 células de espesor. Muchos ejemplares presentan además falsos anillos. Los datos sugieren que este bosque, creció bajo un régimen climático templado-cálido y húmedo, con primaveras lluviosas y veranos secos (Brea et al., 
2005b). Estas condiciones comparables a las obtenidas en los bosques Víctor Szlápelis y a los estudiados en la presente tesis (Cerro Bororó y Las Violetas) (Tabla 5.2).

En síntesis, se puede decir que tanto el bosque de Cerro Bororó como el bosque Las Violetas, presentan leños cuyos rasgos anatómicos sugieren el desarrollo de un clima desde meso-megatérmico $\left(20^{\circ} \mathrm{C}-24^{\circ} \mathrm{C}\right)$ a megatérmico $\left(>24^{\circ}\right)$, con un abundante régimen de lluvias (alrededor de $2000 \mathrm{~mm}$ anuales o más) y una estacionalidad levemente marcada por breves períodos menos lluviosos al final de la temporada de crecimiento. Estos resultados coinciden con los obtenidos previamente por otros autores, tanto en base al estudio de maderas en otros bosques de edad paleocena, como a partir de otros indicadores paleoclimáticos (detallados anteriormente).

\section{EOCENO-OLIGOCENO}

\subsection{Paleoclima inferido previamente en Patagonia y Antártida en base a diferentes indicadores}

En lo que respecta al clima durante el lapso Eoceno-Oligoceno, se han efectuado diferentes aportes (principalmente desde la paleobotánica y la palinología), siempre comparando distintas formaciones y haciendo hincapié en el cambio acaecido desde el Eoceno temprano hacia el Eoceno tardío/Oligoceno.

Hünicken $(1955,1967)$ es el primero en estudiar las impresiones foliares de la Fm. Río Turbio y sugerir el clima imperante durante el desarrollo de la asociación florística. Dada la presencia de una mezcla de componentes de clima cálido y templado, propone un clima cálido y húmedo, aunque no tan acentuado, permitiendo el desarrollo de los elementos de clima templado en la parte alta del relieve. En la sección inferior se trataría de una flora con taxones en su mayoría de clima cálido, comparable a las de otros depósitos eocenos como los de Coronel, Río Pichileufú y Laguna del Hunco, cuyas asociaciones florísticas permiten arribar a las mismas condiciones climáticas (cálido y húmedo) (Hünicken, 1955; Volkheimer, 1971; Romero, 1986). En cambio, hacia la sección superior los taxones de clima cálido se van reduciendo, haciéndose proporcionalmente más abundantes las especies de clima templado y templado frío, hasta volverse los elementos florísticos dominantes de la parte más alta de la Fm. Río Turbio y Río Guillermo (Hünicken, 1955, 1967; Volkheimer, 
1971). La dominancia de taxones de climas templado y templado frío también se observa en la Fm. Ñirihuau (Eoceno superior) al noroeste de la Patagonia (Romero, 1986). Estas conclusiones no son solo avaladas por la composición florística, sino también por los estudios de márgenes foliares, que muestran un descenso en el porcentaje de hojas con margen entero (una mayor proporción de hojas con márgenes enteros es indicador de altas temperaturas y humedad) en las distintas floras a medida que pasamos del Eoceno temprano hacia el Eoceno tardío-Oligoceno (Río Pichileufú, 69\%; Laguna del Hunco, 69\%; Isla 25 de Mayo, 70\%; Río Turbio, 49\%; Ñirihuau, 17\%) (Volkheimer, 1971; Romero, 1986).

En base a la flora fósil estudiada hasta esa fecha, Volkheimer (1971) asigna condiciones climáticas de tipo templado húmedo durante el Eoceno en el sur de la Patagonia, en donde las temperaturas medias del mes más cálido no habrían llegado a los $22^{\circ} \mathrm{C}$. Por otro lado, al norte de la Patagonia (provincias de Río Negro y Chubut), prevaleció un clima subtropical donde la temperatura media de los meses más cálidos sí habría superado los $22^{\circ} \mathrm{C}$ y con precipitaciones mayores a los $1000 \mathrm{~mm}$ anuales. Además, en la Isla Seymour/Marambio (Eoceno, Antártida), los elementos florísticos evidencian un clima templado húmedo. Esto está basado en el alto porcentaje de hojas de ápice acuminado, que indican humedad, y troncos con anillos anuales de crecimiento demarcados que señalan estacionalidad climática (Volkheimer, 1971).

En lo que respecta a la Fm. Río Turbio, Romero (1977) menciona que la palinoflora de Río Turbio posee mayor similitud con el sector norte de la provincia Subantártica. Como resultado de la comparación de asociaciones vegetales actuales, concluye que la vegetación existente durante el Eoceno en la zona de Río Turbio debió desarrollarse en un área ondulada, expuesta a los vientos áridos, con un clima marítimo y templado, sin temperaturas extremas. Las precipitaciones serían abundantes, pero menores a las registradas en la actual selva Valdiviana (Romero, 1977).

Luego, Troncoso \& Romero (1998), según su esquema paleoflorístico (mencionado previamente en lo referente al Paleoceno), afirman que la flora de la Formación Río Turbio puede clasificarse como paleoflora mixta con Nothofagus. La 
misma contiene una mezcla de familias tropicales (Lauraceae, Rubiaceae, Sterculiaceae, etc.) con taxones de linaje austral (Drimys, Embothrium, Eucryphia, Lomatia, Laurelia, etc.) y una importante representación de Nothofagaceae y gimnospermas. Troncoso \& Romero (1998) mencionan que, si se considera la lista de taxones publicada por Hünicken (1967) en la tafoflora de Río Turbio, los géneros acompañantes a Nothofagus, géneros que actualmente son de distribución tropical o subtropical, constituyen el $86,5 \%$ del total. Por tanto, las temperaturas en las que se desarrolló este tipo paleoflorístico deben haber sido más cálidas que las actuales en las mismas regiones. Además, cerca del $38 \%$ de las especies citadas ya se hallaban previamente formando parte de la paleoflora de Arauco o de la mixta sin Nothofagus, lo cual implica que el cambio ambiental no fue tan drástico (Troncoso \& Romero, 1998). Resumiendo, en el Eoceno temprano a medio, las floras tropicales del sur del cono sur fueron reemplazadas por floras mixtas en el Sur de Sudamérica con un aumento de Nothofagus. El desplazamiento de dichas floras fue en aumento hasta culminar con elementos antárticos como dominantes hacia finales del Eoceno y Oligoceno, denotando un descenso de la temperatura (Hinojosa \& Villagrán, 1997; Troncoso \& Romero, 1998).

Hinojosa (2005) utiliza el enfoque fisionómico foliar para evaluar las tendencias y magnitudes del cambio climático continental del Cenozoico del Sur de Sudamérica utilizando una base de datos más amplia que la de Volkheimer (1971) y con varios caracteres foliares que actualmente se correlacionan con la temperatura y las precipitaciones. Este autor, estimó que durante el Eoceno temprano a medio las tafofloras correspondientes a la paleoflora mixta (Pichileufú, Quinamávida, Laguna del Hunco, Río Turbio y Ñirihuau inferior) tuvieron temperaturas que oscilaban los 17,2 $( \pm 2,3)^{\circ} \mathrm{C}$ y $18,3( \pm 2,1)^{\circ} \mathrm{C}$ (modelo multivariado) y entre $17,7( \pm 2,1)^{\circ} \mathrm{C}$ y $20,6( \pm 2,1)^{\circ} \mathrm{C}$ (modelo univariado). Las precipitaciones decaen a partir del Eoceno medio, alcanzando un mínimos de $57,3(+37,2,-22,6) \mathrm{cm}$ anuales, menores respecto del Paleoceno y que podrían significar un aumento de la estacionalidad. Luego durante Eoceno/Oligoceno se registraron temperaturas de $14,5( \pm 3,0)^{\circ} \mathrm{C}$ y $15,3( \pm 3,0)^{\circ} \mathrm{C}$ en la tafoflora de Ñirihuau medio, que se corresponden con los mínimos en todo el Cenozoico. También se 
observa un incremento relativo de las precipitaciones en el Oligoceno tardío, con valores de $87,8(+56,9,-34,5) \mathrm{cm}$ anuales (Hinojosa, 2005).

Según la nomenclatura de las paleofloras propuesta por Hinojosa (2005), desde el comienzo del Eoceno hasta el Eoceno Medio Sudamérica austral estaba poblada por la flora a la cual denominó "Paleoflora Subtropical Gondwánica". Los elementos florísticos característicos de esta paleoflora tienen actualmente una distribución Neotropical y Pantropical, con una menor proporción de los elementos Australásicos (a diferencia de la Paleoflora Gondwánica" mencionada en el Paleoceno). Además, hace su aparición el elemento austral-antárctico, aunque con una representación muy baja. Esta paleoflora se habría desarrollado bajo condiciones climáticas algo menos cálidas que la paleoflora anterior y bajo un régimen de lluvias biestacional, con aportes de humedad provenientes tanto de vientos del este como del oeste. Luego, desde finales del Eoceno hasta comienzos del Mioceno se conformaría la tradicionalmente llamada "Paleoflora Mixta" (sensu Romero, 1978). El rasgo más relevante de esta flora es el aumento sustancial de los elementos de actual distribución austral-antárctica, aunque persisten proporciones equivalentes de los elementos cálidos Neotropical y Pantropical. Las condiciones climáticas de esta flora fueron más frías y menos húmedas que las de sus predecesoras (Hinojosa, 2005).

Wilf et al., (2003, 2005) reestudian impresiones foliares provenientes de las formaciones eocenas de Río Pichileufú y Laguna del Hunco, incorporando numerosos ejemplares nuevos. Estiman el MAT y MAP a partir del estudio de márgenes foliares (Wolfe, 1979; Wing \& Greenwood, 1993; Wilf, 1997) y área foliar (Wilf et al., 1998). En la localidad Laguna del Hunco obtienen valores de MAT de $15,6( \pm 2,0)^{\circ} \mathrm{C}$ (Wilf et al., 2003) y $16,6\left( \pm 2,0^{\circ} \mathrm{C}\right)^{\circ} \mathrm{C}$ (Wilf et al., 2005) y de MAP de 100 a $120 \mathrm{~cm}$ anuales (Wilf et al., 2003, 2005). En los afloramientos de Río Pichileufú el MAT calculado es de 19,2 $( \pm 2,4)^{\circ} \mathrm{C}$ (Wilf et al., 2005). Asimismo, la presencia de palmeras, cicadales, araucariáceas, podocarpáceas y Papuacedrus, sumado a la ausencia de Nothofagus, evidencian un clima con temperaturas por encima de los $10^{\circ} \mathrm{C}$ en invierno (libre de heladas) y abundantes lluvias (Wilf et al., 2003, 2009).

Panti (2010) también estudia impresiones foliares provenientes de formaciones eocenas y oligocenas. Aplica las fórmulas para el cálculo de temperatura media anual 
propuestas por Wing \& Greenwood (1993) y por Hinojosa (2005). Sus resultados sugieren que la Fm. Río Turbio se desarrolló bajo temperaturas que habrían fluctuado entre los $15^{\circ}$ y $20^{\circ} \mathrm{C}$ durante el Eoceno temprano a medio. También destaca el hecho de que hay una diferencia significativa de aproximadamente $7^{\circ} \mathrm{C}$ (la mínima diferencia $4^{\circ} \mathrm{C}$ y la máxima $11,6^{\circ} \mathrm{C}$ ) entre el miembro inferior (más cálido) y el superior (más frío) (Panti, 2010). Además, detalla la presencia de impresiones foliares asignables a las familias Myrtaceae, Vitaceae, Anacardiaceae, Lauraceae, Malpighiaceae y Sapindaceae, las cuales son actualmente componentes megatermales $\left(>20^{\circ} \mathrm{C}\right.$, según Nix, 1982), indicando la presencia de un clima templado cálido y húmedo (Panti, 2010, 2014, 2018). También menciona que estos taxones megatermales, si bien se hallan a lo largo de toda la formación, están más concentrados en el miembro inferior, concordando con las observaciones hechas previamente por Hünicken (1967). En lo que respecta a las impresiones foliares provenientes de las Formaciones supuestamente oligocenas Río Guillermo y Sloggett, concluye que, de acuerdo con los tipos paleoflorísticos reconocidos por Troncoso \& Romero (1998), deberían ser considerada de tipo subantártica. Este tipo de flora predomina en la región hasta la actualidad y ya se la reconoce desde el Paleoceno medio y tardío en Tierra de Fuego. El desarrollo de este tipo de paleofloras es interpretado como una expresión del descenso de las temperaturas globales (Panti et al., 2008; Panti, 2010). La Fm. Sloggett además cuenta con un alto porcentaje de gimnospermas (30\%) que incluyen una Araucaria y cinco taxones afines a las Podocarpaceae. Estas últimas son características de bosques húmedos y actualmente se desarrollan en zonas templadas del hemisferio austral (Olivero et al., 1998; Panti, 2010). A diferencia de la Fm. Río Guillermo, la asociación paleoflorística de la Fm. Sloggett posee un porcentaje mayor de taxones de climas templado frío. 
Método utilizado

\begin{tabular}{|c|c|c|}
\hline \multicolumn{2}{|c|}{ Pátodo utilizado } & Fm. Cerro Bororó \\
\hline \multicolumn{3}{|c|}{ Fm. Salamanca } \\
\hline Wiemann et al. 1998 & --- & --- \\
\hline MAT & --- & --- \\
\hline MART & --- & --- \\
\hline CMMT & $995 \mathrm{~cm}$ & --- \\
\hline DRP & $-6,56$ meses & --- \\
\hline
\end{tabular}

Eoceno - Oligoceno

Fm. Río Turbio-Río Guillermo

Mioceno

Río Leona

Wiemann et al. 1999 (MAT)

\begin{tabular}{|c|c|c|}
\hline+2 & $16,56^{\circ} \mathrm{C}$ & --- \\
\hline 2) & --- & --- \\
\hline 3) & --- & --- \\
\hline 4) & --- & --- \\
\hline 5) & $22^{\circ} \mathrm{C}$ & --- \\
\hline 6) & $\begin{array}{ll}-- \\
\end{array}$ & --- \\
\hline 7) & $\begin{array}{l}-- \\
\end{array}$ & --- \\
\hline 8) & --- & --- \\
\hline 9) & $-0,85^{\circ} \mathrm{C}$ & --- \\
\hline 10) & --- & --- \\
\hline 11) & --- & --- \\
\hline 12) & --- & --- \\
\hline 13) & --- & --- \\
\hline 14) & --- & --- \\
\hline 15) & --- & --- \\
\hline 16) & --- & --- \\
\hline Índice de Vulnerabilidad & $2,26-17,5$ & $0,90-9,75$ \\
\hline Índice de Mesomorfía & $1304,92-7805,04$ & $248,53-12156,04$ \\
\hline \multicolumn{3}{|l|}{ Coexistence Approach } \\
\hline MAT & $25,5^{\circ}-26,7^{\circ} \mathrm{C}$ & --- \\
\hline MAP & $196,7-226,1 \mathrm{~cm}$ & --- \\
\hline $\begin{array}{c}\text { Inferencias a partir de caracteres } \\
\text { ecoxilológicos }\end{array}$ & $\begin{array}{l}\text { Clima meso-megatérmico a } \\
\text { megatérmico y húmedo }\end{array}$ & $\begin{array}{l}\text { Clima meso-megatérmico a } \\
\text { megatérmico y húmedo }\end{array}$ \\
\hline
\end{tabular}

Tabla 5.1: resumen de los resultados obtenidos con cada uno de los métodos en cada formación estudiada. $4,96^{\circ} \mathrm{C}$ $18,72^{\circ} \mathrm{C}$ $-6,86^{\circ} \mathrm{C}$

$525 \mathrm{~cm}$

$-1,17$ meses

\section{$14,40^{\circ} \mathrm{C}$} $21,31^{\circ} \mathrm{C}$ $3,92^{\circ} \mathrm{C}$

$11,50^{\circ} \mathrm{C}$ $22,95^{\circ} \mathrm{C}$ $6,14{ }^{\circ} \mathrm{C}$

$8,74^{\circ} \mathrm{C}$ $28,21^{\circ} \mathrm{C}$ $-1,18^{\circ} \mathrm{C}$

$21,70^{\circ} \mathrm{C}$ $25,30^{\circ} \mathrm{C}$ $22,84^{\circ} \mathrm{C}$ $16,16^{\circ} \mathrm{C}$ $28,2^{\circ} \mathrm{C}$ $15,60^{\circ} \mathrm{C}$ $8,13^{\circ} \mathrm{C}$ 2,32 (Fm. Río Turbio-Miembro inf.) $0,04-0,44$ $5,50-1300$ 11501 (Fm. Río Turbio-Miembro inf.) $8^{\circ}-11,6^{\circ} \mathrm{C}$ $84,4-96,3 \mathrm{~cm}$

Mesotérmico en el Miembro inferior de la Fm. Río Tuebio pasando a microtérmico en el superior

Mesotérmico 


\begin{tabular}{|c|c|c|c|c|c|c|c|c|c|c|c|}
\hline & Referencia & Formación & $\begin{array}{c}\mathrm{N}^{\circ} \text { de } \\
\text { anillos } \\
\text { analizados }\end{array}$ & $\begin{array}{l}\text { Media del } \\
\text { espesor } \\
\text { de los } \\
\text { anillos }\end{array}$ & $\begin{array}{l}\text { Rango medio } \\
\text { de espesor de } \\
\text { los anillos }\end{array}$ & $\begin{array}{c}\text { Anillo } \\
\text { más } \\
\text { delgado }\end{array}$ & $\begin{array}{l}\text { Anillo } \\
\text { más } \\
\text { ancho }\end{array}$ & $\begin{array}{l}\text { Rango de } \\
\text { valores de } \\
\text { SA }\end{array}$ & $\begin{array}{l}\text { Valor medio de } \\
\text { SM }\end{array}$ & $\begin{array}{l}\text { Rango de } \\
\text { valores de } \\
\text { SM }\end{array}$ & $\begin{array}{l}\text { Falsos } \\
\text { anillos }\end{array}$ \\
\hline \multicolumn{12}{|l|}{ PALEOCENO } \\
\hline $\begin{array}{l}\text { Bosque Víctor } \\
\text { Szlápelis, Chubut, } \\
\text { Argentina }\end{array}$ & $\begin{array}{c}\text { Brea et al., } \\
2005 a\end{array}$ & $\begin{array}{l}\text { Fm. } \\
\text { Salamanca }\end{array}$ & 236 & 2,66 & $1,31-6,03$ & 0,17 & 11,30 & $0-1,7$ & $\begin{array}{c}0,68 \\
\text { (sensitivos) }\end{array}$ & $0,39-1,42$ & $P$ \\
\hline $\begin{array}{l}\text { Bosque Ormachaea, } \\
\text { Chubut, Argentina }\end{array}$ & $\begin{array}{c}\text { Brea et al., } \\
2005 \mathrm{~b}\end{array}$ & $\begin{array}{c}\text { Fm. } \\
\text { Salamanca }\end{array}$ & --- & 2,10 & --- & 0,28 & 6,59 & --- & $\begin{array}{c}0,59 \\
\text { (sensitivos) }\end{array}$ & $0,34-0,95$ & $P$ \\
\hline $\begin{array}{l}\text { Bosque Ameghino, } \\
\text { Chubut, Argentina }\end{array}$ & $\begin{array}{l}\text { Brea et al., } \\
2011\end{array}$ & $\begin{array}{c}\text { Fm. } \\
\text { Salamanca }\end{array}$ & 169 & 1,23 & $11,11-2,69$ & 0,63 & 3,62 & $0,05-0,72$ & $\begin{array}{c}0,19 \\
\text { (complacientes) }\end{array}$ & $0,09-0,29$ & --- \\
\hline $\begin{array}{l}\text { Bosque Bororó, } \\
\text { Chubut, Argentina }\end{array}$ & Esta tesis & $\begin{array}{c}\text { Fm. Cerro } \\
\text { Bororó }\end{array}$ & 196 & 0,90 & $0,34-1,61$ & 0,15 & 2,57 & $0,03-1,03$ & $\begin{array}{c}0,38 \\
\text { (sensitivos) }\end{array}$ & $0,28-0,54$ & A \\
\hline $\begin{array}{l}\text { Bosque Las Violetas, } \\
\text { Chubut, Argentina }\end{array}$ & Esta tesis & $\begin{array}{c}\text { Fm. } \\
\text { Salamanca }\end{array}$ & 70 & 2,20 & $0,80-3,75$ & 0,26 & 5,20 & $0,01-1,00$ & $\begin{array}{c}0,29 \\
\text { (complacientes) }\end{array}$ & $0,20-0,4$ & $\mathbf{P}$ \\
\hline \multicolumn{12}{|l|}{ EOCENO/OLIGOCENO } \\
\hline $\begin{array}{l}\text { Nothofagoxylon ruei, } \\
\text { Santa Cruz, Argentina }\end{array}$ & Brea, 1993 & $\begin{array}{l}\text { Fm. Río } \\
\text { Turbio }\end{array}$ & 158 & 1,14 & --- & 0,45 & 3,53 & --- & $\begin{array}{c}0,25 \\
\text { (complacientes) }\end{array}$ & $0,22-0,28$ & A \\
\hline Antártida & Brea 1998 & $\begin{array}{l}\text { Eoceno/Olig } \\
\text { oceno }\end{array}$ & 145 & 0,72 & $0,45-0,95$ & 0,07 & 2,6 & $0,10-1,31$ & 0,39 (sensitivos) & $0,30-0,63$ & A \\
\hline $\begin{array}{l}\text { Bosque de Río Turbio } \\
\text { (miembro inferior) }\end{array}$ & Esta tesis & $\begin{array}{c}\text { Fm. Río } \\
\text { Turbio } \\
\text { (miembro } \\
\text { inferior) } \\
\end{array}$ & 61 & 0,70 & $0,45-0,88$ & 0,21 & 2,12 & $0,02-0,77$ & $\begin{array}{c}0,28 \\
\text { (Complacientes) }\end{array}$ & $0,22-0,39$ & A \\
\hline $\begin{array}{l}\text { Bosque de Río Turbio } \\
\text { (miembro superior) }\end{array}$ & Esta tesis & $\begin{array}{l}\text { Fm. Río } \\
\text { Turbio } \\
\text { (miembro } \\
\text { superior) }\end{array}$ & 498 & 0,46 & $0,23-0,74$ & 0,04 & 1,55 & $0,01-1,01$ & $\begin{array}{c}0,28 \\
\text { (complacientes) }\end{array}$ & $0,20-0,35$ & $\mathbf{P}$ \\
\hline $\begin{array}{l}\text { Bosque de Río } \\
\text { Guillermo }\end{array}$ & Esta tesis & $\begin{array}{l}\text { Fm. Río } \\
\text { Guillermo }\end{array}$ & 234 & 1,53 & $0,64-4,38$ & 0,14 & 5,91 & $0,02-0,86$ & $\begin{array}{c}0,31 \\
\text { (sensitivos) }\end{array}$ & $0,18-0,43$ & A \\
\hline \multicolumn{12}{|l|}{ MIOCENO INFERIOR } \\
\hline Bosque Río Leona & Esta tesis & $\begin{array}{l}\text { Fm. Río } \\
\text { Leona }\end{array}$ & 681 & 1,20 & $0,14-5,31$ & 0,05 & 6,6 & $0,02-0,91$ & $\begin{array}{c}0,27 \\
\text { (complacientes) }\end{array}$ & $0,08-0,90$ & $\mathbf{P}$ \\
\hline
\end{tabular}

Tabla 5.2: datos de los anillos de crecimiento de distintos bosques del Paleógeno y Mioceno estudiados en Patagonia. Espesores en mm. 
Barreda \& Palazzesi (2007) realizan un trabajo de recopilación y revisión del material paleobotánico y paleopalinológico, actualizando la información obtenida hasta el momento y fortaleciendo las conclusiones previas acerca del cambio climático acaecido a lo largo del Eoceno. Durante el Eoceno temprano en Patagonia central se registra una gran diversidad de familias vegetales megatermales (Arecaceae, Myrtaceae, Sapindaceae, Lauraceae, Rubiaceae, Casuarinaceae y Juglandaceae). Sugiriendo un clima con temperaturas medias invernales mayores a $10^{\circ} \mathrm{C}$ y con abundantes Iluvias (Wilf et al., 2003, 2005; Barreda \& Palazzesi, 2007). Luego a lo largo del Eoceno medio-Oligoceno temprano se registra un progresivo descenso de la temperatura marcado por un cambio en la flora donde se incrementan tanto la abundancia como la diversidad de clados meso a microtermales como Nothofagus. Ya en el Eoceno tardío-Oligoceno es evidente una ausencia de registro de taxones megatermales, que junto con la presencia de hiervas y helechos en el sotobosque sugieren un clima templado a templado frío y con abundantes precipitaciones (Barreda \& Palazzesi, 2007).

Recientemente, Fernández (2018) realiza un nuevo estudio detallado de la palinoflora de la Fm. Río Turbio, mencionando la abundante presencia de Nothofagaceae y Podocarpaceae (ambos componentes principales en la actual selva templado-fría de la Patagonia) pero sobre todo con una gran abundancia y diversidad de angiospermas meso/megatérmicas representadas por las familias Arecaceae, Bombacaceae, Aquifoliaceae, Sapindaceae, Malpighiaceae, Olaceae. Estas familias están actualmente distribuidas en regiones cálidas a templado cálidas de los trópicos y subtrópicos. Además, está presente la familia Gunneraceae, la cual tiene una amplia tolerancia térmica, pero siempre en hábitats húmedos o anegados. También se registró esporas de helechos afines a la familia Polypodiaceae, muchas de las cuales tienen un hábito epífito y se desarrollan en regiones cálidas y húmedas, o también en áreas de alta montaña. En base a estos posibles requerimientos de los elementos de las asociaciones palinológicas encontradas en la Fm. Río Turbio, se concluye que se trató de un bosque que se habría desarrollado en condiciones de clima templado cálido, húmedo y marítimo, sin extremos de temperatura y con fluctuaciones menores en el régimen de precipitaciones (Fernández, 2018). 


\subsection{Paleoclima inferido en base a maderas}

\section{Formación Río Turbio}

En lo que refiere a la Formación Río Turbio, los primeros estudios de leños permineralizados se refieren a la presencia de una raíz petrificada de Proteaceae (Ancibor 1989) y de Nothofagoxylon paraprocera Ancibor (1990), posteriormente sinonimizado con Nothofagoxylon ruei Salard (Poole, 2002).

Los anillos de crecimiento de dichas maderas asignadas a Nothofagoxylon fueron analizados con fines paleoclimáticos por Brea (1993). Los anillos tienen un espesor de $0,45-3,53 \mathrm{~mm}$ con un promedio de 1,14 $\mathrm{mm}$ y su clara demarcación demuestra que su crecimiento anual estaba caracterizado por diferencias estacionales (Brea, 1993) (Tabla 5.2). Eran leños complacientes $(S M=0,25)$ y se habrían desarrollado en condiciones climáticas semejantes a las actuales. Brea (1993) compara sus resultados con aquellos obtenidos por otros autores en árboles actuales cercanos a la región de estudio, y observa que Nothofagus pumilio Poepp. et Endl. y N. betuloides (Mirb.) Blume tienen valores de sensibilidad media $(S M=0,27)$ muy similares a los del fósil (Boninsegnna et al., 1988; Brea, 1993). Concluye así, que el taxón fósil habría crecido en una región de clima templado con estacionalidad marcada (Brea, 1993).

Los valores de SA y SM fueron muy similares a aquellos obtenidos por Brea (1993), no así los espesores, que fueron algo mayores en los ejemplares estudiados por Brea (1993) (Tabla 5.2). Cabe destacar que aquí se discriminó entre los ejemplares del miembro inferior y el miembro superior de la Formación Río Turbio y se observaron algunas claras diferencias. Si bien los anillos están presentes en prácticamente todos los ejemplares de ambos miembros (tanto angiospérmicos como gimnospérmicos), en el miembro inferior hay una mayor abundancia de ejemplares de Podocarpoxylon multiparenchymatosum, los cuales tienen anillos casi imperceptibles y de un notable espesor. En tanto que en el miembro superior son más abundantes los ejemplares de Phyllocladoxylon sp. A, cuyos anillos son mucho más angostos y claramente visibles que los de P. multiparenchymatosum. Asimismo, todos los valores de espesores calculados, tanto las medidas medias como los mínimos y máximos, son menores en el miembro superior. Estos datos marcarían que, si bien se mantuvo una estacionalidad 
marcada, la humedad, la temperatura o ambas habrían descendido hacia el final del Eoceno-principio del Oligoceno.

En el miembro superior (Oligoceno) se registran además varios falsos anillos, indicando ceses abruptos de la actividad cambial y que no se continúan en todo su recorrido lateral, siendo un producto de condiciones adversas.

El índice de vulnerabilidad y el índice de mesomorfía obtenidos en el miembro inferior arrojaron valores altos, compatibles con un ambiente mesomórfico. La baja densidad de vasos hallados también concuerda con un abundante aporte de agua (Van der Graaff \& Baas, 1974; Baas \& Xinying, 1986, Schweingruber, 1988; Wheeler \& Baas, 1991, 1993; Baas \& Wheeler, 2011). Esta baja densidad de vasos se mantiene también en el miembro superior. Tampoco se observan paredes de fibras muy gruesas, ni la presencia de cristales, ambos caracteres son indicadores de lugares xéricos (Wheeler et al., 2007; Baas \& Wheeler, 2011).

Cabe esperar que las temperaturas medias hayan sido menores que en el Paleoceno. Esto se ve apoyado por caracteres anatómicos como el menor diámetro en el lumen de los elementos de vaso, que además es aún más pequeño en las muestras del miembro superior, marcando una tendencia de descenso de la temperatura desde al Paleoceno hacia el Oligoceno ya que cuanto más grande el tamaño del lumen mayor la temperatura (Baas \& Xinying, 1986; Schweingruber, 1988; Wheeler \& Baas, 1991, 1993; Carlquist, 2001; Wheeler et al., 2007; Baas \& Wheeler, 2011; Morris et al., 2018). Podría decirse entonces que a lo largo del Eoceno se infiere un cambio desde un clima magatérmico, a uno mesotérmico en el Eoceno medio, y quizás incluso microtérmico en el Eoceno tardío-Oligoceno. Esto es también avalado por la ausencia de porosidad circular o de patrones oblicuo o dendrítico de vasos, así como la escasa presencia de parénquima axial y de cristales (Schweingruber, 1988; Wheeler \& Baas, 1991, 1993; Wheeler et al., 2007; Baas \& Wheeler, 2011; Soffiatti et al., 2016; Morris et al., 2018). Caracteres tales como los engrosamientos helicoidales o las punteaduras ornadas son comunes también en climas templado-fríos (Van der Graaff \& Baas, 1974; Baas \& Xinying, 1986; Baas \& Schweingruber, 1987; Wheeler \& Baas, 1991, 1993; Wheeler et al., 2007; Carlquist, 2012), por lo que cabría esperar registrarlos al menos en los 
ejemplares del miembro superior, pero el material no está lo suficientemente bien preservado ni abundante como para visualizar caracteres de tanto detalle. Las placas de perforación escalariformes son comunes en zonas templado-frías (Baas, 1982; Baas \& Schweingruber, 1987; Wheeler \& Baas, 1991, 1993; Wheeler et al., 2007), por lo que la presencia tanto de placas simples en algunos taxones y escalariformes en otros sería otro indicio de un clima mesotérmico en el miembro inferior.

Vale decir que el registro paleoxilológico de la Fm. Río Turbio, al igual que el registro palinológico y de impresiones foliares mencionado por previos autores (Hinojosa \& Villagrán, 2007; Troncoso \& Romero, 1998; Hinojosa, 2005; Panti, 2010) indica que se produjo un descenso de la temperatura, al menos desde un clima mesotérmico $\left(14^{\circ}-20^{\circ} \mathrm{C}\right)$ en el Eoceno medio hasta uno microtérmico $\left(<14^{\circ} \mathrm{C}\right)$ en el Eoceno tardío-Oligoceno temprano. Las lluvias habrían sido abundantes a lo largo de todo el Eoceno, pero con una estacionalidad más marcada que durante el Paleoceno.

\section{Formación Río Guillermo}

En la Fm. Río Guillermo (Oligoceno superior) los análisis efectuados se vieron aún más limitados por el estado de preservación de los ejemplares (Tabla 5.1). El espesor promedio de los anillos resultó ser notablemente mayor que en aquellos de la Fm. Río Turbio calculados en esta tesis (tanto en el miembro inferior como en el superior) (Tabla 5.2). Esto podría deberse a que hubo un cambio en las condiciones ambientales o bien a factores intrínsecos de los taxones, ya que no se tratan de los mismos géneros en ambas formaciones. Por un lado tenemos distintas especies de Podocarpaceae y una angiosperma indeterminada en la Fm. Río Turbio, mientras que la Fm. Río Guillermo presenta taxones como Agathoxylon y varias especies de Nothofagoxylon. Si además reparamos en los valores de Nothofagoxylon ruei obtenidos por Brea (1993) (Tabla 5.2), toma mayor relevancia la hipótesis de que las diferencias son debidas a factores intrínsecos de los taxones y no al ambiente. Cuando se analiza la sensibilidad media sí se observa un cambio notable, debido a variables ambientales, que se distingue de la subyacente Fm. Río Turbio con un promedio de 0,31 (anillos sensitivos) (Tabla 5.2). Observando los resultados de la Fm. Río Guillermo en forma individual se evidencia que en realidad la mitad de los ejemplares resultaron ser sensitivos y la otra mitad complacientes, por lo que estaríamos frente a un 
ambiente con zonas de condiciones muy cambiantes con áreas más protegidas de microclimas más uniformes; y áreas más expuestas, extremadamente sensibles a cambios abruptos. Estos últimos ejemplares, con altos valores de sensibilidad media podrían también indicar la posición en el área boscosa, por ejemplo, árboles ubicados en el borde de la distribución del bosque. En contraposición, los ejemplares con bajos valores de SM podrían haberse distribuidos en el centro del bosque.

Un importante cambio en los leños de la Fm. Río Guillermo, es que los índices de vulnerabilidad y mesomorfía dieron valores muy bajos, indicando que el agua no era abundante y las sequías podían ser más frecuentes.

Si bien muchos ejemplares de la Fm. Río Guillermo no pudieron ser identificados por su estado de preservación, es claro el cambio en la xiloflora si la comparamos con la Fm. Rio Turbio. Las Araucariaceae (con Agathoxylon) se mantienen, pero la diversidad de Podocarpaceae disminuye notablemente ya en el miembro superior de Río Turbio y se mantiene así hasta el Mioceno (Fm. Río Leona). En Río Guillermo se hacen también más presentes las Nothofagaceae, que si bien ya estaban presentes en el Eoceno de Río Turbio, se diversifican y se hacen mucho más representativas en el Oligoceno y más aún hacia el Mioceno temprano (ver más adelante en este capítulo). Este progresivo aumento de la familia Nothofagaceae ya fue anteriormente mencionado por otros autores en base al estudio de impresiones foliares y palinomorfos (Hinojosa \& Villagrán, 1997; Troncoso \& Romero, 1998). Con lo cual el registro paleoxilológico estaría en concordancia con el resto del registro paleoflorístico estudiado hasta la fecha. También cabe destacar que la xiloflora de Río Guillermo tiene una importante similitud con los bosques andino-patagónicos actuales, restringidos a la porción montañosa de la cordillera patagónica y áreas adyacentes donde prevalecen varias especies de Nothofagus, relacionadas con las especies fósiles de Nothofagoxylon y también con Araucaria araucana afín a las especies fósiles de Agathoxylon. Consecuentemente, se esperaría que el clima del Oligoceno superior hubiera sido microtérmico, similar al que se encuentra actualmente en las zonas cordilleranas. 


\section{MIOCENO TEMPRANO}

\subsection{Paleoclima inferido previamente en Patagonia y Antártida en base a diferentes indicadores}

Landrum (1981, 1985, 1988) postuló la existencia de bosques subtropicales estacionales en el sur de Sudamérica durante el Oligoceno-Mioceno, los cuales se habrían distribuido en forma continua a lo ancho del continente a las latitudes de centro y NW de Argentina y centro de Chile (tomado de Hinojosa \& Villagrán, 1997).

Según Palazzesi et al. (2003), durante el Mioceno temprano se evidencian las primeras comunidades herbáceo-arbustivas xerofíticas, desarrolladas quizás como parches aislados de extensión subordinada. Los taxones xerofíticos tales como los pertenecientes a las familias Ephedraceae, Casuarinaceae, Chenopodiaceae, Anacardiaceae y Fabaceae eran abundantes. Asimismo, se observa un progresivo aumento de familias modernas como las Poaceae y las Asteraceae. El desarrollo de estas comunidades probablemente habrían estado ligadas a un déficit hídrico en áreas abiertas o regiones de márgenes marinos (Palazzesi \& Barreda, 2007).

Hinojosa (2005) en su estudio fisionómico foliar de las tafofloras de Cerro Las Águilas y Navidad-Goterones-Matanzas (ubicadas en Chile), calcula durante el lapso Oligoceno tardío-Mioceno temprano temperaturas que oscilan entre los $15,6( \pm 2,4)^{\circ} \mathrm{C}$ y los $16,9( \pm 2,4)^{\circ} \mathrm{C}$. Estos valores son ligeramente inferiores a los exhibidos por las paleofloras mixtas del Eoceno y vuelven a aumentar hacia el Mioceno medio (Hinojosa, 2005). Asimismo, denomina a las floras desde el Mioceno temprano al superior como "Paleoflora Subtropical Neógena", donde destaca el predominio de elementos cálidos, con disminución del elemento austral-antártico y un significativo aumento de elementos actualmente endémicos de los bosques del sur de Sudamérica. Esta flora se habría desarrollado en condiciones más cálidas y lluviosas que en el periodo anterior, Ilegando a los $112(+72,7,-44,1) \mathrm{cm}$ anuales, aunque con tendencia a la sequía estival (Hinojosa, 2005).

Barreda \& Palazzesi (2007) y Barreda et al., (2009) se basan en información principalmente palinológica para mencionar que durante el Oligoceno tardío-Mioceno temprano hubo nuevos episodios de calentamiento que permitieron la expansión de 
angiospermas meso y megatérmicas a latitudes medias y altas en la Patagonia. Los autores concluyen que las condiciones climáticas durante dicho lapso temporal, habrían sido templadas. Ello lo atribuyen a que el ensamble florístico está dominado por Podocaraceae, Nothofagaceae y Proteaceae (familias que hoy crecen en climas templado-fríos), junto con escasos representantes de linajes adaptados a climas más cálidos (Symplocaceae y Euphorbiaceae). Además, la presencia de helechos señalaría un ambiente húmedo (Barreda \& Palazzesi, 2007; Barreda et al., 2009). A similares conclusiones arriba Césari et al. (2015) quienes encuentran las mismas familias en la flora de la Fm. Río Leona que estudian.

Desde la paleontología de vertebrados, también se señala la presencia de bosques de clima cálido bien desarrollado en la Patagonia debido a la presencia en el registro paleontológico de primates platirrinos lo cuales son climáticamente sensitivos (Pascual, 1970; Pascual \& Odreman Rivas, 1971; Pascual \& Ortiz Jaureguizar, 1990). A su vez también se cuenta con registro de marsupiales y roedores fosoriales (Pascual \& Carlini, 1987; Pascual et al., 1988) que, sumado a evidencia litogenética (Bown \& Larriestra, 1990), indicarían la existencia de eventos climáticos xéricos, o ambientes complejos representados por depósitos de dunas invadiendo áreas de bosques húmedos (Pascual et al., 1996; Ortiz Jaureguizar \& Cladera, 2006).

\subsection{Paleoclima inferido en base a maderas}

La excelente preservación del material proveniente de la Fm. Río Leona, posibilitó que se pudiera aplicar toda la metodología propuesta para el estudio del paleoclima en base a la anatomía de las maderas fósiles (Tabla 5.1).

Las ecuaciones para el cálculo de la temperatura media anual (MAT) dieron valores muy diversos desde $-1,18^{\circ} \mathrm{C}$ hasta $28^{\circ} \mathrm{C}$ (Tabla 5.1). Esto no es de extrañar ya que, como se comprobó con la puesta a prueba de las ecuaciones con la flora arbórea actual de la región, las ecuaciones no están correctamente calibradas para estas latitudes del hemisferio sur. De cualquier manera, al comparar los resultados de Río Leona con los de las localidades actuales testeadas (ver capítulo 4.1), vemos que hay una gran similitud entre las temperaturas calculadas en la Fm. Río Leona y aquellas calculadas en la actual Patagonia, sobre todo con la localidad chilena "Los bellotos del 
Melado" en la VII región de Chile central (Tabla 5.3). Solo tres de los resultados proporcionan valores marcadamente diferentes: la ecuación 4, que en las localidades actuales incrementa sus valores cuanto más austral es la localidad (inversamente a lo esperado), y que da en Río Leona una temperatura que se aproxima a la calculada en el Parque Nacional los Alerces $\left(12,5^{\circ} \mathrm{C}\right)$; y las ecuaciones 6 y 7 que suelen arrojar temperaturas distintas a las esperadas (desfasadas entre $5^{\circ} \mathrm{C}$ y $10^{\circ} \mathrm{C}$ ) en cada localidad actual pero siempre manteniendo cierta relación y resultando en temperaturas mayores cuanto más cálido es realmente el lugar (ver tabla 4.1 y la primer parte de este capítulo). Teniendo en cuenta esto, se podría pensar que el bosque de la Fm. Río Leona se desarrolló bajo un MAT de $14^{\circ} \mathrm{C}$ similar al que actualmente se encuentra en la región del Parque Los Bellotos. Si consideramos las ecuaciones 6 y 7, que indicarían temperaturas algo mayores, podríamos estimar un MAT comprendido entre $14^{\circ} \mathrm{C}$ y $20^{\circ} \mathrm{C}$ aproximadamente, correspondiente con un clima mesotérmico.

El rango anual de temperatura media (MART) proporcionó un valor de $18,72^{\circ} \mathrm{C}$ y la temperatura media de los meses más fríos (CMMT) $-6,86^{\circ} \mathrm{C}$. Las ecuaciones para el cálculo de estos parámetros aún no fueron probadas con especies actuales que habiten en altas latitudes australes, por lo tanto deben ser tomadas en cuenta con cierto recaudo ya que probablemente los valores no estén ajustados correctamente. A pesar de esto, los mismos dan un indicio de que la estacionalidad fue marcada, con veranos cálidos e inviernos fríos con temperaturas bastante bajas.

Por otro lado, el método del Coexistence Approach estima valores de entre $8^{\circ} \mathrm{C}$ y $11,6^{\circ} \mathrm{C}$ (clima microtérmico). Las especies que limitan el valor de $11^{\circ}-12^{\circ} \mathrm{C}$ son Lomatia ferruginea y Araucaria araucana, mientras que el resto de las especies emparentadas con los fósiles soportan temperaturas de $14^{\circ}-15^{\circ} \mathrm{C}$ y algunas incluso más. 


\begin{tabular}{|l|c|c|}
\multicolumn{1}{|c}{ Ecuación } & $\begin{array}{c}\text { Los Bellotos } \\
\text { (VII Región-Chile) }\end{array}$ & Río Leona \\
\hline Ec. 1998 & 4,3 & 5 \\
\hline Ec. 1 & 15,8 & 14,4 \\
\hline Ec. $\mathbf{2}$ & 18,3 & $\mathbf{2 1 , 3}$ \\
\hline Ec. $\mathbf{3}$ & 3,7 & 3,9 \\
\hline Ec. $\mathbf{4}$ & 7,3 & $\mathbf{1 1 , 5}$ \\
\hline Ec. $\mathbf{5}$ & 23,3 & $\mathbf{2 2 , 9}$ \\
\hline Ec. $\mathbf{6}$ & $-3,5$ & $\mathbf{6 , 1 4}$ \\
\hline Ec. $\mathbf{7}$ & 0,2 & $\mathbf{8 , 7}$ \\
\hline Ec. $\mathbf{8}$ & 18,2 & $\mathbf{2 8 , 2}$ \\
\hline Ec. $\mathbf{9}$ & 1 & $-1,2$ \\
\hline Ec. 10 & 20,5 & $\mathbf{2 1 , 7}$ \\
\hline Ec. 11 & 25,3 & 25,3 \\
\hline Ec. 12 & 21,5 & 22,8 \\
\hline Ec. 13 & 16,3 & 16,2 \\
\hline Ec. 14 & 27,7 & 28,2 \\
\hline Ec. 15 & 15,2 & 15,6 \\
\hline Ec. 16 & 7,1 & 8,1 \\
\hline
\end{tabular}

Tabla 5.3: resultados de las ecuaciones propuestas por Wiemann et al. $(1998,1999)$ aplicadas en una localidad actual (Los Bellotos) y una fósil (Río Leona). Valores en ${ }^{\circ} \mathrm{C}$. En rojo los valores actuales calculados por encima del valor real $\left(14^{\circ} \mathrm{C}\right)$ y en azul aquellos por debajo.

Teniendo en cuenta los caracteres xilológicos encontrados en las angiospermas y sus relaciones con el clima vemos una interesante mezcla de rasgos presentes tanto en climas fríos, como en templado cálidos. La porosidad circular (de Doroteoxylon vicente-perezii) y semicircular (de las Nothofagaceae, el Xilotipo 3 de Pujana 2008 y Scalarixylon) son característicos de climas meso-megatérmicos o megatérmicos (Wheeler \& Baas, 1991, 1993; Wheeler et al., 2007; Baas \& Wheeler, 2011). La tendencia diagonal en la distribución de los vasos (en Resinaxylon schinusoides y el Xilotipo 3 de Pujana 2008), las fibras septadas (en Myrceugenellites oligocenum, Doroteoxylon vicente-perezii y Resinaxylon schinusoides) y la presencia de cristales (Nothofagoxylon scalariforme) también son claros indicativos de temperaturas medias templado-cálidas a cálidas (Baas \& Xinying, 1986; Baas \& Schweingruber, 1987; Schweingruber, 1988; Wheeler \& Baas, 1991, 1993; Wheeler et al., 2007). Por otro lado, el diámetro tangencial promedio es menor a $100 \mu \mathrm{m}$ en casi todos los taxones (salvo Doroteoxylon vicente-perezii) y la presencia de engrosamientos helicoidales (Doroteoxylon vicente-perezii y el Xilotipo 3 de Pujana 2008) son un rasgo común en áreas templado-frías o templadas de alta montaña (Baas \& Xinying, 1986; Schweingruber, 1988; Wheeler \& Baas, 1991; Carlquist, 2001). Asimismo, hay una gran variabilidad en el largo de los elementos de vaso $(143-650 \mu \mathrm{m})$, en la frecuencia de 
vasos (desde 40 hasta 430 vasos por $\mathrm{mm}^{2}$ ) y en las placas de perforación (simples, escalariformes o incluso ambas presentes en un mismo taxón). Si promediamos se observa que la frecuencia de vasos ronda los 200 por $\mathrm{mm}^{2}$ (clima templado- frío) y las placas de perforación son en su mayoría simples (clima cálido) (Van der Graaff \& Baas, 1974; Baas \& Xinying; 1986, Schweingruber, 1988; Wheeler \& Baas, 1991, 1993; Baas \& Wheeler, 2011) con lo cual continúa la misma incertidumbre.

Según Schweingruber (1988), es común que las especies que crecen en lugares templados presentan caracteres combinados de zonas áridas, boreales y tropicales. Esta combinación de caracteres presentes les ayudaría a los taxones en este caso a soportar tanto las altas temperatura del verano así como los fríos inviernos. Esto concuerda con la idea de una estacionalidad marcada por la temperatura y es compatible con las temperaturas estimadas empleando las ecuaciones de Wiemann et al. $(1998,1999)$.

Si bien el CA da valores algo menores, éstos siguen siendo valores muy cercanos dentro de un margen aceptable de error. Otro dato a tener en cuenta es que, a pesar de haber analizado un buen número de secuencias de anillos de crecimiento (140), no se observó ningún anillo de crecimiento con marcas de heladas. Por tanto, se infiere que en el área no eran comunes las heladas y/o eran libres de heladas durante el período de crecimiento. Las temperaturas frías extremas se habrían limitado a los meses invernales durante la pausa del desarrollo cambial o bien, aún las temperaturas más bajas encontradas, nunca habrían llegado al punto de congelación.

La ecuación de Wiemann et al. (1998) para el cálculo de la precipitación media anual (MAP) arrojó un valor de $526 \mathrm{~cm}$ anuales. Los autores de la ecuaciones concluían que ésta no era tan precisa como aquellas para el cálculo del MAT, y la puesta a prueba llevada a cabo en la presente tesis con taxones actuales tampoco dio valores acertados, mostrando diferencias de más de $100 \mathrm{~cm}$ con respecto a las precipitaciones reales. Sin embargo, sí se ve una clara tendencia en los resultados, en donde se puede observar al compararlos entre ellos que los valores más altos se corresponden con las zonas de mayores precipitaciones y los más bajos con las zonas más secas (Tabla 4.2 de resultados). Teniendo esto en cuenta se puede inferir que el bosque estudiado se 
desarrolló en un área con abundantes lluvias pero no tanto como en las de los bosques paleocenos estudiados. Esto avalado también por el DRY (largo de la temporada seca en meses) con valor negativo obtenido (-1,17 meses) que indica la ausencia de una temporada seca, aunque esta ecuación tampoco fue testeada en árboles actuales en el hemisferio sur. La abundante humedad también se puede inferir a partir del gran diámetro que presentan las punteaduras intervasculares (Carlquist, 2001).

Esto sin embargo, contradice los resultados obtenidos a partir del índice de vulnerabilidad que señala la presencia de leños capaces de tolerar gran estrés hídrico y/o congelamiento, y del índice de mesomorfía que se corresponde a ambientes con baja disponibilidad de agua.

En este escenario, la alta frecuencia del número de vasos (anteriormente mencionada) como posible indicador de climas fríos, en realidad podría estar indicando una región árida (Van der Graaff \& Baas, 1974; Baas \& Xinying, 1986, Schweingruber, 1988; Wheeler \& Baas, 1991, 1993; Baas \& Wheeler, 2011). De igual manera hay que tener en cuenta que los índices de vulnerabilidad y de mesomorfía se calculan utilizando, entre otros datos, la frecuencia de vasos, por lo que esta información sería redundante. Por otro lado, la presencia de vasos de diferente diámetro en el leño temprano y el leño tardío (presente en Scalarixylon patagonicum, Scalarixylon grandiradiatum y Doroteoxylon vicente-perezii) es un claro indicador de ambientes xéricos (Carlquist, 2001). Otro carácter mencionado anteriormente, que no solo es común en lugares templado-fríos sino también en zonas secas, son los engrosamientos helicoidales (Van der Graaff \& Baas, 1974; Baas \& Xinying, 1986; Baas \& Schweingruber, 1987; Wheeler \& Baas, 1991, 1993; Wheeler et al., 2007; Carlquist, 2012) que están presentes en Doroteoxylon vicente-perezii y el Xilotipo 3 de Pujana, 2008. Además, la mitad de las especies estudiadas presentan fibras de paredes gruesas (otra adaptación a las sequías) y Nothofagoxylon scalariforme tiene cristales los cuales si bien como se dijo puede indicar temperaturas cálidas, también es mayor su presencia en ambientes xéricos (Wheeler et al., 2007; Baas \& Wheeler, 2011).

Por otro lado, el método del Coexistence Approach arrojó un valor de precipitaciones de alrededor de los $90 \mathrm{~cm}$ anuales, pero hay que tener en cuenta que 
este valor está delimitado por las especies Nothofagus alessandri y Nothofagus glauca cuyas distribuciones son muy restringidas, mientras que el resto de las especies relacionas con los fósiles habitan normalmente en áreas con precipitaciones de hasta más de $200 \mathrm{~cm}$ anuales.

En todos los taxones representados en la Formación Río Leona se hallaron anillos de crecimiento bien marcados ya sea por la compresión radial de las últimas hileras de traqueidas y/o fibras, o incluso se observó la presencia de porosidad circular en donde los vasos del leño temprano son mucho más grandes y con una distribución diferente respecto del leño tardío. Esta clara demarcación de los anillos evidencia una estacionalidad muy marcada.

De las 140 secuencias de anillos que pudieron ser analizadas se obtuvo un grosor promedio de 1,2 $\mathrm{mm}$. El anillo más angosto es de 0,05 $\mathrm{mm}$ y el más ancho de 6,6 $\mathrm{mm}$, pero estos extremos son raros y la mayoría de los ejemplares se aproximan más a la media por lo que el crecimiento habría sido bastante uniforme en todo el bosque. La sensibilidad media promedio es de 0,27 , es decir que se tratan de leños complacientes. Teniendo en cuenta los resultados de forma individual se aprecia que hay un importante número de ejemplares marcadamente sensitivos (Tabla 4.27 de resultados) que seguramente se correspondan con árboles que crecieron cerca de los límites del bosque o cerca de los límites climáticos determinados para su distribución. Asimismo, se observaron 10 falsos anillos, 9 de ellos en leños complacientes por lo cual se estima que las alteraciones sufridas no fueron producto de estar expuestos a las condiciones más variables en los límites del bosque, sino que se debieron a acontecimientos climáticos que afectaron a la totalidad del bosque, como por ejemplo, sequías fuera de la temporada de las mismas. Estos eventos, sin embargo no habrían sido muy habituales, dado el bajo número en relación a las muestras estudiadas. El tipo de anillo encontrado es del tipo D, según el esquema de Creber \& Chaloner (1984b) indicando temporadas de crecimiento uniformes.

Se puede consensuar entonces que el clima era mesotérmico, con una temperatura media de al menos $14{ }^{\circ} \mathrm{C}$. Esto concuerda con lo postulado previamente por otros autores (Hinojosa, 2005; Barreda et al., 2009). 
En lo que respecta a la humedad y las precipitaciones los resultados muestran que los leños habrían estado habituados a condiciones relativamente xéricas, al menos durante una estación, con alrededor de $90 \mathrm{~cm}$ anuales. Este valor también es similar al propuesto por Hinojosa (2005) pero contradice lo expuesto por Barreda et al. $(2009$, quienes estimaban un alto porcentaje de humedad debido a la presencia de helechos. Otros mencionan la existencia de taxones más habituados a la sequía que habrían conformado parches en zonas más abiertas del bosque (Palazzesi et al., 2003; Le Roux, 2015b), es decir que además de haber una estación seca muy marcada, las precipitaciones anuales iban igualmente en descenso. Existe la posibilidad de que, si bien las lluvias habrían sido abundantes, las mismas no se habrían distribuido de forma uniforme durante el año. Las precipitaciones y las condiciones de alta humedad se habrían dado solo durante la temporada de crecimiento, para luego experimentar un período de marcada sequía, siendo justamente este factor el determinante de la estacionalidad, similar a los climas mediterráneos actuales como el que se encuentra justamente en Chile en la zona de Los Bellotos del Melado.

\section{RESUMEN DE LOS CAMBIOS CLIMÁTICOS ACAECIDOS DESDE EL PALEOCENO AL MIOCENO}

Los autores citados anteriormente en este capítulo, así como otros que realizaron trabajos de síntesis reuniendo información referente a la evolución del clima en la Patagonia (e.g. Menéndez, 1971; Ortiz-Jaureguizar \& Cladera, 2006; Palazzesi et al., 2003; Palazzesi \& Barreda, 2007; Iglesias et al., 2011; Le Roux, 2012b) en general concuerdan con los acontecimientos climáticos desarrollados a lo largo del Paleógeno y el Mioceno, y estos a su vez concuerdan también con los resultados obtenidos en la presente tesis. La temperatura media alcanzó valores elevados durante el Paleoceno temprano (megatérmico), manteniéndose relativamente constante hasta el Eoceno temprano donde comenzó a disminuir (mesotérmico) y finalmente llegó a valores mínimos a finales del Eoceno-Oligoceno (microtérmico), para luego volver a ascender hacia el Mioceno temprano (mesotérmico).

Hay que tener en cuenta que el territorio patagónico abarcado en este estudio es muy amplio, con alrededor de $500 \mathrm{~km}$ entre las localidades de Chubut (Fm. Cerro Bororó y Fm. Salamanca) y las localidades de Santa Cruz (Fm. Río Turbio, Fm. Río 
Guillermo y Fm. Río Leona). Si bien región era relativamente homogénea como lo es en la actualidad aunque pudo haber leves variaciones en la temperatura por la diferencia latitudinal. También hay que considerar los intervalos temporales en los cuales no hay registro fosilífero, principalmente en el Paleoceno superior y Eoceno inferior.

A nivel global se observa la misma evolución del clima desde el Paleoceno en adelante (Zachos et al., 2001; Le Roux; 2012a), solo que con algunos breves eventos de enfriamiento más marcados que, por una falta de continuidad en el registro, no se llegan a apreciar en la paleoxiloflora aquí estudiada. Le Roux (2012a) menciona un máximo térmico a nivel mundial durante el Paleoceno-Eoceno (Thanetian-Ypresian Warming). Ivany et al., (2008) determinó un descenso de la temperatura de la superficie marina en el Eoceno temprano (Ypresian Cooling) (Le Roux, 2012a), luego del cual se produjo un nuevo evento de progresivo aumento de la temperatura hacia el Eoceno medio (Lutetian Warming) (Le Roux, 2012a). Inmediatamente después comenzó una tendencia al enfriamiento que duró un largo período, culminando con una fuerte caída de la temperatura en el límite Eoceno-Oligoceno (Miller et al., 1987; Zachos et al., 2001; Le Roux, 2012a y bibliografía allí citada). Durante el Oligoceno tardío la temperatura aumentó nuevamente (Chattian Warming) (Le Roux, 2012a). Estos sucesos de cambio en la paleotemperatura global están en concordancia con lo propuesto por otros autores (Zachos et al., 1994, 2001; Greenwood et al., 2004; Bijl et al., 2009; Le Roux, 2012b). 


\section{6}

\section{CONCLUSIONES}

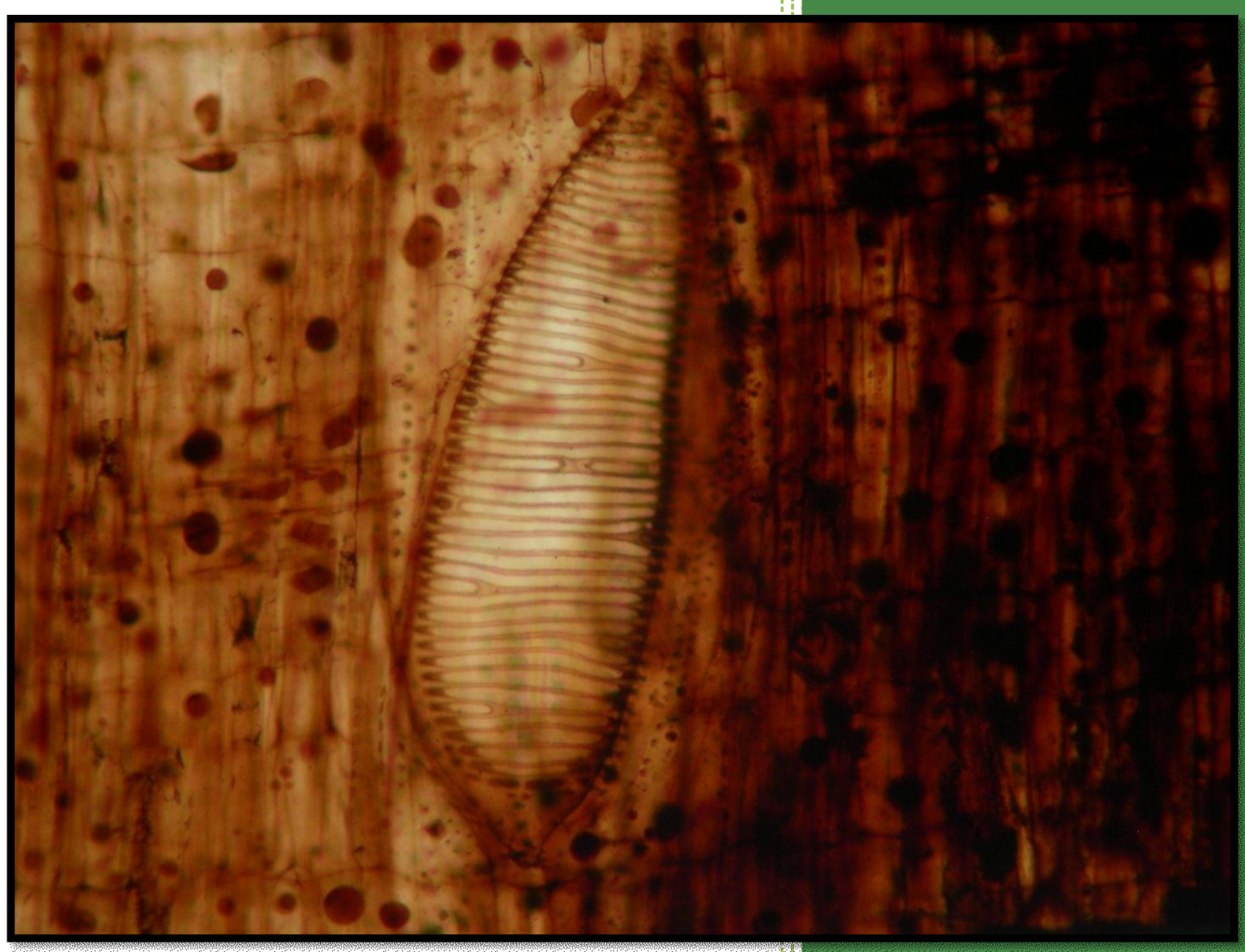

DANIELA P. RUIZ 


\section{PUESTA A PRUEBA DE LAS ECUACIONES DE WIEMANN ET AL. $(1998,1999)$}

Las ecuaciones de Wiemann et al. $(1998,1999)$, para el cálculo de temperaturas y precipitaciones medias anuales, fueron puestas a prueba con numerosos taxones que habitan actualmente zonas protegidas de Argentina y Chile y mostraron no ser del todo útiles en Sudamérica austral. Sin embargo, se observaron ciertas tendencias en los resultados, lo que indicaría que existe una relación entre los caracteres empleados y las condiciones climáticas.

\section{MATERIAL ESTUDIADO}

En la presente tesis se observaron y estudiaron un total de 550 ejemplares de leños permineralizados incluyendo gimnospermas y angiospermas.

Tras la revisión del material estudiado originalmente por Petriella (1972) se concluye que las descripciones y la sistemática no requieren mayores modificaciones con la excepción de las dos especies de Weinmannioxylon que se sugieren sean sinonimizadas ya que no presentan diferencias significativas que justifiquen su separación como especies independientes. También se sugiere que Bridelioxylon americanum sea transferido a otro género y familia (Lauraceae) tras la enmienda de su diagnosis.

En lo referente a la Fm. Salamanca, se dio a conocer un nuevo bosque petrificado de edad daniana (Paleoceno), "Las Violetas". Se describieron cuatro coníferas procedentes de dicho bosque (incluida la especie nueva Cupressinoxylon artabeae) y cuatro angiospermas leñosas que se proponen como cuatro nuevos taxones a ser publicados.

La Fm. Río Turbio ya contaba con descripciones y determinaciones parciales hechas por Pujana (2008) en su tesis doctoral, pero en esta tesis se adicionó nuevo material y se describieron nuevos ejemplares, tres de ellos coníferas y tres angiospermas leñosas no registradas con anterioridad en la formación. 


\section{MÉTODOS DE ESTUDIO PALEOCLIMÁTICOS APLICADOS}

Los métodos del estudio paleoclimático en base maderas fósiles propuestos en los objetivos (ecuaciones de Wiemann et al., 1998, 1999, análisis de anillos de crecimiento, Índice de Vulnerabilidad e Índice de Mesomorfía, Coexistence Approach y estudio de caracteres ecoxilológicos) pudieron ser aplicados de forma diferencial dependiendo la formación. Todos ellos fueron empleados en las Fms. Cerro Bororó y Río Leona, las cuales contaban con mayor diversidad, buena preservación y un número abundante de ejemplares. En las restantes formaciones, la baja diversidad (Fm. Salamanca) y la mala preservación (Fms. Río Turbio y Río Guillermo) impidió la aplicación de uno o varios de los métodos.

En conclusión, la aplicación de dichos métodos aporta resultados más precisos siempre y cuando la preservación sea lo suficientemente buena y se cuente con un buen número de ejemplares de diversos taxones.

\section{PALEOCLIMA A LO LARGO DEL PALEÓGENO Y COMIENZO DEL NEÓGENO}

En base al estudio paleoclimático utilizando leños permineralizados de las Formaciones Cerro Bororó y Salamanca se concluye que el clima durante el Paleoceno temprano (Daniano) era meso-megatérmico $\left(20-24^{\circ} \mathrm{C}\right)$ a incluso megatérmico $\left(>24^{\circ} \mathrm{C}\right)$. Luego en el Eoceno, el registro paleoxilológico de la Fm. Río Turbio evidencia un marcado y progresivo descenso de la temperatura, con un clima mesotérmico (14$\left.20^{\circ} \mathrm{C}\right)$ en el Eoceno medio, y llegando a uno microtérmico $\left(<14^{\circ} \mathrm{C}\right)$ en el Eoceno tardío/Oligoceno temprano. Estas bajas temperaturas probablemente mantuvieron a lo largo del Oligoceno (Fm. Río Guillermo) y comenzaron un nuevo ascenso hacia el Mioceno temprano (Fm. Río Leona) llegando nuevamente a un clima mesotérmico con alrededor de $14^{\circ} \mathrm{C}$ de MAT (Fig. 6.1).

En referencia a las precipitaciones y la humedad, se infirió que durante el Daniano el régimen de lluvias era abundante (200 cm anuales o más), existiendo una estacionalidad muy poco marcada por períodos menos lluviosos al final de la temporada de crecimiento, pero sin llegar a desarrollarse sequías. Las Iluvias habrían continuado siendo abundantes a lo largo de todo el Eoceno, pero con estacionalidad mucho más marcada. En el Oligoceno aparentemente se produce un descenso de las 
precipitaciones que vuelve a ser más abundantes en el Mioceno temprano pero manteniendo una temporada seca que marca estacionalidad (Fig. 6.1).

Estos resultados son generales y debe tenerse en consideración los intervalos temporales donde no se cuenta con registro o el mismo aún no ha sido estudiado.

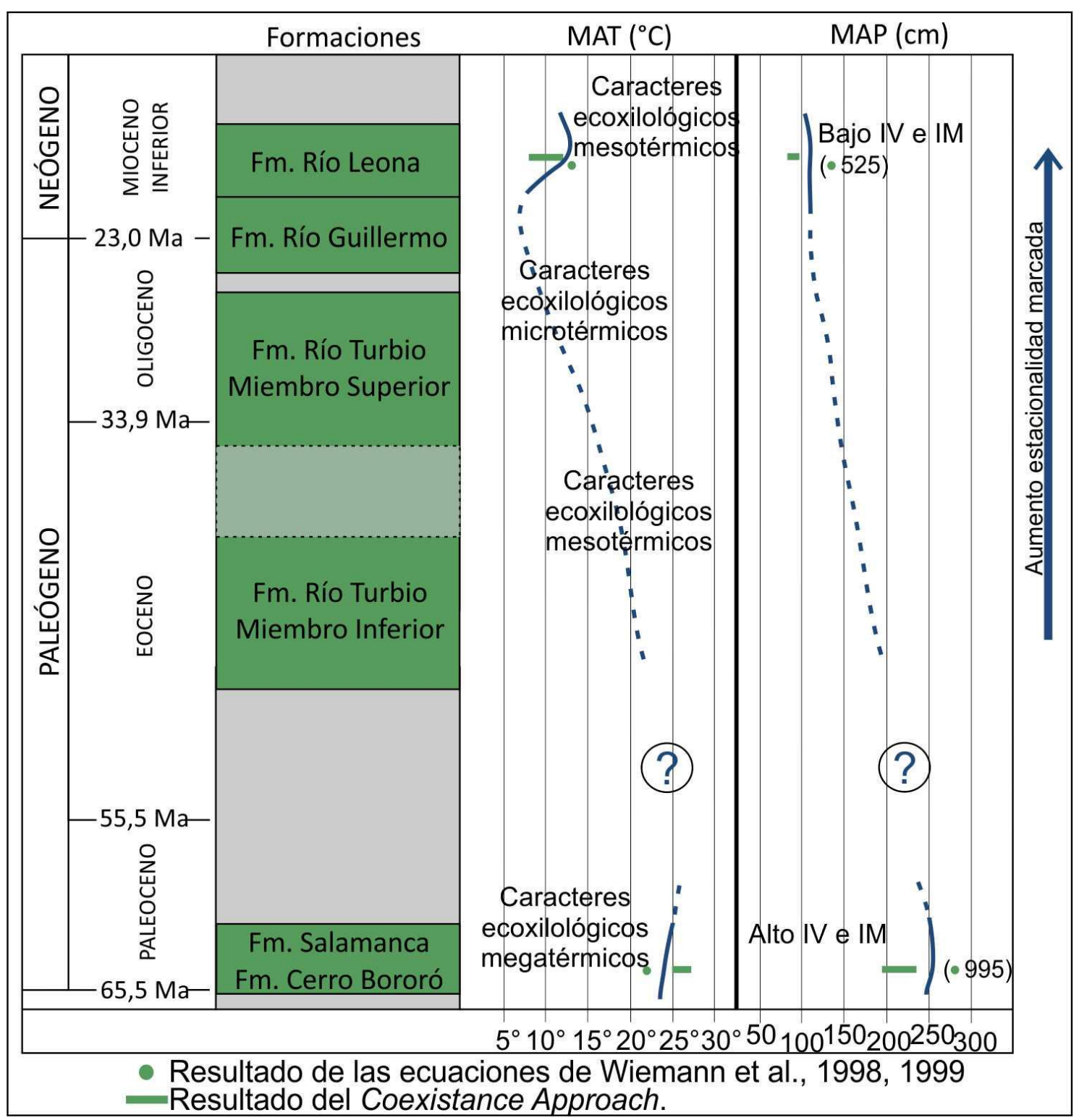

Figura 6.1. Gráfico de variación de la temperatura media anual (MAT) y las precipitaciones medias anuales (MAP) a lo largo del Paleógeno y el Mioceno inferior según la información paleoxilológica. Las lineas enteras de la curva indican mayor certeza de la estimación en base a datos cuantitativos, las líneas punteadas son aproximaciones en base a datos cualitativos y comparación con otros indicadores, el signo de pregunta y ausencia de línea indican falta de registro. IV=índice de vulerabilidad; IM=índice de Mesomorfía. 


\section{COMPARACIÓN CON RESULTADOS OBTENIDOS A PARTIR DE OTROS INDICADORES}

Las conclusiones paleoclimáticas obtenidas concuerdan con aquellas a las que arribaron previamente diversos autores en base a distintos marcadores: registro paleopalinológico, estudio de morfología foliar y estudio de paleofloras en comparación con floras actuales, (entre otros). De esta manera, el estudio de los caracteres anatómicos de los leños permineralizados demuestra ser también una herramienta útil a la hora de analizar las condiciones paleoambientales y paleoclimáticas imperantes en el lugar donde se desarrolló la flora estudiada.

\section{PROYECCIONES FUTURAS}

Luego de la realización de la presente tesis doctoral queda pendiente, como primer objetivo, publicar válidamente según el código de nomenclatura botánico los cambios sistemáticos propuestos para los taxones de Cerro Bororó. Asimismo, según este criterio se completaran y publicaran las nuevas especies descriptas en el Bosque Las Violetas.

Por otro lado, a partir de los resultados y conclusiones arribadas se desprenden varias líneas de investigación que se pretenden continuar a futuro, a saber:

- Continuar el estudio de la relación existente entre los caracteres anatómicos de los leños con la temperatura y las precipitaciones en Sudamérica y formular una nueva ecuación para el cálculo del MAT y el MAP que se adecúe mejor a la región.

- Ampliar el estudio de los leños de Fm. Salamanca incorporando un mayor número de muestras a fin de reconstruir el paleoambiente de forma más precisa y ajustar los análisis paleoclimatológicos. 
BIBLIOGRAFÍA 
Ancibor, E. 1984. Estructura de la madera de Polylepis tomentella Wedd. (Rosaceae). Physis 42(102): 23-28.

Ancibor, E. 1989. Determinación xilológica de una raíz petrificada de Proteaceae de la Formación Río Turbio (Eoceno), Santa Cruz, Argentina. Ameghiniana 25(3): 289-295.

Ancibor, E. 1990. Determinación xilológica de la madera fósil de una Fagacea, de la Formación Río Turbio, (Eoceno), Santa Cruz, Argentina. Ameghiniana 27(1-2): 179-184.

Andreis, R. R., Mazzoni, M. M. \& Spalletti, L. A. 1973. Geología y sedimentología del Cerro Bororó (Provincia de Chubut). Actas del V Congreso Geológico Argentino 3: 21-55.

Andreis, R. R., Mazzoni, M. M. \& Spalletti, L. A. 1975. Estudio estratigráfico y paleoambiental de las sedimentitas terciarias entre Pico Salamanca y Bahía Bustamante, Provincia de Chubut, República Argentina. Revista de la Asociación Geológica Argentina 30(1): 85-103.

Anselmi, G., Gamba M. T. \& Panza, J. L. 2004. Hoja Geológica 4369-IV Los Altares. Boletín del Servicio Geológico Minero 313: 55-58.

Anzulovich, J. C. \& Raso, M. P. 1961. Informe de la comisión de apoyo terrestre, Seccional Austral, $\mathrm{x} / 60-\mathrm{v} / 61$. CNEA, inéd.

APG. 2016. An update of the Angiosperm Phylogeny Group classification for the orders and families of flowering plants: APG IV. Botanical Journal of the Lennean Society 181: 1-20.

Apodaca, M. J., Crisci, J. V. \& Katinas, L. 2015. Las provincias fitogeográficas de la República Argentina: definición y sus principales áreas protegidas. En: Casas, R. \& Albarracin, G. F. (Eds.), El deterioro del suelo y del ambiente en la Argentina, Fundación para la Educación, la Ciencia y la Cultura, Buenos Aires, Argentina, pp. 79-101.

Archangelsky, S. 1968. Sobre el paleomicroplancton del Terciario Inferior de Río Turbio, Provincia de Santa Cruz. Ameghiniana 5(10): 406-416.

Archangelsky, S. 1969. Estudio del paleomicroplancton de la Formación Río Turbio (Eoceno), Provincia de Santa Cruz. Ameghiniana 6(3): 181-218.

Archangelsky, S. 1972. Esporas de la Formación Río Turbio (Eoceno). Revista del Museo de La Plata (NS), Paleontología 6(39): 65-100.

Archangelsky, S. 1973. Palinología del Paleoceno de Chubut. I: descripciones sistemáticas. Ameghiniana 10(4): 339-199.

Archangelsky S. 1976. Palinología del Paleoceno de Chubut. II. Diagramas polínicos. Ameghiniana 13(1): 43-55.

Archangelsky, S. \& Fasola, A. 1971. Algunos elementos del paleomicroplancton del Terciario Inferior de Patagonia (Argentina y Chile). Revista del Museo de la Plata (NS), Paleontología 6(36): 1-18.

Archangelsky, S. \& Romero, E. 1974. Polen de Gimnospermas (Coníferas) del Cretácico Superior y Paleoceno de Patagonia. Ameghiniana 11(3): 217-236. 
Archangelsky, S. \& Zamaloa, M. C. 1986. Nuevas descripciones palinológicas de las Formaciones Salamanca y Bororó, Paleoceno de Chubut (República Argentina). Ameghiniana 23(1-2): 35-46.

Archangelsky, S., Petriella, B. \& Romero, E. 1969. Nota sobre el bosque petrificado del Cerro Bororó (Terciario Inferior), provincia de Chubut. Ameghiniana 6(2): 119-126.

Arguijo, M. H. 1979. Palmoxylon bororoense, n. sp. de la Formación Cerro Bororó (Paleoceno), provincia de Chubut, República Argentina. Physis Sección C 38: 87-96.

Arguijo, M. H. 1981. Palmoxylon vaterum n. sp. del Paleoceno (Daniano) de la provincia de Chubut, Argentina. Physis Sección C 39: 4-59.

Arroyo, M. T. K., Matthei, O., Marticorena, C., Muñoz, M., Pérez, F. \& Humaña, A. M. 2000. The vascular plant flora of the Bellotos del Melado National Reserve, VII Region, Chile: a documented checklist. Gayana Botanica 57(2): 117-139.

Awasthi, N. \& Mehrotra, R.C. 1989. Some fossil woods from Tipam sandstone of Assam and Nagaland. Palaeobotanist 38: 277-284.

Azcuy, C. L. \& Amigo, A. E. 1991. Geología y paleoambiente de la Formación Río Turbio (Eoceno), en la Sierra Dorotea, Provincia de Santa Cruz. Revista de la Asociación Geológica Argentina 46(3-4): 201-206.

Baas, P. 1976. Some functional and adaptative aspects of vessel member morphology. En: Baas, P., Bolton, A, J. \& Catling, D. M (Eds.), Wood Structure in Biological and Technological Research, Leiden Botanical Series 3, pp. 157-181.

Baas, P. 1982. Systematic, phylogenetic, and ecological wood anatomy. History and perspectives. En: Baas, P. (Eds.), New Perspectives in Wood Anatomy. Forestry Sciences 1, Springer, DordrechtIn, pp. 23-58.

Baas, P. 1986. Ecological patterns of xylem anatomy. En: Givnish, T. J. (Eds.), On the Economy of Plant Form and Function, Cambridge University Press, London, pp. 327-352.

Baas, P. \& Wheeler, E. A. 1996. Parallelism and reversibility in xylem evolution: a review. IAWA Journal 17(4): 351-364.

Baas, P. \& Wheeler, E. A. 2011. Wood anatomy and climate change. En: Hodkinson, T. R. \& Jones, M. B. (Eds.), Climate Change, Ecology and Systematic, Cambridge University Press, Cambridge, United Kingdom, pp. 141-155.

Baas, P. \& Schweingruber, F. H. 1987. Ecological trends in the wood anatomy of trees, shrubs and climbers from Europe. IAWA Journal 8(3): 245-274.

Baas, P. \& Xinying, Z. 1986. Wood anatomy of trees and shrubs from China. I. Oleaceae. IAWA Bulletin 7(3): 195-220.

Bailey, I. W. \& Tupper, W. W. 1918. Size variation in tracheary cells. I. A comparison between the secondary xylems of vascular cryptogams, gymnosperms and angiosperms. Proceedings of the American Academy of Arts and Sciences 54: 149-204. 
Barcat, C., Cortiñas, J., Nevistic, V. \& Zucchi, H. 1989. Cuenca del Golfo de San Jorge. In: Chebli, G. \& Spalletti, L. A. (Eds.), Cuencas Sedimentarias Argentinas, Serie de Correlación Geológica 6, Instituto Superior de Correlación Geológica, Buenos Aires, pp. 319-345.

Barreda, V. \& Palazzesi, L. 2007. Patagonian vegetation turnovers during Paleogene-Early Neogene: Origin of arid-adapted floras. The Botanical Review 73(1): 31-50.

Barreda, V., Palazzesi, L. \& Marenssi, S. 2009. Palynological record of the Paleogene Río Leona Formation (southernmost South America): Stratigraphical and paleoenvironmental implications. Review of Palaeobotany and Palynology 154(1-4): 22-33.

Beck, C. B. 2010. An introduction to plant structure and development: plant anatomy for the twenty-first century. Cambridge University Press, Cambridge, United Kingdom, $441 \mathrm{p}$.

Berry, E. W. 1932. Fossil plants from Chubut territory collected by The Scarritt Patagonian Expedition. American Museum Novitates, American Museum of Natural History, New York 536: 1-10.

Berry, E. W. 1937a. A Paleocene flora from Patagonia. The Johns Hopkins University Studies in Geology 12: 33-50.

Berry, E. W. 1937b. Eocene plants from Río Turbio in the territory of Santa Cruz, Patagonia. The Johns Hopkins University Studies in Geology 12: 91-98.

Bertels, A. 1973. Bioestratigrafía del Cerro Bororó, Provincia del Chubut, República Argentina. Actas del V Congreso Geológico Argentino 3: 71-91.

Biddle, K., Uliana, M., Mitchum, R., Fitzgerald, M. \& Wright, R. 1986. The stratigraphic and structural evolution of the central and eastern Magallanes Basin, southern South America. International Association of Sedimentologists, Special Publication 8: 41-61.

Bijl, P. K., Schouten, S., Sluijs, A., Reichart, G., Zachos, J. C \& Brinkhuis, H. 2009. Early Palaeogene temperature evolution of the southwest Pacific Ocean. Nature 461: 776-779.

Bodnar, J., Ruiz, D. P., Artabe, A. E., Morel, E. M. \& Ganuza, D. 2015. Voltziales y Pinales (=Coniferales) de la Formación Cortaderita (Triásico Medio), Argentina y su implicancia en la reconstrucción de las coníferas triásicas. Revista Brasilera de Paleontología 18(1): 141160.

Bona, P. 2005. Sistemática y biogeografía de las tortugas y los cocodrilos Paleocenos de la Formación Salamanca, provincia de Chubut, Argentina. Tesis Doctoral, Facultad de Ciencias Naturales y Museo, Universidad Nacional de La Plata, Argentina, 186 p.

Bona, P. 2007. Una nueva especie de Eocaiman Simpson (Crocodylia, Alligatoridae) del Paleoceno Inferior de Patagonia. Ameghiniana 44(2): 435-445.

Bona, P. \& De La Fuente, M. S. 2005. Phylogenetic and paleobiogeographic implications of Yaminuechelys maior (Staesche, 1929) new comb., a large long-necked chelid turtle from the early Paleocene of Patagonia, Argentina. Journal of Vertebrate Paleontology 25(3): 569-582. 
Bonaparte, J. F. \& Morales, J. 1997. Un primitivo Notonychopidae (Litopterna) del Paleoceno Inferior de Punta Peligro, Chubut, Argentina. Estudios Geológicos 53(5-6): 263-274.

Bonaparte, J. F., Van Valen, L. M. \& Kramartz A. 1993. La fauna local de Punta Peligro, Paleoceno inferior, de la provincia del Chubut, Patagonia, Argentina. Evolutionary monographs 14: 161.

Boninsegna, J. A., \& Holmes, R. L. 1978. Estudios dendroconológicos en los Andes centrales y patagónico-fueguinos. Anales del IANIGLA: 75-91.

Boninsegnna, J. A., Keegan, J., Jacoby, G. C., Amigo, D. \& Holmes, R. L. 1988. Dendrochronological studies in Tierra del Fuego, Argentina. Quaternary of South America and Antarctic Peninsula 7: 305-326.

Boninsegnna, J. A., Argollo, J., Aravena, J. C., Barichivich, J., Christie, D., Ferrero, M. E., Lara, A., Le Quesne, C., Luckman, B. H., Masiokas, M., Morales, M., Oliveira, J. M., Roig, F., Srur, A. \& Villalba, R. 2009. Dendroclimatological reconstructions in South America: A review. Palaeogeography, Palaeoclimatology, Palaeoecology 281(3-4): 210-128.

Bown, T.M., Larriestra, C.N., 1990. Sedimentary paleoenvironments of fossil platyrrhine localities, Miocene Pinturas Formation, Santa Cruz Province, Argentina. Journal of Human Evolution 19: 87-119.

Brandmayr, E. 1945. Contribución al conocimiento geológico del extremo sud-sudoeste del Territorio de Santa Cruz (Región Cerro Cazador - Alto Río Turbio). Boletín de Informaciones Petroleras 256: 415-437.

Brea, M. 1993. Inferencia paleoclimáticas a partir del estudio de los anillos de crecimiento de leños fósiles de la Formación Río Turbio, Santa Cruz, Argentina. I. Nothofagoxylon paraprocera Ancibor, 1990. Ameghiniana 30(2): 135-141.

Brea, M. 1995. Ulminium chubutense nov. sp. (Lauraceae), leño permineralizado del Terciario Inferior de Bahía Solano, Chubut, Argentina. Ameghiniana 32(1): 19-30.

Brea, M. 1998a. Análisis de los anillos de crecimiento en leños fósiles de coníferas de la Formación La Meseta, Isla Seymour (Marambio), Antártida. Asociación Paleontológica Argentina. Publicación Especial 5 Paleógeno de América del Sur y de la Península Antártica: 163-175.

Brea, M. 1998b. Ulminium mucilaginosum n. sp. y Ulminium artabeae n. sp., dos leños fósiles de Lauraceae en sedimentos de la Formación El Palmar, provincia de Entre Ríos, Argentina. Ameghiniana 35(2): 193-204.

Brea, M., Matheos, S., Zamuner, A \& Ganuza, D. 2005a. Análisis de los anillos de crecimiento del bosque fósil de Víctor Szlápelis, Terciario inferior del Chubut, Argentina. Ameghiniana 42(2): 407-418.

Brea, M., Zucol, A. F., Matheos, S., Raingemborn, M. S. 2005b. Growth-ring analysis of Lower Paleocene gymnosperm woods from the central Patagonia, Argentina. Ameghiniana 42 Suplemento: $17 \mathrm{R}-18 \mathrm{R}$. 
Brea, M., Matheos, S. D., Raigemborn, M. S., Iglesias, A., Zucol, A. F. \& Prámparo, M. 2007. Aspectos paleoecológicos y paleoambientales del Bosque Petrificado Ameghino (Daniano), Chubut, Argentina. 4th European Meeting on the Palaeontology and Stratigraphy of Latin America. Cuadernos del Museo Geominero 8: 45-50.

Brea, M., Artabe, A. \& Spalletti, L. 2008a. Ecological reconstruction of a mixed Middle Triassic forest from Argentina. Alcheringa: An Australasian Journal of Palaeontology 32(4): 365393.

Brea, M., Zamuner, A. B., Matheos, S. D., Iglesias, A. \& Zucol, A. F. 2008b. Fossil wood of the Mimosoideae from the early Paleocene of Patagonia, Argentina. Alcheringa 32: 427-441.

Brea, M., Zucol, A. F., Matheos. S. D. 2010. El bosque fósil de Estancia Las Violetas (Formación Salamanca, Daniano), Patagonia, Argentina. $X$ Congreso Argentino de Paleontología y Bioestratigrafía y VII Congreso Latinoamericano de Paleontología, Simposio 2: El Paleogeno de América del Sur y Central: 60.

Brea, M., Matheos., S. D., Raigemborn, M. S., Iglesias, A., Zucol, A. F. \& Prámparo, M., 2011. Paleoecology and paleoenvironments of Podocarp trees in the Ameghino Forest (Golfo San Jorge Basin, Patagonia, Argentina): Constraints for Early Paleogene paleoclimate. Geological Acta 9: 13-28.

Brea, M., Zucol, A. F. \& Iglesias, A. 2012. Fossil plant studies from late Early Miocene of the Santa Cruz Formation: paleoecology at the passive margin of Patagonia, Argentina. En: Vizcaíno, S. F., Kay, R. F. \& Bargo, M. S. (Eds.), Early Miocene Paleobiology in Patagonia. HighLatitude Paleocommunities of the Santa Cruz Formation, Cambridge University Press, pp. 104-128.

Brea, M., Artabe, A. E., Franzese, J. R., Zucol, A. F., Spalletti, L. A., Morel, E. M., Veiga, G. D. \& Ganuza, D. G. 2015. Reconstruction of a fossil forest reveals details of the palaeoecology, palaeoenvironments and climatic conditions in the late Oligocene of South America. Palaeogeography, Palaeoclimatology, Palaeoecology 418: 19-42.

Brown, A., Blendinger, P., Lomáscolo, T. \& García Bez, P. 2009. Selva Pedemontana de las Yungas. Historia Natural, Ecología y manejo de un ecosistema en peligro. Ediciones del Subtrópico, Tucumán, Argentina, 487 p.

Burkart, A. 1975. Evolution of grasses and grasslands in South América. Taxon 24(1): 53-66.

Camacho, H. H. 1967. Las transgresiones del Cretácico superior y Terciario de la Argentina. Revista de la Asociación Geológica Argentina 22(4): 253-280.

Camacho, H. H., Chiesa, J. O., Parma, S. G. \& Reichler, V. 2000. Invertebrados marinos de la Formación Man Aike (Eoceno medio), Provincia de Santa Cruz, Argentina. Boletín de la Academia Nacional de Ciencias (Córdoba) 64: 187-208.

Carlquist, S. 1977. Ecological factors in wood evolution: a floristic approach. American Journal of Botany 64: 887-896.

Carlquist, S. 1995. Wood anatomy of Berberidaceae: ecological and phylogenetic considerations. Aliso 14(2): 85-103. 
Carlquist, S. 2001. Comparative Wood Anatomy. Systematic, Ecological, and Evolutionary Aspects of Dicotyledon Wood. Springer-Verlag, Berlin, $436 \mathrm{p}$.

Carlquist, S. 2003. Wood anatomy of Aetoxicaceae and Berberidopsidaceae is compatible with their inclusion in Berberidopsidales. Systematic Botany 28(2): 317-325.

Carlquist, S. 2012. How Wood evolves: a new synthesis. Botany 90: 901-940.

Cevallos-Ferriz, S. R. S., Ceren López, G. \& Flores Rocha, L. A. 2016. Laurinoxylon chalatenangensis sp. nov. From the Miocene Chalatenango Formation, El Salvador. Review of Palaeobotany and Palynology 233: 186-192.

Césari, S. N., Panti, C., Pujana, R. R., Francis, J. E. \& Marenssi, S. A. 2015. The late Oligocene flora from the Río Leona Formation, Argentinian Patagonia. Review of Palaeobotany and Palynology 216: 143-158.

Chaloner, W. G. \& Creber, G. T. 1973. Growth rings in fossil woods as evidence of past climates. En: Tarling, D. H. \& Runcorn, S. K. (Eds.), Implication of continental drift to the earth sciences, Academic Press, London, pp. 425-437.

Chapman, J. L. 1994. Distinguishing internal developmental characteristics from external palaeoenvironmental effects in fossil wood. Review of Palaeobotany and Palynology 81(1): 19-32.

Chase, M. W. \& Reveal, J. L. 2009. A phylogenetic classification of the land plants to accompany APG III. Botanical Journal of the Linnean Society 161(2): 122-127.

Chebli, G. \& Serraiotto, A. 1974. Nuevas localidades del Paleoceno marino en la región central de la Provincia del Chubut. Revista de la Asociación Geológica Argentina 29(3): 311-318.

Christenhusz, M. J. M., Reveal, J. L., Farjon, A., Gardner, M. F., Mill, R. R. \& Chese, M. W. 2011. A new classification and linear sequence of extant gymnosperms. Phytotaxa 19: 55-70.

Clyde, W. C., Wilf, P., Iglesias, A., Slingerland, R. L., Barnum, T., Bijl, P. K., Bralower, T. J., Brinkhuis, H., Comer, E. E., Huber, B. T., Ibañez-Mejia, M., Jicha, B. R., Krause, J. M., Schueth, J. D., Singer, B. S., Raigemborn, M. S., Schmitz, M. D., Sluijs, A. \& Zamaloa, M. C. 2014. New age constraints for the Salamanca Formation and lower Río Chico Group in the western San Jorge Basin, Patagonia, Argentina: Implications for Cretaceous-Paleogene extinction recovery and land mammal age correlations. Geological Society of America Bulletin 126: 289-306.

Coode, M. J. E. 2004. Elaeocarpaceae. En: Flowering Plants. Dicotyledons. Springer, Berlin, Heidelberg, pp. 135-144

Conwentz, H. 1885. Árboles fósiles del Río Negro. Boletín de la Academia Nacional de Ciencias 7: 435-456.

Creber, G. T. 1977. Tree-rings: a natural data-storage system. Biological Reviews 52: 349-383.

Creber, G. T. \& Chaloner, W. G. 1984a. Climatic indications from growth rings in fossil woods. Geological Journal, Special issue 11: 49-74. 
Creber, G. T. \& Chaloner, W. G. 1984b. Influence of environmental factors on the wood structure of living and fossil trees. The Botanical Review 50(4): 357-448.

Creber, G. T. \& Francis, J. E. 1999. Fossil tree-ring analysis: palaeodendrology. Fossil Plants and Spores: Modern Techniques: Geological Society, London: 245-250.

Cuitiño, J. I. \& Scasso, R. A. 2010. Sedimentología y paleoambientes del patagoniano y su transición a la Formación Santa Cruz al sur del Lago Argentino, Patagonia austral. Revista de la Asociación Geológica Argentina 66(3): 406-417.

Cuitiño, J. I., Pimentel, M. M., Ventura Santos, R. \& Scasso, R. 2012. High resolution isotopic ages for the early Miocene "Patagoniense" transgression in Southwest Patagonia: Stratigraphic implications. Journal of South American Earth Sciences 38: 110-122.

Cuitiño, J. I., Scasso, R. A., Ventura Santos, R. \& Mancini, L. H. 2015. Sr ages for the Chenque Formation in the Comodoro Rivadavia Region (Golfo San Jorge basin, Argentina): stratigraphic implications. Latin American Journal of Sedimentology and Basin Analysis 22(1): 3-12.

Dickinson, W. C. 1977. Wood anatomy of Weinmannia (Cunoniaceae). Bulletin of the Torrey Botanical Club 104(1): 12-23.

Dimitri, M. J., Volkart de Hualde, I. R., Ambrosius de Brizuela, C. \& Tiburcio Fano, F. A. 1974. La flora arbórea del Parque Nacional Iguazú. Servicio Nacional de Parques Nacionales, Buenos Aires, Argentina, $180 \mathrm{p}$.

Dimitri, M. J. 1979. Pequeña flora ilustrada de los parques nacionales andino patagonicos. Buenos Aires: Servicio Nacional de Parques Nacionales XIII, Buenos Aires, Argentina, 122 p.

Donoso Zegers, C. 2006. Las especies arbóreas de los bosques templados de Chile y Argentina autoecologí,. Cuneo, Valdivia, Chile, 678 p.

Douglass, A. E. 1919. Climatic cycles and tree-growth. A study of the annual rings of trees in relation to climate and solar activity. Volume 1 . Carnegie Institution of Washington, Washington, DC, $127 \mathrm{p}$.

Douglass, A. E. 1920. Evidence of climatic effects in the annual rings of trees. Ecology 1: 24-32.

Douglass, A. E. 1928. Climatic cycles and tree-growth. A study of the annual rings of trees in relation to climate and solar activity. Volume 2. Carnegie Institution of Washington, Washington, DC, $166 \mathrm{p}$.

Douglass, A. E. 1936. Climatic cycles and tree-growth. A study of the annual rings of trees in relation to climate and solar activity. Volume 3 . Carnegie Institution of Washington, Washington, DC, $171 \mathrm{p}$.

Dupéron, J., Dupéron-Laudoueneix, M., Sakala, J. \& De Franceschi, D. 2008. Ulminium diluviale Unger: historique de la découverte et nouvelle étude. Annales de Paléontologie 94: 1-12.

Dusén, P. 1899. Über die tertiäre Flora der Mag Nordenskjšld (eds.), Wissenschaftliche Ergebnisse der Schwedischen Expedition nach den Megallans- Länder 1895-97. Geologie, Geographine und Anthropologie 1: 87-108 
Falcon-Lang, H. J. 2000a. The relationship between leaf longevity and growth ring markedness in modern conifer woods and its implications for paleoclimatic studies. Paleography, Palaeoclimatology, Palaecology 160: 317-328.

Falcon-Lang, H. J. 2000b. A method to distinguish between woods produced by evergreen and deciduous coniferopsids on the basis of growth ring anatomy: a new palaeoecological tool. Palaeontology 43(4): 785-793.

Fernández, D. A. 2018. Análisis paleoflorístico de la Fm. Río Turbio (Eoceno de la Provincia de Santa Cruz) y su relación con los cambios paleoclimáticos globales: evidencias esporopolínicas. Tesis doctoral, Universidad Nacional de la Plata, La Plata, 235 p.

Fernández, D. A., Panti, C., Palazzesi, L. \& Barreda, V. D. 2012. La presencia de una familia neotropical (Malpighiaceae) en el extremo más austral de Sudamérica durante el Eoceno. Revista Brasilera de Paleontología 15(3): 386-391.

Feruglio, E. 1944. Estudios geológicos y glaciológicos en la región del Lago Argentino (Patagonia). Boletín de la Academia Nacional de Ciencias 37: 3-255.

Feruglio. E. 1949. Descripción geológica de la Patagonia I, II, III. Dirección General de Yacimientos Petrolíferos Fiscales, Buenos Aires, Argentina, $750 \mathrm{p}$.

Fitzgerald, M. G., Mitchum Jr, R. M., Uliana, M. A. \& Biddle, K. T. 1990. Evolution of the San Jorge Basin, Argentina. AAPG Bulletin 74: 879-920.

Fletcher, T., Moss, P. \& Salisbury, S. 2015. Wood growth indices as climate indicators from the Upper Cretaceous (Cenomanian-Turonian) portion of the Winton Formation, Australia. Palaeogeography, Palaeoclimatology, Palaeoecology 417: 35-43.

Flores, S, Promis, A, \& Faúndez, L. 2016. Caracterización florística y estructural de la población natural de Jubaea chilensis (Molina) Baill. más austral de Chile. Phyton 85(2): 324-332.

Forasiepi, A. M. \& Martinelli, A. 2003. Femur of a monotreme (Mammalia, Monotremata) from the Early Paleocene Salamanca Formation of Patagonia, Argentina. Ameghiniana 40(4): 625630.

Fosdick, J. C., Romans, B. W., Fildani, A., Bernhardt, A., Calderón, M. \& Graham, S. A. 2011. Kinematic evolution of the Patagonian retroarc fold-and-thrust belt and Magallanes foreland basin, Chile and Argentina, 51 ${ }^{\circ} 30^{\prime}$ S. Bulletin 123(9-10): 1679-1698.

Fosdick, J. C., Bostelmann, J. E., Leonard, J., Ugalde, R., Oyarzún, J. L. \& Griffin, M. 2015. Timing and rates of foreland sedimentation: New detrital zircon $\mathrm{U} / \mathrm{Pb}$ geochronology of the Cerro Dorotea, Río Turbio, and Río Guillermo Formations, Magallanes basin. Actas XIV Congreso Geológico Chileno 1: 763-766.

Franco, M. J. 2012. Maderas fósiles de Lauraceae de la Formación Ituzaingó (PliocenoPleistoceno), cuenca del río Paraná, Argentina. Revista del Museo Argentino de Ciencias Naturales 14(2): 307-324.

Frenguelli, J. 1941. Los elementos florísticos del Magellaniano de Patagonia Austral. Notas del Museo de La Plata, Paleontología 6(30): 173-202. 
Fritts, H. C. 1976. Tree-rings and Climate. Academic Press New York, New York, 567 p.

Frost, F. H. 1930a. Specialization in secondary xylem of Dicotyledons. I. Origin of vessel. Botanical Gazette 89(1): 67-94.

Frost, F. H. 1930b. Specialization in secondary xylem of Dicotyledons. II. Evolution of end wall of vessel segment. Botanical Gazette 90(2): 198-212.

Frost, F. H. 1931. Specialization in secondary xylem of Dicotyledons. III. Specialization of lateral wall of vessel segment. Botanical Gazette 91(1): 88-96.

Furque, G. 1973. Hoja geológica 58b Lago Argentino. Boletín de los Servicios Geológicos Mineros Argentinos 140: 1-49.

Furque, G. \& Caballé, M. 1993. Estudio geológico y geomorfológico de la cuenca superior del Río Turbio, provincia de Santa Cruz. Consejo Nacional de Inversiones. Serie investigaciones aplicadas. Colección Hidrología Subterránea 6: 8-39.

Futey, M. K., Gandolfo, M. A., Zamaloa, M. C., Cúneo, R. \& Cladera, G. 2012. Arecaceae fossil fruits from the Paleocene of Patagonia, Argentina. Botanical Review 78(3): 205-234.

Gelfo, J. N. 2007. The "Condylarth" Raulvaccia peligrensis (Mammalia: Didolodontidae) from the Paleocene of Patagonia, Argentina. Journal of Vertebrate Paleontology 27(3): 651-660.

Gelfo, J.N. \& Pascual, R. 2001. Peligrotherium tropicalis (Mammalia, Dryolestida) from the early Paleocene of Patagonia, a survival from a Mesozoic Gondwanan radiation. Geodiversitas 23 (3): 369-379.

Gelfo, J. N., Goin, F. J., Woodburne, M. O. \& De Muizon, C. 2009. Biochronological relationships of the earliest South American Paleogene mammalian faunas. Palaeontology 52(1): 251-269.

Gelfo, J. N., Ortiz-Jaureguizar, E., Rougier, G. W. 2007. New remains and species of the "condylarth" genus Escribania (Mammalia: Didolodontidae) from the Palaeocene of Patagonia, Argentina. Earth and Environmental Science Transactions of the Royal Society of Edinburgh 98: 127-138.

González Estebenet, M. S., Espinosa, M. A., Guerstein, R. \& Rodriguez Raising, M. R. 2012. Diatomeas de la Formación Río Turbio (Eoceno Medio), sudoeste de Santa Cruz, Argentina. Ameghiniana 49(3): 389-394.

González Estebenet, Guerstein, R. \& Rodriguez Raising, M. R. 2014. Middle Eocene dinoflagellate cysts from Santa Cruz Province, Argentina: Biostratigraphy and paleoenvironment. Review of Palaeobotany and Palynology 211: 55-65.

Gonzáles Estebenet, M. S., Guerstein, R. \& Casadío, S. 2015. Estudio bioestratigráfico y paleoambiental de la Formación Río Turbio (Eoceno medio-superior) en el sudoeste de Patagonia (Argentina) basado en quistes e dinoflagelados. Revista Brasilera de Paleontología 18(3): 429-442.

Gornitz, V. 1995. Encyclopedia of paleoclimatology and ancient environments. Springer, Dordrecht, The Netherlands. 
Gottwald, H. 1997. Alttertiäre Kieselhölzer aus Miozänen Schottern der ostbayerischen Molasse bei Ortenberg. Documentae Naturae 109: 1-83.

Greenwood, D. R. 1994. Palaeobotanical evidence for Tertiary climates. History of the Australian vegetation cretaceous to recent: $44-59$.

Greenwood, D. R., Wilf, P., Wing, S. L. \& Christophel, D. C. 2004. Paleotemperature estimation using leaf-margin analysis: Is Australia Different? Palaios 19: 129-142.

Greguss, P. 1955. Identification of living Gymnosperms on the basis of xylotomy. Akádemia Kiadó, Budapest, $263 \mathrm{p}$.

Guerra, P. E., González, S. B., Kirner, H. J., Retta, D. S., Di Leo, P. \& Gómez, M. F. 2012. Aspectos anatómicos del leño y composición de los aceites esenciales de especies arbustivo-leñosas del ecotono y la estepa del noroeste de la Provincia del Chubut. Dominguezia 28(1): 13-44

Guerstein, G. R., Rodriguez Raising, M. R., Casadío, S., Marenssi, S. A. \& Cárdenas, O. 2010. Palinología del Miembro Inferior de la Formación Río Turbio (Eoceno inferior a medio) en el cañón del río Guillermo, suroeste de Santa Cruz, Argentina. Resúmenes X Congreso Argentino de Paleontología y Bioestratigrafía 93.

Guerstein, G. R., González Estebenet, M. S., Alperín, M. I., Casadío, S. A. \& Archangelsky, S. 2014. Correlation and paleoenvironments of middle Paleogene marine beds based on dinoflagellate cysts in southwestern Patagonia, Argentina. Journal of South American Earth Sciences 52: 166-178.

Hinojosa, L. F. 2005. Cambios climáticos y vegetacionales inferidos a partir de paleofloras cenozoicas del sur de Sudamérica. Revista geológica de Chile 32(1): 1-16.

Hinojosa, L. F. \& Villagrán, C. 1997. Historia de los bosques del sur de Sudamérica, antecedentes paleobotánicos, geológicos y climáticos del Terciario del cono sur de América. Revista Chilena de Historia Natural 70: 225-239.

Hughes, M. K., Kelly, P. M., Pilcher, J. R. \& Lamarche Jr, V. C. 1982. Climate from tree rings. Cambridge University Press, New York, 223 p.

Hünicken, M. 1955. Depósitos neocretácicos y terciarios del extremo SSW de Santa Cruz (Cuenca carbonífera de Río Turbio). Revista del Instituto Nacional de Investigaciones de las Ciencias Naturales. Museo Argentino de Ciencias Naturales "Bernardino Rivadavia". Ciencias Geológicas, 4(1): 1-161.

Hünicken, M. 1967. Flora terciaria de los estratos de Río Turbio, Santa Cruz. Niveles plantíferos del arroyo. Revista Facultad de Ciencias Santa Flavia Exactas Físicas y Naturales Universidad Nacional de Córdoba 27(3-4): 139-227.

Hünicken, M. A. 1995. Floras cretácicas y terciarias. Revisión y actualización de la obra paleobotánica de Kurtz en la República Argentina. Actas de la Academia Nacional de Ciencias: 199-219.

IAWA Committee. 1989. List of microscopic features for hardwood identification. IAWA Bulletin 10: 219-329. 
IAWA Committee. 2004. IAWA list of microscopic features for softwood identification. IAWA Journal 25: 1-70.

Iglesias, Ari. 2007. Estudio paleobotánico, paleoecológico y paleoambiental en secuencias de la Formación Salamanca, del Paleoceno Inferior en el sur de la Provincia del Chubut, Patagonia, Argentina.Tesis Doctoral, Facultad de Ciencias Naturales y Museo, Universidad Nacional de La Plata, Argentina, p. 244.

Iglesias, A., Wilf, P., Zamuner, A. B., Johnson K., Cúneo, R. \& Singer, B. 2007. A Paleocene lowland macroflora from Patagonia reveals significantly greater richness than North American analogs. Geology 35: 947-950.

Iglesias, A., Artabe, A. E. \& Morel, E. M. 2011. The evolution of Patagonian climate and vegetation from the Mesozoic to the present. Biological Journal of the Linnean Society 103: 409-422.

InsideWood, 2004. Onwards. Published on the Internet. http://insidewood.lib.ncsu.edu/ search.

Ivany, L. C., Lohmann, K. C., Hasiuk, F., Blake, D. B., Glass, A., Aronson, R. B. \& Moody, R. M. 2008. Eocene climate record of a high southern latitude continental shelf: Seymour Island, Antarctica. Geological Society of America Bulletin 120: 659-678.

Jud, N. A., Gandolfo, M. A., Iglesias, A. \& Wilf, P. 2017. Flowering after disaster: Early Danian buckthorn (Rhamnaceae) flowers and leaves from Patagonia. Plos One 12(5): e0176164.

Kräusel, R. 1924. Beiträge zur Kenntnis der fossilen Flora Südamerikas 1. Fossile Hölzer aus Patagonien und benachbarten Gebieten. Ark. Bot. 19: 1-36.

Landrum, L. 1981. The phylogeny and geography of Myrceugenia (Myertaceae). Brittonia 33: 105129.

Landrum, L. 1985. Monograph of the genus Myrceugenia (Myrtaceae). Flora Neotropica monograph 29: 1-126.

Landrum, L. 1988. The Myrtle family (Myrtaceae) in Chile. Proceedings California Academy of Science 45: 277-317.

Le Roux J. P. 2015a. A review of Tertiary climate changes in southern South America and the Antartic Peninsula. Part 1: Oceanic conditions. Sedimentary Geology 247-248: 1-20.

Le Roux, J. P. 2015b. A review of Tertiary climate changes in southern South America and the Antartic Peninsula. Part 2: continental conditions. Sedimentary Geology 247-248: 21-38.

Leanza, A. F. 1972. Andes patagónicos australes. En: Leanza, A. F. (Eds.), Geología Regional Argentina, Academia Nacional de Córdoba, pp. 689-706.

Lesta, P. J. \& Ferello, R. 1972. Región extrandina de Chubut y norte de Santa Cruz. Geología Regional Argentina. Academia Nacional de Ciencias de Córdoba: 601-654.

Licht, A., Boura, A., De Franceschi, D., Utescher, T., Sein, C. \& Jaeger J. J. 2015. Late middle Eocene fossil wood of Myanmar: implications for the landscape and the climate of the Eocene Bengal Bay. Review of Palaeobotany and Palynology 216: 44-54. 
Malumián, N. \& Caramés, A. 1997. Upper Campanian-Paleogene from the Río Turbio coal measures in southern Argentina: micropaleontology and the Paleocene/Eocene boundary. Journal of South American Earth Sciences 10(2): 189-201.

Malumián, N. \& Panza, J. 2000. Hoja Geológica 5172-III Yacimiento Río Turbio 1:250.000. Servicio Geológico Minero Argentino 247: 1-108.

Marenssi, S. A., Limarino, C. O., Tripaldi, A. \& Net, L. I. 2005. Fluvial systems variations in the Río Leona Formation: Tectonic and eustatic controls on the Oligocene evolution of the Austral (Magallanes) Basin, southernmost Argentina. Journal of South American Earth Sciences 19: 359-372.

Martínez, G. A. 1992. Paleoambiente de la Formación Salamanca en la Pampa María Santísima, Departamente de Sarmiento, Provincia de Chubut. Revista de la Asociación Geológica Argentina 47(3): 293-303.

Martínez-Cabrera, H. I., Ramérez-Garduño, J. L. \& Estrada-Ruiz. E. 2014. Plantas fósiles e inferencia paleoclimática: aproximaciones metodológicas y algunos ejemplos para México. Boletín de la Sociedad Geológica Mexicana 66(1): 41-52.

Matheos, S. D., Brea, M., Zucol, A.F., Prámparo, M., Raigemborn, M. S., Iglesias, A. \& Fischer, A. 2005. Análisis paleoambiental de las sedimentitas del Daniano del sector sur de los Lagos Musters y Colhué Huapi (Chubut, Argentina). Actas XVI Congreso Geológico Argentino III: 83-90.

Méndez, I. 1966. Foraminíferos, edad y correlación estratigráfica del Salamanquense de Punta Peligro (4530's; $67^{\circ} 11^{\prime} \mathrm{W}$ ), Provincia del Chubut. Revista de la Asociación Geológica Argentina 21: 127-157.

Menéndez, C. 1971. Floras terciarias de la Argentina. Ameghiniana 8: 357-370.

Metcalfe, C.R. \& Chalk, L. 1950. Anatomy of the dicotyledons. Clarendon Press, Oxford, 1500 p.

Mirabelli, S. L., Pujana, R. R., Marenssi, S. A. \& Santillana, S. N. 2017. Conifer Fossil Woods from the Sobral Formation (Lower Paleocene, Western Antarctica). Ameghiniana 55(1): 91-108.

Miller, K. G., Fairbanks, R. G. \& Mountain, G. S. 1987. Tertiary oxygen isotope synthesis, sea level history, and continental margin erosion. Paleoceanography 2: 1-19.

Morris, H., Gillingham, M. A. F., Plavcová, L., Gleason, S. M., Olson, M. E., Coomes, D. A., Fichetler, E., Klepsch; M. M., Martínez-Cabrera, H. I., McGlinn, D. J., Wheeler, E. A., Zheng, J., Zieminska, K. \& Jansen, S. 2018. Vessel diameter is related to amount and spatial arrangement of axial parenchyma in wood angiosperms. Plant Cell Environ 41: 245-260.

Morris, H., Plavcová, L., Cvecko, P., Fichetler, E., Gillingham, M. A. F., Martínez-Cabrera, H. I., McGlinn, D. J., Wheeler, E. A., Zheng, J., Zieminska, K. \& Jansen, S. 2015. A global analysis of parenchyma tissue fractions in secondary xylem of seed plants. New Phytologist 209: 1553-1565. 
Mosbrugger, V. \& Utescher, T. 1997. The coexistence approach - a method for quantitative reconstructions of Tertiary terrestrial palaeoclimate data using plant fossils. Palaeogeography, Palaeoclimatology, Palaeoecology 134: 61-86.

Müller-Stoll, W. R. \& Schultze-Motel, J. 1990. Gymnospermen- Hölzer des Deutschen Jura Teil: Abietoid (modern) getüpfelte Hölzer. Zeitschrift der Deutschen Geologischen Gessellschaft 141: 61-77.

Nishida, M. 1984a. The anatomy and affinities of the petrified plants from the Tertiary of Chile. I. En: Nishida, M. (Ed.), Contributions to the botany in the Andes I. Academia Scientific Book Inc, Tokyo, Japan, pp. 81-85.

Nishida, M. 1984b. The anatomy and affinities of the petrified plants from the Tertiary of Chile. III. Petrified woods from Mocha Island, Central Chile. En: Nishida, M. (Ed.), Contributions to the Botany in the Andes I. Academia Scientific Book Inc, Tokyo, Japan, pp. 96-110.

Nishida, M., Nishida, A. \& Nasa, T. 1988. Anatomy and affinities of the petrifies plants from the Tertiary of Chile V. The Botanical Magazine, Tokio 101: 293-309.

Nishida, M., Ohsawa, T. \& Nishida, H. 1990. Anatomy and affinities of the petrified plants from the Tertiary of Chile (VI). The Botanical Magazine, Tokyo, 103: 255-268.

Nix, H. 1982. Environmental determinants of biogeography and evolution in Terra Australis. Barker, W. R. \& Greenslade, P. J. M. (Eds.), Evolution of the Flora and Fauna of Arid Australia, Peacock Publications, pp. 47-66.

Olivero, E. B., Barreda, V., Marenssi, S. A., Santillana, S. N. \& Martinioni, D. R. 1998. Estratigrafía, sedimentología y palinología de la Formación Sloggett (Paleogeno continental), Tierra del Fuego. Revista de la Asociación Geológica Argentina 53(4): 504-516.

Ortiz-Jaureguizar, E. \& Cladera, G. A. 2006. Paleoenvironmental evolution of southern South America during Cenozoic. Journal of Arid Environments 66: 498-532.

Palazzesi, L. \& Barreda, V. 2007. Major vegetative trends in the Tertiary of Patagonia (Argentina): A qualitative paleoclimatic approach based on palynological evidence. Flora 202: 328-337.

Palazzesi, L., Barreda, V. \& Prieto, A. R. 2003. Análisis evolutivo de la vegetación cenozoica en las provincias de Chubut y Santa Cruz (Argentina) con especial atención en las comunidades herbáceo-arbustivas. Revista del Museo Argentino de Ciencias Naturales n.s. 5(2): 151161.

Panti, C. 2010. Diversidad florística durante el Paleógeno en Patagonia austral. Tesis doctoral, Universidad de Buenos Aires, Buenos Aires, p. 290.

Panti, C. 2011. Análisis paleoflorístico de la Formación Río Guillermo (Eoceno Tardío-Oligoceno Temprano?), Santa Cruz, Argentina. Ameghiniana 48(3): 320-335.

Panti, C. 2014. Myrtaceae fossil leaves from the Río Turbio Formation (Middle Eocene), Santa Cruz Province, Argentina. Historical Biology: An International Journal of Paleobiology, DOI: 10.1080/08912963.2014.976635. 
Panti, C. 2018. Fossil leaves of subtropical lineages in the Eocene-?Oligocene of southern Patagonia. Historical Biology: 1-16.

Panti, C., Marenssi, S. A. \& Olivero, E. B. 2008. Paleogene flora of the Sloggett Formation, Tierra del Fuego Argentina. Ameghiniana 45(4): 677-692.

Panza, J. L. 1981. Descripción geológica de las hojas 46e "Gran Laguna Salada" y 47f "Meseta Cuadrada" (escala 1:100.000), provincia del Chubut. Dirección Nacional del Servicio Geológico, Informe inédito, $241 \mathrm{p}$.

Paritsis, J. \& Veblen, T. T. 2011. Dendroecological analysis of defoliator outbreaks on Nothofagus pumilio and their relation to climate variability in the Patagonian Andes. Global Change Biology 17: 239-253.

Parma, S. G. \& Casadío, S. 2005. Upper Cretaceous-Paleocene Equinoids from Northern Patagonia, Argentina. Journal of Paleontology 79(6): 1072-1087.

Parras, A., Griffin, M., Feldmann, R., Casadío, S., Schweitzer, C. \& Marenssi, S. 2008. Isotopic ratios and faunal affinities in the correlation of marine beds across the Paleogene/Neogene boundary in southern Patagonia, Argentina. Journal of South American Earth Science 26: 204-216.

Pascual, R., 1970. Evolución de comunidades, cambios faunísticos e integraciones biocenóticas de los vertebrados cenozoicos de Argentina. En: Actas del IV Congreso Latinoamericano de Zoología, vol. 2, Caracas, pp. 991-1088.

Pascual, R. \& Carlini, A. A. 1987. A new superfamily in the extensive radiation of South American Paleogene marsupials. Fieldiana: Zoology NS 39: 99-110.

Pascual, R. \& Odreman Rivas, O. E. 1971. Evolución de las comunidades de los Vertebrados del Terciario argentino. Los aspectos paleozoogeográficos y paleoclimáticos. Ameghiniana 8(34): 372-412.

Pascual, R. \& Ortiz-Jaureguizar, E. 1990. Evolving climates and mammal faunas in Cenozoic South America. Journal of Human Evolution 19: 23-60.

Pascual, R., Carlini, A.A., De Santis, L.J.M., 1988. Dentition and ways of life in Cenozoic South American rodentlike marsupials. Outstanding examples of convergence. En: Russell, D. E., Santoro, J. P., Sigogneau-Russell, D. (Eds.), Proceedings of the VII International Symposium on Dental Morphology, Paris, pp. 217-226.

Pascual, R. Archer, M., Ortiz Jaureguizar, E., Prado, J. L., Godthelp, H. \& Hand, S. J. 1992. First discovery of monotremes in South America. Nature 356: 704-706.

Pascual, R., Ortiz-Jaureguizar, E., Prado, J.L., 1996. Land mammals: paradigm of Cenozoic South American geobiotic evolution. En: Arratia G. (Ed.), Contribution of Southern South America to Vertebrate Paleontology, Müncher Geowissenschaftliche Abhandlungen (A) 30, pp. 265-319. 
Pascual, R., Goin, F., Balarino, L. \& Udrizar, D. E. 2002. New data on the Paleocene monotreme Monotrematum sudamericanum, and the convergent evolution of triangulate molars. Acta Palaeontologica Polonica 47 (3): 487-492.

Petriella, B. 1972. Estudio de maderas petrificadas del Terciario Inferior del área central de Chubut (Cerro Bororó). Revista del Museo de La Plata (NS), Paleontologia 6: 159-254.

Petriella, B. T. \& Archangelsky, S. 1975. Vegetación y ambiente en el Paleoceno de Chubut. I Congreso Argentino de Paleontología y Bioestratigrafía, Actas 2: 257-270.

Philippe, M. \& Bamford, M. K. 2008. A key to morphogenera used for Mesozoic conifer-like woods. Review of Palaeobotany and Palynology 148: 184-207.

Plavcová, L., Hoch, G., Morris, H., Ghiasi, S. \& Jansen, S. 2016. The amount of parenchyma and living fibers affects storage of nonstructural carbohydrates in young stems and roots of temperate trees. American Journal of Botany 103(4): 603-612.

Poole, I. 2002. Systematics of Cretaceous and Tertiary Nothofagoxylon: implications for southern hemisphere biogeography and evolution of the Nothofagaceae. Australian Systematic Botany 15: 247-276.

Poole, I., \& Cantrill, D. 2001. Fossil woods from Williams Point beds, Livingston Island, Antarctica: a late Cretaceous southern high latitude flora. Palaeontology 44(6): 1081-1112.

Poole, I., Cantrill, D. \& Utescher, T. 2005. A multi-proxy approach to determine Antarctic terrestrial palaeoclimate during the Late Cretaceous and Early Tertiary. Palaeogeography, Palaeoclimatology, Palaeoecology 222: 95-121.

Prakash, U. \& Tripathi, P.P. 1972. Fossil woods from the Tertiary of Assam. Palaeobotanist 21: 305-316.

Pujana, R. R. 2007. New fossil woods of Proteaceae from the Oligocene of southern Patagonia. Australian Systematic Botany 20: 119-125.

Pujana, R. R. 2008. Estudio paleoxilológico del Paleógeno de Patagonia austral (Formaciones Río Leona, Río Guillermo y Río Turbio) y Antártida (Formación La Meseta). Tesis doctoral, Universidad de Buenos Aires, Buenos Aires, $182 \mathrm{p}$.

Pujana, R. R. 2009a. Fossil woods from the Oligocene of southwestern Patagonia (Río Leona Formation). Atherospermataceae, Myrtaceae, Leguminosae and Anacardiaceae. Ameghiniana 46(3): 523-535.

Pujana, R. R. 2009b. Fossil woods from the Oligocene of southwestern Patagonia (Río Leona Formation). Rosaceae and Nothofagaceae. Ameghiniana 46(4): 621-636.

Pujana, R. R. \& Ruiz, D. P. 2017. Podocarpoxylon Gothan reviewed in light of a new species from the Eocene of Patagonia. IAWA Journal 38: 220-244.

Pujana, R. R., Burrieza, H. P. \& Castro, M. A. 2009a. Wood anatomy of Ribes magellanicum (Crossulariaceae). Boletín de la Sociedad Argentina de Botánica 42(1-2): 61-65. 
Pujana, R. R., García Massini, J. L., Rodríguez Brizuela, R. \& Burrieza, H. P. 2009b. Evidence of fungal activity in silicified gymnosperm wood from the Eocene of southern Patagonia (Argentina). Geobios 42: 639-647.

Pujana, R. R., Panti, C., Cuitiño, J. I., García Massini, J. L. \& Mirabelli, S. L. 2015. A new megaflora (fossil Woods and leaves) from the Miocene of southwestern Patagonia. Ameghiniana 52(3): 350-366.

Pujana, R. R., Santillana, S. N. \& Marenssi, S. A. 2014. Conifer fossil Woods from the La Meseta Formation (Eocene of Western Antarctica): evidence of Podocarpaceae-dominated forest. Review of Palaeobotany and Palynology 200: 122-137.

Ragonese, A. M. 1980. Leños fósiles de dicotiledóneas del Paleoceno de Patagonia, Argentina. I. Myrceugenia chubutense n. sp. (Myrtaceae). Ameghiniana 17(4): 297-311.

Raigemborn, M. S., Krause, J. M., Bellosi, E. \& Matheos, S. D. 2010. Redefinición estratigráfica del Grupo Río Chico (Paleógeno inferior), en el norte de la cuenca del Golfo San Jorge, Chubut, Argentina. Revista de la Asociación Geológica Argentina 67: 239-256.

Raigemborn, M. S., Gómez-Peral, L. E., Krause, J. M. \& Matheos, S. D. 2014. Controls on clay mineral assemblages in an Early Paleogene nonmarine succession: Implications for the volcanic and paleoclimatic record of extra-Andean Patagonia, Argentina. Journal of South American Earth Sciences 52: 1-23.

Ramanujam, C. G. K. 1956. Fossil woods of Euphorbiaceae from the Tertiary rocks of South Arcot district, Madras. Journal of the Indian Botanical Society 35: 284-307.

Rancusi, H. M., Nishida, M. \& Nishida, H. 1987. Xylotomy of important Chilean Woods. En: Nishida, M. (Ed.), Contributions to the botany in the Andes II. Academia Scientific Book Inc., Tokyo, pp. 68-158.

Rivera, S. M. 1988. Revisión xilológica del genero Nothofagus Bl. (Fagaceae) para la Argentina. Monografías de la Academia Nacional de Ciencias Exactas, Físicas y Naturales (Buenos Aires) 4: 73-84.

Roig Juñent, F. A. \& Videla, E. 2009. Anatomía de la madera de arbustos de montaña del NW de Mendoza, Argentina. Xama 19-23: 157-238.

Romero, E. J. 1968. Palmoxylon patagonicum n. sp. del Terciario Inferior de la Provincia del Chubut, Argentina. Ameghiniana 5(10): 417-432.

Romero, E. J. 1970. Ulminium atlanticum n. sp. Tronco petrificado de Lauraceae del Eoceno de Bahía Solano, Chubut, Argentina. Ameghiniana 7(3): 205-224.

Romero, E. J. 1973. Polen fósil de "Nothofagus" ("Nothofagidites") de Cretácico y Paleoceno de Patagonia. Revista del Museo de La Plata (NS), Paleontología 7: 291-303.

Romero, E. J. 1977. Polen de Gimnospermas y fagáceas de la Formación Río Turbio (Eoceno), Santa Cruz, Argentina. Fundación para la Educación, la Ciencia y la Cultura, Buenos Aires, Argentina, 219 p. 
Romero, E. J. 1978. Paleoecología y paleofitogeografía de las tafofloras del Cenofítico de Argentina y áreas vecinas. Ameghiniana 15(1-2): 209-217.

Romero, E. J. 1986. Paleogene phytogeography and climatology of South America. Annals of the Missouri Botanical Garden 73(2): 449-461.

Romero, E. J. \& Castro, M. T. 1986. Material fúngico y granos de polen de angiospermas de la Formación Río Turbio (Eoceno), provincia de Santa Cruz, República Argentina. Ameghiniana 23(1-2): 101-118.

Romero, E. J. \& Zamaloa, M. C. 1985. Polen de Angiospermas de la Formación Río Turbio (Eoceno), Provincia de Santa Cruz. República Argentina. Ameghiniana 22(1-2): 43-51.

Roth, I. \& Giménez de Bolzón, A. M. 1997. Argentine Chaco forests. Dendrology, tree structure, and economic use. 1. The semi-arid Chaco. Gebrüder Borntraeger, Berlin, Germany, 180 p.

Roth, I. \& Giménez, A. M. 2006. Argentine Chaco forests. Dendrology, tree structure, and economic use. 2. The humid Chaco. Druckerei zu Altenburg, Germany, 204 p.

Ruiz, D. P., Brea, M., Raigemborn, M. S. \& Matheos, S. D. 2017. Conifer woods from the Salamanca Formation (early Paleocene), Central Patagonia, Argentina: Paleoenvironmental implications. Journal of South American Earth Sciences 76: 427-445.

Russo, A, Flores, M. A. \& Di Benedetto, H. 1980. Patagonia Austral Extraandina. En: Geología Regional Argentina. Academia Nacional de Ciencias de Córdoba, Córdoba, Argentina, 1431-1462

Sakala, J. 2007. The potential of fossil angiosperm wood to reconstruct the palaeoclimate in the Tertiary of Central Europe (Czech Republic, Germany). Acta Paleobotanica 47(1): 127-133.

Santos Biloni, J. 1990. Árboles autóctonos argentinos. Tipográfica Editora Argentina, Buenos Aires Argentina, $335 \mathrm{p}$.

Scafati, L., Melendi, D. L. \& Volkheimer, W. 2009. A Danian subtropical lacustrine palynobiota from South America (Bororó Formation, San Jorge Basin, Patagonia - Argentina). Geologica Acta 7: 35-61.

Scott, D. 1972. Correlation between tree-ring width and climate in two areas in New Zeland. Journal of the Royal Society of New Zeland 2(4): 545-560.

Schweingruber, F. H. 1988. Tree rings. Basics and Applications of dendrochronology. Kluwer Academic Publishers, Dordrecht, Holland.

Schweingruber, F. H. 2007. Wood Structure and Environment. Springer-Verlag, Berlin Heidelberg, German.

Simpson, G. G. 1937. An ancient eusuchian crocodile from Patagonia. American Museum Novitates 965: 1-20.

Soffiatti, P., Torres Boeger, M. R., Nisgoski, S. \& Kauai, F. 2016. Wood anatomical traits of the Araucaria Forest, Southern Brazil. Bosque 37(1): 21-31. 
Somoza, R., Cladera, G. \& Archangelsky, S. 1995. Una nueva tafoflora paleocena de Chubut, Patagonia. Su edad y ambiente de depositación. VI Congreso Argentino de Paleontología y Biostratigrafía, Actas: 265-269.

Spalletti, L. A. 1980. Paleoambientes sedimentarios, en secuencias silicoclasticas. Asociación Geológica Argentina, Publicación Especial, Serie B (Didáctica y Complementaria) №8, pp. $1-175$.

Staesche, K. 1929. Schildrkrötenreste aus der oberen Kreide Patagoniens. Paläeontographica 72: 103-112.

Süss, H. \& Mädel, E. 1958. Über Lorbeerhölzer aus miozänen Schichten von Randeck (Schwäbische Alb) und Ipolytarnoc (Ungarn). Geologie 7: 80-99.

Sylwan, C. A. 2001. Geology of the Golfo San Jorge Basin, Argentina. Journal of Iberian Geology 27: 123-157.

Taylor, E. L \& Ryberg, P. E. Tree growth at polar latitudes based on fossil tree ring analysis. Palaeogeography, Palaeoclimatology, Palaeoecology 255: 246-264.

Tortorelli, L. A. 1956. Maderas y bosques argentinos. Acme, Buenos Aires, Argentina, 910 p.

Troncoso A., \& Romero, E. J. 1998. Evolución de las comunidades florísticas en el extremo sur de Sudamérica durante el Cenofítico. Monographs in Systematic Botany: 149-172.

Torres, T. 1990. Etude paléobotanique du Tertiaire des iles Roi Georges et Seymour, Antarctique. Tesis, I'UniversiteÂ Claude Bernard, Lyon, 210 p.

Vaganov, E. A., Hughes, M. K. \& Shashkin, A. V. 2006. Growth dynamics of Conifer tree rings. Springer-Verlag Berlin Heidelberg, Germany.

Van der Graaff, N. A. \& Baas, P. 1974. Wood anatomical variation in relation to latitude and altitude. Blumea 22: 101-121.

Vasquez Correa, Á. M., Alcántara Vara, E., \& Herrera Machuca, M. Á. 2010. Wood anatomy of colombian Podocarpaceae (Podocarpus, Prumnopitys and Retrophyllum). Botanical Journal of Linnean Society 164: 293-302.

Vento, B., Gandolfo, M. A., Nixon, K. C. \& Prámparo M. Paleofloristic assamblage from the Paleogene Río Guillermo Formation, Argentina: preliminary results of phylogenetic relationships of Nothofagus in South America. Historical Biology, DOI: 0.1080/08912963.2015.1136930.

Volkheimer, W. 1971. Aspectos paleoclimáticos del Terciario argentino. Revista del Museo Argentino de Ciencias Naturales. Paleontologia 1(8): 243-264.

Volkheimer, W., Scafati, L. \& Melendi, D. L. 2007. Palynology of a Danian warm climatic wetland in Central Northern Patagonia, Argentina. Revista Española de Micropaleontología 39(1-2): 117-134.

Wagemann, W. 1948. Maderas chilenas, contribución a su anatomía e identificación. Lilloa 16: 263-375. 
Wheeler, E. A. \& Baas, P. 1991. A survey of the fossil record for Dicotiledonous rood and its significance for evolutionary and ecological Wood Anatomy. IAWA Journal 12: 275-332.

Wheeler, E. A. \& Baas, P. 1993. The potentials and limitations of dicotyledonous wood anatomy for climatic reconstructions. Paleobiology 19: 487-498.

Wheeler, E. A., Baas, P. \& Rodgers, S. 2007. Variations in dicot wood anatomy: global analysis based on the insidewood database. IAWA Journal 28(3): 229-258.

Wiemann, M. C., Wheeler, E. A., Manchester, S. R. \& Portier, K. M. 1998. Dicotyledonous wood anatomical characters as predictors of climate. Palaeogeography, Palaeoclimatology, Palaeoecology 139: 83-100.

Wiemann, M. C., Manchester, S. R. \& Wheeler, E. A. 1999. Paleotemperature estimation from dicotyledonous wood anatomical characters. Palaios 14: 459-474.

Wilf, P., Cúneo, N. R., Johnson, K. R., Hicks, J. F., Wing, S. L. \& Obradovich, J. D. 2003. High plant diversity in Eocene South America: Evidence from Patagonia. Science 300: 122-125.

Wilf, P., Johnson, K. R., Cúneo, N. R., Smith, M. E., Singer, B. S. \& Gandolfo, M. A. 2005. Eocene plant diversity at Laguna del Hunco and Río Pichileufú, Patagonia, Argentina. The American Naturalist 165(6): 634-650.

Wilf, P., Little, S. A., Iglesias, A., Zamaloa, M. del C., Gandolfo, M. A., Cúneo, R. \& Johnson, K. R. 2009. Papuacedrus (Cupressaceae) in Eocene Patagonia: fossil link to Australasian rainforest. American Journal of Botany 96(11): 2031-2047.

Wing, S. L. \& Greenwood, D. R. 1993. Fossils and fossil climate: the case for equable continental interiors in the Eocene. Philosophica Transactions: Biological Sciences 341: 243-252.

Zachos, J. C., Stott, L. D \& Lohmann, K. C. 1994. Evolution of early Cenozoic marine temperatures. Paleoceanography 9(2): 353-387.

Zachos, J., Pagani, M., Sloan, L., Thomas, E. \& Billups, K. 2001. Trends, rhythms, and aberrations in global climate $65 \mathrm{Ma}$ to present. Science 292: 686-693.

Zamuner, A. B., Brea, M., Ganuza, D. \& Matheos S. D. 2000. Resultados anatómico-sistemáticos preliminares en la lignoflora del Bosque de Szlápelis (Terciario inferior), provincia del Chubut, Argentina. Ameghiniana 37(4)R: 80R.

Zhang S. \& Wang, Q. 1994. Palaeocene petrified wood on the west side of Collins glacier in the King George Island, Antarctica. En: Shen, Y. (Ed.), Stratigraphy and palaeontology of Fildes Peninsula King George Island, Antarctica, State Antarctic Committee Monograph 3, Science Press, Beijing, pp. 231-238.

Zucol, A. F., Brea, M. \& Matheos, S. 2008. Estudio preliminar de microfósiles silíceos de la Formación Salamanca (Paleoceno Inferior), Chubut, Argentina. En: Zucol, A. F., Osterrieth, M. L. \& Brea, M. (Eds.), Fiolitos. Estado actual de su conocimiento en América del Sur, 171178. 


\section{APÉNDICE}


Apéndice I: listado de especies actuales con los caracteres utilizados en las ecuaciones de Wiemann et al. $(1998,1999)$

Abreviaciones: A/B - Árbol/Arbusto; RP - Porosidad circular; tang - patrones de distribución tangencial de los vasos; mult - placa escalariforme; spir - engrosamientos helicoidales; $<100 \mu \mathrm{m}$ - diámetro tangencial de los vasos menos a $100 \mu \mathrm{m}$; sept - fibras septadas; $>10$ ser - radios multiseriados con más de 10 células de ancho; het 4+ - radios heterogéneos con extremos uniseriados de más de 4 células de alto; homo - radios exclusivamente homogéneos; stor - radios estratificados; abs - parénquima axial escaso o ausente; marg - presencia de parénquima marginal; para - parénquima axial en su mayoría de tipo paratraqueal. 0=ausente; $1=$ presente; $0,5=$ varía; ?=dato faltante.

\section{Parque Nacional Los Glaciares}

\begin{tabular}{|c|c|c|c|c|c|c|c|c|c|c|c|c|c|c|c|}
\hline Familia & Especie & $\mathbf{R P}$ & tang & mult & spir & $\begin{array}{c}<100 \\
\mu \mathrm{m}\end{array}$ & sept & $\begin{array}{l}>10 \\
\text { ser }\end{array}$ & $\begin{array}{l}\text { het } \\
4+\end{array}$ & $\begin{array}{c}\text { hom } \\
0\end{array}$ & stor & abs & marg & para & Referencia \\
\hline \multirow{3}{*}{ Nothofagaceae } & Nothofagus antarctica & 0 & 0 & 0 & 1 & 0 & 1 & 0 & 0 & 0 & 0 & 1 & 0 & 0 & Rancusi et al., 1987 \\
\hline & Nothofagus betuloides & 0 & 0 & 1 & 0 & 1 & 0 & 0 & 0 & 0 & 0 & 1 & 0 & 0 & Rancusi et al., 1987 \\
\hline & Nothofagus pumilio & 0 & 0 & 0 & 0 & 1 & 1 & 0 & 0 & 0 & 0 & 1 & 0 & 0 & Rancusi et al., 1987 \\
\hline Myrtaceae & Amomyrtus luma & 0 & 0 & 0 & 0 & 1 & 0 & 0 & 0 & 0 & 0 & 0 & 0 & 1 & Rancusi et al., 1987 \\
\hline Berberidaceae & Berberis microphylla & 0 & 0 & ? & 1 & 1 & ? & 0 & ? & ? & 0 & 1 & 0 & 0 & Carlquist, 1995 \\
\hline \multirow{2}{*}{ Proteaceae } & Embothrium coccineum & 1 & 1 & 0 & 0 & 0 & 0 & 0 & 0 & 0 & 0 & 1 & 0 & 1 & Rancusi et al., 1987 \\
\hline & Ribes magellanicum & 0 & 0 & 1 & 0 & 1 & 0 & 0 & 0 & 0 & 0 & 1 & 0 & 0 & Pujana, 2008 \\
\hline Celastraceae & Maytenus magellanica & 0 & 0 & 0 & 1 & 1 & 1 & 0 & 1 & 0 & 0 & 1 & 0 & 0 & Rancusi et al., 1987 \\
\hline Araliaceae & Raukaua laetevirens & 0 & 0 & 0 & 0 & 1 & 0 & 0 & 0 & 0 & 0 & 1 & 0 & 0 & Rancusi et al., 1987 \\
\hline
\end{tabular}


Parque Nacional Los Alerces

\begin{tabular}{|c|c|c|c|c|c|c|c|c|c|c|c|c|c|c|c|}
\hline Familia & Especie & RP & tang & mult & spir & $\begin{array}{l}<100 \\
\mu \mathrm{m}\end{array}$ & sept & $\begin{array}{l}>10 \\
\text { ser }\end{array}$ & $\begin{array}{l}\text { het } \\
4+\end{array}$ & $\begin{array}{c}\text { hom } \\
\text { o }\end{array}$ & stor & abs & marg & para & Referencia \\
\hline Aextoxicaceae & Aextoxicon punctatum & 0 & 0 & 1 & 0 & 1 & 1 & 0 & 1 & 0 & 0 & 1 & 0 & 0 & Rancusi et al., 1987 \\
\hline Araliaceae & Raukaua laetevirens & 0 & 0 & 0 & 0 & 1 & 0 & 0 & 0 & 0 & 0 & 1 & 0 & 0 & Rancusi et al., 1987 \\
\hline Berberidaceae & Berberis microphylla & 0 & 0 & ? & 1 & 1 & ? & 0 & ? & ? & 0 & 1 & 0 & 0 & Carlquist, 1995 \\
\hline \multirow{2}{*}{ Celastraceae } & Maytenus boaria & 0 & 0 & 0 & 1 & 1 & 1 & 0 & 1 & 0 & 0 & 1 & 0 & 0 & Rancusi et al., 1987 \\
\hline & Maytenus magellanica & 0 & 0 & 0 & 0 & 1 & 1 & 0 & 1 & 0 & 0 & 1 & 0 & 0 & Rancusi et al., 1987 \\
\hline Cunoniaceae & $\begin{array}{l}\text { Weinmannia } \\
\text { trichosperma }\end{array}$ & 0 & 0 & 1 & 0 & 1 & 1 & 0 & 0 & 0 & 0 & 1 & 1 & 0 & Rancusi et al., 1987 \\
\hline Elaeocarpaceae & Aristotelia chilensis & 0 & 0 & 0 & 0 & 1 & 1 & 0 & 1 & 0 & 0 & 0 & 0 & 0 & Rancusi et al., 1987 \\
\hline Eucryphiaceae & Eucryphia cordifolia & 0 & 0 & 0,5 & 0 & 1 & 1 & 0 & 0 & 0 & 0 & 0 & 1 & 0 & Rancusi et al., 1987 \\
\hline Grossulariaceae & Ribes magellanicum & 0 & 0 & 1 & 0 & 1 & 0 & 0 & 0 & 0 & 0 & 1 & 0 & 0 & Pujana, 2008 \\
\hline Lauraceae & Persea lingue & 0 & 0 & 0 & 1 & 0 & 0 & 0 & 1 & 0 & 0 & 0 & 0 & 1 & Rancusi et al., 1987 \\
\hline \multirow{2}{*}{ Myrtaceae } & Amomyrtus luma & 0 & 0 & 0 & 0 & 1 & 0 & 0 & 0 & 0 & 0 & 0 & 0 & 1 & Rancusi et al., 1987 \\
\hline & Luma apiculata & 0 & 0 & 1 & 0 & 1 & 1 & 1 & 1 & 0 & 0 & 0 & 0 & 0 & Rancusi et al., 1987 \\
\hline \multirow{3}{*}{ Nothofagaceae } & Nothofagus antartica & 0 & 0 & 0 & 1 & 1 & 1 & 0 & 0 & 0 & 0 & 1 & 0 & 0 & Rancusi et al., 1987 \\
\hline & Nothofagus dombeyi & 0 & 0 & 0 & 0 & 1 & 1 & 0 & 0 & 0 & 0 & 1 & 0 & 0 & Rancusi et al., 1987 \\
\hline & Nothofagus pumilio & 0 & 0 & 0 & 0 & 1 & 1 & 0 & 0 & 0 & 0 & 1 & 0 & 0 & Rancusi et al., 1987 \\
\hline \multirow{3}{*}{ Proteaceae } & Lomatia hirsuta & 0 & 0 & 0 & 0 & 1 & 0 & 1 & 0 & 0 & 0 & 1 & 0 & 1 & Rancusi et al., 1987 \\
\hline & Gevuina avellana & 1 & 1 & 0 & 1 & 1 & 0 & 0 & 0 & 0 & 0 & 1 & 0 & 1 & Rancusi et al., 1987 \\
\hline & Embothrium coccineum & 1 & 1 & 0 & 0 & 1 & 0 & 0 & 0 & 0 & 0 & 1 & 0 & 1 & Rancusi et al., 1987 \\
\hline Salicaceae & Azara lanceolata & 0 & 0 & 0,5 & 0 & 1 & 1 & 0 & 1 & 0 & 0 & 1 & 0 & 0 & Rancusi et al., 1987 \\
\hline Solanaceae & Fabiana imbricata & 0 & 0 & 0 & 0 & 1 & 0 & 0 & 0 & $?$ & 0 & 0 & 0 & 0 & Guerra et al., 2012 \\
\hline Thymelaeaceae & Ovidia andina & 0 & $?$ & 0 & 1 & 1 & 0 & 0 & 0 & $?$ & 0 & 0 & 0 & $?$ & $\begin{array}{l}\text { InsideWood, } 2004 \text { en } \\
\text { adelante }\end{array}$ \\
\hline Verbenaceae & Rhaphithamnus spinosus & 0 & 0 & 0 & 1 & 1 & 1 & 0 & 1 & 0 & 0 & 1 & 0 & 0 & Rancusi et al., 1987 \\
\hline Aextoxicaceae & Aextoxicon punctatum & 1 & 1 & 2 & 1 & 2 & 2 & 1 & 2 & 1 & 1 & 2 & 1 & 1 & Carlquist, 2003 \\
\hline
\end{tabular}


Parque Nacional Nahuel Huapi

\begin{tabular}{|c|c|c|c|c|c|c|c|c|c|c|c|c|c|c|c|}
\hline Familia & Especie & RP & tang & mult & spir & $\begin{array}{l}<100 \\
\mu \mathrm{m}\end{array}$ & sept & $\begin{array}{l}>10 \\
\text { ser }\end{array}$ & $\begin{array}{l}\text { het } \\
4+\end{array}$ & $\begin{array}{l}\text { hom } \\
\text { o }\end{array}$ & stor & abs & marg & para & Referencia \\
\hline Araliaceae & Raukaua laetevirens & 0 & 0 & 0 & 0 & 1 & 0 & 0 & 0 & 0 & 0 & 1 & 0 & 0 & Rancusi et al., 1987 \\
\hline Atherospermataceae & $\begin{array}{l}\text { Laureliopsis } \\
\text { philippiana }\end{array}$ & 0 & 0 & 1 & 0 & 1 & 0 & 0 & 0 & 0 & 0 & 1 & 0 & 0 & Rancusi et al., 1987 \\
\hline Berberidaceae & Berberis microphylla & 0 & 0 & $?$ & 1 & 1 & $?$ & 0 & $?$ & ? & 0 & 1 & 0 & 0 & Carlquist, 1995 \\
\hline \multirow[b]{2}{*}{ Celastraceae } & Maytenus boaria & 0 & 0 & 0 & 1 & 1 & 1 & 0 & 1 & 0 & 0 & 1 & 0 & 0 & Rancusi et al., 1987 \\
\hline & $\begin{array}{l}\text { Maytenus } \\
\text { magellanica }\end{array}$ & 0 & 0 & 0 & 1 & 1 & 1 & 0 & 1 & 0 & 0 & 1 & 0 & 0 & Rancusi et al., 1987 \\
\hline \multirow{2}{*}{ Cunoniaceae } & $\begin{array}{l}\text { Caldcluvia } \\
\text { paniculata }\end{array}$ & 0 & 0 & 1 & 0 & 0 & 1 & 0 & 0 & 0 & 0 & 1 & 0 & 0 & Rancusi et al., 1987 \\
\hline & $\begin{array}{l}\text { Weinmannia } \\
\text { trichosperma }\end{array}$ & 0 & 0 & 1 & 0 & 1 & 1 & 0 & 0 & 0 & 0 & 1 & 1 & 0 & Rancusi et al., 1987 \\
\hline Elaeocarpaceae & Aristotelia chilensis & 0 & 0 & 0 & 0 & 1 & 1 & 0 & 1 & 0 & 0 & 1 & 0 & 0 & Rancusi et al., 1987 \\
\hline Grossulariaceae & Ribes magellanicum & 0 & 0 & 1 & 0 & 1 & 0 & 0 & 0 & 0 & 0 & 1 & 0 & 0 & Pujana, 2008 \\
\hline \multirow{4}{*}{ Myrtaceae } & Amomyrtus luma & 0 & 0 & 0 & 0 & 1 & 0 & 0 & 0 & 0 & 0 & 0 & 0 & 1 & Rancusi et al., 1987 \\
\hline & Luma apiculata & 0 & 0 & 1 & 0 & 1 & 1 & 1 & 1 & 0 & 0 & 0 & 0 & 0 & Rancusi et al., 1987 \\
\hline & $\begin{array}{l}\text { Myrceugenia } \\
\text { chrysocarpa }\end{array}$ & $?$ & $?$ & 0,5 & 1 & $?$ & $?$ & 0 & $?$ & $?$ & 0 & 0 & 0 & $?$ & Rancusi et al., 1987 \\
\hline & $\begin{array}{l}\text { Myrceugenia } \\
\text { exsucca }\end{array}$ & 0 & 0 & 0,5 & 1 & 1 & 1 & 0 & 1 & 0 & 0 & 0 & 0 & 0 & Rancusi et al., 1987 \\
\hline \multirow{3}{*}{ Nothofagaceae } & $\begin{array}{l}\text { Nothofagus } \\
\text { antartica }\end{array}$ & 0 & 0 & 0 & 1 & 1 & 1 & 0 & 0 & 0 & 0 & 1 & 0 & 0 & Rancusi et al., 1987 \\
\hline & $\begin{array}{l}\text { Nothofagus } \\
\text { dombeyi }\end{array}$ & 0 & 0 & 0 & 0 & 1 & 1 & 0 & 0 & 0 & 0 & 1 & 0 & 0 & Rancusi et al., 1987 \\
\hline & Nothofagus pumilio & 0 & 0 & 0 & 0 & 1 & 1 & 0 & 0 & 0 & 0 & 1 & 0 & 0 & Rancusi et al., 1987 \\
\hline \multirow[t]{2}{*}{ Proteaceae } & $\begin{array}{l}\text { Embothrium } \\
\text { coccineum }\end{array}$ & 1 & 1 & 0 & 0 & 1 & 0 & 0 & 0 & 0 & 0 & 1 & 0 & 1 & Rancusi et al., 1987 \\
\hline & Lomatia hirsuta & 0 & 0 & 0 & 0 & 1 & 0 & 1 & 0 & 0 & 0 & 1 & 0 & 1 & Rancusi et al., 1987 \\
\hline Salicaceae & Azara lanceolata & 0 & 0 & 0,5 & 0 & 1 & 1 & 0 & 1 & 0 & 0 & 1 & 0 & 0 & Rancusi et al., 1987 \\
\hline Solanaceae & Fabiana imbricata & 0 & 0 & 0 & 0 & 1 & 0 & 0 & 0 & $?$ & 0 & 0 & 0 & 0 & Guerra et al., 2012 \\
\hline Thymelaeaceae & Ovidia andina & 0 & $?$ & 0 & 1 & 1 & 0 & 0 & 0 & $?$ & 0 & 0 & 0 & $?$ & $\begin{array}{l}\text { InsideWood, } 2004 \text { en } \\
\text { adelante }\end{array}$ \\
\hline Winteraceae & Drimys winteri & 0 & 0 & 0 & 0 & 0 & 0 & 0 & 1 & ? & 0 & 1 & ? & ? & Rancusi et al., 1987 \\
\hline
\end{tabular}


Reserva Nacional Los Bellotos del Melado (Chile)

\begin{tabular}{|c|c|c|c|c|c|c|c|c|c|c|c|c|c|c|c|}
\hline Familia & Especie & RP & tang & mult & spir & $\begin{array}{l}<100 \\
\mu \mathrm{m}\end{array}$ & sept & $\begin{array}{l}>10 \\
\text { ser }\end{array}$ & $\begin{array}{l}\text { het } \\
4+\end{array}$ & $\begin{array}{l}\text { hom } \\
\text { o }\end{array}$ & stor & abs & marg & para & Referencia \\
\hline Aextoxicaceae & Aextoxicon punctatum & 0 & 0 & 1 & 0 & 1 & 1 & 0 & 1 & 0 & 0 & 1 & 0 & 0 & Rancusi et al., 1987 \\
\hline Anacardiaceae & Lithraea caustica & 0 & $?$ & 0,5 & 1 & 1 & 1 & 0 & 0 & $?$ & 0 & 0 & 1 & $?$ & Rancusi et al., 1987 \\
\hline Elaeocarpaceae & Aristotelia chilensis & 0 & 0 & 0 & 0 & 1 & 1 & 0 & 1 & 0 & 0 & 1 & 0 & 0 & Rancusi et al., 1987 \\
\hline Lauraceae & Cryptocarya alba & 0 & 1 & 0 & 0 & 1 & 0 & 0 & 0 & 0 & 0 & 0 & 1 & 0 & Rancusi et al., 1987 \\
\hline \multirow{2}{*}{ Monimiaceae } & Laurelia sempervirens & 0 & 0 & 1 & 0 & 1 & 1 & 0 & 1 & 0 & 0 & 1 & 0 & 0 & Rancusi et al., 1987 \\
\hline & Peumus boldus & 0 & 0 & 0 & 1 & 1 & 0 & 0 & 0 & 0 & 0 & 1 & 0 & 0 & Rancusi et al., 1987 \\
\hline \multirow{2}{*}{ Myrtaceae } & Amomyrtus luma & 0 & 0 & 0 & 0 & 1 & 0 & 0 & 0 & 0 & 0 & 0 & 0 & 1 & Rancusi et al., 1987 \\
\hline & Luma apiculata & 0 & 0 & 1 & 0 & 1 & 1 & 1 & 1 & 0 & 0 & 0 & 0 & 0 & Rancusi et al., 1987 \\
\hline \multirow{2}{*}{ Nothofagaceae } & Lophozonia oblicua & 0 & 0 & 0 & 1 & 1 & 1 & 0 & 0 & 0 & 0 & 1 & 0 & 0 & Rancusi et al., 1987 \\
\hline & Nothofagus glauca & 0 & 0 & 0 & 0 & 1 & 0 & 0 & 0 & 0 & 0 & 1 & 0 & 0 & Rancusi et al., 1987 \\
\hline \multirow{2}{*}{ Proteaceae } & Lomatia dentata & 0 & 1 & 0,5 & 0 & 1 & 0 & 0 & 0 & $?$ & 0 & 1 & 0 & 1 & Rancusi et al., 1987 \\
\hline & Lomatia hirsuta & 0 & 0 & 0 & 0 & 1 & 0 & 1 & 0 & 0 & 0 & 1 & 0 & 1 & Rancusi et al., 1987 \\
\hline Quillajaceae & Quillaja saponaria & 0 & 0 & 0 & 1 & 1 & 0 & 0 & 0 & $?$ & 0 & 0 & 0 & 1 & Rancusi et al., 1987 \\
\hline \multirow{2}{*}{ Rosaceae } & Kageneckia oblonga & 0 & 0 & 0 & 1 & 1 & 0 & 0 & 0 & 0 & 0 & 1 & 0 & 0 & Rancusi et al., 1987 \\
\hline & Tetraglochin alatum & 0 & 0 & 0 & 1 & 0 & 0 & 0 & 0 & 0 & 0 & 1 & 0 & 1 & Roig \& Videla, 2009 \\
\hline Salicaceae & Azara petiolaris & 1 & 0 & 0 & 0 & 0 & 0 & 0 & 0 & $?$ & 0 & 1 & 0 & 0 & Rancusi et al., 1987 \\
\hline Solanaceae & Fabiana imbricata & 0 & 0 & 0 & 0 & 1 & 0 & 0 & 0 & $?$ & 0 & 0 & 0 & 0 & Guerra et al., 2012 \\
\hline
\end{tabular}


Parque Nacional Iguazú

\begin{tabular}{|c|c|c|c|c|c|c|c|c|c|c|c|c|c|c|c|}
\hline Familia & Especie & RP & tang & mult & spir & $<100 \mu \mathrm{m}$ & sept & $>10$ ser & Het 4+ & homo & stor & abs & marg & para & Referencia \\
\hline \multirow{2}{*}{ Apocynaceae } & Aspidosperma polyneuron & 0 & 0 & 0 & 0 & 1 & 1 & 0 & 0 & 1 & 0 & 0 & 0 & 0 & Tortorelli, 1956 \\
\hline & Aspidosperma australe & 0 & 1 & 0 & 0 & 1 & 1 & 0 & 0 & 1 & 0 & 1 & 1 & 0 & Tortorelli, 1956 \\
\hline Araliaceae & Schefflera morototoni & 0 & 0 & 1 & 0 & 0 & 1 & 0 & 0 & $?$ & 0 & 1 & 0 & 1 & $\begin{array}{l}\text { InsideWood, } 2004 \\
\text { en adelante }\end{array}$ \\
\hline Bignoniaceae & $\begin{array}{l}\text { Handroanthus } \\
\text { heptaphyllus }\end{array}$ & 0 & 1 & 0 & 0 & 1 & 0 & 0 & 0 & $?$ & 1 & 0 & 0 & 1 & $\begin{array}{l}\text { InsideWood, } 2004 \\
\text { en adelante }\end{array}$ \\
\hline \multirow{2}{*}{ Boraginaceae } & Cordia trichotoma & 0 & 0 & 0 & 0 & 0 & 0 & 0 & 0 & 0 & 0 & 0 & 1 & 0 & Tortorelli, 1956 \\
\hline & Cordia americana & 0 & 1 & 0 & 0 & 1 & 1 & 0 & 0 & 0 & 0 & 0 & 0 & 1 & Tortorelli, 1956 \\
\hline \multirow{2}{*}{ Euphorbiaceae } & Alchornea glandulosa & 0 & 0 & 0 & 0 & 0 & 0 & 0 & 1 & 0 & 0 & 1 & 0 & 0 & $\begin{array}{l}\text { InsideWood, } 2004 \\
\text { en adelante }\end{array}$ \\
\hline & Croton urucurana & 0 & 0 & 0 & 0 & 1 & 0 & 0 & 0 & 0 & 0 & 0 & 0 & 1 & $\begin{array}{l}\text { Roth \& Giménez } \\
\text { de Bolzón, } 1997\end{array}$ \\
\hline \multirow{11}{*}{ Fabaceae } & Anadenanthera colubrina & 0 & 0 & 0 & 0 & 1 & 0 & 0 & 0 & $?$ & 0 & 0 & 0 & 1 & $\begin{array}{l}\text { InsideWood, } 2004 \\
\text { en adelante }\end{array}$ \\
\hline & Apuleia leiocarpa & 0 & 1 & 0 & 0 & 1 & 1 & 0 & 0 & 0 & 1 & 0 & 0 & 1 & Tortorelli, 1956 \\
\hline & $\begin{array}{l}\text { Enterolobium } \\
\text { contortisiliqum }\end{array}$ & 0 & 0 & 0 & 0 & 0 & 1 & 0 & 0 & 1 & 0 & 1 & 0 & 1 & Tortorelli, 1956 \\
\hline & Erythrina crista-galli & 0 & 1 & 0 & 0 & 0 & 0 & 0 & 0 & 0 & 0 & 0 & 0 & 1 & Tortorelli, 1956 \\
\hline & Erytrhrina falcata & 0 & 1 & 0 & 0 & 0 & 0 & $?$ & $?$ & 0 & 1 & 0 & 0 & 1 & Tortorelli, 1956 \\
\hline & Gleditsia amorphoides & 0 & 0 & 0 & 0 & 1 & 0 & 0 & 0 & 0 & 0 & 0 & 0 & 1 & Tortorelli, 1956 \\
\hline & Holocalyx balansae & 0 & 1 & 0 & 0 & 1 & 0 & 0 & 0 & 0 & 1 & 0 & 0 & 1 & $\begin{array}{l}\text { InsideWood, } 2004 \\
\text { en adelante }\end{array}$ \\
\hline & Inga uraguensis & 0 & 0 & 0 & 0 & 0 & 0 & 0 & 0 & 1 & 0 & 0 & 0 & 1 & Tortorelli, 1956 \\
\hline & Myrocarpus frondosus & 0 & 1 & 0 & 0 & 1 & 0 & 0 & 0 & 0 & 1 & 0 & 0 & 1 & Tortorelli, 1956 \\
\hline & Parapiptadenia rigida & 0 & 1 & 0 & 0 & 0 & 0 & 0 & 0 & 0 & 0 & 0 & 0 & 1 & Tortorelli, 1956 \\
\hline & Peltophorum dubium & 0 & 0 & 0 & 0 & 0 & 1 & 0 & 0 & 1 & 0 & 0 & 0 & 1 & Tortorelli 2009 \\
\hline Malvaceae & Bastardiopsis densiflora & 0 & 0 & 0 & 0 & 1 & 0 & 0 & 0 & 0 & 1 & 1 & 0 & 1 & Tortorelli, 1956 \\
\hline \multirow[t]{2}{*}{ Meliaceae } & Cabralea canjerana & 0 & 1 & 0 & 0 & 0 & 0 & 0 & 0 & $?$ & 0 & 0 & 0 & 1 & $\begin{array}{l}\text { InsideWood, } 2004 \\
\text { en adelante }\end{array}$ \\
\hline & Cedrela fissilis & 0 & 1 & 0 & 0 & 1 & 0 & 0 & 0 & 0 & 0 & 0 & 1 & 1 & Tortorelli, 1956 \\
\hline Moraceae & Maclura tinctoria & 0 & 0 & 0 & 0 & 0 & 0 & 0 & 0 & 1 & 0 & 0 & 0 & 1 & Tortorelli, 1956 \\
\hline Polygonaceae & Ruprechtia laxiflora & 0 & 0 & 0 & 0 & 1 & 0 & 0 & 0 & 1 & 0 & 1 & 0 & 1 & Tortorelli, 1956 \\
\hline Rutaceae & $\begin{array}{l}\text { Balfourodendron } \\
\text { riedelianum }\end{array}$ & 0 & 1 & 0 & 0 & 1 & 0 & 0 & 0 & 0 & 0 & 0 & 1 & 1 & Tortorelli, 1956 \\
\hline \multirow{2}{*}{ Sapindaceae } & Allophyllus edulis & 0 & 1 & 0 & 0 & 1 & 1 & 0 & 0 & 1 & 0 & 1 & 1 & 0 & Tortorelli, 1956 \\
\hline & Diatenopteryx sorbifolia & 0 & 0 & 0 & 0 & 1 & 1 & 0 & 0 & 0 & 0 & 0 & 0 & 1 & Tortorelli 2009 \\
\hline \multirow[t]{2}{*}{ Sapotaceae } & $\begin{array}{l}\text { Chrysophyllum } \\
\text { gonocarpum }\end{array}$ & 0 & 0 & 0 & 0 & 1 & 1 & 0 & 1 & 0 & 0 & 1 & 0 & 0 & $\begin{array}{l}\text { Roth \& Giménez, } \\
2006\end{array}$ \\
\hline & Pouteria gardneriana & 0 & 0 & 0 & 0 & 1 & 0 & 0 & 0 & 0 & 0 & 0 & 1 & 0 & InsideWood, 2004 \\
\hline
\end{tabular}




\begin{tabular}{|c|c|c|c|c|c|c|c|c|c|c|c|c|c|c|c|}
\hline & & & & & & & & & & & & & & & en adelante \\
\hline Styracaceae & Styrax leprosus & 0 & 0 & 1 & 0 & 0 & 0 & 0 & 1 & 0 & 0 & 1 & 0 & 0 & $\begin{array}{l}\text { InsideWood, } 2004 \\
\text { en adelante }\end{array}$ \\
\hline Tiliaceae & Luehea divaricata & 0 & 0 & 0 & 0 & 1 & 0,5 & 0 & 0 & 0 & 1 & 0 & 0 & 0 & Tortorelli, 1956 \\
\hline
\end{tabular}

\section{Reserva Provincial Acambuco (Salta)}

\begin{tabular}{|c|c|c|c|c|c|c|c|c|c|c|c|c|c|c|c|}
\hline Familia & Especie & $\mathbf{R P}$ & tang & mult & spir & $\begin{array}{l}<100 \\
\mu \mathrm{m}\end{array}$ & sept & $\begin{array}{l}>10 \\
\text { ser }\end{array}$ & $\begin{array}{c}\text { het } \\
4+\end{array}$ & $\begin{array}{c}\text { hom } \\
\text { o }\end{array}$ & stor & abs & marg & para & Referencia \\
\hline \multirow{2}{*}{ Bignoniaceae } & Jacaranda mimosifolia & 0 & 0 & 0 & 0 & 1 & 0 & 0 & 0 & 1 & 0 & 0 & 0 & 1 & Tortorelli, 1956 \\
\hline & Jacaranda cuspidifolia & 0 & 0 & 0 & 0 & ? & $?$ & ? & ? & ? & $?$ & $?$ & $?$ & $?$ & Alves et al., 2000 \\
\hline \multirow{2}{*}{ Boraginaceae } & Cordia trichotoma & 0 & 0 & 0 & 0 & 0 & 0 & 0 & 0 & 0 & 0 & 0 & 1 & 0 & Tortorelli, 1956 \\
\hline & Cordia americana & 0 & 1 & 0 & 0 & 1 & 1 & 0 & 0 & 0 & 0 & 0 & 0 & 1 & Tortorelli, 1956 \\
\hline Caricaceae & Carica quercifolia & 0 & 0 & 0 & 0 & 0 & 0 & 1 & 0 & 1 & 0 & 0 & 0 & 1 & Roth \& Giménez, 2006 \\
\hline Combretaceae & Terminalia triflora & 0 & 0 & 0 & 0 & 1 & 1 & 0 & 0 & 1 & 0 & 0 & 0 & 1 & Tortorelli, 1956 \\
\hline \multirow{14}{*}{ Fabaceae } & Acacia aroma & 0 & 0 & 0 & 0 & 0 & 0 & 0 & 0 & 0 & 0 & 0 & 0 & 1 & Roth \& Giménez, 2006 \\
\hline & Acacia caven & 0 & 0 & 0 & 0 & 1 & 0 & 0 & 0 & 1 & 0 & 0 & 0 & 1 & Tortorelli, 1956 \\
\hline & Acacia visco & 0 & 0 & 0 & 0 & 0 & 1 & 0 & 0 & 1 & 0 & 0 & 0 & 1 & Tortorelli, 1956 \\
\hline & Amburana cearensis & 0 & 0 & 0 & 0 & 0 & 0 & 0 & 0 & 0 & 0 & 0 & 0 & 1 & Tortorelli, 1956 \\
\hline & $\begin{array}{l}\text { Anadenanthera } \\
\text { colubrina }\end{array}$ & 0 & 0 & 0 & 0 & 1 & 0 & 0 & 0 & $\dot{c}$ & 0 & 0 & 0 & 1 & Tortorelli, 1956 \\
\hline & $\begin{array}{l}\text { Caesalpinia } \\
\text { paraguariensis }\end{array}$ & 0 & 0 & 0 & 0 & 1 & 0 & 0 & 0 & 1 & 1 & 0 & 1 & 1 & Tortorelli, 1956 \\
\hline & $\begin{array}{l}\text { Enterolobium } \\
\text { contortisiliquum }\end{array}$ & 0 & 0 & 0 & 0 & 0 & 1 & 0 & 0 & 1 & 0 & 1 & 0 & 1 & Tortorelli, 1956 \\
\hline & Erythrina crsita-galli & 0 & 1 & 0 & 0 & 0 & 0 & 0 & 0 & 0 & 0 & 0 & 0 & 1 & Tortorelli, 1956 \\
\hline & Geoffroea decorticans & 0 & 0 & 0 & 0 & 1 & 0 & 0 & 0 & 1 & 1 & 0 & 1 & 1 & Tortorelli, 1956 \\
\hline & Gleditsiaa amorphoides & 0 & 0 & 0 & 0 & 1 & 0 & 0 & 0 & 0 & 0 & 0 & 0 & 1 & Tortorelli, 1956 \\
\hline & Myroxylon peruiferum & 0 & 0 & 0 & 0 & 0 & 0 & 0 & 0 & 1 & 1 & 0 & 0 & 1 & Tortorelli, 1956 \\
\hline & Parapiptadenia excelsa & 0 & 0 & 0 & 0 & 1 & 0 & 0 & 0 & 0 & 0 & 0 & 0 & 1 & Tortorelli, 1956 \\
\hline & Pterogyne nitens & 0 & 0 & 0 & 0 & 0 & 0 & 0 & 0 & 0 & 1 & 0 & 1 & 1 & Tortorelli, 1956 \\
\hline & Tipuana tipu & 0 & 0 & 0 & 0 & 0 & 0 & 0 & 0 & 1 & 1 & 0 & 1 & 1 & Tortorelli, 1956 \\
\hline Lauraceae & Ocotea puberula & 0 & 0 & 0 & 0 & 0 & 1 & 0 & 0 & 0 & 0 & 1 & 0 & 1 & Tortorelli, 1956 \\
\hline Meliaceae & Cedrela balansae & 0 & 0 & 0 & 0 & 0 & 0 & 0 & 0 & 0 & 0 & 0 & 1 & 0 & Tortorelli, 1956 \\
\hline Moraceae & Maclura tinctoria & 1 & 0 & 0 & 0 & 0 & 0 & 0 & 0 & 1 & 0 & 0 & 0 & 0 & Tortorelli, 1956 \\
\hline Nyctaginaceae & Pisonia zapallo & 0 & 0 & 0 & 0 & 1 & 0 & 0 & 0 & 0 & 1 & 1 & 0 & 1 & Tortorelli, 1956 \\
\hline Polygonaceae & Ruprechtia laxiflora & 0 & 0 & 0 & 0 & 1 & 0 & 0 & 0 & 1 & 0 & 1 & 0 & 1 & Tortorelli, 1956 \\
\hline Rubiaceae & $\begin{array}{l}\text { Calycophyllum } \\
\text { multiflorum }\end{array}$ & 0 & 0 & 0 & 0 & 1 & 0 & 0 & 0 & 0 & 0 & 1 & 0 & 0 & Tortorelli, 1956 \\
\hline Salicaceae & Salix humboldtiana & 0 & 0 & 0 & 0 & 1 & 1 & 0 & 0 & 1 & 0 & 1 & 0 & 0 & Tortorelli, 1956 \\
\hline \multirow{2}{*}{ Sapindaceae } & Allophylus edulis & 0 & 1 & 0 & 0 & 1 & 1 & 0 & 0 & 1 & 0 & 1 & 1 & 0 & Tortorelli, 1956 \\
\hline & Diatenopteryx sorbifolia & 0 & 0 & 0 & 0 & 1 & 0,5 & 0 & 0 & 1 & 0 & 1 & 1 & 0 & Tortorelli, 1956 \\
\hline
\end{tabular}




\begin{tabular}{|c|c|c|c|c|c|c|c|c|c|c|c|c|c|c|c|}
\hline Sapotaceae & Sideroxylon obtusifolium & 0 & 0 & 0 & 0 & 0 & 0 & 0 & 0 & 0 & 0 & 0 & 0 & 1 & Tortorelli, 1956 \\
\hline Ulmaeae & Phyllostylon rhamnoides & 0 & 0 & 0 & 0 & 1 & 0 & 0 & 0 & 1 & 1 & 0 & 0 & 1 & Tortorelli, 1956 \\
\hline
\end{tabular}

\section{Chaco Seco}

\begin{tabular}{|c|c|c|c|c|c|c|c|c|c|c|c|c|c|c|c|}
\hline Familia & Especie & RP & tang & mult & spir & $\begin{array}{l}<100 \\
\mu \mathrm{m}\end{array}$ & sept & $\begin{array}{l}>10 \\
\text { ser }\end{array}$ & $\begin{array}{l}\text { het } \\
4+\end{array}$ & $\begin{array}{c}\text { hom } \\
\text { o }\end{array}$ & stor & abs & marg & para & Referencia \\
\hline Anarcadiaceae & $\begin{array}{l}\text { Schinopsis quebracho- } \\
\text { colorado }\end{array}$ & 0 & 0 & 0 & 0 & 0 & 0 & 0 & 0 & 0 & 0 & 1 & 0 & 1 & $\begin{array}{l}\text { Roth \& Giménez de } \\
\text { Bolzón, } 1997\end{array}$ \\
\hline Apocynaceae & $\begin{array}{l}\text { Aspidosperma } \\
\text { quebracho-blanco }\end{array}$ & 0 & 0 & 0 & 0 & 0 & 0 & 0 & 0 & 0 & 0 & 0 & 0 & 0 & Tortorelli 2009 \\
\hline Bignoniaceae & Tabebuia nodosa & 0 & 0 & 0 & 0 & 1 & 0 & 0 & 0 & 0 & 1 & 0 & 1 & 1 & $\begin{array}{l}\text { Roth \& Giménez de } \\
\text { Bolzón, } 1997\end{array}$ \\
\hline Bombacaceae & Chorisia insignis & 0 & 0 & 0 & 0 & 0 & 0,5 & 1 & 0 & 0 & 0 & 0 & 0 & 0 & Tortorelli 2009 \\
\hline \multirow{11}{*}{ Fabaceae } & $\begin{array}{l}\text { Caesalpinia } \\
\text { paraguariensis }\end{array}$ & 0 & 0 & 0 & 0 & 1 & 0 & 0 & 0 & 1 & 1 & 0 & 1 & 1 & Tortorelli 2009 \\
\hline & Parkinsonia aculeata & 0 & 0 & 0 & 0 & 0 & 0 & 0 & 0 & $?$ & 0 & 0 & 0 & 1 & $\begin{array}{l}\text { Roth \& Giménez de } \\
\text { Bolzón, } 1997\end{array}$ \\
\hline & Acacia aroma & 0 & 0 & 0 & 0 & 0 & 0 & 0 & 0 & 0 & 0 & 0 & 0 & 1 & $\begin{array}{l}\text { Roth \& Giménez de } \\
\text { Bolzón, } 1997\end{array}$ \\
\hline & $\begin{array}{l}\text { Anadenanthera } \\
\text { colubrina }\end{array}$ & 0 & 0 & 0 & 0 & 1 & 0 & 0 & 0 & $?$ & 0 & 0 & 0 & 1 & Tortorelli 2009 \\
\hline & Prosopis alba & 0 & 0 & 0 & 0 & 0 & 0 & 0 & 0 & 1 & 0 & 0 & 0 & 1 & Tortorelli 2009 \\
\hline & Prosopis kuntzei & 0 & 0 & 0 & 0 & 1 & 0 & 0 & 0 & 0 & 0 & 0 & 0 & 1 & Tortorelli 2009 \\
\hline & Prosopis nigra & 0 & 0 & 0 & 0 & 0 & 0 & 0 & 0 & 1 & 0 & 0 & 0 & 1 & Tortorelli 2009 \\
\hline & Prosopis ruscifolia & 0 & 0 & 0 & 0 & 0 & 0 & 0 & 0 & 1 & 0 & 0 & 0 & 1 & Tortorelli 2009 \\
\hline & Prosopis vinalillo & 0 & 0 & 0 & 0 & 1 & 1 & 0 & 0 & 1 & 0 & 0 & 1 & 1 & $\begin{array}{l}\text { Roth \& Giménez de } \\
\text { Bolzón, } 1997\end{array}$ \\
\hline & Erythrina crista-galli & 0 & 1 & 0 & 0 & 0 & 0 & 0 & 0 & 0 & 0 & 0 & 0 & 1 & Tortorelli 2009 \\
\hline & Geoffroea decorticans & 0 & 0 & 0 & 0 & 1 & 0 & 0 & 0 & 1 & 1 & 0 & 1 & 1 & Tortorelli 2009 \\
\hline Rhamnaceae & Zizyphus mistol & 0 & 0 & 0 & 0 & 1 & 0 & 0 & 0 & 0 & 0 & 0 & 0 & 1 & Tortorelli 2009 \\
\hline Rutaceae & Fagara coco & 0 & 0 & 0 & 0 & 1 & 0 & 0 & 0 & 1 & 0 & 1 & 1 & 1 & Tortorelli 2009 \\
\hline Ulmaceae & Celtis tala & 0 & 0 & 0 & 0 & 1 & 0 & 0 & 0 & 0 & 0 & 0 & 1 & 1 & $\begin{array}{l}\text { Roth \& Giménez de } \\
\text { Bolzón, } 1997\end{array}$ \\
\hline Zygophyllaceae & Bulnesia sarmientoi & 0 & 0 & 0 & 0 & 1 & 0 & 0 & 0 & 1 & 1 & 0 & 0 & 1 & Tortorelli 2009 \\
\hline
\end{tabular}




\section{Chaco Húmedo}

\begin{tabular}{|c|c|c|c|c|c|c|c|c|c|c|c|c|c|c|c|}
\hline Familia & Especie & $\mathbf{R P}$ & tang & mult & spir & $\begin{array}{l}<100 \\
\mu \mathrm{m}\end{array}$ & sept & $\begin{array}{l}>10 \\
\text { ser }\end{array}$ & $\begin{array}{l}\text { het } \\
4+\end{array}$ & $\begin{array}{c}\text { hom } \\
\text { o }\end{array}$ & stor & abs & marg & para & Referencia \\
\hline \multirow{4}{*}{ Anacardiaceae } & Astronium balansae & 0 & 0 & 0 & 0 & 1 & 0 & 0 & 0 & 0 & 0 & 1 & 0 & 1 & Roth \& Giménez, 2006 \\
\hline & Lithraea molleoides & 0 & 0 & 0 & 1 & 1 & 1 & 0 & 0 & 0 & 0 & 1 & 0 & 0 & Tortorelli, 1956 \\
\hline & Schinopsis balansae & 0 & 0 & 0 & 0 & 0 & 0 & 0 & 0 & 0 & 0 & 0 & 1 & 0 & Roth \& Giménez, 2006 \\
\hline & $\begin{array}{l}\text { Schinopsis quebracho- } \\
\text { colorado }\end{array}$ & 0 & 0 & 0 & 0 & 0 & 0 & 0 & 0 & 0 & 0 & 1 & 0 & 1 & Roth \& Giménez, 2006 \\
\hline \multirow{2}{*}{ Apocynaceae } & $\begin{array}{l}\text { Aspidosperma } \\
\text { quebracho-blanco }\end{array}$ & 0 & 0 & 0 & 0 & 0 & 0 & 0 & 0 & 0 & 0 & 0 & 0 & 0 & Tortorelli, 1956 \\
\hline & $\begin{array}{l}\text { Tabernaemontana } \\
\text { australis }\end{array}$ & 0 & 0 & 0 & 0 & 1 & 1 & 0 & 1 & 0 & 0 & 1 & 0 & 0 & Roth \& Giménez, 2006 \\
\hline Araliaceae & $\begin{array}{l}\text { Didymopanax } \\
\text { morototoni }\end{array}$ & 0 & 0 & 0 & 0 & 0 & 1 & 0 & 0 & 0 & 0 & 1 & 0 & 1 & Tortorelli, 1956 \\
\hline \multirow{2}{*}{ Bignoniaceae } & Tabebuia ipe & 0 & 0 & 0 & 0 & 0 & 0 & 0 & 0 & 1 & 1 & 0 & 1 & 1 & Tortorelli, 1956 \\
\hline & Tabebuia nodosa & 0 & 0 & 0 & 0 & 1 & 0 & 0 & 0 & 0 & 1 & 0 & 1 & 1 & Roth \& Giménez, 2006 \\
\hline Bombacaceae & Chorisia speciosa & 0 & 0 & 0 & 0 & 0 & 0,5 & 1 & 0 & 0 & 0 & 0 & 0 & 1 & Tortorelli, 1956 \\
\hline \multirow{6}{*}{ Boraginaceae } & Cordia americana & 0 & 1 & 0 & 0 & 1 & 1 & 0 & 0 & 0 & 0 & 0 & 0 & 1 & Tortorelli, 1956 \\
\hline & Cercidium australe & 0 & 0 & 0 & 0 & 1 & 0 & 0 & 0 & 1 & 0 & 0 & 0 & 1 & Tortorelli, 1956 \\
\hline & Gleditsia amorphoides & 0 & 0 & 0 & 0 & 1 & 0 & 0 & 0 & 0 & 0 & 0 & 0 & 1 & Tortorelli, 1956 \\
\hline & Parkinsonia aculeata & 0 & 0 & 0 & 0 & 0 & 0 & 0 & 0 & & 0 & 0 & 0 & 1 & Roth \& Giménez, 2006 \\
\hline & Peltophorum dubium & 0 & 0 & 0 & 0 & 0 & 1 & 0 & 0 & 1 & 0 & 0 & 0 & 1 & Tortorelli, 1956 \\
\hline & Pterogyne nitens & 0 & 0 & 0 & 0 & 0 & 0 & 0 & 0 & 0 & 1 & 0 & 1 & 1 & Tortorelli, 1956 \\
\hline Caricaceae & Carica quercifolia & 0 & 0 & 0 & 0 & 0 & 0 & 1 & 0 & 1 & 0 & 0 & 0 & 1 & Roth \& Giménez, 2006 \\
\hline Combretaceae & Terminalia triflora & 0 & 0 & 0 & 0 & 1 & 1 & 0 & 0 & 1 & 0 & 0 & 0 & 1 & Tortorelli, 1956 \\
\hline Compositae & Tessaria integriflora & 0 & 0 & 0 & 0 & 1 & 0 & 0 & 1 & 0 & 0 & 1 & 0 & 1 & Tortorelli, 1956 \\
\hline \multirow[b]{2}{*}{ Euphorbiaceae } & Croton urucurana & 0 & 0 & 0 & 0 & 1 & 0 & 0 & 0 & 0 & 0 & 0 & 0 & 1 & Roth \& Giménez, 2006 \\
\hline & $\begin{array}{l}\text { Sapium } \\
\text { haematospermum }\end{array}$ & 0 & 0 & 0 & 0 & 0 & 1 & 0 & 0 & 0 & 0 & 0 & 0 & 0 & Tortorelli, 1956 \\
\hline \multirow{14}{*}{ Fabaceae } & Acacia aroma & 0 & 0 & 0 & 0 & 0 & 0 & 0 & 0 & 0 & 0 & 0 & 0 & 1 & Roth \& Giménez, 2006 \\
\hline & Acacia caven & 0 & 0 & 0 & 0 & 1 & 0 & 0 & 0 & 1 & 0 & 0 & 0 & 1 & Tortorelli, 1956 \\
\hline & $\begin{array}{l}\text { Enterolobium } \\
\text { contortisiliquum }\end{array}$ & 0 & 0 & 0 & 0 & 0 & 1 & 0 & 0 & 1 & 0 & 1 & 0 & 1 & Tortorelli, 1956 \\
\hline & Cathormion polyanthum & 0 & 0 & 0 & 0 & 0 & 0 & 0 & 0 & 1 & 0 & 0 & 1 & 1 & Roth \& Giménez, 2006 \\
\hline & Inga uraguensis & 0 & 0 & 0 & 0 & 0 & 0 & 0 & 0 & 1 & 0 & 0 & 0 & 1 & Tortorelli, 1956 \\
\hline & Pithecellobium scalare & 0 & 0 & 0 & 0 & 0 & 1 & 0 & 0 & 1 & 0 & 0 & 1 & 1 & Roth \& Giménez, 2006 \\
\hline & Prosopis alba & 0 & 0 & 0 & 0 & 0 & 0 & 0 & 0 & 1 & 0 & 0 & 0 & 1 & Tortorelli, 1956 \\
\hline & Prosopis kuntzei & 0 & 0 & 0 & 0 & 1 & 0 & 0 & 0 & 0 & 0 & 0 & 0 & 1 & Tortorelli, 1956 \\
\hline & Prosopis nigra & 0 & 0 & 0 & 0 & 0 & 0 & 0 & 0 & 1 & 0 & 0 & 0 & 1 & Tortorelli, 1956 \\
\hline & Prosopis ruscifolia & 0 & 0 & 0 & 0 & 0 & 0 & 0 & 0 & 1 & 0 & 0 & 0 & 1 & Tortorelli, 1956 \\
\hline & Prosopis vinalillo & 0 & 0 & 0 & 0 & 1 & 1 & 0 & 0 & 1 & 0 & 0 & 1 & 1 & Roth \& Giménez, 2006 \\
\hline & Erytrhina crista-galli & 0 & 1 & 0 & 0 & 0 & 0 & 0 & 0 & 0 & 0 & 0 & 0 & 1 & Tortorelli, 1956 \\
\hline & Geoffroea decoricans & 0 & 0 & 0 & 0 & 1 & 0 & 0 & 0 & 1 & 1 & 0 & 1 & 1 & Tortorelli, 1956 \\
\hline & Geoffroea striata & 0 & 0 & 0 & 0 & 1 & 0 & 0 & 0 & 1 & 1 & 0 & 1 & 1 & Roth \& Giménez, 2006 \\
\hline Moraceae & Cecropia adenopus & 0 & 0 & 0 & 1 & 0 & 0 & 0 & 0 & 0 & 0 & 0 & 0 & 1 & Roth \& Giménez, 2006 \\
\hline
\end{tabular}




\begin{tabular}{|c|c|c|c|c|c|c|c|c|c|c|c|c|c|c|c|}
\hline & Maclura tinctoria & 1 & 0 & 0 & 0 & 0 & 0 & 0 & 0 & 1 & 0 & 0 & 0 & 0 & Roth \& Giménez, 2006 \\
\hline Nyctaginaceae & Pisonia zapallo & 0 & 0 & 0 & 0 & 1 & 0 & 0 & 0 & 0 & 1 & 1 & 0 & 1 & Tortorelli, 1956 \\
\hline Phytholaccaceae & Phytolacca dioica & 0 & 0 & 0 & 0 & 1 & 1 & 1 & 0 & 0 & 0 & 0 & 1 & 0 & Roth \& Giménez, 2006 \\
\hline Polygonaceae & Ruprechtia laxiflora & 0 & 0 & 0 & 0 & 1 & 0 & 0 & 0 & 1 & 0 & 1 & 0 & 1 & Tortorelli, 1956 \\
\hline Rhamnaceae & Zyphus mistol & 0 & 0 & 0 & 0 & 1 & 0 & 0 & 0 & 0 & 0 & 0 & 0 & 1 & Tortorelli, 1956 \\
\hline Salicaceae & Salix humboldtiana & 0 & 0 & 0 & 0 & 1 & 1 & 0 & 0 & 0 & 0 & 1 & 0 & 0 & Tortorelli, 1956 \\
\hline Santalaceae & Acanthorsyris falcata & 0 & 0 & 0 & 0 & 1 & 0 & 0 & 0 & 0 & 0 & 1 & 0 & 1 & Roth \& Giménez, 2006 \\
\hline \multirow{3}{*}{ Sapindaceae } & Allophylus edulis & 0 & 1 & 0 & 0 & 1 & 1 & 0 & 0 & 1 & 0 & 1 & 1 & 0 & Tortorelli, 1956 \\
\hline & Diplokeleba floribunda & 0 & 0 & 0 & 0 & 1 & 0 & 0 & 0 & 0 & 0 & 0 & 1 & 0 & Tortorelli, 1956 \\
\hline & Sapindus saponaria & 0 & 0 & 0 & 0 & 1 & 0,5 & 0 & 0 & 1 & 0 & 0 & 1 & 0 & Tortorelli, 1956 \\
\hline \multirow[b]{2}{*}{ Sapotaceae } & Sideroxylon obtusifolium & 0 & 0 & 0 & 0 & 0 & 0 & 0 & 0 & 0 & 0 & 0 & 0 & 1 & Tortorelli, 1956 \\
\hline & $\begin{array}{l}\text { Chrysophyllum } \\
\text { gonocarpum }\end{array}$ & 0 & 0 & 0 & 0 & 1 & 1 & 0 & 1 & 0 & 0 & 1 & 0 & 0 & Roth \& Giménez, 2006 \\
\hline Solanaceae & Solanum donianum & 0 & 0 & 0 & 0 & 0 & 1 & 0 & 0 & 0 & 0 & 0 & 1 & 1 & Roth \& Giménez, 2006 \\
\hline Tiliaceae & Luehea divaricata & 0 & 0 & 0 & 0 & 1 & 0,5 & 0 & 0 & 0 & 1 & 0 & 0 & 0 & Tortorelli, 1956 \\
\hline \multirow{2}{*}{ Ulmaceae } & Celtis tala & 0 & 0 & 0 & 0 & 1 & 0 & 0 & 0 & 0 & 0 & 0 & 1 & 1 & Roth \& Giménez, 2006 \\
\hline & Phyllostylon rhamnoides & 0 & 0 & 0 & 0 & 1 & 0 & 0 & 0 & 1 & 1 & 0 & 0 & 1 & Tortorelli, 1956 \\
\hline
\end{tabular}


Apéndice II: Listado de maderas fósiles estudiadas.

Se listan los ejemplares estudiados detallando colector, lugar de depósito, nombre del morfogénero o morfoespecie y № de repositorio. Se indica con una " $x$ " aquellos en los cuales fue posible la medición de los anillos de crecimiento (A).

Material de la Formación Cerro Bororó. Depositado en la Colección de la División de Paleobotánica del Museo de La Plata, La Plata, Buenos Aires, Argentina.

\begin{tabular}{|c|c|l|c|}
\hline № de colección & No de preparado microscópico & \multicolumn{1}{|c|}{ Morfogénero/morfoespecie } & A \\
\hline LP-PB 9062 & $763-765$ & Podocarpoxylon mazzonii & $\mathrm{x}$ \\
\hline LP-PB 9063 & $766-768$ & Podocarpoxylon mazzonii & $\mathrm{x}$ \\
\hline LP-PB 9064 & $769-770 / 800-801$ & Podocarpoxylon mazzonii & $\mathrm{x}$ \\
\hline LP-PB 9065 & $802-804$ & Elaeocarpoxylon sloaneoides & \\
\hline LP-PB 9066 & $805-810$ & Euxylophoroxylon chiquichanense & \\
\hline LP-PB 9067 & $811-813$ & Weinmannioxylon multiperforatum & \\
\hline LP-PB 9068 & $814-820$ & Weinmannioxylon pluriradiatum & \\
\hline LP-PB 9069 & $821-824$ & Rhizophoroxylon spallettii \\
\hline LP-PB 9070 & $825-830$ & Bridelioxylon americanum \\
\hline
\end{tabular}

Material de la Formación Cerro Bororó. depositado en la Colección de la División Paleobotánica del Museo Egidio Feruglio, Trelew, Chubut, Argentina.

\begin{tabular}{|c|l|c|c|c|c|}
\hline $\begin{array}{c}\text { No de preparado } \\
\text { microscópico }\end{array}$ & $\begin{array}{c}\text { Morfogénero/ } \\
\text { morfoespecie }\end{array}$ & A & $\begin{array}{c}\text { No de preparado } \\
\text { microscópico }\end{array}$ & $\begin{array}{c}\text { Morfogénero/ } \\
\text { morfoespecie }\end{array}$ \\
\hline MPEF-Pb 9275 & Podocarpoxylon mazzonii & $\mathrm{x}$ & MPEF-Pb 9281 & Podocarpoxylon mazzonii & $\mathrm{A}$ \\
\hline MPEF-Pb 9276 & Podocarpoxylon mazzonii & & MPEF-Pb 9282 & Podocarpoxylon mazzonii & $\mathrm{x}$ \\
\hline MPEF-Pb 9277 & Podocarpoxylon mazzonii & $\mathrm{x}$ & MPEF-Pb 9283 & Podocarpoxylon mazzonii & $\mathrm{x}$ \\
\hline MPEF-Pb 9278 & Podocarpoxylon mazzonii & $\mathrm{x}$ & MPEF-Pb 9284 & Podocarpoxylon mazzonii \\
\hline MPEF-Pb 9279 & Podocarpoxylon mazzonii & $\mathrm{x}$ & MPEF-Pb 9285 & Podocarpoxylon mazzonii & \\
\hline MPEF-Pb 9280 & Podocarpoxylon mazzonii & $\mathrm{x}$ & MPEF-Pb 9286 & Podocarpoxylon mazzonii \\
\hline
\end{tabular}

Material de la Formación Salamanca. Depositado en Colección de la División

Paleobotánica del Museo Egidio Feruglio, Trelew, Chubut, Argentina.

\begin{tabular}{|c|c|c|c|c|c|}
\hline $\begin{array}{l}\text { № de preparado } \\
\text { microscópico }\end{array}$ & $\begin{array}{l}\text { Morfogénero/ } \\
\text { morfoespecie }\end{array}$ & A & $\begin{array}{l}\text { № de preparado } \\
\text { microscópico }\end{array}$ & $\begin{array}{l}\text { Morfogénero/ } \\
\text { morfoespecie }\end{array}$ & A \\
\hline MPEF-Pb 8385 & Podocarpoxylon multiparenchymatosum & $x$ & MPEF-Pb 8394 & Mirceugellenites sp. & \\
\hline MPEF-Pb 8386 & Podocarpoxylon multiparenchymatosum & $x$ & MPEF-Pb 8395 & Mirceugellenites sp. & \\
\hline MPEF-Pb 8387 & Cupressinoxylon austrocedroides & $x$ & MPEF-Pb 8396 & Mirceugellenites sp. & \\
\hline MPEF-Pb 8388 & Cupressinoxylon artabeae sp. nov. & $x$ & MPEF-Pb 8397 & Mirceugellenites sp. & \\
\hline MPEF-Pb 8389 & cf. Cupressinoxylon & $\mathrm{x}$ & MPEF-Pb 8398 & Mirceugellenites sp. & \\
\hline MPEF-Pb 8390 & cf. Cupressinoxylon & $x$ & MPEF-Pb 8399 & Xilotipo 2 & \\
\hline MPEF-Pb 8391 & Xilotipo 1 & & MPEF-Pb 8400 & Xilotipo 3 & \\
\hline MPEF-Pb 8392 & Mirceugellenites sp. & & MPEF-Pb 8401 & Xilotipo 3 & \\
\hline MPEF-Pb 8393 & Mirceugellenites sp. & & & & \\
\hline
\end{tabular}


Material de la Formación Río Turbio. Depositado en las colecciones paleobotánicas

del Museo Provincial Padre Jesús Molina, Río Gallegos, Santa Cruz, Argentina.

\begin{tabular}{|c|c|c|c|c|c|}
\hline $\begin{array}{c}\text { № de } \\
\text { preparado } \\
\text { microscópico }\end{array}$ & $\begin{array}{l}\text { Morfogénero/ } \\
\text { Morfoespecie }\end{array}$ & A & $\begin{array}{c}\text { № de preparado } \\
\text { microscópico }\end{array}$ & $\begin{array}{l}\text { Morfogénero/ } \\
\text { morfoespecie }\end{array}$ & A \\
\hline MPM PB 2224 & Mal preservado-Gimnosperma & & MPM PB 2265 & Mal preservado-Angiosperma & \\
\hline MPM PB 2225 & Mal preservado-Gimnosperma & & MPM PB 2266 & Mal preservado & \\
\hline MPM PB 2226 & cf. Scalaroxylon & & MPM PB 2267 & Mal preservado & \\
\hline MPM PB 2227 & Mal preservado-Angiosperma & & MPM PB 17920 & Mal preservado-Gimnosperma & \\
\hline MPM PB 2228 & Mal preservado & & MPM PB 17921 & Mal preservado-Gimnosperma & \\
\hline MPM PB 2229 & Mal preservado-Angiosperma & & MPM PB 17922 & Angiosperma indet. & \\
\hline MPM PB 2230 & Mal preservado-Angiosperma & $x$ & MPM PB 17923 & Gimnosperma indet. & \\
\hline MPM PB 2231 & Phyllocladoxylon antarcticum & $x$ & MPM PB 17924 & Mal preservado & \\
\hline MPM PB 2232 & Mal preservado-Angiosperma & & MPM PB 17925 & Mal preservado-Angiosperma & \\
\hline MPM PB 2233 & Mal preservado-Angiosperma & & MPM PB 17926 & Angiospermae indet. & \\
\hline MPM PB 2234 & Mal preservado-Gimnosperma & & MPM PB 17927 & Agathoxylon sp. & \\
\hline MPM PB 2235 & Mal preservado-Angiosperma & & MPM PB 17928 & Phyllocladoxylon sp. A & $x$ \\
\hline MPM PB 2236 & Xilotipo 2 (Pujana 2008) & & MPM PB 17929 & Phyllocladoxylon sp. A & $x$ \\
\hline MPM PB 2237 & Mal preservado & & MPM PB 17930 & Phyllocladoxylon sp. A & $x$ \\
\hline MPM PB 2238 & Mal preservado-Angiosperma & & MPM PB 17931 & Agathoxylon sp. & $x$ \\
\hline MPM PB 2239 & Mal preservado-Angiosperma & & MPM PB 17932 & Gimnosperma indet. & \\
\hline MPM PB 2240 & Mal preservado & & MPM PB 17933 & Gimnosperma indet. & $x$ \\
\hline MPM PB 2241 & Mal preservado-Angiosperma & & MPM PB 17934 & cf. Agathoxylon antarcticus & \\
\hline MPM PB 2242 & Phyllocladoxylon sp. A & & MPM PB 17935 & Gimnosperma indet. & \\
\hline MPM PB 2243 & Gimnosperma indet. & & MPM PB 17936 & Gimnosperma indet. & \\
\hline MPM PB 2244 & Phyllocladoxylon sp. A & & MPM PB 17937 & Gimnosperma indet. & \\
\hline MPM PB 2245 & Phyllocladoxylon sp. A & & MPM PB 17938 & cf. Phyllocladoxylon & \\
\hline MPM PB 2246 & Phyllocladoxylon sp. A & & MPM PB 17939 & cf. Phyllocladoxylon & \\
\hline MPM PB 2247 & Gimnosperma indet. & $x$ & MPM PB 17940 & Gimnosperma indet. & \\
\hline MPM PB 2248 & Phyllocladoxylon sp. A & & MPM PB 17941 & Podocarpoxylon multiparenchymatosum & \\
\hline MPM PB 2249 & Podocarpoxylon multiparenchymatosum & $x$ & MPM PB 17942 & Podocarpoxylon multiparenchymatosum & \\
\hline MPM PB 2250 & Podocarpoxylon multiparenchymatosum & $x$ & MPM PB 17943 & Podocarpoxylon multiparenchymatosum & \\
\hline MPM PB 2251 & Gimnosperma indet. & $x$ & MPM PB 17944 & Podocarpoxylon multiparenchymatosum & \\
\hline MPM PB 2252 & Mal preservado & & MPM PB 17945 & Podocarpoxylon multiparenchymatosum & $x$ \\
\hline MPM PB 2253 & Mal preservado & $x$ & MPM PB 17946 & Podocarpoxylon multiparenchymatosum & \\
\hline MPM PB 2254 & Mal preservado & & MPM PB 17947 & Podocarpoxylon multiparenchymatosum & \\
\hline MPM PB 2255 & Mal preservado & & MPM PB 17948 & Podocarpoxylon multiparenchymatosum & \\
\hline MPM PB 2256 & cf. Agathoxylon antarcticus & & MPM PB 17949 & Podocarpoxylon multiparenchymatosum & \\
\hline MPM PB 2257 & Gimnosperma indet. & & MPM PB 17950 & Mal preservado-Gimnosperma & \\
\hline MPM PB 2258 & Phyllocladoxylon sp. A & & MPM PB 17951 & Angiosperma indet. & \\
\hline MPM PB 2259 & Mal preservado & & MPM PB 17952 & Angiosperma & \\
\hline MPM PB 2260 & Mal preservado-Angiosperma & & MPM PB 17953 & Angiosperma indet. & \\
\hline MPM PB 2261 & Mal preservado-Angiosperma & & MPM PB 17954 & Podocarpoxylon multiparenchymatosum & \\
\hline MPM PB 2262 & Mal preservado-Gimnosperma & & MPM PB 17955 & Mal preservado & \\
\hline MPM PB 2263 & Mal preservado-Angiosperma & & MPM PB 17956 & Gimnosperma indet. & $x$ \\
\hline MPM PB 2264 & Mal preservado-Angiosperma & & & & \\
\hline
\end{tabular}


Material de la Formación Río Guillermo. Depositado en las colecciones paleobotánicas del Museo Provincial Padre Jesús Molina, Río Gallegos, Santa Cruz, Argentina.

\begin{tabular}{|c|c|c|c|c|c|}
\hline $\begin{array}{c}\text { № de preparado } \\
\text { microscópico }\end{array}$ & $\begin{array}{l}\text { Morfogénero/ } \\
\text { morfoespecie }\end{array}$ & $A$ & $\begin{array}{c}\text { № de preparado } \\
\text { microscópico }\end{array}$ & $\begin{array}{l}\text { Morfogénero/ } \\
\text { morfoespecie }\end{array}$ & A \\
\hline MPM PB 2279 & Agathoxylon sp. A & $\mathrm{x}$ & MPM PB 2324 & Nothofagoxylon scalariforme & $x$ \\
\hline MPM PB 2283 & Mal preservado-Angiosperma & & MPM PB 2325 & Mal preservado & \\
\hline MPM PB 2285 & Nothofagoxylon sp. & $\mathrm{x}$ & MPM PB 2328 & Mal preservado-Angiosperma? & \\
\hline MPM PB 2286 & Nothofagoxylon sp. & $\mathrm{x}$ & MPM PB 2329 & Mal preservado-Angiosperma? & \\
\hline MPM PB 2287 & Mal preservado-Angiosperma & & MPM PB 2330 & Mal preservado-Gimnosperma? & \\
\hline MPM PB 2288 & Nothofagoxylon sp. & $x$ & MPMPB 2331 & Mal preservado-Gimnosperma? & \\
\hline MPM PB 2289 & Nothofagoxylon sp. & $x$ & MPM PB 2336 & Mal preservado-Angiosperma? & \\
\hline MPM PB 2290 & Mal preservado-Gimnosperma? & & MPMPB 2341 & Nothofagoxylon sp. & \\
\hline MPM PB 2292 & Mal preservado-Angiosperma & & MPM PB 2342 & Nothofagoxylon kraeuseli & $x$ \\
\hline MPM PB 2296 & Mal preservado & & MPM PB 2343 & Mal preservado & \\
\hline MPM PB 2297 & Conifera indet. & $x$ & MPM PB 2344 & Mal preservado-Angiosperma? & \\
\hline MPM PB 2298 & Mal preservado-Angiosperma & & MPM PB 2345 & Angiosperma indet. & $x$ \\
\hline MPM PB 2302 & Mal preservado-Gimnosperma? & & MPM PB 2346 & Nothofagoxylon sp. & $\mathrm{x}$ \\
\hline MPM PB 2304 & Mal preservado & & MPM PB 2348 & Mal preservado & \\
\hline MPM PB 2305 & Mal preservado & & MPM PB 2349 & Angiosperma indet. & $x$ \\
\hline MPMPB 2310 & Mal preservado & & MPM PB 2352 & Angiosperma indet. & $x$ \\
\hline MPM PB 2312 & Mal preservado & & MPM PB 17957 & Nothofagoxylon sp. & $x$ \\
\hline MPM PB 2314 & Angiosperma indet. & & MPM PB 17962 & Mal preservado & \\
\hline MPM PB 2318 & Mal preservado & & MPM PB 17963 & Mal preservado & \\
\hline MPM PB 2320 & Mal preservado-Angiosperma? & & & & \\
\hline
\end{tabular}

Material de la Formación Río Leona. Depositado en las colecciones paleobotánicas del Museo Provincial Padre Jesús Molina, Río Gallegos, Santa Cruz, Argentina.

\begin{tabular}{|c|c|c|c|c|c|}
\hline $\begin{array}{c}\text { № de preparado } \\
\text { microscópico }\end{array}$ & $\begin{array}{l}\text { Morfogénero/ } \\
\text { morfoespecie }\end{array}$ & A & $\begin{array}{l}\text { № de preparado } \\
\text { microscópico }\end{array}$ & $\begin{array}{l}\text { Morfogénero/ } \\
\text { morfoespecie }\end{array}$ & A \\
\hline MPM PB 1950 & Nothofagoxylon scalariforme & & MPM PB 1963 & Mal preservado-Angiosperma? & \\
\hline MPM PB 1951 & Nothofagoxylon sp. & & MPM PB 1964 & Nothofagoxylon sp. & $x$ \\
\hline MPM PB 1952 & Scalarixylon grandiradiatum & & MPM PB 1965 & Myrceugenellites oligocenum & $x$ \\
\hline MPM PB 1953 & Mal preservado & & MPM PB 1966 & Nothofagoxylon triseriatum & \\
\hline MPM PB 1954 & Mal preservado-Angiosperma? & $x$ & MPM PB 1967 & Nothofagoxylon triseriatum & \\
\hline MPM PB 1955 & Doroteoxylon vicente-perezii & $x$ & MPM PB 1968 & Conifera indet. & $x$ \\
\hline MPM PB 1956 & Nothofagoxylon scalariforme & $x$ & MPM PB 1969 & Maloidoxylon cesariae & \\
\hline MPM PB 1957 & Nothofagoxylon sp. & & MPM PB 1970 & Maloidoxylon cesariae & \\
\hline MPM PB 1958 & Nothofagoxylon sp. & & MPM PB 1971 & Myrceugenellites oligocenum & $x$ \\
\hline MPM PB 1959 & Nothofagoxylon sp. & & MPM PB 1972 & Myrceugenellites oligocenum & $\mathrm{x}$ \\
\hline MPM PB 1960 & Nothofagoxylon sp. & & MPM PB 1973 & Laurelites doroteaensis & $x$ \\
\hline MPM PB 1961 & Scalarixylon grandiradiatum & & MPM PB 1974 & Nothofagoxylon sp. & \\
\hline MPM PB 1962 & Nothofagoxylon scalariforme & $x$ & MPM PB 1975 & Myrceugenellites oligocenum & $x$ \\
\hline MPM PB 1963 & Mal preservado-Angiosperma? & & MPM PB 1976 & Scalarixylon patagonicum & \\
\hline
\end{tabular}




\begin{tabular}{|c|c|c|c|c|c|}
\hline MPM PB 1977 & Conífera indet. & $\mathrm{x}$ & MPM PB 2125 & Podocarpoxylon sp. A & \\
\hline MPM PB 1978 & Scalarixylon grandiradiatum & & MPM PB 2126 & Mal preservado & \\
\hline MPM PB 1979 & Conífera & $x$ & MPM PB 2127 & Podocarpoxylon sp. A & \\
\hline MPM PB 1980 & Agathoxylon sp. A & $x$ & MPM PB 2128 & Podocarpoxylon sp. A & $\mathrm{x}$ \\
\hline MPM PB 1981 & Mal preservado & & MPM PB 2129 & Nothofagoxylon sp. & \\
\hline MPM PB 1982 & Nothofagoxylon kraeuseli & & MPM PB 2130 & Gimnosperma indet. & \\
\hline MPM PB 1983 & Gimnosperma indet. & $x$ & MPM PB 2131 & Podocarpoxylon sp. A & \\
\hline MPM PB 1984 & Nothofagoxylon sp. & $x$ & MPM PB 2132 & Gimnosperma indet. & \\
\hline MPM PB 1985 & Mal preservado-Angiosperma & & MPM PB 2133 & Mal preservado & \\
\hline MPM PB 1986 & Nothofagoxylon sp. & $x$ & MPM PB 2134 & Nothofagoxylon sp. & \\
\hline MPM PB 1987 & Mal preservado & & MPM PB 2135 & Gimnosperma indet. & $\mathrm{x}$ \\
\hline MPM PB 1988 & Gimnosperma indet. & & MPM PB 2136 & Podocarpoxylon sp. A & $\mathrm{x}$ \\
\hline MPM PB 1989 & Nothofagoxylon sp. & & MPM PB 2137 & Podocarpoxylon sp. A & $x$ \\
\hline MPM PB 1990 & Nothofagoxylon sp. & & MPM PB 2138 & Nothofagoxylon kraeuseli & $\mathrm{x}$ \\
\hline MPM PB 1991 & Nothofagoxylon sp. & & MPM PB 2139 & Gimnosperma indet. & \\
\hline MPM PB 1992 & Nothofagoxylon kraeuseli & & MPM PB 2140 & Mal preservado & \\
\hline MPM PB 1993 & Nothofagoxylon sp. & & MPM PB 2141 & Angiosperma & $\mathrm{x}$ \\
\hline MPM PB 1994 & Nothofagoxylon kraeuseli & $x$ & MPM PB 2142 & Nothofagoxylon scalariforme & $\mathrm{x}$ \\
\hline MPM PB 1995 & Mal preservado-Gimnosperma & $x$ & MPM PB 2143 & Nothofagoxylon sp. & $x$ \\
\hline MPM PB 1996 & Mal preservado-Angiosperma? & & MPM PB 2144 & Mal preservado-Angiosperma & \\
\hline MPM PB 1997 & Nothofagoxylon aggregatum & & MPM PB 2145 & Nothofagoxylon sp. & \\
\hline MPM PB 1998 & Nothofagoxylon sp. & & MPM PB 2146 & Nothofagoxylon scalariforme & $\mathrm{x}$ \\
\hline MPM PB 1999 & Agathoxylon sp. A & $x$ & MPM PB 2147 & Mal preservado-Angiosperma & \\
\hline MPM PB 2100 & Nothofagoxylon sp. & & MPM PB 2148 & Nothofagoxylon sp. & $\mathrm{x}$ \\
\hline MPM PB 2101 & Nothofagoxylon sp. & $x$ & MPM PB 2149 & Nothofagoxylon scalariforme & $\mathrm{x}$ \\
\hline MPM PB 2102 & Xilotipo 3 (Pujana, 2008) & & MPM PB 2150 & Nothofagoxylon sp. & \\
\hline MPM PB 2103 & Mal preservado & & MPM PB 2151 & Nothofagoxylon sp. & $x$ \\
\hline MPM PB 2104 & Mal preservado & & MPM PB 2152 & Nothofagoxylon scalariforme & \\
\hline MPM PB 2105 & Nothofagoxylon sp. & $x$ & MPM PB 2153 & Nothofagoxylon sp. & $\mathrm{x}$ \\
\hline MPM PB 2106 & Nothofagoxylon kraeuseli & & MPM PB 2154 & Nothofagoxylon sp. & \\
\hline MPM PB 2107 & Resinaxylon schinusoides & & MPM PB 2155 & Nothofagoxylon scalariforme & \\
\hline MPM PB 2108 & Nothofagoxylon sp. & $x$ & MPM PB 2156 & Nothofagoxylon sp. & $\mathrm{x}$ \\
\hline MPM PB 2109 & Nothofagoxylon sp. & & MPM PB 2157 & Maloidoxylon cesariae & \\
\hline MPM PB 2110 & Xilotipo 3 (Pujana, 2008) & & MPM PB 2158 & Maloidoxylon cesariae & \\
\hline MPM PB 2111 & Nothofagoxylon sp. & & MPM PB 2159 & Maloidoxylon cesariae & \\
\hline MPM PB 2112 & Xilotipo 3 (Pujana, 2008) & & MPM PB 2160 & Maloidoxylon cesariae & $\mathrm{x}$ \\
\hline MPM PB 2113 & Nothofagoxylon sp. & & MPM PB 2161 & Angiosperma indet. & $\mathrm{x}$ \\
\hline MPM PB 2114 & Mal preservado - Angiosperma? & & MPM PB 2162 & Mal preservado & \\
\hline MPM PB 2115 & Xilotipo 3 (Pujana, 2008) & & MPM PB 2163 & Maloidoxylon cesariae & \\
\hline MPM PB 2116 & Nothofagoxylon kraeuseli & $x$ & MPM PB 2164 & Maloidoxylon cesariae & \\
\hline MPM PB 2117 & Xilotipo 3 (Pujana, 2008) & & MPM PB 2165 & Myrceugenellites oligocenum & \\
\hline MPM PB 2118 & Nothofagoxylon sp. & $x$ & MPM PB 2166 & Myrceugenellites oligocenum & \\
\hline MPM PB 2119 & Angiosperma & $x$ & MPM PB 2167 & Mal preservado-Angiosperma? & \\
\hline MPM PB 2120 & Xilotipo 3 (Pujana, 2008) & & MPM PB 2168 & Mal preservado-Angiosperma? & \\
\hline MPM PB 2121 & Xilotipo 3 (Pujana, 2008) & & MPM PB 2169 & Myrceugenellites oligocenum & \\
\hline MPM PB 2122 & Nothofagoxylon sp. & & MPM PB 2170 & Nothofagoxylon scalariforme & $\mathrm{x}$ \\
\hline MPM PB 2123 & Mal preservado & & MPM PB 2171 & Nothofagoxylon scalariforme & $\mathrm{x}$ \\
\hline MPM PB 2124 & Nothofagoxylon scalariforme & $x$ & MPM PB 2172 & Mal preservado & \\
\hline MPM PB 2125 & Podocarpoxylon sp. A & & MPM PB 2173 & Maloidoxylon cesariae & \\
\hline
\end{tabular}




\begin{tabular}{|c|c|c|c|c|c|}
\hline MPM PB 2174 & Laurelites doroteaensis & $\mathrm{x}$ & MPM PB 2269 & Mal preservado-Angiosperma? & \\
\hline MPM PB 2175 & Mal preservado-Angiosperma? & & MPM PB 2270 & Mal preservado-Angiosperma? & \\
\hline MPM PB 2176 & Maloidoxylon cesariae & & MPM PB 2271 & Nothofagoxylon sp. & $\mathrm{x}$ \\
\hline MPM PB 2177 & Nothofagoxylon kraeuseli & $x$ & MPM PB 2272 & Laurelites doroteaensis & $\mathrm{x}$ \\
\hline MPM PB 2178 & Mal preservado & & MPM PB 2273 & Laurelites doroteaensis & $\mathrm{x}$ \\
\hline MPM PB 2179 & Mal preservado & & MPM PB 2275 & Mal preservado-Angiosperma? & \\
\hline MPM PB 2180 & Mal preservado & & MPM PB 2277 & Laurelites doroteaensis & $\mathrm{x}$ \\
\hline MPM PB 2181 & Maloidoxylon cesariae & $x$ & MPM PB 2278 & Angiosperma indet. & $\mathrm{x}$ \\
\hline MPM PB 2182 & Nothofagoxylon kraeuseli & $x$ & MPM PB 14382 & Conífera indet. & $\mathrm{x}$ \\
\hline MPM PB 2183 & Mal preservado & & MPM PB 14383 & Conífera indet. & \\
\hline MPM PB 2184 & Laurelites doroteaensis & $x$ & MPM PB 14384 & Mal preservado & \\
\hline MPM PB 2185 & Myrceugenellites oligocenum & $x$ & MPM PB 14385 & Cf. Podocarpoxylon & \\
\hline MPM PB 2186 & Mal preservado & & MPM PB 14386 & Conífera indet. & $x$ \\
\hline MPM PB 2187 & Myrceugenellites oligocenum & $x$ & MPM PB 14387 & Conífera indet. & \\
\hline MPM PB 2188 & Mal preservado & & MPM PB 14388 & Cf. Podocarpoxylon & \\
\hline MPM PB 2189 & Mal preservado & & MPM PB 14389 & Conífera indet. & \\
\hline MPM PB 2190 & Mal preservado-Angiosperma? & & MPM PB 14390 & Cf. Podocarpoxylon & \\
\hline MPM PB 2191 & Mal preservado & & MPM PB 14393 & Nothofagoxylon sp. & $\mathrm{x}$ \\
\hline MPM PB 2192 & Maloidoxylon cesariae & & MPM PB 14394 & Nothofagoxylon sp. & \\
\hline MPM PB 2193 & Nothofagoxylon ruei & & MPM PB 14396 & Nothofagoxylon sp. & $\mathrm{x}$ \\
\hline MPM PB 2194 & Nothofagoxylon sp. & & MPM PB 14397 & Angiosperma indet. & \\
\hline MPM PB 2195 & Gimnosperma & & MPM PB 14398 & Conífera indet. & $\mathrm{x}$ \\
\hline MPM PB 2196 & Mal preservado-Angiosperma? & & MPM PB 14399 & Angiosperma indet. & \\
\hline MPM PB 2197 & Mal preservado-Angiosperma? & & MPM PB 14400 & Nothofagoxylon sp. & $\mathrm{x}$ \\
\hline MPM PB 2198 & Nothofagoxylon sp. & $x$ & MPM PB 14401 & Nothofagoxylon sp. & $\mathrm{x}$ \\
\hline MPM PB 2199 & Nothofagoxylon sp. & $x$ & MPM PB 14402 & Cf. Podocarpoxylon & $x$ \\
\hline MPM PB 2200 & Nothofagoxylon scalariforme & $x$ & MPM PB 14403 & Angiosperma indet. & \\
\hline MPM PB 2201 & Nothofagoxylon scalariforme & & MPM PB 14404 & Nothofagoxylon sp. & $\mathrm{x}$ \\
\hline MPM PB 2202 & Nothofagoxylon kraeuseli & $x$ & MPM PB 14405 & Nothofagoxylon sp. & $\mathrm{x}$ \\
\hline MPM PB 2203 & Mal preservado-Angiosperma? & & MPM PB 14406 & Mal preservado-Angiosperma? & \\
\hline MPM PB 2204 & Nothofagoxylon scalariforme & $x$ & MPM PB 14407 & Angiosperma indet. & $\mathrm{x}$ \\
\hline MPM PB 2205 & Mal preservado-Angiosperma? & & MPM PB 14408 & Angiosperma indet. & \\
\hline MPM PB 2206 & Nothofagoxylon sp. & & MPM PB 14409 & Angiosperma indet. & \\
\hline MPM PB 2207 & Nothofagoxylon sp. & $x$ & MPM PB 14407 & Angiosperma indet. & $\mathrm{x}$ \\
\hline MPM PB 2208 & Nothofagoxylon sp. & & MPM PB 14408 & Angiosperma indet. & \\
\hline MPM PB 2209 & Nothofagoxylon sp. & & MPM PB 14409 & Angiosperma indet. & \\
\hline MPM PB 2210 & Nothofagoxylon sp. & & MPM PB 14410 & Cf. Podocarpoxylon & $\mathrm{x}$ \\
\hline MPM PB 2211 & Gimnosperma indet. & $x$ & MPM PB 14411 & Angiosperma indet. & $\mathrm{x}$ \\
\hline MPM PB 2212 & Nothofagoxylon sp. & $x$ & MPM PB 14412 & Nothofagoxylon sp. & $\mathrm{x}$ \\
\hline MPM PB 2213 & Gimnosperma indet. & & MPM PB 14413 & Nothofagoxylon sp. & $\mathrm{x}$ \\
\hline MPM PB 2214 & Mal preservado-Angiosperma? & & MPM PB 14415 & Nothofagoxylon sp. & \\
\hline MPM PB 2215 & Nothofagoxylon sp. & $x$ & MPM PB 14416 & Nothofagoxylon sp. & $x$ \\
\hline MPM PB 2216 & Nothofagoxylon sp. & $x$ & MPM PB 14417 & Angiosperma indet. & \\
\hline MPM PB 2217 & Nothofagoxylon sp. & & MPM PB 14418 & Mal preservado-Angiosperma & \\
\hline MPM PB 2219 & Mal preservado-Angiosperma? & & MPM PB 14419 & Nothofagoxylon sp. & $\mathrm{x}$ \\
\hline MPM PB 2220 & Nothofagoxylon sp. & $x$ & MPM PB 14420 & Nothofagoxylon sp. & $\mathrm{x}$ \\
\hline MPM PB 2221 & Mal preservado-Angiosperma? & $x$ & MPM PB 14421 & Nothofagoxylon sp. & $\mathrm{x}$ \\
\hline MPM PB 2222 & Nothofagoxylon sp. & & MPM PB 14422 & Mal preservada & \\
\hline MPM PB 2223 & Nothofagoxylon sp. & & MPM PB 14423 & Nothofagoxylon sp. & $\mathrm{x}$ \\
\hline
\end{tabular}




\begin{tabular}{|c|c|c|c|c|c|}
\hline MPM PB 14424 & Nothofagoxylon sp. & $x$ & MPM PB 14967 & Nothofagoxylon sp. & \\
\hline MPM PB 14425 & Nothofagoxylon sp. & $x$ & MPM PB 14968 & Nothofagoxylon sp. & $x$ \\
\hline MPM PB 14426 & Nothofagoxylon sp. & $x$ & MPM PB 14969 & Conífera indet. & $x$ \\
\hline MPM PB 14427 & Nothofagoxylon sp. & & MPM PB 14970 & Angiosperma indet. & $x$ \\
\hline MPM PB 14428 & Nothofagoxylon sp. & $x$ & MPM PB 14971 & Angiosperma indet. & \\
\hline MPM PB 14429 & Nothofagoxylon sp. & $x$ & MPM PB 14974 & Mal presevado & \\
\hline MPM PB 14430 & Nothofagoxylon sp. & $x$ & MPM PB 14975 & Conífera indet. & \\
\hline MPM PB 14431 & Angiosperma indet. & $x$ & MPM PB 14977 & Nothofagoxylon sp. & \\
\hline MPM PB 14432 & Mal preservado & & MPM PB 14980 & Nothofagoxylon sp. & $\mathrm{x}$ \\
\hline MPM PB 14433 & Mal preservado & & MPM PB 14985 & Nothofagoxylon sp. & $x$ \\
\hline MPM PB 14434 & Angiosperma indet. & & MPM PB 17976 & Nothofagoxylon sp. & \\
\hline MPM PB 14436 & Nothofagoxylon sp. & & MPM PB 17977 & Nothofagoxylon sp. & \\
\hline MPM PB 14437 & Angiosperma indet. & & MPM PB 17978 & Nothofagoxylon sp. & \\
\hline MPM PB 14438 & Angiosperma indet. & & MPM PB 17979 & Nothofagoxylon sp. & \\
\hline MPM PB 14439 & Angiosperma indet. & $x$ & MPM PB 17980 & Nothofagoxylon sp. & \\
\hline MPM PB 14441 & Scalarixylon sp. & & MPM PB 17981 & Angiosperma indet. & \\
\hline MPM PB 14442 & Angiosperma indet. & & MPM PB 17982 & Mal preservado-Angiosperma & \\
\hline MPM PB 14445 & Mal preservado & & MPM PB 17983 & Mal preservado-Angiosperma & \\
\hline MPM PB 14446 & Conífera indet. & & MPM PB 17984 & Angiosperma indet. & \\
\hline MPM PB 14447 & Angiosperma indet. & $\mathrm{x}$ & MPM PB 17985 & Mal preservado-Angiosperma & \\
\hline MPM PB 14448 & Conífera indet. & $x$ & MPM PB 17986 & Mal preservado-Angiosperma & \\
\hline MPM PB 14449 & Scalarixylon sp. & & MPM PB 17987 & Mal preservado-Angiosperma & \\
\hline MPM PB 14450 & Conífera indet. & $\mathrm{x}$ & MPM PB 17988 & Nothofagoxylon sp. & \\
\hline MPM PB 14451 & Angiosperma indet. & & MPM PB 17989 & Angiosperma indet. & \\
\hline MPM PB 14452 & Angiosperma indet. & & MPM PB 17990 & Angiosperma indet. & \\
\hline MPM PB 14453 & Mal preservado-Angiosperma & & MPM PB 17991 & Angiosperma indet. & \\
\hline MPM PB 14454 & Mal preservado-Angiosperma & & MPM PB 17992 & Mal preservado-Angiosperma & \\
\hline MPM PB 14456 & Nothofagoxylon sp. & $x$ & MPM PB 17993 & Angiosperma indet. & $x$ \\
\hline MPM PB 14457 & Nothofagoxylon sp. & & MPM PB 17994 & Angiosperma indet. & \\
\hline MPM PB 14458 & Nothofagoxylon sp. & & MPM PB 17995 & Nothofagoxylon sp. & \\
\hline MPM PB 14459 & Nothofagoxylon sp. & & MPM PB 17996 & Angiosperma indet. & \\
\hline MPM PB 14460 & Nothofagoxylon sp. & & MPM PB 17997 & Nothofagoxylon sp. & \\
\hline MPM PB 14461 & Nothofagoxylon sp. & $x$ & MPM PB 17998 & Angiosperma indet. & \\
\hline MPM PB 14462 & Nothofagoxylon sp. & & MPM PB 17999 & Angiosperma indet. & \\
\hline MPM PB 14463 & Nothofagoxylon sp. & & MPM PB 18000 & Nothofagoxylon sp. & \\
\hline MPM PB 14464 & Nothofagoxylon sp. & & MPM PB 18001 & Mal preservado-Angiosperma & \\
\hline MPM PB 14465 & Nothofagoxylon sp. & $x$ & MPM PB 18002 & Nothofagoxylon sp. & $\mathrm{x}$ \\
\hline MPM PB 14466 & Nothofagoxylon sp. & & MPM PB 18003 & Nothofagoxylon sp. & $x$ \\
\hline MPM PB 14467 & Nothofagoxylon sp. & & MPM PB 18004 & Nothofagoxylon sp. & $x$ \\
\hline MPM PB 14468 & Cf. Podocarpoxylon & $x$ & MPM PB 18005 & Nothofagoxylon sp. & \\
\hline MPM PB 14469 & Cf. Podocarpoxylon & $x$ & MPM PB 18006 & Angiosperma indet. & \\
\hline MPM PB 14954 & Nothofagoxylon sp. & $\mathrm{x}$ & MPM PB 18007 & Nothofagoxylon sp. & $x$ \\
\hline MPM PB 14955 & Nothofagoxylon sp. & & MPM PB 18008 & Mal preservado-Angiosperma & \\
\hline MPM PB 14956 & Nothofagoxylon sp. & $x$ & MPM PB 18009 & Conífera indet. & $x$ \\
\hline MPM PB 14957 & Angiosperma indet. & & MPM PB 18010 & Nothofagoxylon sp. & \\
\hline MPM PB 14958 & Nothofagoxylon sp. & & MPM PB 18011 & Mal preservado-Angiosperma & \\
\hline MPM PB 14962 & Mal preservado-Angiosperma? & & MPM PB 18012 & Angiosperma indet. & \\
\hline MPM PB 14963 & Cf. Podocarpoxylon & & MPM PB 18013 & Mal preservado-Angiosperma & \\
\hline MPM PB 14965 & Angiosperma indet. & & MPM PB 18014 & Nothofagoxylon sp. & $x$ \\
\hline
\end{tabular}




\begin{tabular}{|c|c|c|c|c|c|}
\hline MPM PB 18015 & Angiosperma indet. & $x$ & MPM PB 18063 & Conífera indet. & \\
\hline MPM PB 18016 & Agathoxylon sp. & $x$ & MPM PB 18064 & Agathoxylon sp. & $x$ \\
\hline MPM PB 18017 & Nothofagoxylon sp. & $x$ & MPM PB 18072 & Angiosperma indet. & $\mathrm{x}$ \\
\hline MPM PB 18022 & Nothofagoxylon sp. & $x$ & MPM PB 18073 & Angiosperma indet. & $x$ \\
\hline MPM PB 18024 & Agathoxylon sp. & $x$ & MPM PB 18074 & Conífera indet. & $x$ \\
\hline MPM PB 18033 & Angiosperma indet. & & MPM PB 18075 & Mal preservado-Angiosperma & \\
\hline MPM PB 18094 & Conífera indet. & & MPM PB 18076 & Nothofagoxylon sp. & \\
\hline MPM PB 18095 & Conífera indet. & & MPM PB 18077 & Angiosperma indet. & \\
\hline MPM PB 18096 & Conífera indet. & & MPM PB 18078 & Mal preservado-Angiosperma & \\
\hline MPM PB 18119 & Nothofagoxylon sp. & $x$ & MPM PB 18079 & Mal preservado-Angiosperma & \\
\hline MPM PB 18122 & Angiosperma indet. & $x$ & MPM PB 18080 & Mal preservado-Angiosperma & \\
\hline MPM PB 18123 & Conífera indet. & & MPM PB 18081 & Mal preservado-Angiosperma? & \\
\hline MPM PB 18129 & Conífera indet. & & MPM PB 18082 & Mal preservado-Angiosperma & \\
\hline MPM PB 18135 & Mal preservado-Gimnosperma? & & MPM PB 18083 & Mal preservado-Gimnosperma? & \\
\hline MPM PB 18137 & Mal preservado-Gimnosperma? & & MPM PB 18084 & Mal preservado-Gimnosperma? & \\
\hline MPM PB 18038 & Mal preservado-Angiosperma & & MPM PB 18085 & Nothofagoxylon sp. & \\
\hline MPM PB 18039 & Angiosperma indet. & & MPM PB 18086 & Mal preservado-Angiosperma & \\
\hline MPM PB 18040 & Angiosperma indet. & & MPM PB 18087 & Conífera indet. & \\
\hline MPM PB 18041 & Mal preservado-Angiosperma & & MPM PB 18091 & Angiosperma indet. & \\
\hline MPM PB 18042 & Conífera indet. & $x$ & MPM PB 18092 & Angiosperma indet. & \\
\hline MPM PB 18044 & Conífera indet. & $x$ & MPM PB 18093 & Angiosperma indet. & $x$ \\
\hline MPM PB 18047 & Nothofagoxylon sp. & & MPM PB 18138 & Nothofagoxylon sp. & \\
\hline MPM PB 18048 & Mal preservado-Angiosperma & & MPM PB 18142 & Nothofagoxylon sp. & $\mathrm{x}$ \\
\hline MPM PB 18049 & Mal preservado-Angiosperma & & MPM PB 18143 & Conífera indet. & $\mathrm{x}$ \\
\hline MPM PB 18050 & Nothofagoxylon sp. & & MPM PB 18144 & Angiosperma indet. & \\
\hline MPM PB 18051 & Mal preservado-Angiosperma & & MPM PB 18145 & Mal preservado-Angiosperma & \\
\hline MPM PB 18052 & Mal preservado-Angiosperma & & MPM PB 18146 & Mal preservado-Angiosperma & \\
\hline MPM PB 18053 & Mal preservado-Angiosperma & & MPM PB 18147 & Nothofagoxylon sp. & \\
\hline MPM PB 18054 & Nothofagoxylon sp. & & MPM PB 18148 & Conífera indet. & \\
\hline MPM PB 18056 & Angiosperma indet. & $x$ & MPM PB 18149 & Conífera indet. & \\
\hline MPM PB 18057 & Angiosperma indet. & $x$ & MPM PB 18150 & Mal preservado-Angiosperma & \\
\hline MPM PB 18058 & Nothofagoxylon sp. & & MPM PB 18151 & Nothofagoxylon sp. & $x$ \\
\hline MPM PB 18060 & Mal preservado-Gimnosperma & & MPM PB 18152 & Mal preservado & \\
\hline MPM PB 18061 & Mal preservado-Gimnosperma? & & MPM PB 18156 & Conífera indet. & $x$ \\
\hline
\end{tabular}

